\title{
Graph Theory of Chemical Series and Broad Categorization of Clusters
}

\author{
Enos Masheija Rwantale Kiremire
}

Correspondence: Enos Masheija Rwantale Kiremire, Retired Professor of Chemistry, University of Namibia, Tauben Glen, Hochland Park, P. O. Box 98013 Pelican Square, Windhoek, Namibia. E-mail: kiremire15@yahoo.com

Received: November 15, 2017 Accepted: December 29, $2017 \quad$ Online Published: January 25, 2018

doi:10.5539/ijc.v10n1p17

URL: https://doi.org/10.5539/ijc.v10n1p17

\begin{abstract}
The recent introduction of skeletal numbers has made it much easier to analyze and categorize a wide range of many chemical clusters. In the process, it has been found that a large number of transition metal clusters with and without ligands are capped and do possess closo nuclear clusters. On the basis of the nuclear index, the clusters have been categorized into groups. The categorization of the clusters will greatly assist in promoting deeper understanding and the synthesis of novel clusters and their applications. A simple concept of graph theory of capping clusters has been introduced.
\end{abstract}

Keywords: graphs, categorization, capping, index, clusters, numbers, series, ligands, distribution, valence, numerical, groups, period

\section{Introduction}

The recently published excellent article by Alan Welch outlines the historical development of chemical clusters (Welch, 2013).The major highlights include STYX numbers (Lipscomb, 1963), Wade's rules (Wade, 1971, 1976), Mingo's rules (Mingos, 1972, 1984, 1987), Rudolph's symmetry correlation system (Rudolph, 1976) and Jemmis research group work (Jemmis, 2005, 2006, 2008) among others. The current 4n series method being utilized to analyze clusters was developed by the identification of a simple pattern within clusters (Kiremire, 2014, 2015, 2016). The method regards all clusters comprising of skeletal elements from the main group and transition metals as interrelated and can be categorized by the $4 \mathrm{n}$ series method. The method uses skeletal numbers to analyze and categorize clusters (Kiremire, 2016a, 2016b, 2017a, 2017b, 2017c).

\section{Results and Discussions}

\subsection{Brief Background}

The early research on clusters pointed to the possibility of explaining boranes using numbers (Lipscomb, 1963), Jemmis' MNO numbers (Jemmis, 2008), topological numbers (Teo et al, 1984), and cluster shapes numbers (Fehlner and Halet, 2007) (18-monomer, 34-dimer, 48-trimer, 60-tetrahedron, and so on). The existence of cluster series was also detected and implied through the work of Wade (Wade, 1976), Mingos (Mingos, 1987) and the correlation of cluster symmetries by Rudolph (Rudolph, 1976). This is confirmed by the current work of applying skeletal numbers derived from the $4 \mathrm{n}$ series method (Kiremire, 2015b) which clearly indicate the existence of a whole vast universe of clusters linking up naked metallic elements to metal carbonyls (Kiremire, 2016b), metalloboranes (Kiremire, 2016c), Zintyl ions (Kiremire, 2016d), carboranes and other heteroboranes, boranes, and main group element clusters (Kiremire, 2017c). Using the skeletal numbers, a cluster comprising of a mono-skeletal element to a giant one of several hundred skeletal elements can readily be decomposed and represented by a single number now referred to as a cluster number Kor [K(n)parameter] (Kiremire, 2017b). The method can be broken into the following simple steps of analysis summarized in Scheme 1(SC-1). Further simplification is shown in Scheme 2(SC-2). 


\section{CLUSTER FORMULA}

Add them together<smiles></smiles>

Identify skeletal elements and ligands of the formula

Assign skeletal numbers positive to skeletal elements and negative to ligands

Cluster $\mathrm{K}$ value

Assignment
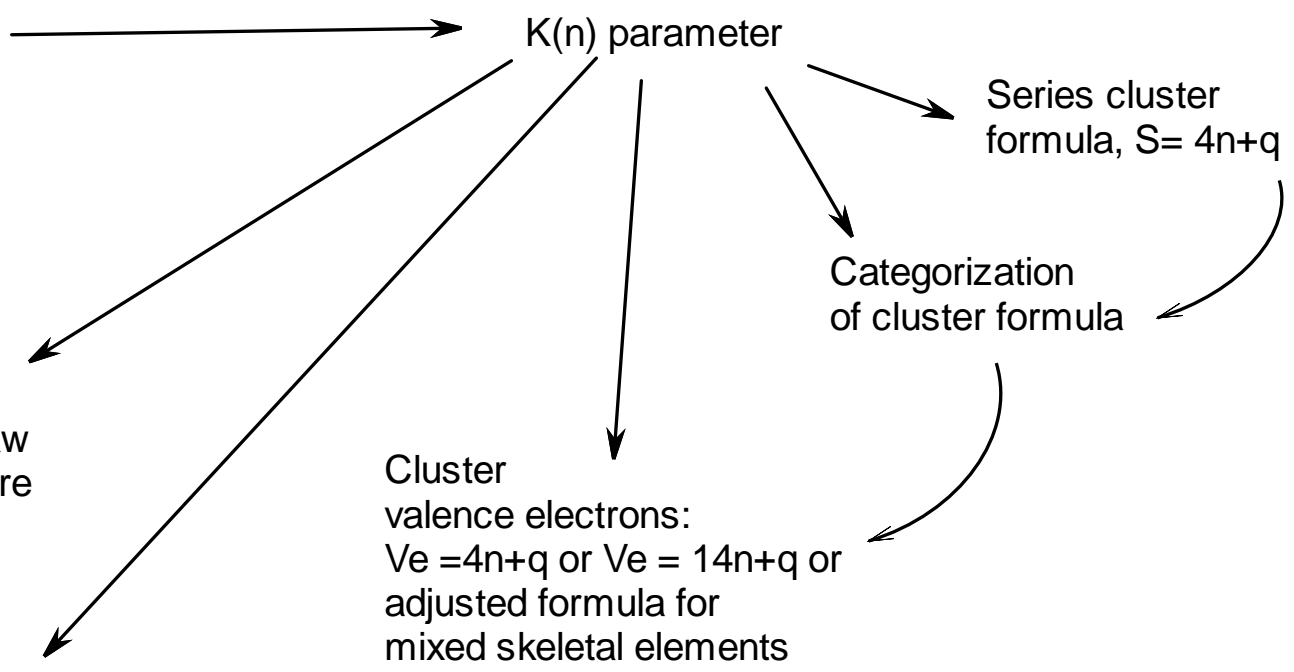

Tentative ligand distribution to raw skeletal structure

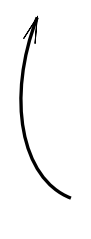

of tentative raw isomeric skeletal structure

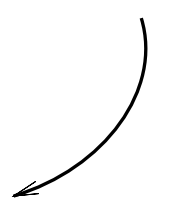

SC-1. Simple step for categorizing a cluster using skeletal numbers

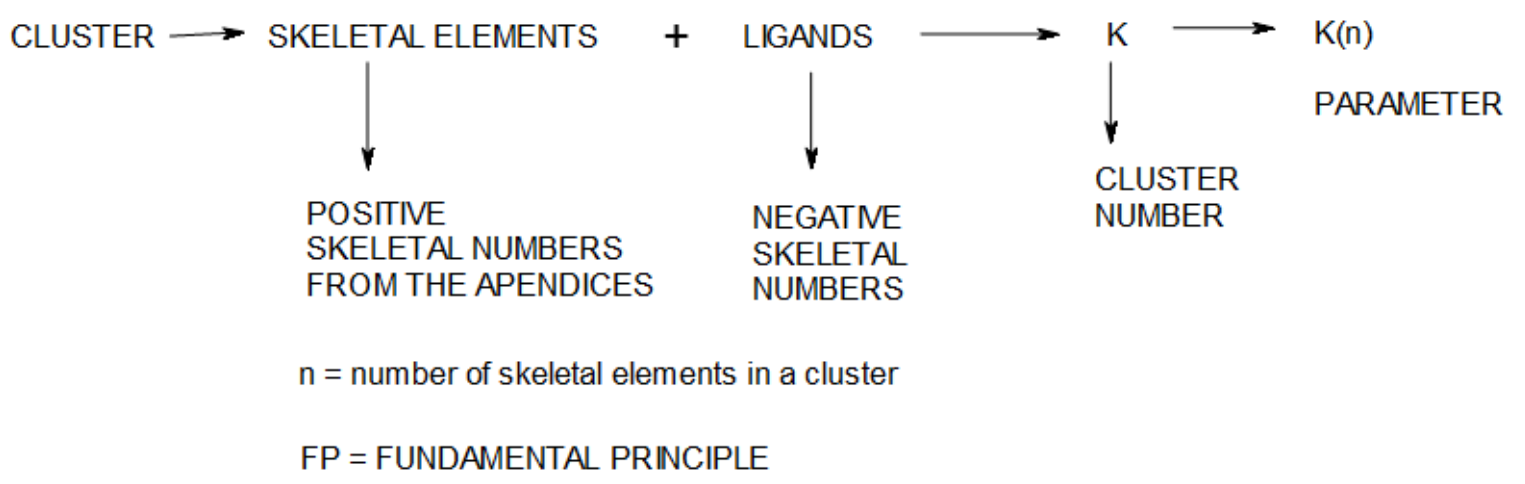

SC-2. Simplified principle for calculating the cluster number K

\section{Outline of Cluster Analysis}

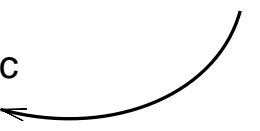

3.1 Construction of a Cluster

- The FORMULA of a cluster is categorized first using skeletal numbers. For capped clusters the series $\mathrm{S}=4 \mathrm{n}+\mathrm{q}$ $(\mathrm{q} \leq 0)$.

- If the cluster is a capped one, the type of CLOSO nucleus is deduced from the series formula, $S=4 n+q$.

- The CLOSO nucleus is then sketched according to its $\mathrm{K}$ value determined from the CLOSO SERIES, $\mathrm{S}=4 \mathrm{n}+2$, and $\mathrm{K}=2 \mathrm{n}-1$. 
- The number of capping elements are deduced from the overall cluster formula (capped cluster).

- The capping elements are added to the nuclear geometry each with 3 linkages as the capping mono-skeletal fragment has $\mathrm{S}=4 \mathrm{n}-2$ and $K=2 \mathrm{n}-1=2(1)-(-1)=3$.

- Verify to ensure the $\mathrm{K}$ value of the constructed structure is the same as that originally calculated from the parent formula [to ensure goodness of fit of the cluster].

- Using the skeletal number of each element and considering each linkage behaving as a hydrogen ligand (since $1 \mathrm{e}$ is involved as a donation), the $\mathrm{K}$ value of the skeletal element in the skeletal structure is calculated for each element.

- The $\mathrm{K}$ value for an individual skeletal element obtained for the raw skeletal structure, represents the number of ligands to be attached to that skeletal element.

- Once the ligands have been distributed according to the skeletal numbers obtained for each skeletal element, the framework is referred to as a raw skeletal structure. Ideally, the individual skeletal element obeys the noble gas configuration. The cluster formula derived from the raw skeletal structure will then correspond to the original cluster formula. The sum of the ligands added to the skeletal structure will be equal to the number of ligands including the charges (if present), in the parent cluster formula (the goodness of fit).

These concepts will be demonstrated in the examples of the chemical clusters Ex-1 to Ex-6. The series method is a good guide to construct isomeric skeletal shapes in agreement with 18 or 8 electron rules. The fine details of the structures can be established by X-ray structural analysis. For ease of structural drawing and ligand distribution, it is better and easier to leave them in the RAW SKELETAL FORMS. The concept of 'raw skeletal form' has recently been introduced (Kiremire, 2017c).

The principle for calculating the cluster parameter, $\mathrm{K}(\mathrm{n})$ as derived from the series method (Kiremire, 2016b), can be summarized as shown in the fundamental principle in SC-2.

EVERY 1 ELECTRON (1e) DONATED BY LIGAND, $\mathrm{K}=-0.5$.

Examples: $\mathrm{H}(\mathrm{K}=-0.5), \mathrm{CO}[\mathrm{K}=2(-0.5)=-1], \mathrm{Cp}[\mathrm{K}=-5(0.5)=-2.5], \mathrm{PR}_{3}(\mathrm{~K}=2(-0.5)=-1]$ and $\mathrm{C}_{2} \mathrm{H}_{4}[\mathrm{~K}=2(-0.5)=$ $-1]$, negative charge $\left[1^{-}, \mathrm{K}=-0.5\right]$ and positive charge $\left[1^{+}, \mathrm{K}=0.5\right]$.

\subsection{Graph Theory of Clusters Based upon Series}

The concept of graph theory of chemical clusters is based upon the K(n) parameter of the cluster. It simply means the distribution of K skeletal linkages and their corresponding valences to $n$ skeletal elements according to the law of $4 \mathrm{n}$ series in a precise manner. Let us take a few examples as illustrations.

$\mathrm{Ex}-1 \mathrm{Os}_{5}(\mathrm{CO})_{16}$

(a) Using $14 \mathrm{n}$ fragments: $\mathrm{F}=\mathrm{Os}_{5}(\mathrm{CO})_{16}=5\left[\mathrm{Os}(\mathrm{CO})_{3}\right]+\mathrm{CO}$

Each of the 5 fragments $\left[\mathrm{Os}(\mathrm{CO})_{3}\right]$ has $8+3(2)=14$ valence electron content. The additional $\mathrm{CO}$ ligand simply provides an additional 2 electrons. Clearly, the overall valence electron content of the cluster can be expressed as $\mathrm{Ve}=\mathrm{S}=$ $14 n+2(n=5) ; V e=$ cluster valence electron content and $S=$ cluster series. The $S$ symbol is introduced as many other clusters obey the same law of series. If we substitute $n=5$ in $\mathrm{Ve}=14 n+2$, we get $\mathrm{Ve}=14(5)+2=72$. This can be verified by substituting the valence electrons of the cluster elements and ligands $V F=5[8]+16(2)=72$. By analyzing many clusters, it was discovered that the skeletal linkages of the skeletal elements is given by another simple formula $\mathrm{K}$ $=2 n-1$ when $S=14 n+2$. Therefore the skeletal linkages $K=2 n-1=2(5)-1=9$. This means that the 5 skeletal osmium elements in $\mathrm{Os}_{5}(\mathrm{CO})_{16}$ are bound by 9 skeletal linkages. A cluster parameter for this was introduced as $\mathrm{K}(\mathrm{n})=9(5)$. We know that this cluster has a trigonal bipyramid $\left(D_{3 h}\right)$ skeletal shape, hence, a sketch of 5 elements joined by 9 linkages to mimic a trigonal bipyramid shape can be drawn as shown in Figure 1. It was also discovered that the main group clusters follow the series, $S=4 n+q$. However there is an isolobal relationship $14 n+q$ between $4 n+q$ and hence $S=4 n+q$ formula works very well for all types of clusters and has been adopted for application to all the clusters (Kiremire, 2016b) except when the number of cluster valence electrons are being calculated when $S=14 n+q$ is retained for transition metals clusters. 

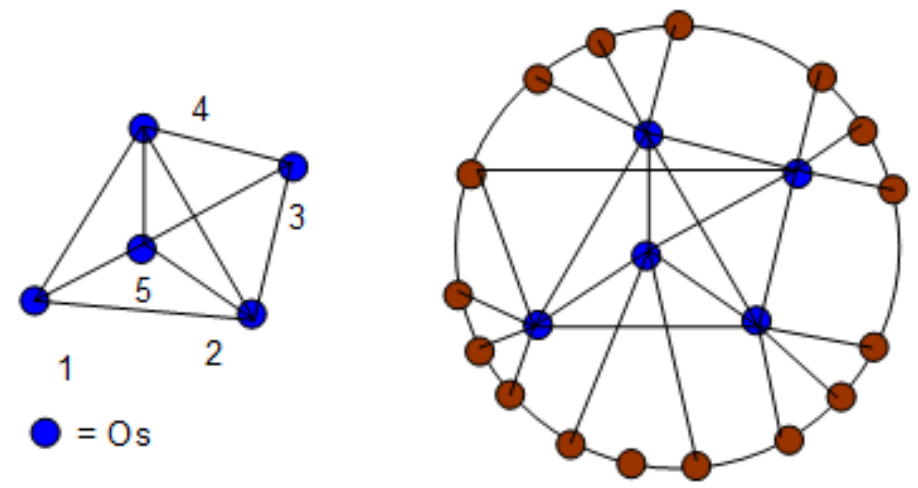

Figure 1 The skeletal sketch of $\mathrm{Os}_{5}(\mathrm{CO})_{16}$
$\mathrm{O}=\mathrm{CO}$

The osmium 1 and 3 will have to share i $\mathrm{CO}$ in order to obey the 18 electron rule.

\section{LIGAND DISTRIBUTION Os $(\mathrm{K}=5, \mathrm{~V}=10), \mathrm{CO}(\mathrm{K}=-1)$}

The skeletal elements have been numbered. Each of the lines to a skeletal element can be regarded as donating 1 electron to the skeletal element under consideration. Let us focus on the skeletal element number one. We can use the skeletal number of osmium $\mathrm{K}=5$ as obtained from appendix 2 .

$K 1=5-3(0.5)=3.5$. That there are 3.5 electron pairs needed by osmium 1 after obtaining 3 electrons from skeletal linkages. Since a CO ligand is a 2 electron donor, then it means that osmium 1 will need $3.5 \mathrm{CO}$ ligands in order for it to obey the 18 electron rule. Other K values of the skeletal ele ments can similarly be calculated.

$\mathrm{K} 2=5-4(0.5)=5-2=3$. This means o smium 2 which has 4 linkages supplying (4)electrons to it, will need $3 \mathrm{CO}$ ligands in order to obey the 18 electron rule.

$\mathrm{K} 3=\mathrm{K} 1=3.5 ; \mathrm{K} 4=\mathrm{K} 2=3$; and $\mathrm{K} 5=\mathrm{K} 2=3$. It is now easy to distribute the $16 \mathrm{CO}$ ligands to the skeletal frameworkin Figure 1. A circle has been added as a quide to draw a nice sketch of $\mathrm{CO}$ ligands.

Figure 1. The skeletal sketch of $\mathrm{Os}_{5}(\mathrm{CO})_{16}$

(b) Calculating $\mathrm{K}$ using skeletal numbers: $\mathrm{Os}(\mathrm{K}=5), \mathrm{CO}(\mathrm{K}=-1)$

For $\mathrm{Os}_{5}(\mathrm{CO})_{16}, \mathrm{~K}=5[5]-16(1)=9$. This calculation is based on the observation from series that the skeletal elements act as providers of skeletal number values some of which are utilized by the ligands in a cluster. It is based on the observation that for every ONE electron donated the skeletal number value decreases by 0.5 . Thus, $1 \mathrm{H}(\mathrm{K}=-0.5)$ when acting as a ligand while a $\mathrm{CO}(\mathrm{K}=-1)$ since it is a 2 electron donor. The $\mathrm{K}$ value can be utilized to calculate the q value in the series $S=4 n+q$. Thus, $K=2 n-1 / 2 q=2(5)-1 / q=9,1 / 2 q=1$ and $q=2$. The cluster belongs to the series $S=$ $4 \mathrm{n}+2$ as derived earlier. The use of skeletal numbers to derive the cluster number, $\mathrm{K}$ is much faster than using the cluster fragments. The method used in Ex-1(b) has been applied in most of the cluster categorizations in this paper.

\subsection{The Double Meaning of K(n) Parameter}

This concept will be discussed further in this paper. We have seen that $K(n)=9(5)$ in $\mathrm{Os}_{5}(C O)_{16}$ cluster represents 9 linkages to bind 5 skeletal osmium skeletal elements and in so doing figure is obtained. However, after scrutinizing the series deeper, K also represents the SHORTAGE of the number of the electron pairs needed to ensure that every skeletal element attains the Nobel gas configuration. Let us use this same cluster to demonstrate this concept.

$\mathrm{Os}_{5}(\mathrm{CO})_{16}+9 \mathrm{CO} \rightarrow \mathrm{Os}_{5}(\mathrm{CO})_{25} \rightarrow 5\left[\mathrm{Os}(\mathrm{CO})_{5}\right]$

As we know $\left[\mathrm{Os}(\mathrm{CO})_{5}\right]$ fragment obeys the 18 electron rule. Alternatively, the 9 electron pairs could be added directly to the cluster.

$$
\mathrm{Os}_{5}(\mathrm{CO})_{16}+9(2 \mathrm{e}) \rightarrow \mathrm{Os}_{5}(\mathrm{CO})_{16}{ }^{18-} \rightarrow 4\left[\mathrm{Os}(\mathrm{CO})_{3}{ }^{4-}\right]+1\left[\mathrm{Os}(\mathrm{CO})_{4}{ }^{2-}\right]
$$

In this alternative option, both $\left[\mathrm{Os}(\mathrm{CO})_{3}{ }^{4-}\right]$ and $\left[\mathrm{Os}(\mathrm{CO})_{4}{ }^{2-}\right]$ fragments obey the 18 electron rule.

\subsection{Capping Clusters}

Let use the VERTICAL series as a reference. The scheme for linking up series are given in Table 1 . The capping series begin when the cluster series becomes $S=4 n+0$ and $K p=C^{1} C[M x]$. The $C^{1}$ symbol means the cluster is mono-capped. The inner symbol $[\mathrm{Mx}]$ in the capping cluster represents a cluster nucleus which belongs to the CLOSO series $\mathrm{S}=4 \mathrm{n}+2$. 
Table 1. Capping series scheme

\begin{tabular}{|c|c|c|c|c|}
\hline SERIES, $-S=4 n+q+$ & 8 & CAPPIN & $=\mathrm{C}^{\mathrm{n}} \mathrm{C}[\mathrm{M}-\mathrm{x}]$ & NAME \\
\hline $4 n-40$ & $2 n+20$ & $\mathrm{C}^{21} \mathrm{C}$ & & +4 \\
\hline $4 n-38$ & $2 n+19$ & $\mathrm{C}^{20} \mathrm{C}$ & & -4 \\
\hline $4 n-36$ & $2 n+18$ & $\mathrm{C}^{19} \mathrm{C}^{7}$ & \multirow{4}{*}{7} & -4 \\
\hline $4 n-34$ & $2 n+17$ & $\mathrm{C}^{18} \mathrm{C}^{7}$ & & -4 \\
\hline $4 n-32$ & $2 n+16$ & $\mathrm{C}^{17} \mathrm{C}^{7}$ & & 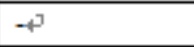 \\
\hline $4 n-30$ & $2 n+15$ & $\mathrm{C}^{16} \mathrm{C}$ & & 4 \\
\hline $4 n-28$ & $2 n+14$ & $\mathrm{C}^{15} \mathrm{C}^{7}$ & \multirow{3}{*}{$\frac{14}{4}$} & -4 \\
\hline $4 n-26$ & $2 n+13$ & $\mathrm{C}^{14} \mathrm{C}^{\mathrm{P}}$ & & 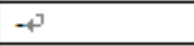 \\
\hline $4 n-24$ & $2 n+12$ & $\mathrm{C}^{13} \mathrm{C}^{7}$ & & 4 \\
\hline $4 n-22$ & $2 n+11$ & $\mathrm{C}^{12} \mathrm{C}^{2}$ & \multirow{2}{*}{$\geq$} & 4 \\
\hline $4 n-20$ & $2 n+10$ & $\mathrm{C}^{11} \mathrm{C}^{2}$ & & 4 \\
\hline $4 n-18$ & $2 n+9$ & $\mathrm{C}^{10} \mathrm{C}^{7}$ & \multirow{2}{*}{$\frac{\partial}{2}$} & 4 \\
\hline $4 n-16$ & $2 n+8$ & $\mathrm{C}^{9} \mathrm{C}^{7}$ & & 4 \\
\hline $4 n-14$ & $2 n+7$ & $\mathrm{C}^{8} \mathrm{C}$ & $(6)$ & OCTACAP \\
\hline $4 n-12$ & $2 n+6$ & $\mathrm{C}^{7} \mathrm{C}^{7}$ & & HEPTACAP \\
\hline $4 n-10$ & $2 n+5$ & $\mathrm{C}^{6} \mathrm{C}^{7}$ & & HEXACAP \\
\hline $4 n-8$ & $2 n+4$ & $\mathrm{C}^{5} \mathrm{C}^{3}$ & & PENTACAP \\
\hline $4 n-6$ & $2 n+3$ & $\mathrm{C}^{4} \mathrm{C}^{3}$ & & TETRACAP \\
\hline $4 n-4$ & $2 n+2$ & $\mathrm{C}^{3} \mathrm{C}^{3}$ & & TRICAP \\
\hline $4 n-2$ & $2 n+1$ & $\mathrm{C}^{2} \mathrm{C}$ & & BICAP \\
\hline $4 n+0$ & $2 n-0$ & $\mathrm{C}^{1} \mathrm{C}$ & & MONOCAP \\
\hline $4 n+2$ & $2 n-10$ & \multicolumn{2}{|l|}{$\mathrm{C}^{0} \mathrm{C}+$} & CLOSO \\
\hline $4 n+4$ & $2 n-2$ & \multicolumn{2}{|l|}{$\mathrm{C}^{-1} \mathrm{C}^{-1}$} & NIDO \\
\hline $4 n+6$ & $2 n-3$ & \multicolumn{2}{|l|}{$\mathrm{C}^{-2} \mathrm{C}^{3}$} & ARACHNO \\
\hline $4 n+8$ & $2 n-4$ & \multicolumn{2}{|l|}{$\mathrm{C}^{-3} \mathrm{C}^{-3}$} & HYPHO \\
\hline $4 n+10$ & $2 n-5$ & \multicolumn{2}{|l|}{$\mathrm{C}^{-4} \mathrm{C}^{3}$} & KLADO \\
\hline
\end{tabular}

Ex-2 $\mathrm{Os}_{5}(\mathrm{CO})_{18}$ : Skeletal numbers: $\mathrm{Os}(\mathrm{K}=5, \mathrm{~V}=10), \mathrm{CO}(\mathrm{K}=-1) ; \mathrm{Os}_{6}(\mathrm{CO})_{18}: \mathrm{K}=6[5]-18=12 ; \mathrm{n}=6, \mathrm{~K}(\mathrm{n})=12(6), \mathrm{S}$ $=4 n+0, K p=C^{1} C[M 5] ; \mathrm{Ve}=14 n+0=14(6)+0=84, V F=6[8]+18(2)=84$. Since the skeletal number of osmium $K=5$, its valence $\mathrm{V}=10$. The $\mathrm{K}=5$ means that the osmium element has a shortage of 5 electron pairs in order for it to obey the 18 electron rule. That is why osmium can form the complex $\mathrm{Os}(\mathrm{CO})_{5}$ or $\mathrm{OsH}_{10}\left[\mathrm{OsH}_{6}{ }^{4-}\right]$ (Yvon, 2004).

The symbol $\mathrm{Kp}=\mathrm{C}^{1} \mathrm{C}[\mathrm{M} 5]$ means that the cluster is a mono-capped trigonal bipyramid. This is sketched in Figure 2.
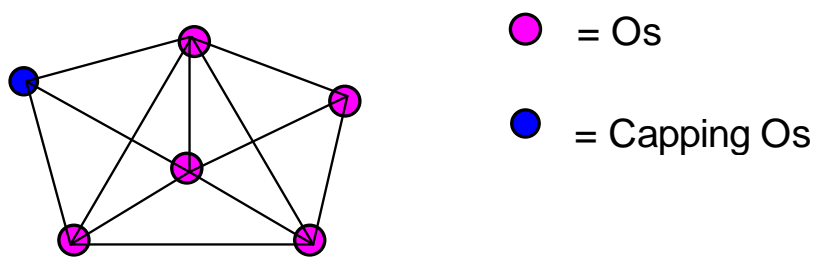

Figure 2 Sketch of skeletal shape of $\mathrm{Os}_{6}(\mathrm{CO})_{18}$

$\mathrm{Ex}-3 \mathrm{Ru}_{9}(\mathrm{CO})_{23}{ }^{2-}$ : Using skeletal numbers, $\mathrm{Ru}(\mathrm{K}=5, \mathrm{~V}=10), \mathrm{CO}(\mathrm{K}=-1),(-1 \mathrm{e})(\mathrm{K}=-0.5) ; \mathrm{K}=9[5]-23-1=21, \mathrm{n}=9$, $\mathrm{K}(\mathrm{n})=21(9), \mathrm{S}=4 \mathrm{n}-6, \mathrm{Kp}=\mathrm{C}^{4} \mathrm{C}[\mathrm{M} 5] ; \mathrm{Ve}=14 \mathrm{n}-6=14(9)-6=120$,

$\mathrm{VF}=9[8]+23(2)+2=120$. The capping symbol $\mathrm{Kp}=\mathrm{C}^{4} \mathrm{C}[\mathrm{M} 5]$ means it is a tetra-capped trigonal bipyramid. This shape is sketched in Figure 3. 


$$
\begin{aligned}
& \text { Ex-3 Rug }(\mathrm{CO})_{23^{2-}}{ }^{2-} \quad S=4 n-6, K p=C^{4} C[M 5] \\
& K=9[5]-23-1=21, n=9, K(n)=21(9), S=4 n-6
\end{aligned}
$$

Skeletal numbers: $\mathrm{Ru}(\mathrm{K}=5, \mathrm{~V}=10), \mathrm{CO}(\mathrm{K}=-1),(-1)(\mathrm{K}=-0.5)$

$$
K(n)=21(9)
$$

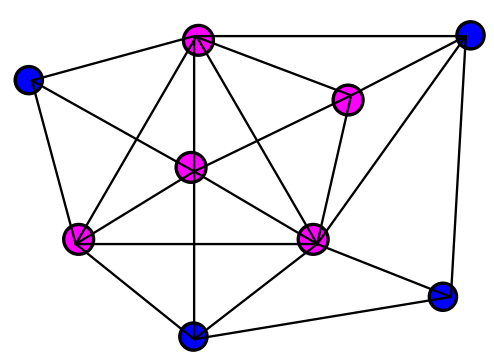

$O=$ Os

= Capping Os

Figure 3 Sketch of skeletal shape of tetra-capped trigonalbipyramid.

A short-cut for extracting the $\mathrm{K}$ value from a cluster formula is given in SC-3.

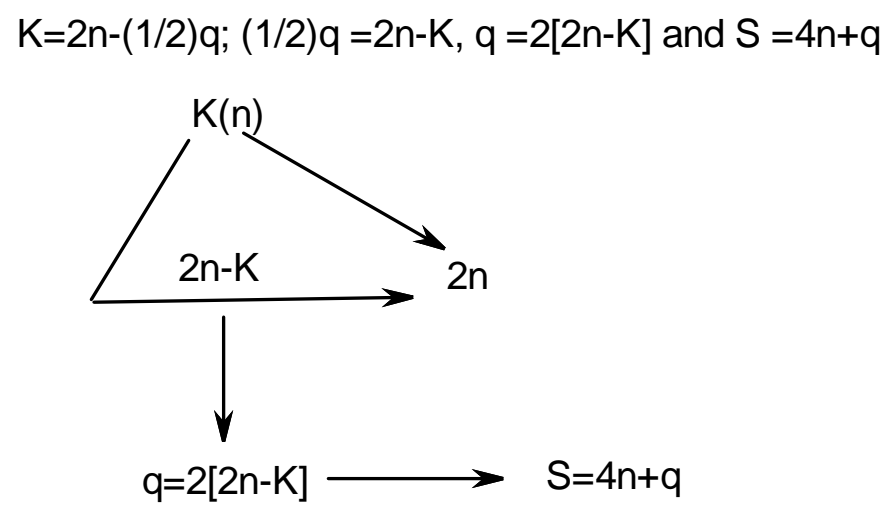

SHORT-CUT DERIVATION OF SERIES FROM K(n) PARAMETER

\section{SC-3}

Ex-4 $\mathrm{Pd}_{30}(\mathrm{CO})_{30} \mathrm{~L}_{10}$ : Skeletal numbers, $\mathrm{Pd}(\mathrm{K}=4, \mathrm{~V}=8), \mathrm{CO}(\mathrm{K}=-1), \mathrm{L}(\mathrm{K}=-1)$; for the cluster, $\mathrm{K}=30[4]-30-10=80$; $\mathrm{K}(\mathrm{n})=80(30), \mathrm{S}=4 \mathrm{n}-40 ; \mathrm{Kp}=\mathrm{C}^{21} \mathrm{C}[\mathrm{M} 9]$. This capping symbol can be verified numerically. Thus, $\mathrm{K}=21(3)+2(9)-1=$ 80 ; or the flow of $\mathrm{K}(\mathrm{n})$ numbers: 80(30), 77(29), 74(28), 71(27),68(26), 65(25), 62(24), 59(23), 56(22), 53(21), 50(20), $47(19), 44(18), 41(17), 38(16), 35(15), 32(14), 29(13), 26(12), 23(11), 20(10)$ and 17(9). The $K(n)=17(9)$ is for the nucleus [M9] which belongs to the CLOSO SERIES, $S=4 n+2$ and $K=2 n-1=2(9)-1=17$. The capping involves an electron valence content fragment of 12. In this case of the palladium cluster, the $[\mathrm{Pd}(\mathrm{CO})]$ is the right fragment $[\mathrm{Ve}=$ $10+2=12]$ while in osmium clusters it is $\left[\mathrm{Os}(\mathrm{CO})_{2}\right]$ fragment $[\mathrm{Ve}=8+2(2)=12]$. The series formula for such a fragment is $S=14 n-2$ or $S=4 n-2$ and $K=2 n+1$ which is numerically equal to $K=2(1)+1=3$. Thus, the $K$ value changes by $\Delta \mathrm{K}= \pm 3$. We can also verify the cluster valence electrons, for the cluster $\operatorname{Pd}_{30}(\mathrm{CO})_{30} \mathrm{~L}_{10}, \mathrm{Ve}=14 \mathrm{n}-40=$ $14(30)-40=380$ using the series formula; $\mathrm{VF}=30[10]+30(2)+10(2)=380 \mathrm{using}$ the cluster formula. A sketch of the skeletal graph is shown in Figure 4. The number of skeletal linkages $=3[7 x 3]+17$ from[M9] nucleus $\}=80$. A seven sided ring (figure) was arbitrarily used since it is a multiple of 21 - the number of capping elements. Hence, we will get 3 rings comprising 21 skeletal elements around the nucleus of 9 skeletal elements. The final sketch of the cluster $\mathrm{Pd}_{30}(\mathrm{CO})_{30} \mathrm{~L}_{10}$ is shown in Figure 4. 
Ex-4 $\mathrm{Pd}_{30}(\mathrm{CO})_{30} \mathrm{~L}_{10}: \mathrm{K}(\mathrm{n})=80(30) ; \mathrm{S}=4 \mathrm{n}-40, \mathrm{Kp}=\mathrm{C}^{21} \mathrm{C}[\mathrm{M} 9]$

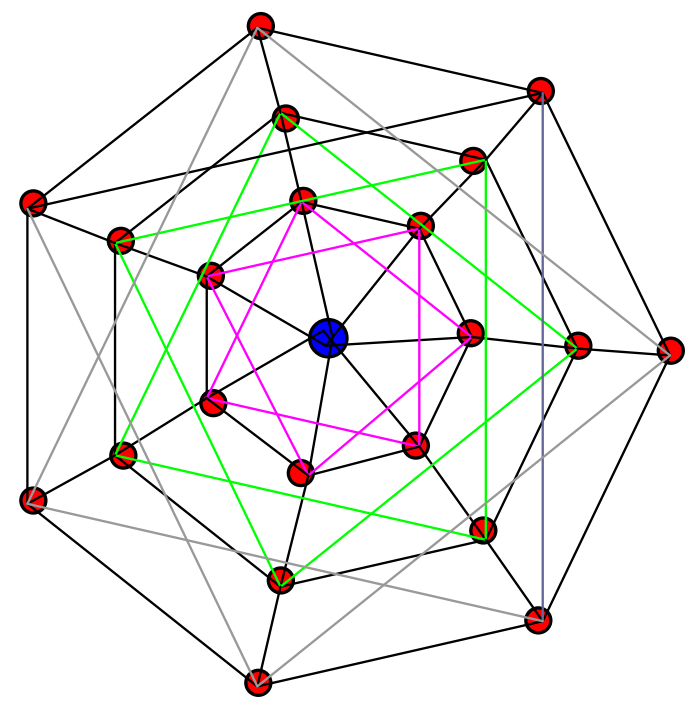

$$
K=80
$$

- capping $\mathrm{Pd}$

$=[\mathrm{M} 9]$ Nucleus

Figure 4 The skeletal graph of $\mathrm{Pd}_{30}(\mathrm{CO})_{30} \mathrm{~L}_{10}$ cluster

If we focus on the inner ring (circle) of Figure 4, there are 7 lines linked to the nucleus. This is followed by another 7 linkages to the 7 skeletal elements themselves. Then the internal periphery linkages of one to the next jumping the middle one, gives another 7 linkages. Thus, in total, we have 21 linkages from the inner "circle". The next circle also contributes to another set of 21 linkages. The last circle gives the last 21 linkages. Thus, the gross total of capping linkages is $21(3)=63$. Then the CLOSO NUCLEUS is nine skeletal elements [M9], which gives us $K=2 n-1=2(9)-1=$ 17. This means that the total linkages of the cluster as sketched in the isomeric Figure 4 will be $63+17=80$. This is an example of one form of representation of the graph of the cluster $\mathrm{Pd}_{30}(\mathrm{CO})_{30} \mathrm{~L}_{10}$. The cluster $\mathrm{Pd}_{30}(\mathrm{CO})_{26} \mathrm{~L}_{10}$ can be treated in the same manner as $\operatorname{Pd}_{30}(\mathrm{CO})_{30} \mathrm{~L}_{10}$. Its graph is shown in Figure 5. 


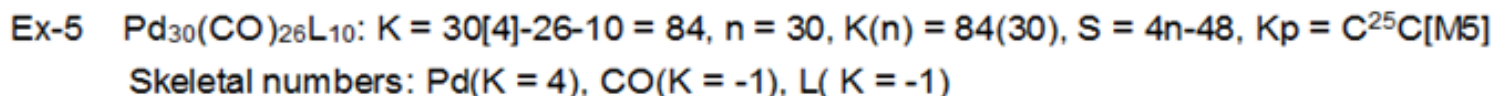

This is a cluster with a trigonal bipyram id nucleus surrounded by 25 skeletal elements.

$\mathrm{Ve}=14 \mathrm{n}-48=14(30)-48=372, \mathrm{VF}=30[10]+26(2)+10(2)=372$

$$
\mathrm{K}=84
$$

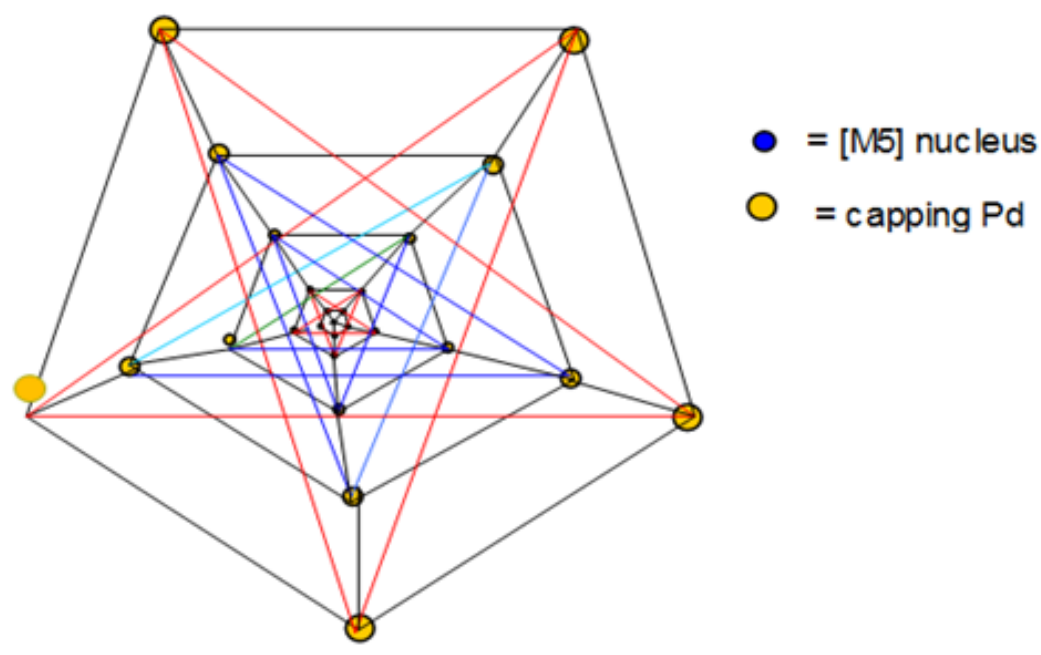

Figure 5 The sketch of the skeletal graph of $\mathrm{Pd}_{30}(\mathrm{CO})_{26} \mathrm{~L}_{10}$

The number of skeletal linkages $=5[5 \times 3]$ from 'rings' +9 from the trigonal bipyramid $=84$. For every ring around the nucleus, there are 15 linkages. Since there are 5 rings, then there will be a total of $15 \times 5=75$. Since the inner nucleus obeys the closo series $S=4 n+2$, then $K=2 n-1=2(5)-1=9$. The grand total is $75+9=84$. In order to test the concept of ligand distribution in Figure 5, we can make a simple calculation on the outer Pd skeletal element and they are all similar. The palladium skeletal number is 4 (appendix 2). Since there are 5 skeletal linkages to it, that means it is already receiving 2.5 electron pairs internally from the skeletal linkages. The deficit of the electron pairs will be provided by the ligands. Hence, $\mathrm{K}=4-5(0.5)=1.5$. This means that each of the Pd skeletal elements in the outermost ring will need $1.5 \mathrm{CO}$ ligands. A similar calculation can be done for each of the inner rings. The cluster $\mathrm{Pd}_{30}(\mathrm{CO})_{26} \mathrm{~L}_{10}$ was obtained from literature (Mednikov and Dahl, 2010). 


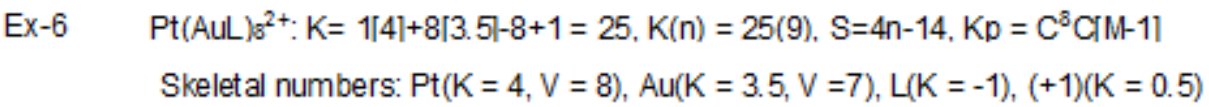

[M-1]. $K=2 n-1=2(1)-1=1 \quad \mathrm{Pt}(\mathrm{K}=4, \mathrm{~V}=8), \mathrm{Au}(\mathrm{K}=3.5, \mathrm{~V}=7)$

FROM SHAPE, UNKAGES $=8+8+8+$ K[M1] $=24+1=25$

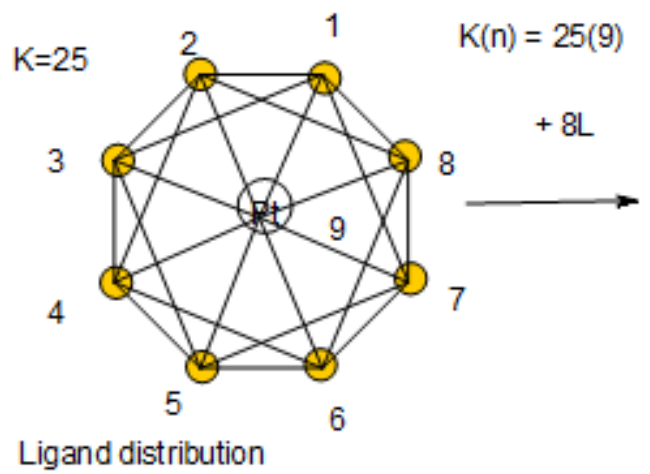

$$
\begin{array}{ll}
K 1=3 \cdot 5-2 \cdot 5=1 & K 5=3 \cdot 5-2 \cdot 5=1 \quad K 9=4-4=0 \\
K 2=3 \cdot 5-2 \cdot 5=1 & K 6=3 \cdot 5-2 \cdot 5=1 \\
K 3=3 \cdot 5-2 \cdot 5=1 & K 7=3 \cdot 5-2 \cdot 5=1 \\
K 4=3 \cdot 5-2 \cdot 5=1 & K 7=3 \cdot 5-2 \cdot 5=1 \\
& K 8=3 \cdot 5-2 \cdot 5=1
\end{array}
$$

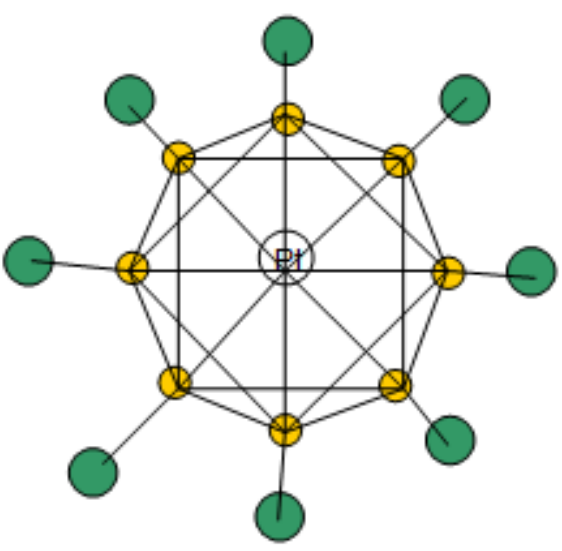

\section{Figure 6 The skeletal structure of $\mathrm{Pt}(\mathrm{AuL}) s^{2+}$}

IDEAL SHAPE, Dsn
Ve $=14 n-14=14(9)-14=112$
CHECK, FROM CLUSTER FORMULA
VF $=1[10]+8[11]+8(2)-2=112$

In Ex-6, the series method predicts that the platinum golden cluster will have a single nuclear skeletal atom [M1] surrounded by 8 other skeletal elements, $\mathrm{Kp}=\mathrm{C}^{8} \mathrm{C}[\mathrm{M} 1]$. This has been found to be the case and the $\mathrm{Pt}$ is in the nucleus while $8 \mathrm{Au}$ skeletal elements occupy the periphery. This is sketched in Figure 6. Since the cluster is small, one ring of $\mathrm{C}^{8}$ can readily be utilized to sketch its graph. The number of skeletal linkages $=8 \times 3+[M 1]$ linkages. Surprisingly, even the one skeletal nuclear element obeys the CLOSO series formula, $S=4 n+2$ and $K=2 n-1=2(1)-1=1$. This means the single skeletal nuclear element is entitled to 1 skeletal linkage. Hence, the TOTAL number of skeletal linkages $=24+1=$ 25. What is also interesting is that there are 5 linkages to each periphery Au skeletal element. Since the Au element has a $\mathrm{K}$ value of 3.5 , then the shortfall on the periphery element is $\mathrm{K}=3.5-2.5=1$. This means each of the 8 periphery Au elements is allowed to accommodate ONE ligand in order for it to obey the 18 electron rule, hence the predominance of [AuL] fragments (Mingos, 1884) in the golden clusters. In summary the graph theory of series involves the construction of skeletal structures in such a way that the skeletal elements (n) are linked in a mathematical precision with the corresponding $\mathrm{k}$ skeletal linkages as derived from the cluster formula. In other words, the K(n) parameter of a cluster must obey the 'goodness of fit' principle. The concepts that have been revealed in examples Ex-1 to Ex-6 have been applied as closely as possible in the rest of the clusters in this paper.

\subsection{More Examples to Illustrate the Categorization of Clusters Using 4n Series Method}

The examples have been arranged according to nuclearity index. 


\section{DIATOMIC (N2) MOLECULES AND SKELETAL NUMBERS}

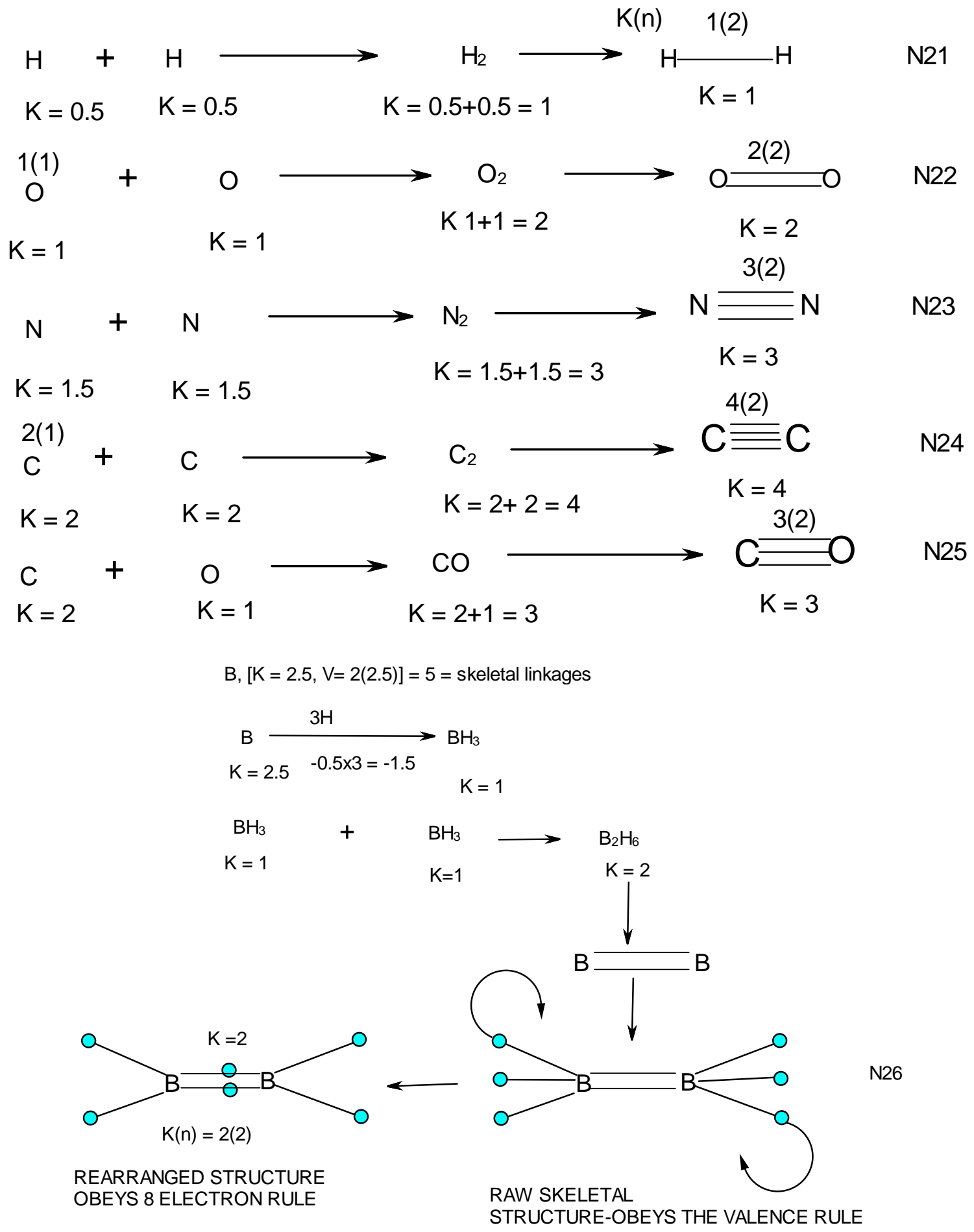


N27 AuRh(H) $\mathrm{L}_{6}{ }^{+}: \mathrm{K}=1[3.5]+1[4.5]-0.5-6+0.5=2$

$\mathrm{n}=1+1=2, K(\mathrm{n})=2(2), K=2 n-(1 / 2) \mathrm{q}=2=2(2)-(1 / 2) \mathrm{q}, \mathrm{q}=4 ; \mathrm{S}=4 \mathrm{n}+\mathrm{q}=4 \mathrm{n}+4$

$\mathrm{Ve}=14 n+4=14(2)+4=32 ; \mathrm{VF}=1[11]+1[9]+1+6(2)-1=32$

$\mathrm{Ve}=$ CLUSTER VALENCE ELECTRONS FROM SERIES FORMULA

$\mathrm{VF}=$ CLUSTER VALENCE ELECTRONS FROM CLUSTER FORMULA

Skeletal numbers: $\mathrm{Au}(\mathrm{K}=3.5), \mathrm{Rh}(\mathrm{K}=4.5), \mathrm{H}(\mathrm{K}=-0.5), \mathrm{L}(\mathrm{K}=-1),+1(\mathrm{~K}=0.5)$

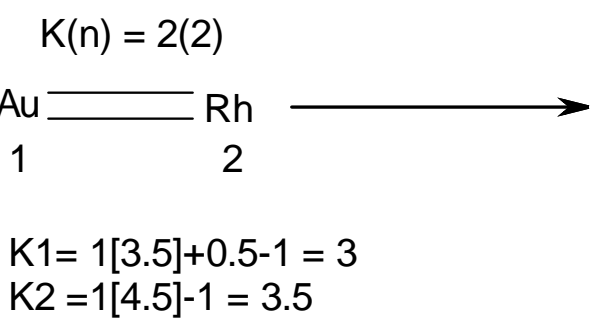

$\mathrm{K} 2=1[4.5]-1=3.5$

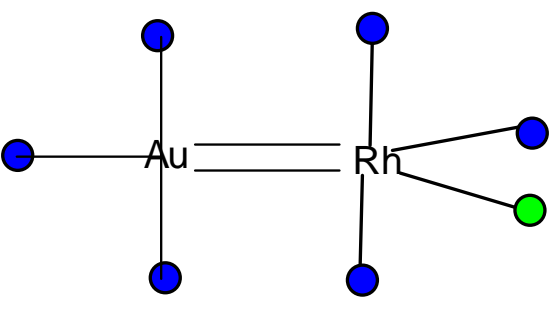

$=\mathrm{L}=\mathrm{PR}_{3} \quad \mathrm{O}=\mathrm{H}$

N4 CLUSTERS

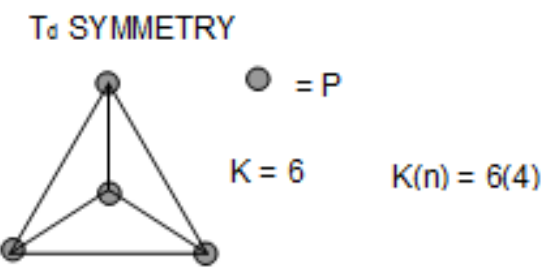

Skeletal shape of $\mathrm{P}_{4}$

N41

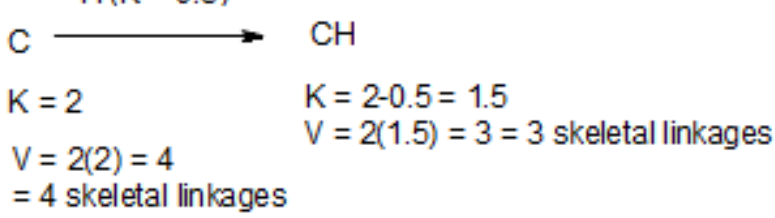

Hence, $\mathrm{CH}=\mathrm{P}$ in terms of $\mathrm{K}$ value and skeletal linkages or valences. Hence,. $\mathrm{P} \rightarrow \mathrm{O} \rightarrow \mathrm{CH}$

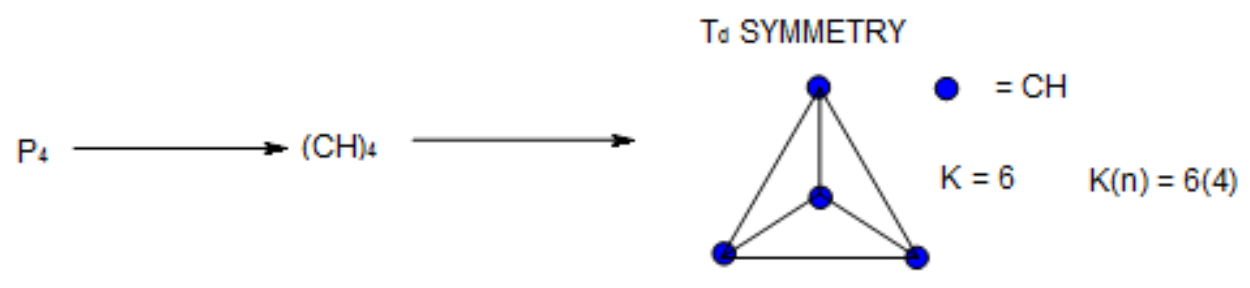

Possible isomeric skeletal shape of $\mathrm{C}_{4} \mathrm{H}_{4}$

$\mathrm{N} 42$ 
Skeletal numbers: $\operatorname{Ir}(K=4.5, \mathrm{~V}=9), \mathrm{CO}(\mathrm{K}=-1)$

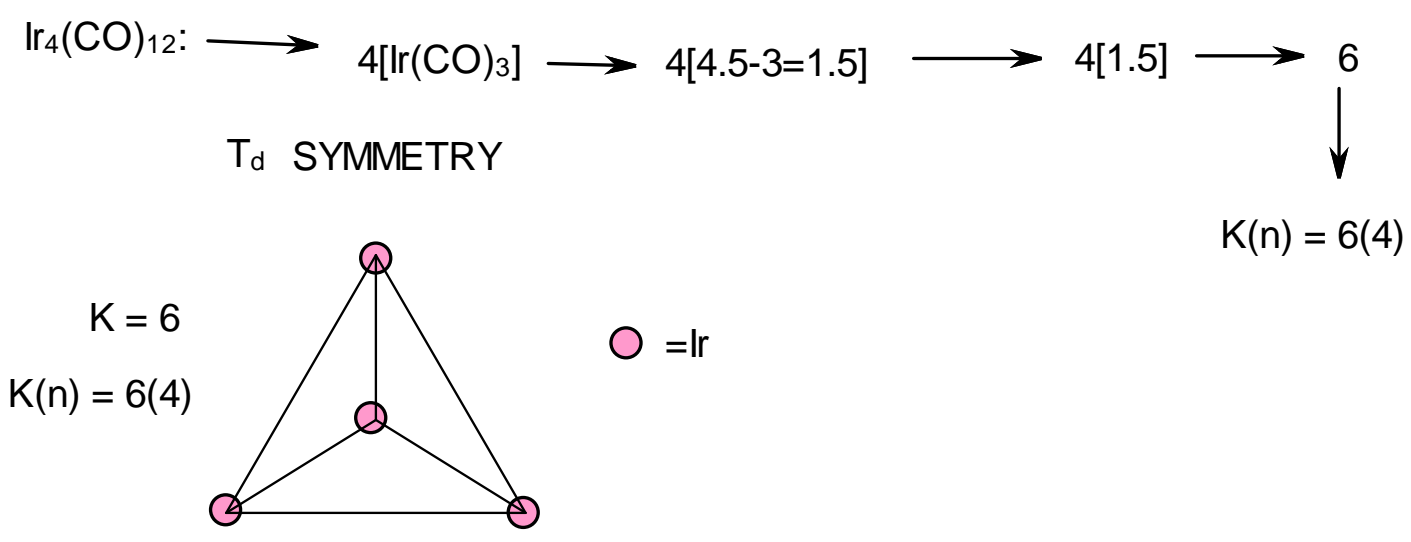

Ideal skeletal shape of $\operatorname{Ir}_{4}(\mathrm{CO})_{12}$

N43

$\mathrm{N} 44 \quad \mathrm{Pt}_{4}(\mathrm{ac})_{8} ; \mathrm{ac}=\mathrm{CH}_{3} \mathrm{COO}, \mathrm{K}=4[4]-8(1.5)=4 ; \mathrm{K}(\mathrm{n})=4(4), \mathrm{S}=4 \mathrm{n}+8$,

$\mathrm{Ve}=14 \mathrm{n}+8=14(4)+8=64 ; \mathrm{VF}=4[10]+8[3]=64 \quad$ Skeletal numbers: $\operatorname{Pt}(\mathrm{K}=4, \mathrm{~V}=8), \mathrm{ac}(\mathrm{K}=-1.5)$

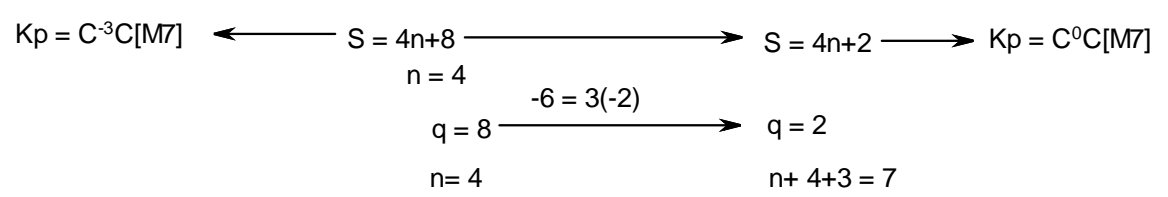

CHECK: [M7]; $S=4 n+2, K=2 n-1=2(7)-1=13, K(n)=13(7)$

K(n) SERIES: 13(7), 10(6), 7(5), 4(4); thus, the cluster 4(4) is 3 steps below the CLOSO REFERENCE.[M7].

The ideal shape is a square.

$\mathrm{K}(\mathrm{n})=4(4)$

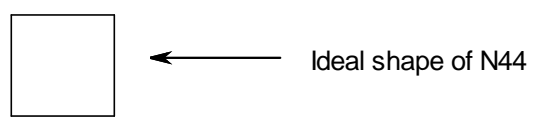

N44 


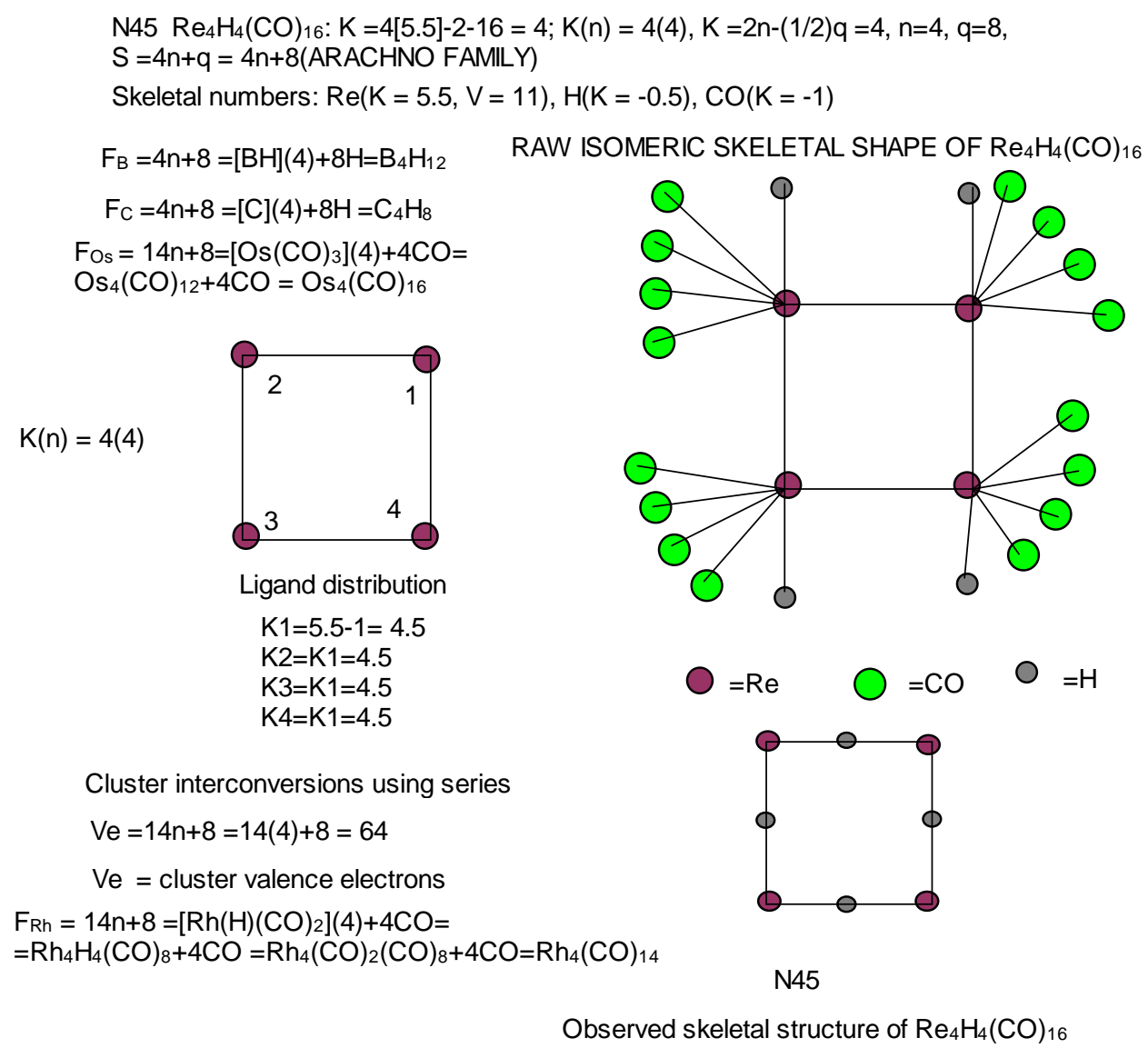

In example $1(\mathrm{~N} 45), \operatorname{Re}(\mathrm{K}=5.5$,see Appendix 2$)$, the hydrogen atom $(\mathrm{H} \bullet)$ when regarded as a single electron donor is assigned a $\mathrm{K}$ value of -0.5 . Similarly, the (:CO) ligand when is regarded as a two electron donor ligand is assigned a value $[\mathrm{K}=2(-0.5)=-1]$. In case of ligands, the assigned negative $\mathrm{K}$ value is directly proportional to the number of electrons donated. For instance a 3 electron donor has a $\mathrm{K}$ value of $3[-0.5]=-1.5$ while for a cyclopentadienyl ligand, $\mathrm{Cp}$ which donates 5 electrons, $\mathrm{K}=5[-0.5]=-2.5$. The cluster $\mathrm{K}$ value is calculated as indicated in $\mathrm{N} 45$. This means the 4 rhenium skeletal elements are connected by 4 linkages (bonds) and a reasonable possible ISOMERIC shape is a square. In constructing skeletal shapes, there may be more than one structure. In order to assign tentative ligand distribution to a skeletal element, its $\mathrm{k}$ value is utilized. Just as in the $\mathrm{CH}_{4}$ molecule each $\mathrm{H}$ atom is considered to donate an electron to the carbon atom for it to attain an octet rule (noble gas configuration), in the $\mathrm{Re}_{4}$ skeletal shape (N45), each linkage to Re skeletal element behaves as a hydrogen atom donor and hence it is assigned a $\mathrm{K}$ value of -0.5 . In the skeletal cluster shape, each skeletal element receives electron donations from the ligands as well as SKELETAL linkages to it. Using this knowledge, we can determine the skeletal linkages AVAILABLE to the external ligands after the linkages to the elements have been taken into account. For instance, in N45 there are 2 linkages to each Re skeletal atom and therefore skeletal linkages available to each skeletal element $\mathrm{K} 1=\mathrm{K} 2=\mathrm{K} 3=\mathrm{K} 4=5.5-2(0.5)=4.5$ as indicated in N45. Clearly, a $\mathrm{K}$ value of 4.5 implies, in principle, there will be $4 \mathrm{CO}+1 \mathrm{H}$ distributed to each Re skeletal element since a CO ligand is a 2 electron donor and $\mathrm{H}$ ligand a 1 electron donor. Essentially, a $\mathrm{K}$ value of 1 represents or corresponds to 1 electron pair. The actual structure can be determined from X-ray structural analysis. In this case, one of the skeletal isomers of $\mathrm{Re}_{4} \mathrm{H}_{4}(\mathrm{CO})_{16}$ is found to have bridged $\mathrm{H}$ ligands as sketched in CC-1. The skeletal shape without taking into account ligand rearrangements, has been referred to as a "raw skeletal structure". Once the raw skeletal structure has been constructed and ligands distributed according to skeletal numbers and valences, then it is expected that each skeletal element obeys the noble gas configuration. This can be illustrated by the N45 sketch: Re 1, valence electrons, $\mathrm{Ve}=1[\mathrm{Re}]+4 \mathrm{CO}+2[\mathrm{Re}-\mathrm{Re}]+1[\mathrm{H}]=7+4(2)+2+1=18$. We can also use skeletal numbers to verify if the rhenium elements in the cluster obey the 18 electron rule: $K=1[5.5]-4-1-0.5=0$. The concepts applied in $\mathrm{N} 45$ have been used in the rest of the clusters summarized in the following sections of this paper. A wide range of examples have been analyzed using the skeletal numbers so as to expose the readers to a wide scope of applications of the skeletal numbers to cluster analysis. Note: for every single 1 electron donated by a ligand to a skeletal element, $\mathrm{k}=-0.5$. Also all the skeletal numbers used in the calculations are given in the appedices 1 and 2. 
N46 $\operatorname{Re}_{4}(\mathrm{CO}){ }_{16^{2-}}: \mathrm{K}=4[5.5]-16-1=5 ; \mathrm{K}(\mathrm{n})=5(4), \mathrm{K}=2(4)-(1 / 2) \mathrm{q}=5, \mathrm{n}=4, \mathrm{q}=6$, $S=4 n+q=4 n+6$ (ARACHNO FAMLY)

Skeletal numbers: $\operatorname{Re}(\mathrm{K}=5.5), \mathrm{CO}(\mathrm{K}=-1),(-1)(\mathrm{K}=-0.5)$

RAW ISOMERIC SKELETAL SHAPE OF $\mathrm{Re}_{4}(\mathrm{CO}){ }_{16}{ }^{2-}$

$\mathrm{F}_{\mathrm{B}}=4 \mathrm{n}+6=[\mathrm{BH}](4)+6 \mathrm{H}=\mathrm{B}_{4} \mathrm{H}_{10}$

$\mathrm{F}_{\mathrm{C}}=4 \mathrm{n}+6=[\mathrm{C}](4)+6 \mathrm{H}=\mathrm{C}_{4} \mathrm{H}_{6}$

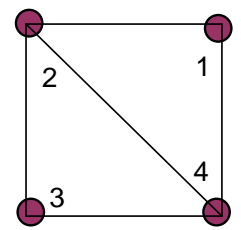

Ligand distribution

$\mathrm{K} 1=5.5-1=4.5$

$\mathrm{K} 2=5.5-1.5=4$

$\mathrm{K} 3=\mathrm{K} 1=4.5$

$\mathrm{K} 4=\mathrm{K} 2=4$

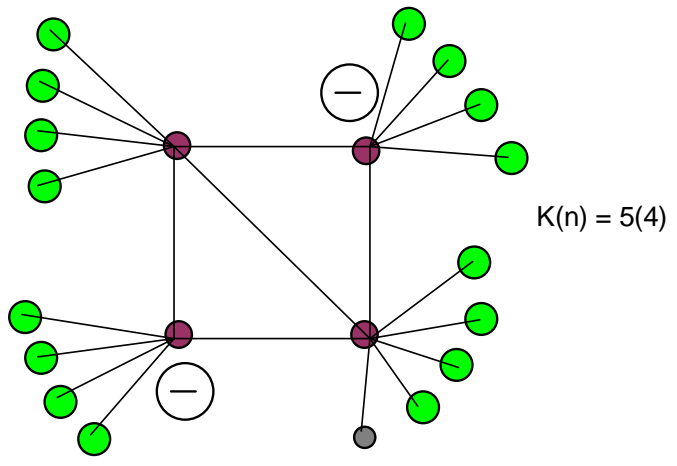

$\mathrm{O}=\mathrm{Re} \quad \mathrm{O}=\mathrm{CO}$

Cluster interconversions using series

$\mathrm{Ve}=14 \mathrm{n}+6=14(4)+6=62 \quad \mathrm{Fos}_{\mathrm{Os}}=14 \mathrm{n}+6=\left[\mathrm{Os}(\mathrm{CO})_{3}\right](4)+3 \mathrm{CO}=\mathrm{Os}_{4}(\mathrm{CO})_{15}$

$\mathrm{F}_{\mathrm{Rh}}=14 \mathrm{n}+6=\left[\mathrm{Rh}(\mathrm{H})(\mathrm{CO})_{2}\right](4)+3 \mathrm{CO}=\mathrm{Rh}_{4} \mathrm{H}_{4}(\mathrm{CO})_{11}=\mathrm{Rh}_{4}(\mathrm{CO})_{13}$

N46

N47 $\mathrm{Re}_{4} \mathrm{H}_{4}(\mathrm{CO})_{12}: \mathrm{K}=4[5.5]-2-12=8 ; \mathrm{K}(\mathrm{n})=8(4) ; \mathrm{K}=2(4)-(1 / 2) \mathrm{q}=8, \mathrm{q}=0, \mathrm{~S}=4 n+0, \mathrm{Kp}=\mathrm{C}^{1} \mathrm{C}[\mathrm{M} 3]$

Skeletal numbers: $\operatorname{Re}(K=5.5, V=11), H(K=-0.5), C O(K=-1)$

[M3], $S=4 n+2, K=2 n-1=2(3)-1=5 \quad F_{B}=4 n+0=[B H](4)+0=B_{4} H_{4}$

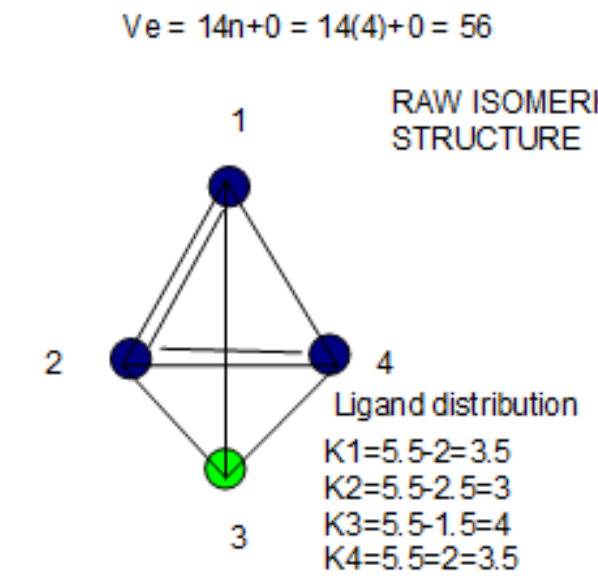

$\mathrm{FOs}_{\mathrm{s}}=14 \mathrm{n}+0=\left[\mathrm{OS}(\mathrm{CO})_{3}\right](4)+0=\mathrm{Os}_{4}(\mathrm{CO})_{12}$

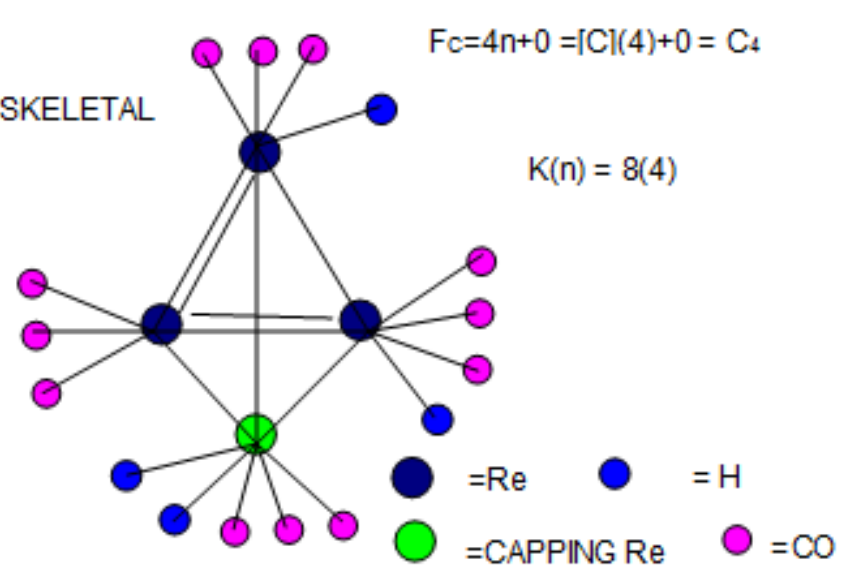

$F_{F h}=14 n+0=\left[R h(H)(C O)_{2}\right](4)=R_{4} H_{4}(C O)_{8}=R_{4}(C O)_{10}$

N47 


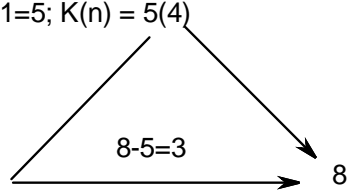

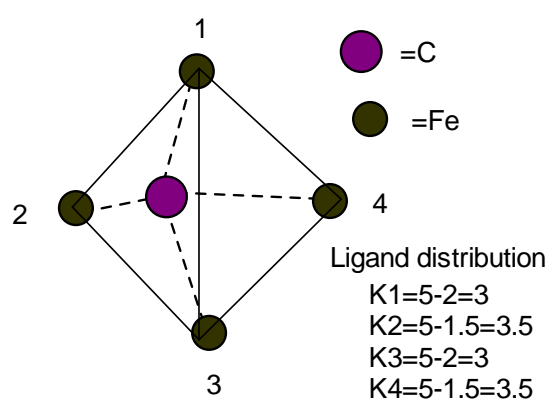

$\mathrm{Fe}(\mathrm{K}=5, \mathrm{~V}=10)$

$\mathrm{K} 4=5-1.5=3.5$

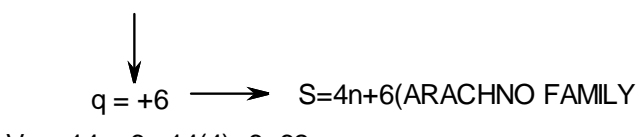

$\mathrm{Ve}=14 n+6=14(4)+6=62$

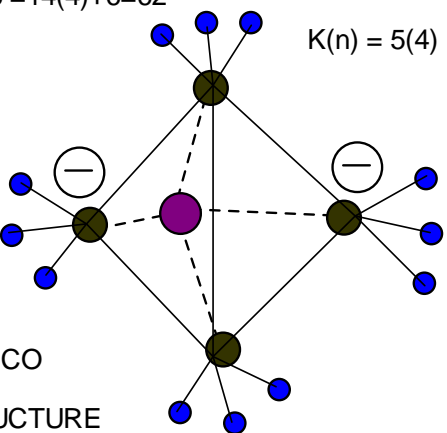

N48

Felr $_{3}(\mathrm{CO}){ }_{12} \because \mathrm{K}=1[5]+3[4.5]-12-0.5=6, \mathrm{~K}(\mathrm{n})=6(4), \mathrm{S}=4 \mathrm{n}+4(\mathrm{NIDO})$

Skeletal numbers: $\mathrm{Fe}(\mathrm{K}=5), \operatorname{lr}(\mathrm{K}=4.5), \mathrm{CO}(\mathrm{K}=-1)),(-1)(\mathrm{K}=-0.5)$

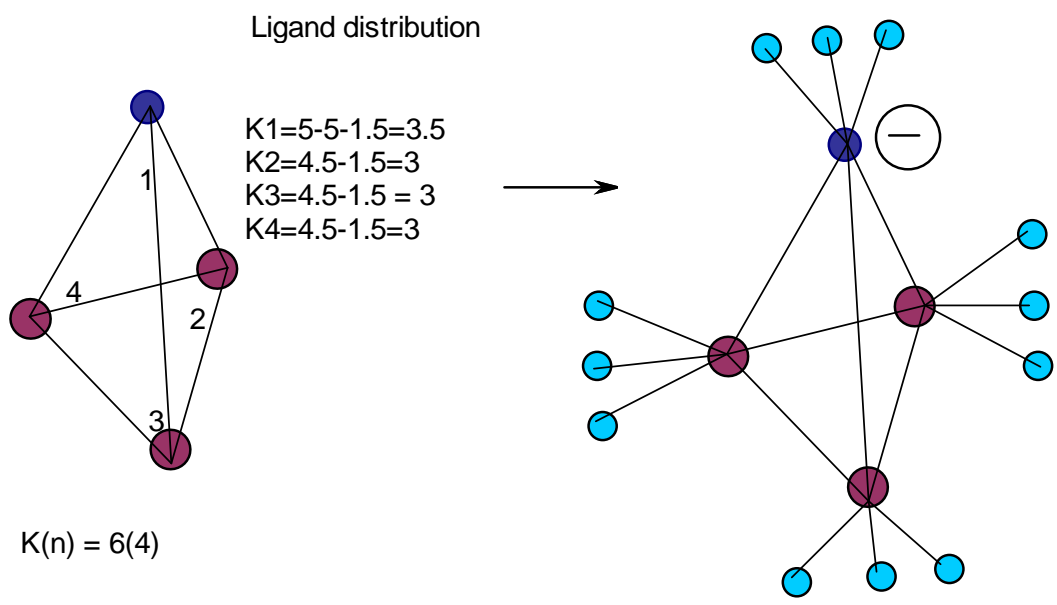

RAW SKELETAL STRUCTURE

N49

\subsection{N5 Clusters}

\section{$\mathrm{B}_{5} \mathrm{H}_{9}$ Cluster}

Skeletal numbers: $\mathrm{B}(\mathrm{K}=2.5, \mathrm{~V}=5), \mathrm{H}(\mathrm{K}=-0.5)$; $\mathrm{K}=5[2.5]-9(0.5)=8$. This means there are 5 skeletal elements linked by 8 lines. In 3 dimensions, such a shape will be a square pyramid. When presented in a 2 dimensional form and the hydrogen ligand atoms are added, the figure N51 (N51 means a cluster with 5 defined skeletal elements, and the last digit refers to the position of such a skeletal sketch - in this case it is the first sketch involving 5 skeletal elements) can be constructed. Deducing from N51, we have 5 skeletal elements [5B] and 9 hydrogen atoms to give a geometrical shape whose skeletal elements hypothetically obey the 8 electron rule by just referring to each of the linkages as a provider of 1 electron to the skeletal element, rather than the normal concept of 2 valence electrons provided by each bond. In orderto get the semblance of the normal 2 electron type of bond, we can assume that the structure N51 
undergoes some re-arrangement to give us the structure N52 where some $4 \mathrm{H}$ hydrogen atoms form bridges. Since all the boron skeletal elements in B5H9 are observed to have a $\mathrm{H}$ ligand each, then the apex B skeletal element in N52 can be viewed as retaining its linkage of 5 while the 4 basal B skeletal elements have 4 'usual' 2-electron bonds. Figure N51 was referred to as a raw isomeric skeletal structure and N52 as the rearranged isomeric skeletal structure. The raw skeletal structure when done correctly according to series fulfilling the rule of skeletal valences, generally gives a derivation of the cluster formula as is illustrated in N51. The last figure N53 just gives us insight on the general shape of the cluster.

\section{$\mathrm{N} 51-\mathrm{N} 53 \quad \mathrm{~B}_{5} \mathrm{H}_{9}$}

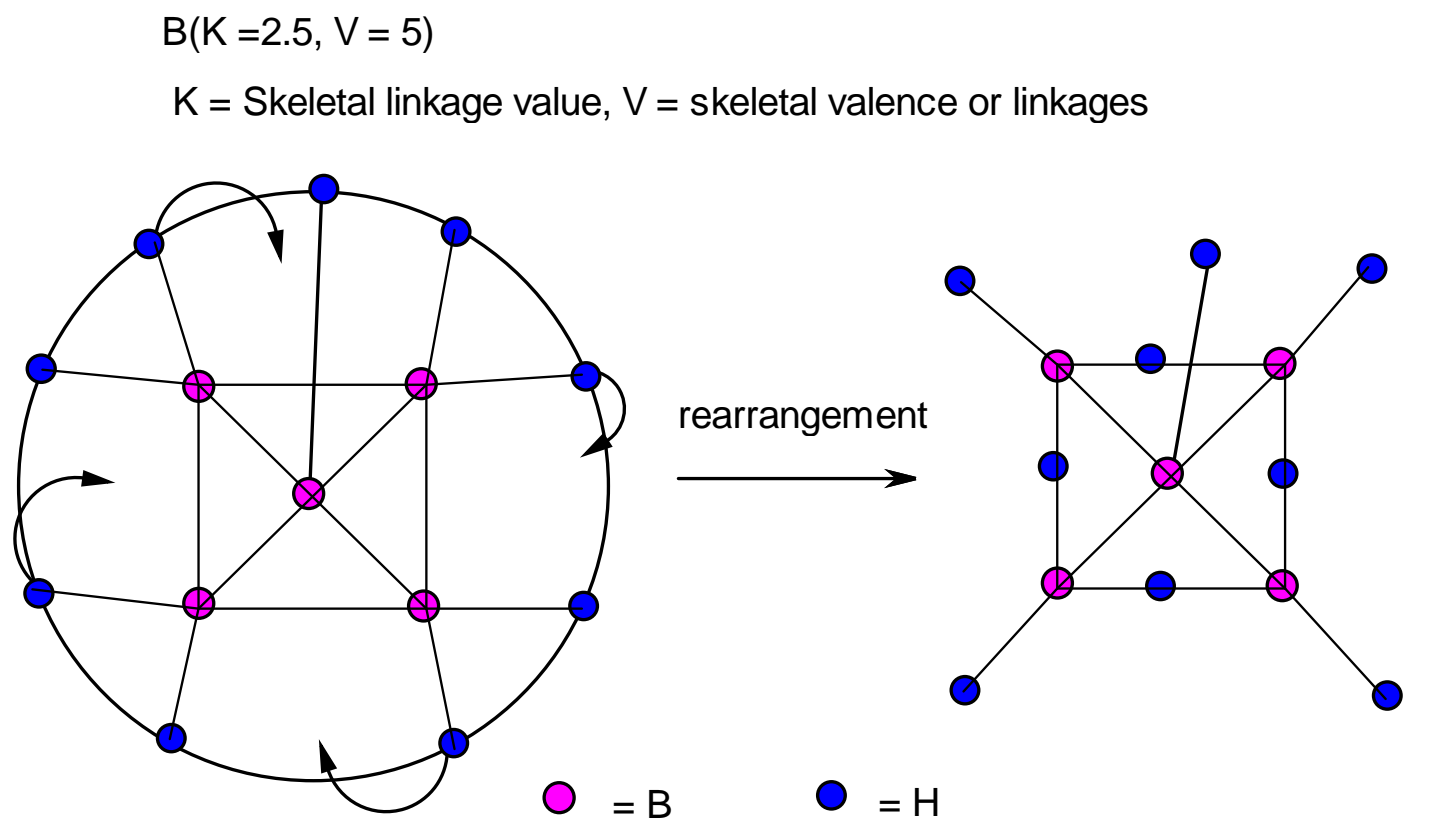

Raw skeletal structure of $\mathrm{B}_{5} \mathrm{H}_{9}$

N51
Rearranged structure of $\mathrm{B}_{5} \mathrm{H}_{9}$

N52

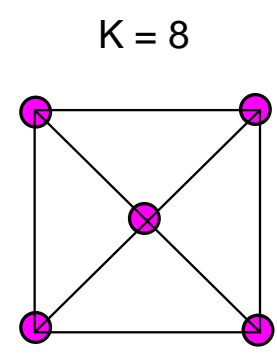

N53 
$\mathrm{N} 54 \mathrm{Os} 5(\mathrm{CO}) 16: \mathrm{K}=5[5]-16=9$;

Ligand distribution

Skeletal numbers: $\mathrm{Os}(\mathrm{K}=5, \mathrm{~V}=10), \mathrm{CO}(\mathrm{K}=-1)$

$K(n)=9(5)$
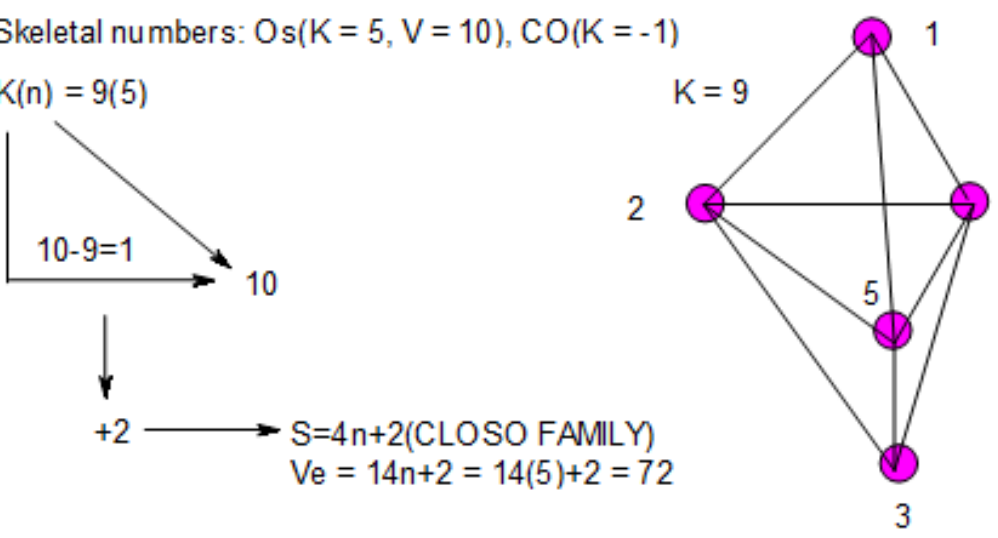

$\mathrm{K} 1=5-1.5=3.5$

$\mathrm{K} 2=5-2=3$

$\mathrm{K} 3=5-1.5=3.5$

$\mathrm{K} 4=5-2=3$

$4 \quad \mathrm{~K} 5=5-2=3$

$O=\mathrm{Os}$
$=\mathrm{CO}$

RAW SKELETAL SHAPE OF $\mathrm{Os} 5(\mathrm{CO}) 18$

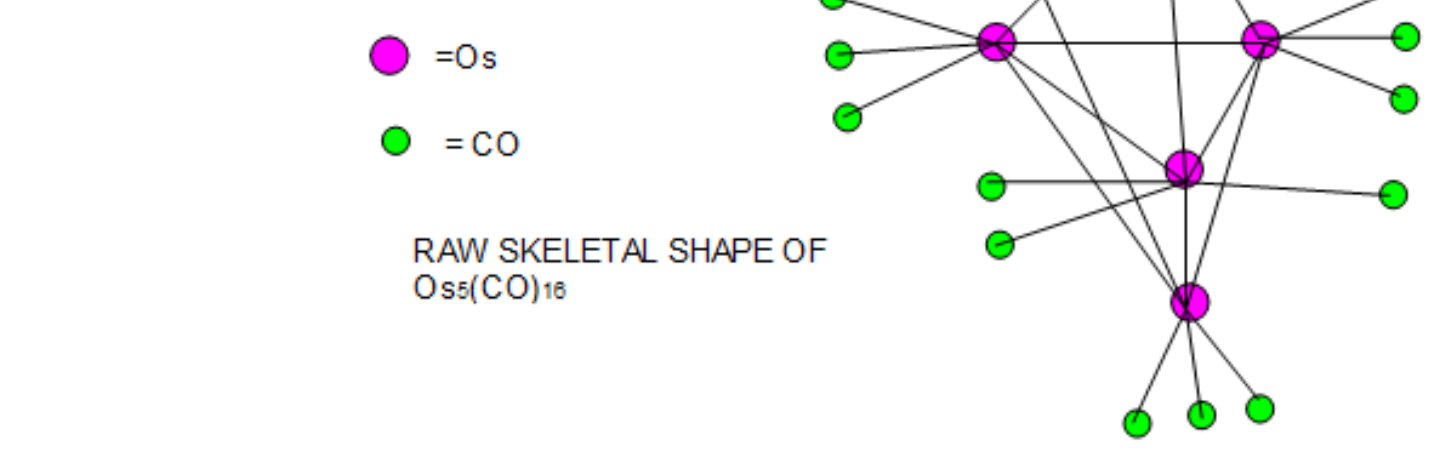

N54

N55 AU4Re $(H) 4 L 6^{*}: K=4[3.5]+1[5.5\}-4(0.5)-\Theta(1)+1(0.5)=12 ; n=4+1=5, K(n)=12(5), S=4 n-4$, $K p=C^{3} \mathrm{C}[\mathrm{MR}]$

Skeletal numbers : $A u(K=3.5), \operatorname{Re}(K=5.5), H(K=-0.5), L(K=-1),(+1)(K=0.5)$

$V e=14 n-4=14(5)-4=68 ; V F=4[11]+1[7]+4+6(2)-1=68$

Ve $=$ CLUSTER VALENCE ELEC TRONS FROMSERIES FORMULA VF= VALENCE ELECTRONS FROMCLUSTER FORMULA

$K 1=1[3.5]-6(0.5)=0.5, K 2=1[3.5]+0.5-3=1$

$\mathrm{K} 3=5.5-2=3.5, \mathrm{~K} 4=3.5-2=1.5, \mathrm{~K} 5=3.5-2=1.5$
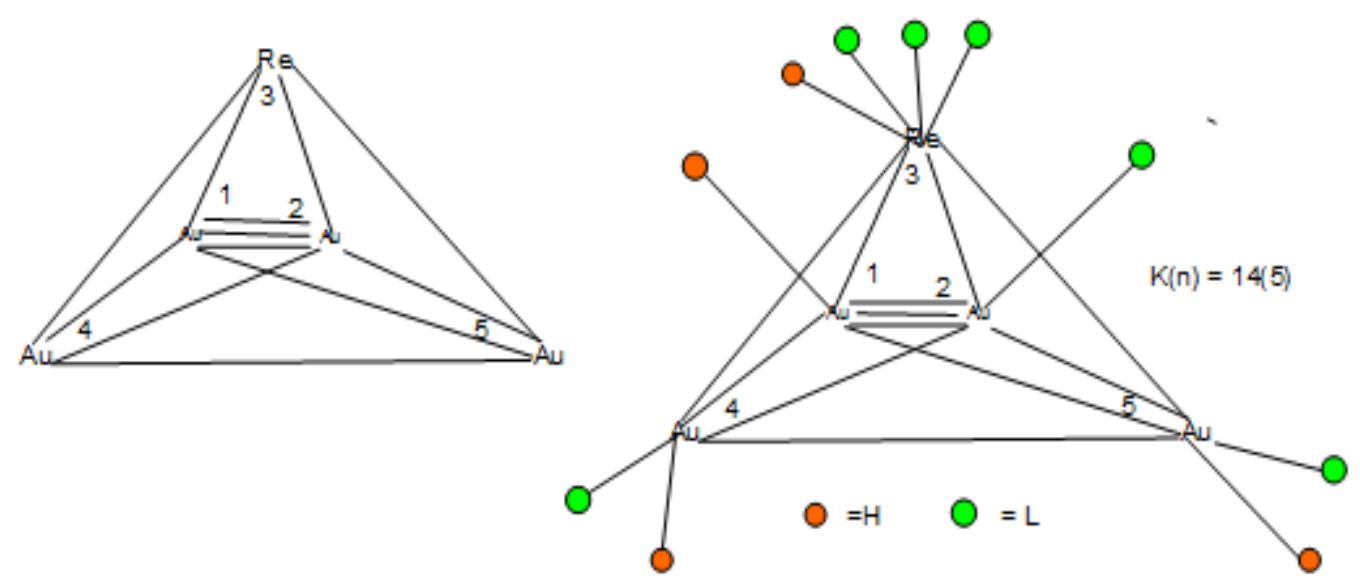

N55 


\section{N6 CLUSTERS}

N61

$$
\mathrm{Os}_{6}(\mathrm{CO})_{18}: \mathrm{K}=6[5]-18=12, \mathrm{n}=6, \mathrm{~K}(\mathrm{n})=12(6) ; \mathrm{S}=4 \mathrm{n}+0, \mathrm{Kp}=\mathrm{C}^{1} \mathrm{C}[\mathrm{M} 5]
$$

The capping symbol tells us the cluster is a mono-capped trigonal bipyramid.

Let us also have a look at the flow of $\mathrm{K}(\mathrm{n})$ numbers:

[12(6), monocapped]; [9(5), trigonal bipyramid]; [6(4), terahedral], [3(3), triangle] Hence, $K(n)=12(6)$ is not an $O_{h}$ symmetry.

$$
K(n)=3(3)
$$

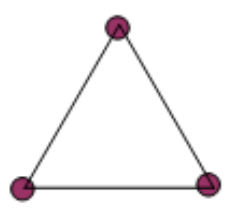

$$
\begin{aligned}
& S=4 n+6 \\
& K p=C^{-2} C[M 5]
\end{aligned}
$$

$$
K(n)=6(4)
$$
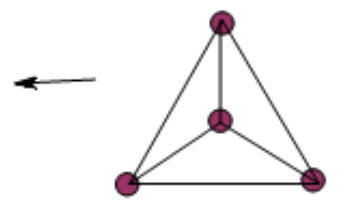

$$
\begin{aligned}
& S=4 n+4 \\
& K p=C^{-1} C[M 5]
\end{aligned}
$$

$$
K(n)=9(5)
$$
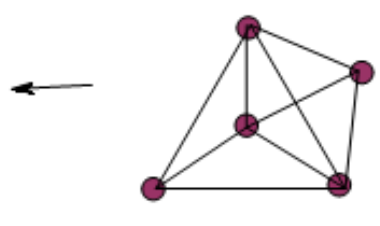

$$
\begin{aligned}
& S=4 n+2 \\
& K p=C^{0} C[M 5]
\end{aligned}
$$

$K(n)=12(6)$

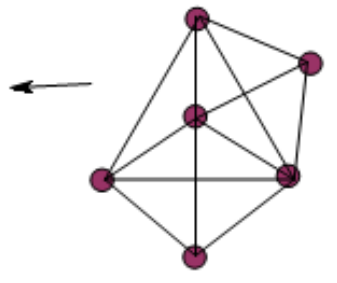

$$
\begin{aligned}
& S=4 n+0 \\
& K p=C^{1} C[M 5]
\end{aligned}
$$

N61

$K(n)=12(6)$ cluster is described as a mono-capped trigonal bipyramid or a bi-capped tetrahedral. Despite the expectation for it to be an octahedral since $\mathrm{K}=12$, it is not, as the cluster is obeying the series rules rather than geometrical rules.

\section{AN EXAMPLE ILLUSTRATING THE CORRELATION OF VERTICAL(RUDOLPH TYPE) CLUSTERS.}

$$
\mathrm{Os}_{6}(\mathrm{CO}){ }_{18^{2-:}} \mathrm{K}=6[5]-18-1=11 ; \mathrm{K}(\mathrm{n})=11(6), \mathrm{S}=4 \mathrm{n}+2 \mathrm{OR} \mathrm{K}=2 \mathrm{n}-1=2(6)-1=11
$$

According to the series, this cluster has an ideal $\mathrm{O}_{\mathrm{h}}$ symmetry, despite its having a $\mathrm{K}$ value of 11 .

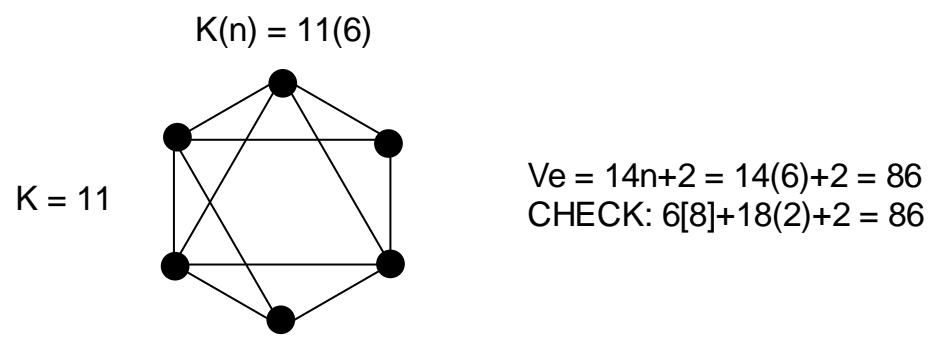

N62 
N63 $\mathrm{Fe}_{4}(\mathrm{CO})_{12}(\mathrm{PR})_{2}: \mathrm{K}=4[5]+2[1.5-0.5]-12=10 ; \mathrm{K}(\mathrm{n})=10(6), \mathrm{S}=4 \mathrm{n}+4$

$$
\mathrm{Kp}=\mathrm{C}^{-1} \mathrm{C}[\mathrm{M} 7]
$$

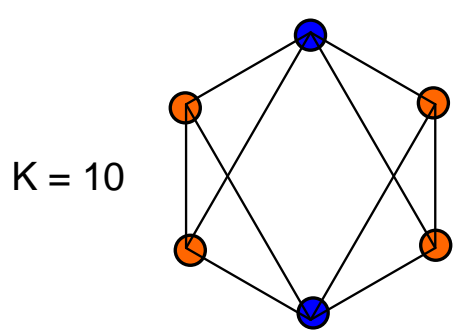

$K(n)=10(6)$

NIDO CLUSTER

N63

N64 $\mathrm{Fe}_{4}(\mathrm{CO})_{12}(\mathrm{PR})_{2}: \mathrm{K}=4[5]+2[1.5-0.5]-11=11 \mathrm{~K}(\mathrm{n})=11(6), \mathrm{S}=4 \mathrm{n}+2$

$$
\mathrm{Kp}=\mathrm{C}^{0} \mathrm{C}[\mathrm{M} 6]
$$

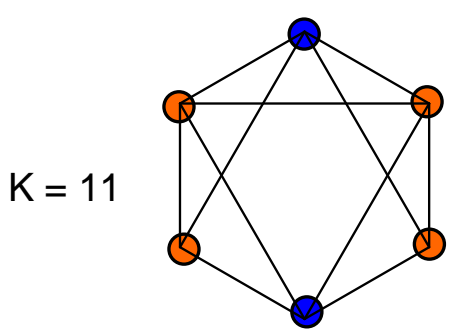

N64
$K(n)=11(6)$

CLOSO CLUSTR

DERIVATION OF K FROM CLUSTER FRAGMENTS AND SKELETAL NUMBERS

$$
\mathrm{B}_{6} \mathrm{H}_{6}{ }^{2-}
$$
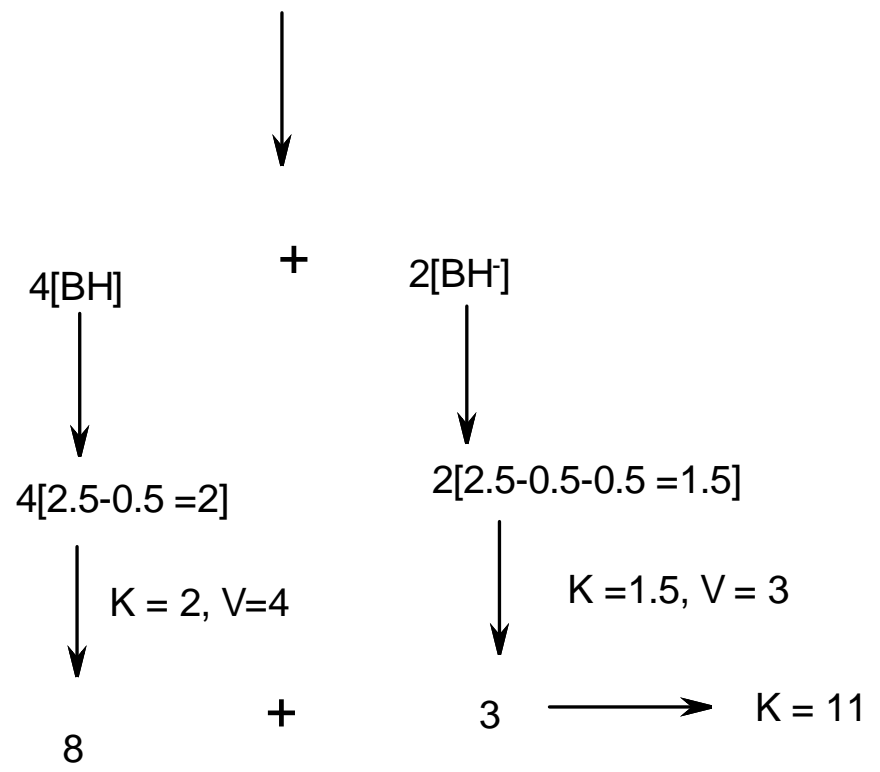


\section{DERIVATION OF K FROM CLUSTER FRAGMENTS AND SKELETAL NUMBERS}

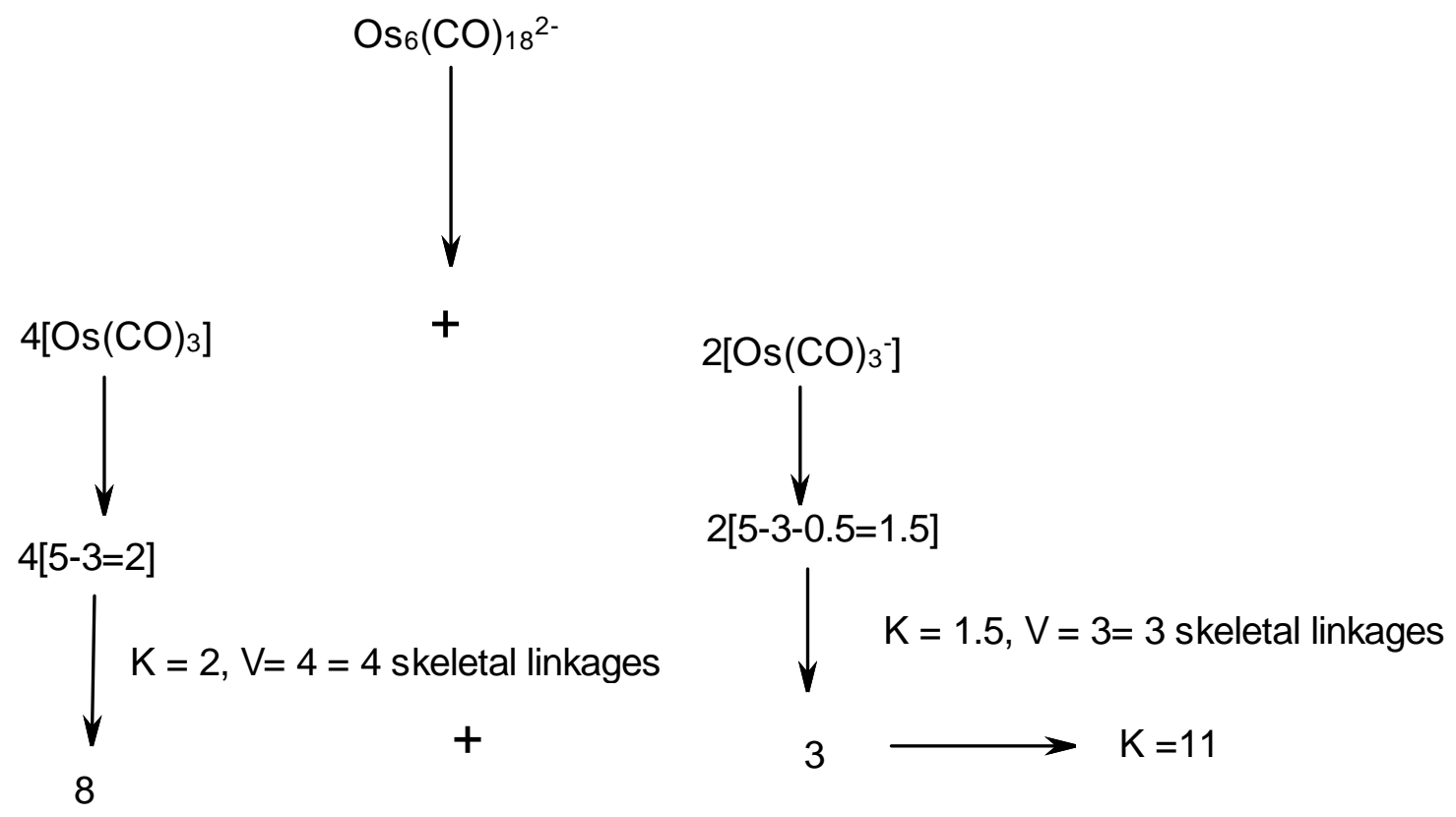

THE SIMILARITY OF SKELETAL STRUCTURES OF $\mathrm{B}_{6} \mathrm{H}_{6}{ }^{2-}$ AND Os ${ }_{6}(\mathrm{CO}){ }_{18^{2-}}$

$$
K(n)=11(6)
$$

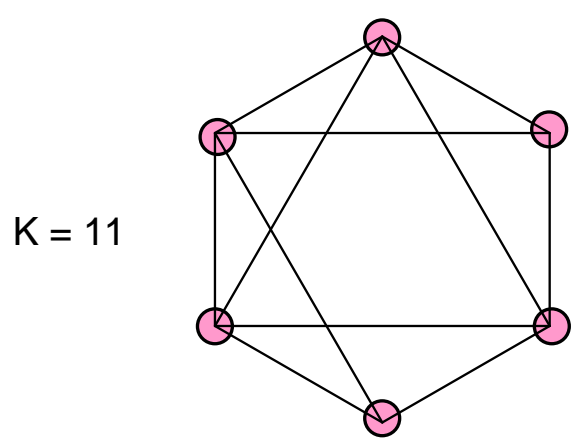

$O=B$

N65

$$
K(n)=11(6)
$$

$\mathrm{K}=11$

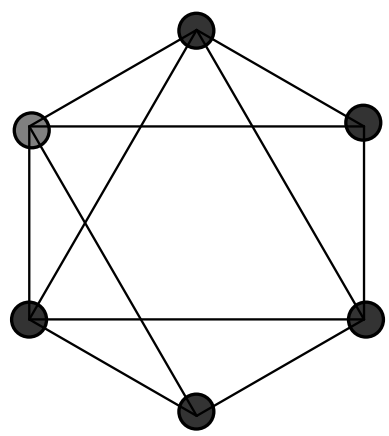

$=$ Os

N66 
DIFFERENT FORM OF K(n) = 11(6) SKELETAL ISOMER THAT OBEYS THE SKELETAL VALENCE RULE

DERIVATION OF K(n) FROM FRAGMENTS

N67 (CoCp) $\mathrm{C}_{2} \mathrm{~B}_{3} \mathrm{H}_{5}$
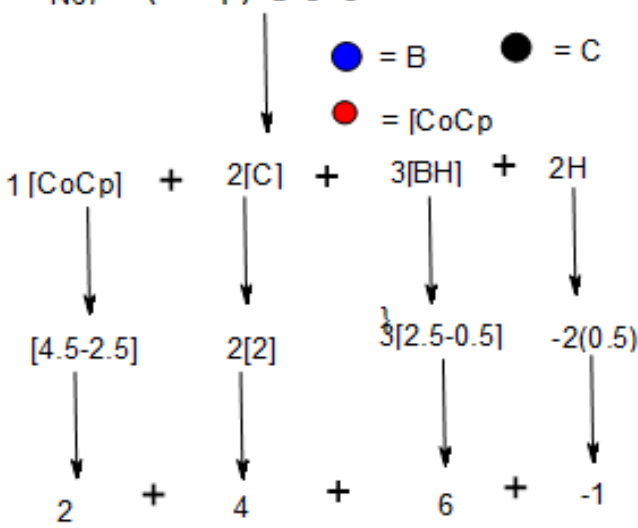

$K(n)=11(6)$

The hydrogen atoms and $\mathrm{Cp}$ are ligands.

$[\mathrm{CoC}], \mathrm{K}=2, \mathrm{~V}=4$
$\mathrm{K}=11, \mathrm{n}=6$

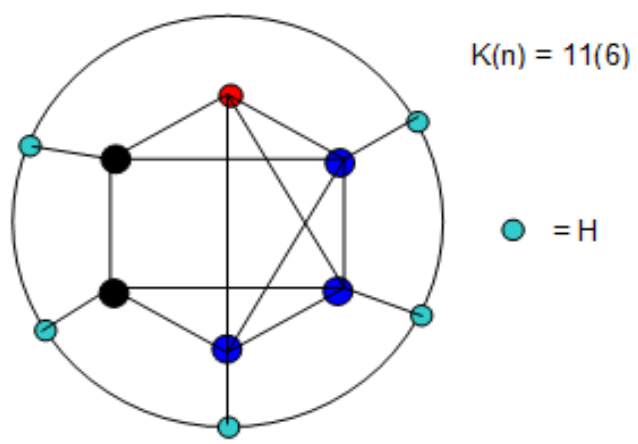

Raw isomeric skeletal structure of $(\mathrm{CoCp}) \mathrm{C}_{2} \mathrm{~B}_{3} \mathrm{H}_{5}$

$[\mathrm{B}], \mathrm{V}=5$

$[\mathrm{C}], \mathrm{V}=4$

[CoCpl, V= 4

The valences of the fragments are obeyed.

N67

As can be seen from the skeletal figures of both $\mathrm{B}_{6} \mathrm{H}_{6}{ }^{2-}$ and $\mathrm{Os}_{6}(\mathrm{CO})_{18}{ }^{2-}$, each figure has 4 corners of 4 linkages each and 2 corners of 3 linkages each.

N68 Ru6 $(\mathrm{C})(\mathrm{CO})_{17}: \mathrm{K}=6[5]-2-17=11, \mathrm{~K}(\mathrm{n})=11(6), \mathrm{S}=4 \mathrm{n}+2(\mathrm{CLOSO} F A M I L Y)$

Skeletal numbers: $\mathrm{Ru}(\mathrm{K}=5, \mathrm{~V}=10), \mathrm{C}(\mathrm{K}=-2), \mathrm{CO}(\mathrm{K}=-1)$

$$
K(n)=11(6)
$$

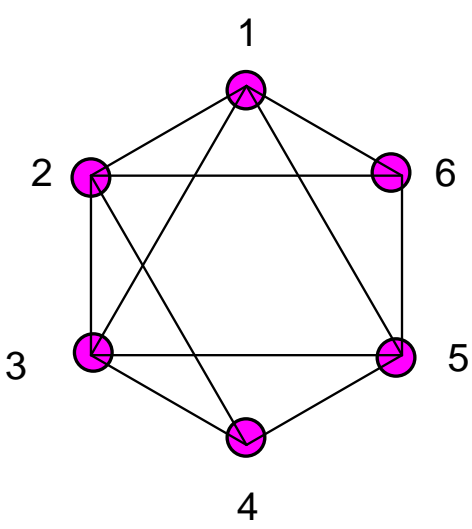

Ligand distribution
$\mathrm{K} 1=5-2=3$
$\mathrm{O}=\mathrm{Ru}$
$\mathrm{K} 2=5-2.5=2.5$
$\mathrm{K} 3=5-2.5=2.5$
$\mathrm{K} 4=5-1.5=3.5$
$\mathrm{K} 5=5-2.5=2.5$
$\mathrm{K} 6=5-2=3$
$\mathrm{KT}=17$

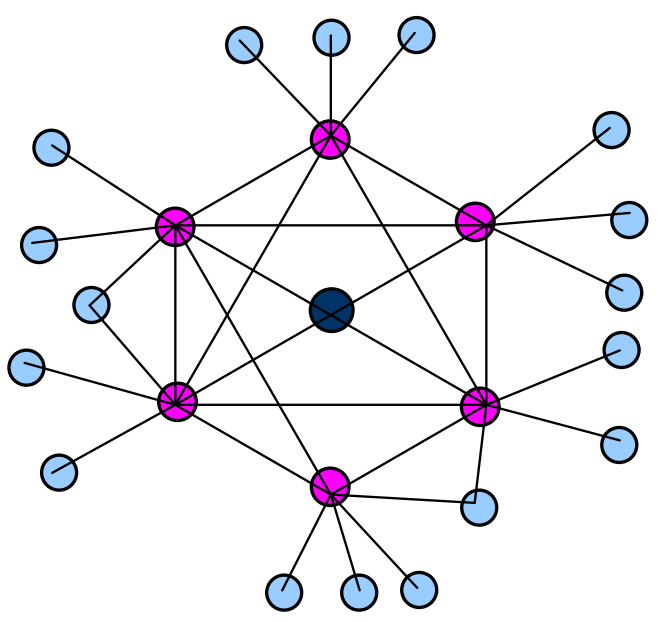

RAW SKELETAL STRUCTURE

N68 


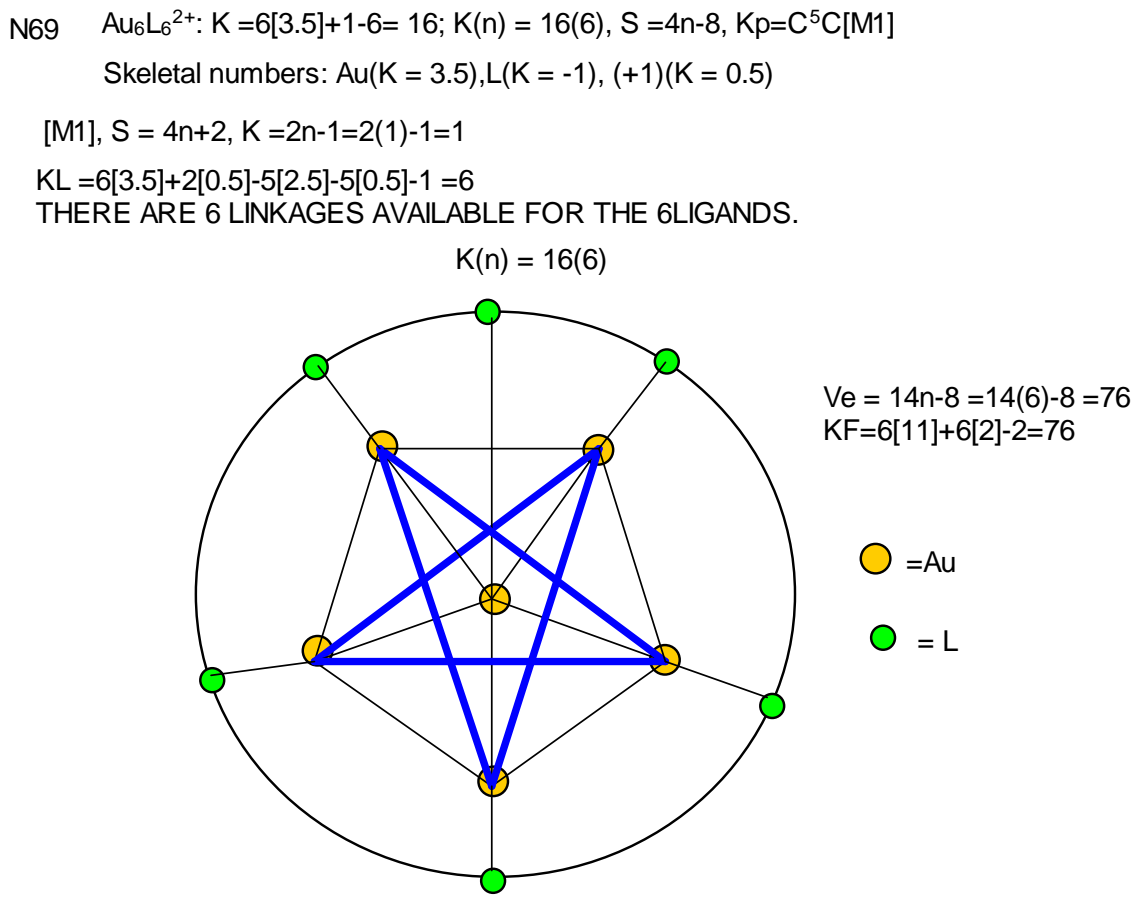

N69

According to the series method, there is one atom in the nucleus which is capped by 5 others.

According to the series symbol $\mathrm{Kp}=\mathrm{C}^{5} \mathrm{C}[\mathrm{M} 1]$, it implies that the cluster has ONE skeletal element in the nucleus with 5 other capping elements. Each of the 5 capping elements has 3 linkages giving a total of 15 linkages. Since the cluster has a $\mathrm{K}$ value 16 the nuclear element [M1] has an intrinsic $\mathrm{K}$ value of 1 , and this is in agreement with the series prediction. According to the series, the nuclear cluster fragment, [M1] obeys the CLOSO series formula $\mathrm{S}=4 \mathrm{n}+2$ and $\mathrm{K}$ $=2 \mathrm{n}-1=2(1)-1=1$ in agreement with the above prediction. It has been found easier for clusters with nuclearity index 1-13 (N1-N13) (Kiremire, 2017d) to use the capping symbol as a guide to construct the RAW SKELETAL STRUCTURE of clusters. In this regard, the symbol $\mathrm{C}^{5}$ acts as a guide to enable us construct a 2-dimensional shape of the cluster. Thus, we can use a 5-membered structure for the capping cluster with a mono-skeletal nucleus; thus the $\mathrm{Au}_{6} \mathrm{~L}_{6}{ }^{2+}$ structural frame-work shown in figure N69. There are 5 capping elements and each is connected to the nuclear skeletal element. This utilizes 5 linkages. The 5 periphery skeletal elements are connected to one another giving us another 5 skeletal linkages. Then there are internal alternating linkages which are also 5 . This gives us a total of $5+5+5$ $=15$. This agrees with the capping symbol $\mathrm{C}^{5}$ which indicates there are 5 capping elements each of which consumes 3 linkages. The calculation of $\mathrm{K}$ value from $\mathrm{Au}_{6} \mathrm{~L}_{6}{ }^{2+}$, gives us $\mathrm{K}=16$ for the entire cluster. On the surface, it appears as if there is ONE missing linkage. In order to find it, we must look at the whole capping symbol, $\mathrm{Kp}=\mathrm{C}^{5} \mathrm{C}[\mathrm{M} 1]$. If $\mathrm{C}^{5}$ represents 15 linkages, then the missing link must be hidden within the [M1] CLOSO fragment. Since the capping nuclei belong to the CLOSO FAMILY, the mono-skeletal nucleus obeys the series formula $S=4 n+2$ and $K=2 n-1$. Since $\mathrm{n}=1$ for a mono-skeletal fragment, then its $\mathrm{K}$ value is given by $\mathrm{K}=2 \mathrm{n}-1=2(1)-1=1$. Therefore the grand total of cluster linkages $=5+5+5+1=16$ which takes into account the one linkage associated with the nucleus.

\subsection{Distribution of Ligands in Golden Clusters}

The number of ligands associated with golden clusters is usually relatively small. Therefore a simple calculation can act as a guide on how the ligands are distributed among all the skeletal elements. 
N610 Aus $\mathrm{L6}^{2+}$

$$
\begin{aligned}
& \text { Skeletal numbers: } \mathrm{Au}(\mathrm{K}=3.5, \mathrm{~V}=7), \mathrm{L}(\mathrm{K}=-1),(+1)(\mathrm{K}=0.5) \\
& \mathrm{K}=6[3.5]-6(1)+2(0.5)=16, n=6, K(n)=16(6), S=4 n-8, K p=C^{5} \mathrm{C}[\mathrm{M} 1]
\end{aligned}
$$

This means, there is one skeletal element in the cluster nucleus surrounded by other 5 capping skeletal elements

skeletal elements are numbered as shown in N610.

\section{UGAND DISTRIBUTION SUMMARIZED}

\section{PERIPHERY AU ELEMENTS}

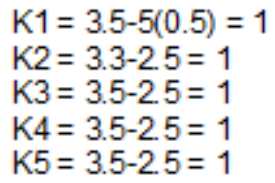

\section{NUCLEAR ELEMENT $\left[\mathrm{Au}^{2+}\right\rceil$} The closo element [M1] obeys $S=4 n+2$, $K=2 n-1=2(1)-1=1$ Hence $K 6=3.5+2(0.5)-5(0.5)-1=1$ THIS MEANS EACH OF THE NUMBERED Au SKELETAL ELEMENTS, 1-6 WIL BIND 1 UGAND. THIS IS REFLECTED IN N69.

3

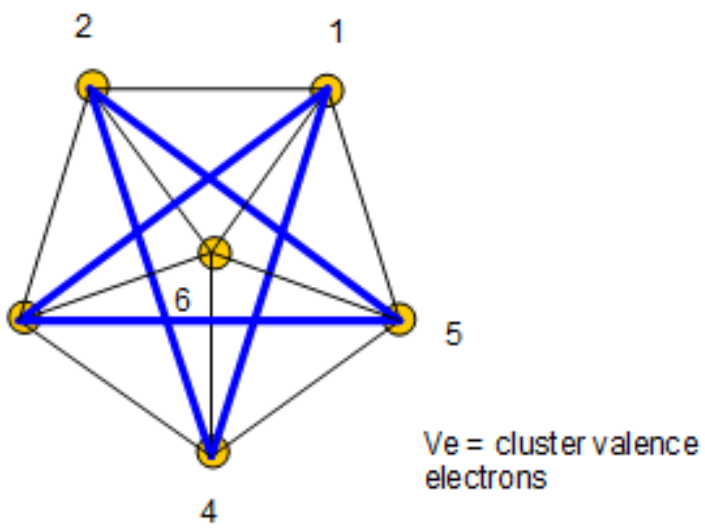

N610

The first approach is to consider the cluster $\mathrm{Au}_{6} \mathrm{~L}_{6}{ }^{2+}$ as comprising of $\mathrm{Au}_{6}{ }^{2+}$ fragment and $6 \mathrm{~L}$. The skeletal linkages of the naked fragment $\mathrm{Au}_{6}{ }^{2+}$ subtracting the skeletal linkages of the cluster will give us the linkages remaining to bind the ligands.

$\mathrm{The} \mathrm{Au}_{6}{ }^{2+}$ fragment has a total of $6[3.5]+2(0.5)=22$ linkages available. According to the calculation, 16 of those are utilized for the internal binding of the skeletal elements. Hence, the remaining linkages are available for the ligands. That is, $\mathrm{KL}=22-16=6$, This means there are 6 linkages available for 6 ligands distributed onto 6 gold skeletal elements as shown in $\mathrm{N} 69$.

Alternatively, we can calculate the number of skeletal linkages available for every individual skeletal element as follows:

$\mathrm{K} 1=1[3.5]-5(0.5)=3.5-2.5=1 ; \mathrm{K} 2$ is the same as $\mathrm{K} 1=1=\mathrm{K} 3=\mathrm{K} 4=\mathrm{K} 5=\mathrm{K} 6$. This information indicates that each skeletal element will be assigned to one ligand as indicated in N69. The ideal raw skeletal structure will have a 2-dimentional symmetry of $\mathrm{D}_{5 \mathrm{~h}}$. The outside circle in $\mathrm{N} 69$ is to assist in adding the ligands to the periphery gold atoms. The actual shape has been described as octahedral or edge-sharing bi-tetrahedral (Mingos, 1984). The two dimensional skeletal framework N69 looks like a star. The cluster valence electrons: The cluster valence electrons have been calculated using the series formula (Ve) and the result was compared with the one calculated from the cluster formula, VF. Always, Ve = VF indicating the authenticity of the series formula. Clearly, the skeletal structural frameworks of clusters follow an exact mathematical precision of $4 \mathrm{n}$ cluster series. 
N611 Aus $\mathrm{R}_{6} \mathrm{Br}_{2}(\mathrm{CO})_{2}{ }^{2-}: \mathrm{R}=\mathrm{CF}_{3} \quad \mathrm{~K}=6\left[3.51-3-1-2-1=14, \mathrm{n}=6, \mathrm{~K}(\mathrm{n})=14(6), \mathrm{S}=4 \mathrm{n}-4, \mathrm{Kp}=\mathrm{C}^{3} \mathrm{ClM} 3\right]$

$\mathrm{Ve}=14 n-4=14(6)-4=80 ; \mathrm{VF}=6[11]+6+2+4+2=80$

The cluster has a nucleus of 3 skeletal elements surrounded by three capping skeletal elements.

Possible skeletal shape as in figure N611

$\mathrm{K} 1=3.5-5(0.5)=3.5-2.5=1 ; \mathrm{K} 2=3.5+1(-.5)-4(0.5)=3.5-2.5=1 ; \mathrm{K} 3=\mathrm{K} 2=1, \mathrm{~K} 4=3.5-5(0.5)=1$, $\mathrm{K} 5=\mathrm{K} 4=1, \mathrm{~K} 6=\mathrm{K} 5=1$

Skeletal numbers: $\mathrm{Au}(\mathrm{K}=3.5, \mathrm{~V}=7), \mathrm{R}(\mathrm{K}=-0.5), \mathrm{Br}(\mathrm{K}=-0.5), \mathrm{CO}(\mathrm{K}=-1),(-1)(\mathrm{K}=-0.5)$
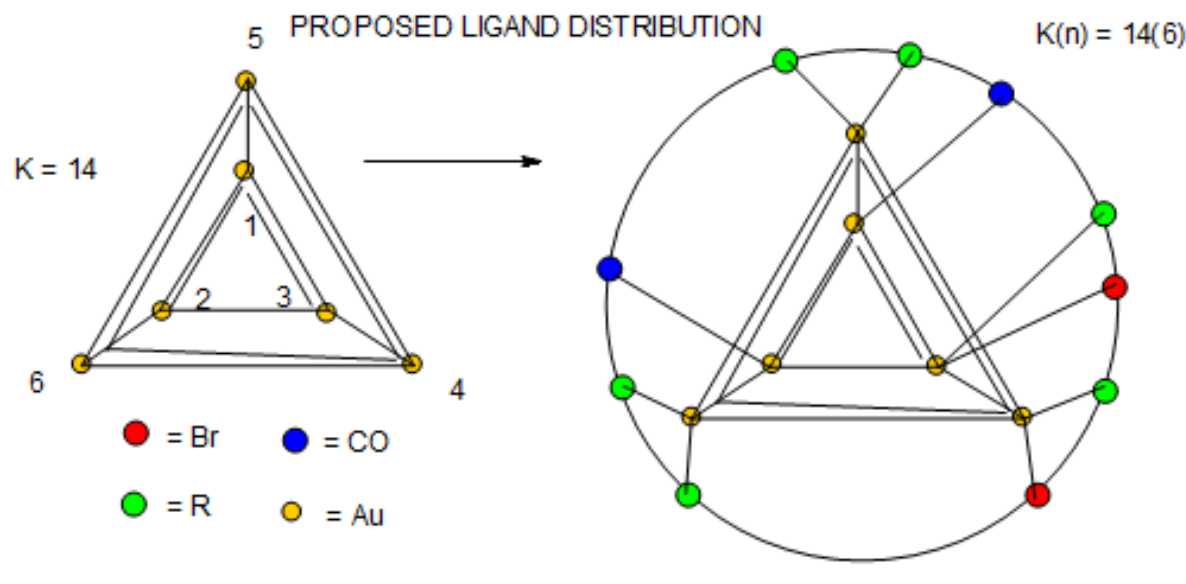

ideal skeletal sketch of $\mathrm{Au}_{5} \mathrm{R}_{6} \mathrm{Br}_{2}(\mathrm{CO})_{2}{ }^{2-}$

N611

The series acts as a guide. Although the prediction is 3 skeletal elements capping on another set of three skeletal elements, what is observed is simply two sets of 3 golden skeletal elements as shown in N612.

$\mathrm{Kp}=\mathrm{C}^{3} \mathrm{C}[\mathrm{M} 3]$

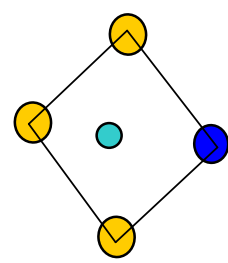

$\mathrm{O}=\mathrm{Au}$

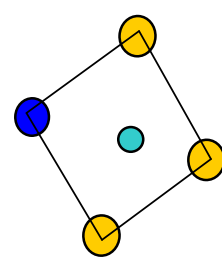

$=\mathrm{Br}$
$\mathrm{O}=\mathrm{CO}$

Sketch of the observed skeletal structure of $\mathrm{Au}_{6} \mathrm{R}_{6} \mathrm{Br}_{2}(\mathrm{CO})_{2}{ }^{2-}$

N612

N71 $\mathrm{Os}_{7}(\mathrm{CO})_{21}$ : Skeletal numbers; Os $(\mathrm{K}=5, \mathrm{~V}=10), \mathrm{CO}(\mathrm{K}=-1), \mathrm{K}=7[5]-21=14, \mathrm{n}=7, \mathrm{~K}(\mathrm{n})=14(7), \mathrm{S}=4 \mathrm{n}+0, \mathrm{Kp}$ $=\mathrm{C}^{1} \mathrm{C}[\mathrm{M} 6]$. This symbol predicts a mono-capped octahedral complex and this is what is observed (Hughes \&Wade, 200; Housecroft \& Sharpe, 2005). 


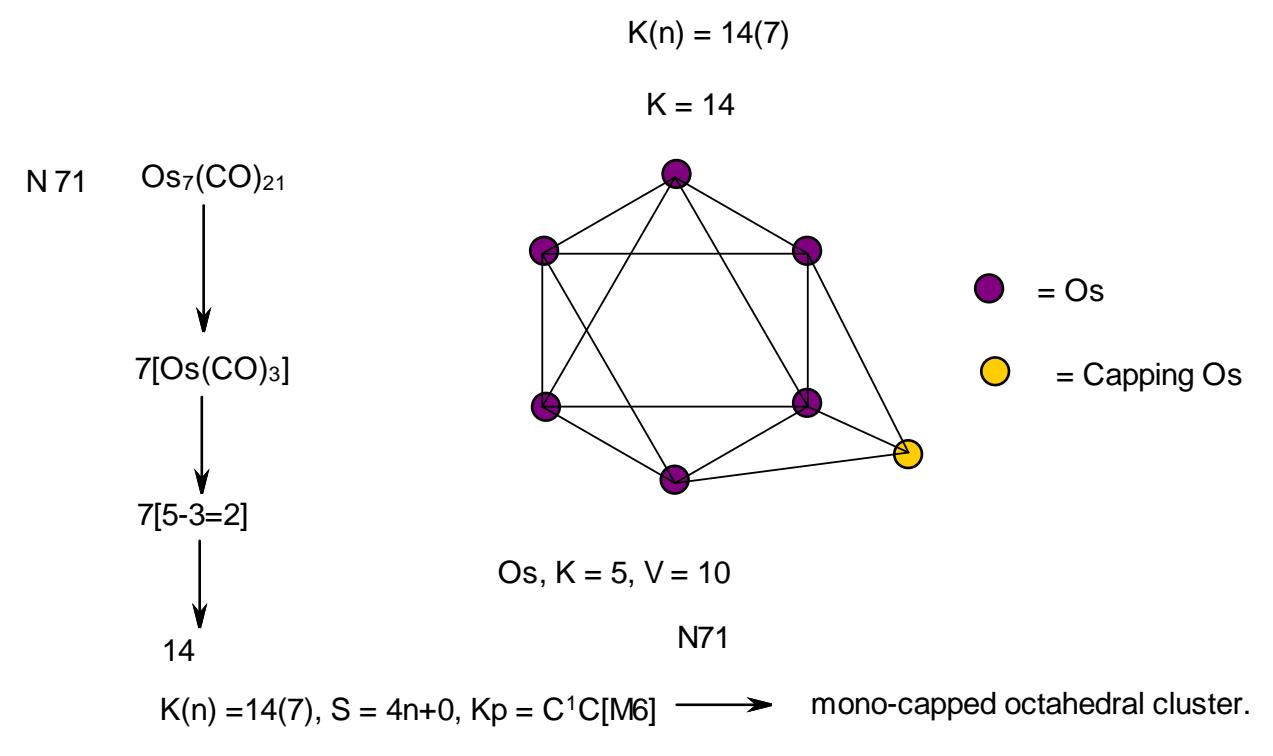

$\mathrm{Ve}=14 \mathrm{n}+0=14(7)+0=98 ;$ CHECK: $\mathrm{VF}=7[8]+21(2)=98$

The cluster valence electrons number from the series formula $(\mathrm{Ve})$ is the same as the number of valence electrons calculated from the cluster formula (VF) itself.

$N 72$ IrRu6 $(C O)_{23}: K=1[4.5]+6[5]-23-0.5=11 ; K(n)=11(7), S=4 n+6, K p=C^{-2} C[M 9]$

$V e=14 n+6=14(7)+6=104 ; V F=1[9]+6[8]+23(2)+1=104$

\section{LIGAND DISTRIBUTION}

$\mathrm{K} 1=4.5-2.5=2 ; \mathrm{K} 2=5-1.5=3.5 ; \mathrm{K} 3=3.5 ; \mathrm{K} 4=3.5 ; \mathrm{K} 5=5-1=4, \mathrm{~K} 6=3.5 ; \mathrm{K} 7=3.5$
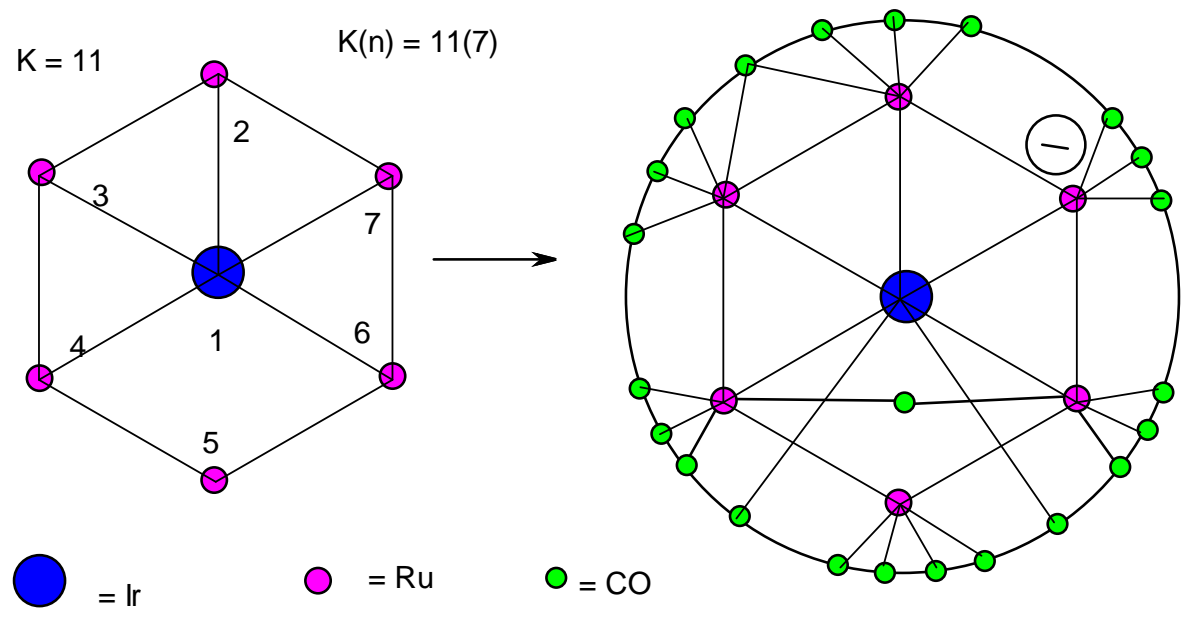

Ideal skeletal sketch of IrRu(CO) $23^{-}$(Adams, et al, 2011)

N72 


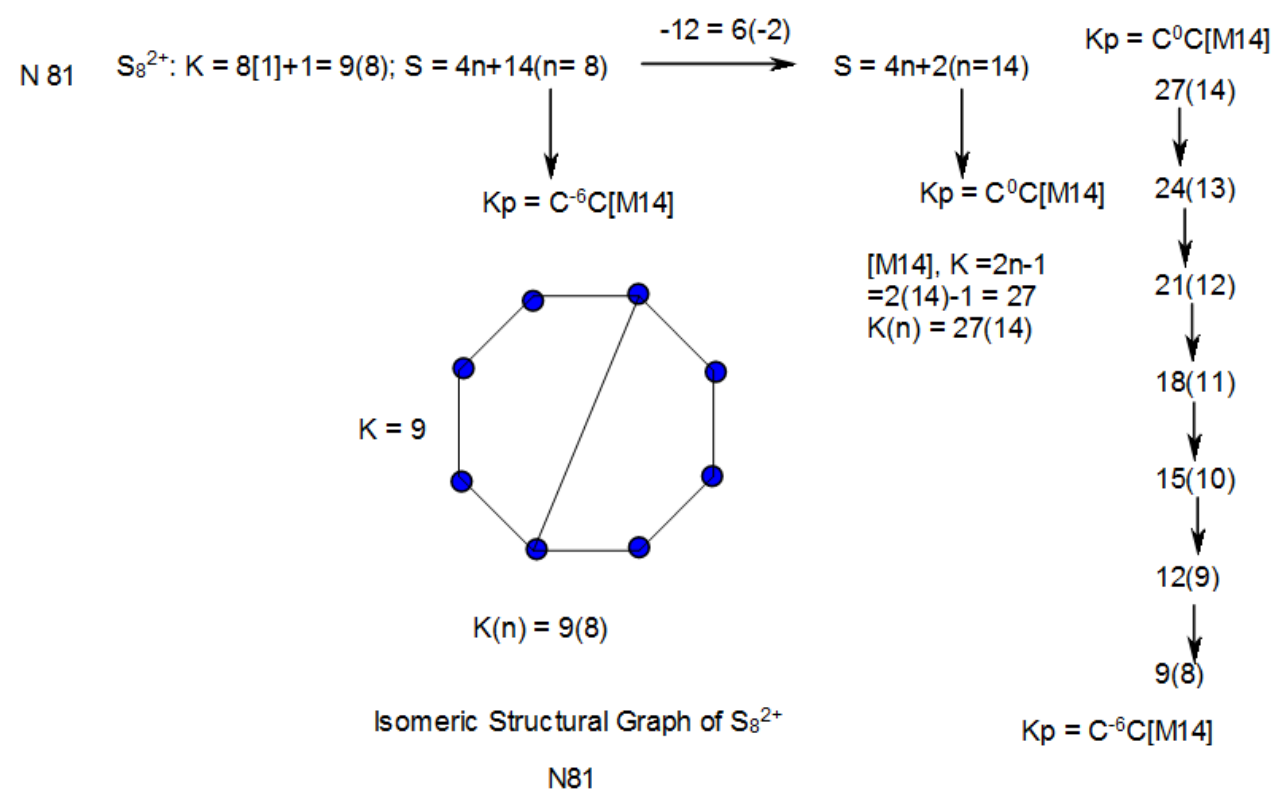

Let us consider the first example $\mathrm{G} 1 \mathrm{~S}_{8}{ }^{2+}$ cluster as an illustration. From the appendix 1, sulphur has a $\mathrm{K}$ value of 1 . The $\mathrm{K}$ value of $8 \mathrm{~S}$ skeletal elements is simply $8 \times 1=8$. Also we know from series, that a unit of positive charge $(+1)$ is assigned a $K$ value of 0.5 . So for $2+$ charge the $K$ value $=2 \times 0.5=1$. Hence the $K$ value of $S_{8}{ }^{2+}=8+1=9$. Since there are 8 skeletal elements the $K(n)$ parameter is $K(n)=9(8)$. This means that the cluster will have 9 linkages and this has been found to be the case (Housecroft \& Sharpe, 2005). We also know that K =2n- $1 / 2 \mathrm{q}$; hence $9=2(8)-1 / 2 \mathrm{q}$ and this gives the value of $q=2[16-9]=14$. Since the cluster series $S=4 n+q$, this gives $u s=4 n+14$. We also know that there are a good number of isomers with $\mathrm{K}=9$ (nine linkages) that can be constructed, but we can only sketch one. This is given in G1 below. Categorization of the cluster based on CLOSO $(\mathrm{S}=4 \mathrm{n}+2)$ vertical series $(\Delta \mathrm{K}= \pm 3, \Delta \mathrm{n}= \pm 1)$ has been developed. Since the cluster belongs to the series $S=4 n+14(n=8)$, it has to go through the stages $4 n+12(n=9) \rightarrow 4 n+10(n=10) \rightarrow 4 n+8(n=11) \rightarrow 4 n+6(n=12) \rightarrow 4 n+4(n=13) \rightarrow 4 n+2(n=14)$. Clearly, the cluster is 6 steps below the CLOSO step and hence its capping symbol can be expressed as $\mathrm{Kp}=\mathrm{C}^{-6} \mathrm{C}[\mathrm{M} 14]$. Thus, the cluster belongs to the CLUSTER GROUP [M14] on the Rudolph type of numerical categorization (Rudolph, 1976). The symbol [M14] means that $S=4 n+2$ and $n=14 ; K=2 n-1=2(14)-1=27$. Hence $K(n)=27(14)$. The numerical series of this will be $27(14) \rightarrow 24(13) \rightarrow 21(12) \rightarrow 18(11) \rightarrow 15(10) \rightarrow 12(9) \rightarrow 9(8)$. Clearly, the cluster $S_{8}{ }^{2+}, K(n)=9(8)$ is numerically 6 steps below the Closo [M14] level. This cluster is graphically linked by 9 lines(linkages). According to the series, is it possible for us to say that cluster linkages are similar or identical to the conventional chemical bonds?

N82

$\mathrm{Kp}=\mathrm{C}^{7} \mathrm{C}[\mathrm{M} 1]$ means there is 1 skeletal element in the nucleus surrounded by 7 others.

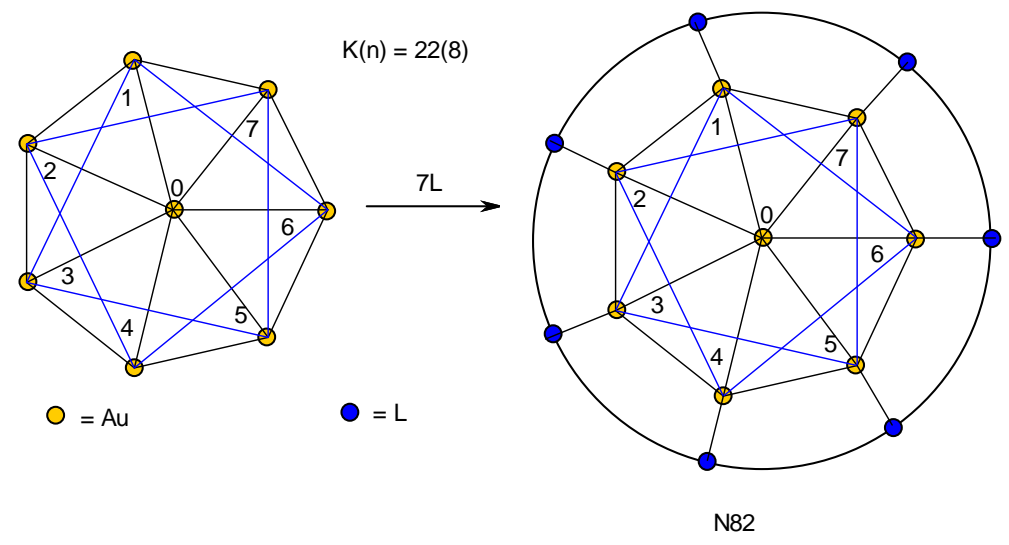

The $\mathrm{Pt}^{+}$fragment has a $\mathrm{K}$ value is $=4+1(0.5)-7(0.5)-1=0$. Since each of the periphery Au element is assumed to have a zero oxidation state, the positive charge can be assigned to the platinum element. In summary, each of the periphery Au 
element will bind to a 2 electron donor ligand while the central Pt element will have no ligand. According to this model the ligand distribution is according to simple mathematical precision. The sketch is shown in N82.

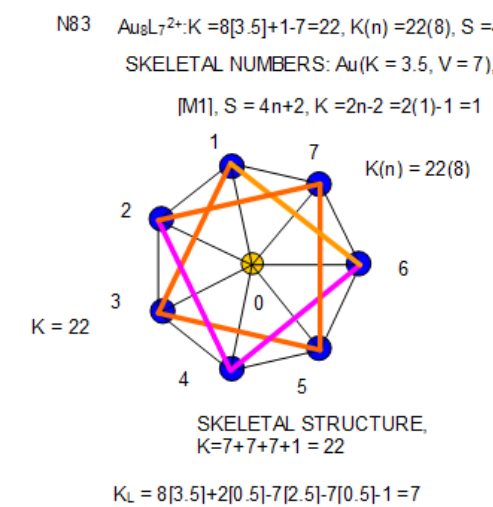

N83

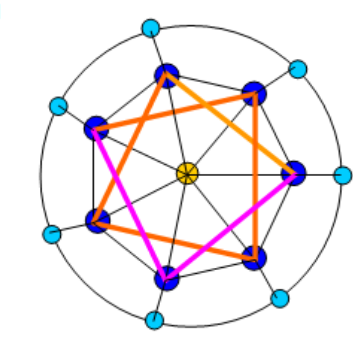

$=$ NUCLEAR AU

$=$ CAPPING AU

$\mathrm{O}=\mathrm{L}$

THIS MEANS THERE ARE 7 LIGAND LINKAGES AVALABLE FOR 7 LIGANDS

$V e=14 n-12=14(8)-12=100 ;$ STRUCTURE, $V e=8[11]+7(2)-2=100$

\section{LIGAND DISTRIBUTION}

$\mathrm{K} 1=3 \cdot 5-5(0.5)=3,5-25=1, \mathrm{~K} 2=\mathrm{K} 1=1, \mathrm{~K} 3=\mathrm{K} 1=1, \mathrm{~K} 4=\mathrm{K} 1=1, \mathrm{~K} 5=\mathrm{K} 1=1, \mathrm{~K} 6=\mathrm{K} 1=1, \mathrm{~K} 7=\mathrm{K} 1=1$

$\mathrm{K} 0=3.5+2(0.5)-7(0.5)-1=4.5-4.5=0$

THIS MEANS THAT EVERYPERIPHERY SKELETAL ELEMENT WILL BIND 1 TWO

ELECTRON DONOR LIGAND. BUT THE NUCLEAR SKELETAL ELEMENT WILL BE NAKED

Let us consider another example $\mathrm{N} 83: \mathrm{Au}_{8} \mathrm{~L}_{7}^{2+}\left(\mathrm{L}=\mathrm{PPh}_{3}\right): \mathrm{K}=8[3.5]-7+1=22 ; \mathrm{n}=8, \mathrm{~K}(\mathrm{n})=22(8), \mathrm{K}=2 \mathrm{n}-1 / 2 \mathrm{q}, 22=$ 2(8)- $1 / 2 \mathrm{q}, 1 / 2 \mathrm{q}=16-22=-6, \mathrm{q}=-12, \mathrm{~S}=4 \mathrm{n}-12, \mathrm{Kp}=\mathrm{C}^{7} \mathrm{C}[\mathrm{M} 1]$. According to the series, the prediction is that this will be a cluster of 7 skeletal elements surrounding one skeletal element that is a member of CLOSO SERIES, $\mathrm{S}=4 \mathrm{n}+2, \mathrm{~K}$ $=2 \mathrm{n}-1=2(1)-1=1$. Thus the closo nucleus has $\mathrm{K}(\mathrm{n})$ parameter $=1(1)$. The rest of the 7 skeletal elements will be capped around it. A capping fragment of the series has a formula $S=4 n-2, K=2 n+1 ; n=1, K=2(1)+1=3$. This means the symbol $\mathrm{C}^{7}$ with seven cappings involves $7(3)=21$ linkages. This gives us a graphical guide of the diagram, $\mathrm{N} 83$. There are 7 linkages to the central closo skeletal nuclear element and 14 linkages on the periphery structure of the diagram giving a total of 21 linkages. Then the [M1] closo nucleus has 1 skeletal linkage $(K=1)$ in its own right. This makes a grand total of 22 cluster linkages. This provides us with a graphical representation of $\mathrm{Au}_{8}$ skeletal elements in $\mathrm{Au}_{8} \mathrm{l}_{7}^{2+}$ cluster. On a planar view point, the diagram has $\mathrm{D}_{7 \mathrm{~h}}$ symmetry. How are the ligands distributed? This means that each of the periphery au will bind a 2 electron donor ligand such as $\mathrm{pph}_{3}$, while the nuclear au will have no ligands (naked) as sketched in the skeletal graph $\mathrm{N} 83$.

The outer circle just acts a guide to sketch ligands. Let us see the flow of $K(n)$ numbers of $K p=C^{7} C[M 1]$; $1(1) \rightarrow 4(2) \rightarrow 7(3) \rightarrow 10(4) \rightarrow 13(5) \rightarrow 16(6) \rightarrow 19(7) \rightarrow 22(8)$. 
$\mathrm{N} 84 \mathrm{Os8}(\mathrm{CO}) 22^{2-}$

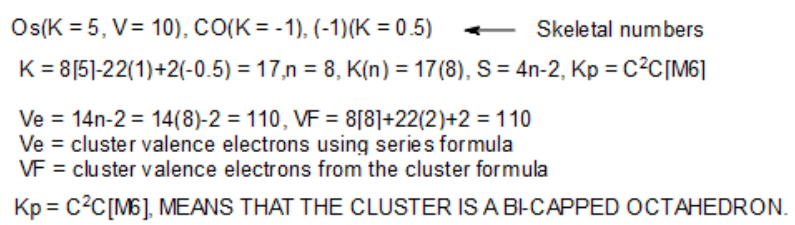

LIGAND DISTRIBUTION

$\mathrm{K} 1=5-5(0.5)=2.5, \mathrm{~K} 2=5-2=3, \mathrm{~K} 3=5-5(0.5)=2.5, \mathrm{~K} 4=5-4(0.5)=3, \mathrm{~K} 5=5-6(0.5)=2, \mathrm{~K} 6=5-4(0.5)=3$ $\mathrm{K} 7=5-3(0.5)=3.5, \mathrm{~K} 8=5-3(0.5)=3.5$
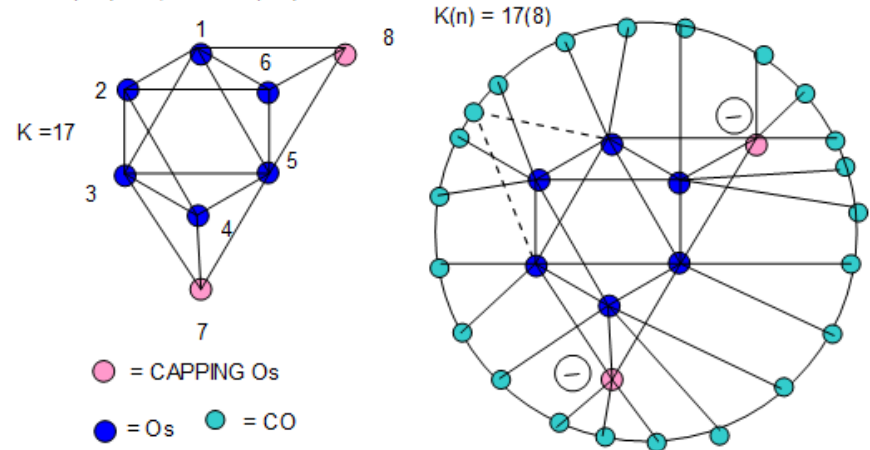

The capping symbol $\mathrm{Kp}=\mathrm{C}^{2} \mathrm{C}[\mathrm{M} 6]$ derived from the series predicts a bi-capped octahedral complex and this is what was found (Hughes and Wade, 2000).

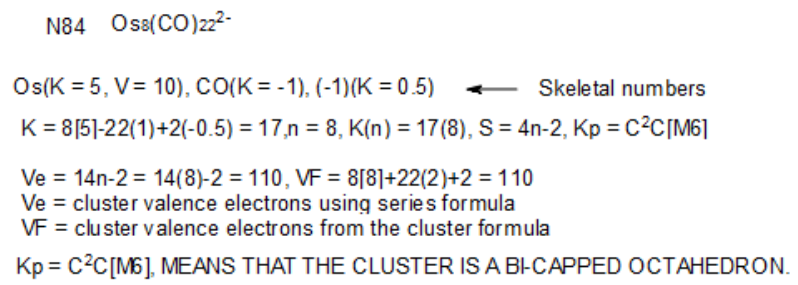

LIGAND DISTRIBUTION

$\mathrm{K} 1=5-5(0.5)=2.5, \mathrm{~K} 2=5-2=3, \mathrm{~K} 3=5-5(0.5)=2.5, \mathrm{~K} 4=5-4(0.5)=3, \mathrm{~K} 5=5-6(0.5)=2, \mathrm{~K} 6=5-4(0.5)=3$ $\mathrm{K} 7=5-3(0.5)=3.5, \mathrm{~K} 8=5-3(0.5)=3.5$
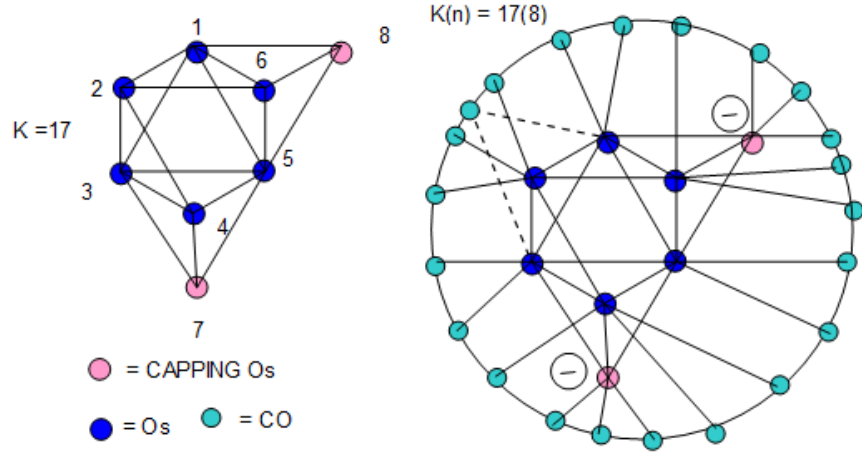


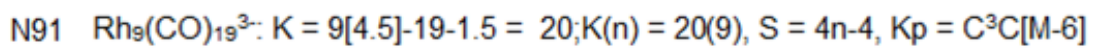

$\operatorname{Rh}(K=4.5, V=9), \mathrm{CO}(\mathrm{K}=-1),(-1)(\mathrm{K}=-0.5)$

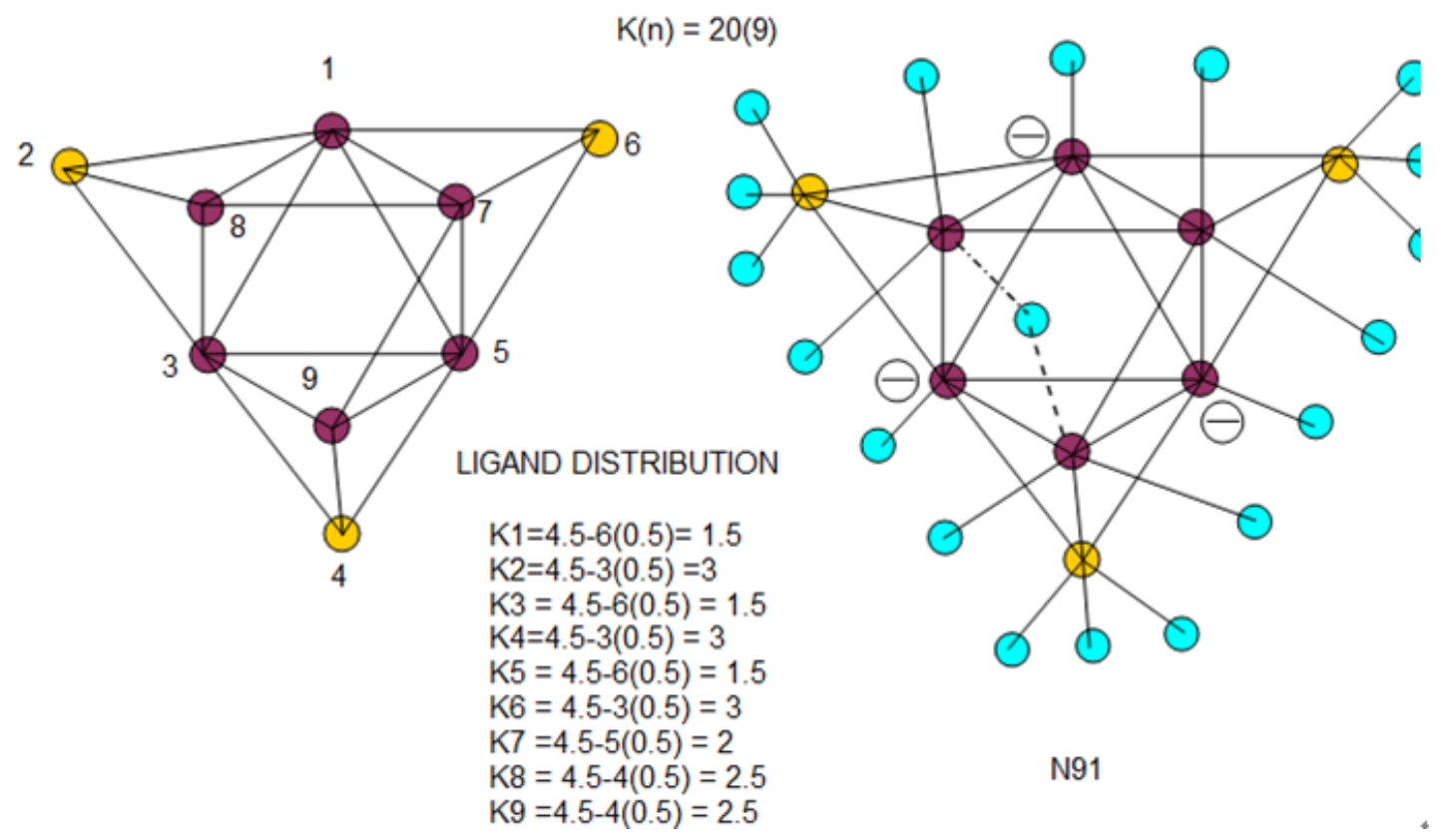

N85

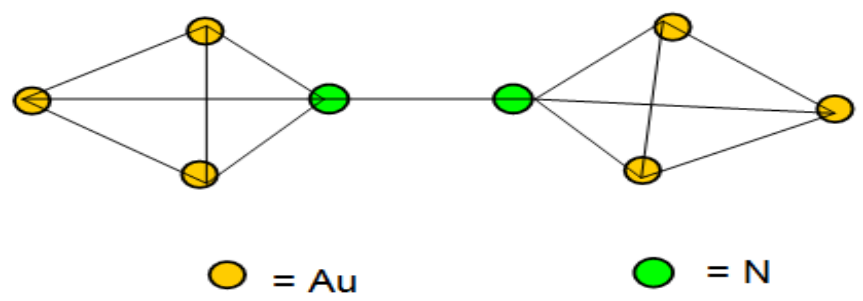

Skeletal sketch of $\mathrm{N}_{2}$ (AuL6 $^{2+}$ as observed(Gimeno, 2008)

$\mathrm{Au}_{8} \mathrm{~L}_{7}{ }^{2+}: \mathrm{K}=22 ; \mathrm{Au}_{8}{ }^{2+}: \mathrm{K}=29, \mathrm{KL}=29-22=7$. There will be 7 linkages available for 7 skeletal elements. The skeletal elements are the periphery ones as indicated in CC-25. This is in agreement with observation and is described as capped centered chair (Konishi). In 2 dimensional form, it forms a nice $\mathrm{D}_{7 \mathrm{~h}}$ symmetry.

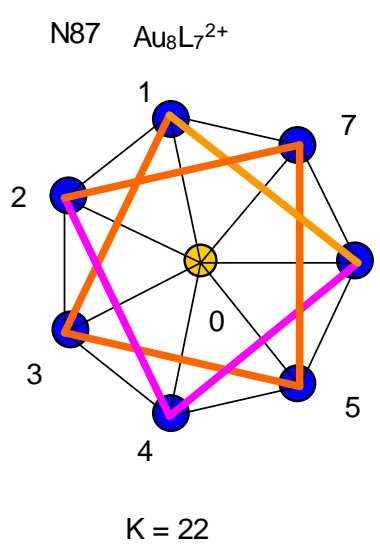

$\mathrm{K} 1=3.5-5(0.5)=3.5-2.5=1$

$\mathrm{K} 2=\mathrm{K} 1=1$

$\mathrm{K} 3=\mathrm{K} 1=1$

$\mathrm{K} 4=\mathrm{K} 1=1$

$\mathrm{K} 5=\mathrm{K} 1=1$

$\mathrm{K} 6=\mathrm{K} 1=1$

$\mathrm{K} 7=\mathrm{K} 1=1$

[M1], $S=4 n+2, K=2 n-1=2(1)-1=1$

Fragment $=\mathrm{Au}^{2+}$

$\mathrm{KO}=3.5+2(0.5)-7(0.5)-1=0$

THIS PREDICTS EACH PERIPHERY ELEMENT WILL

BIND ONE 2 ELECTRON DONOR LIGAND WHILE THE

NUCLEAR ELEMENT HAS NONE

THE GRAPH OF THE SKELETAL STRUCTURE IS SHOWN IN N87. 


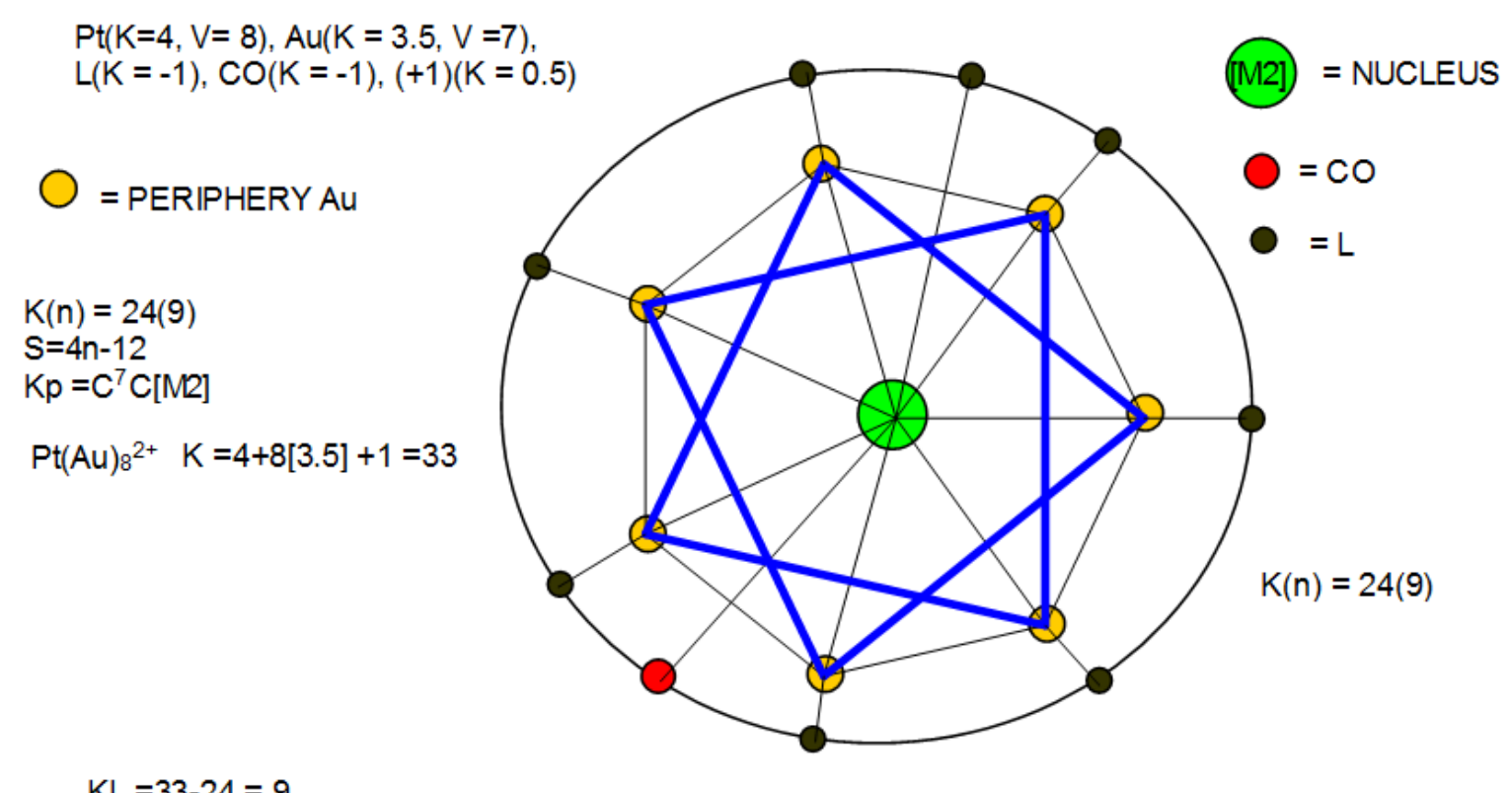

$\mathrm{KL}=33-24=9$

THS IMPLIES THAT EACH SKELETAL ELEMENT WILL HAVE A LIGAND.

N92 


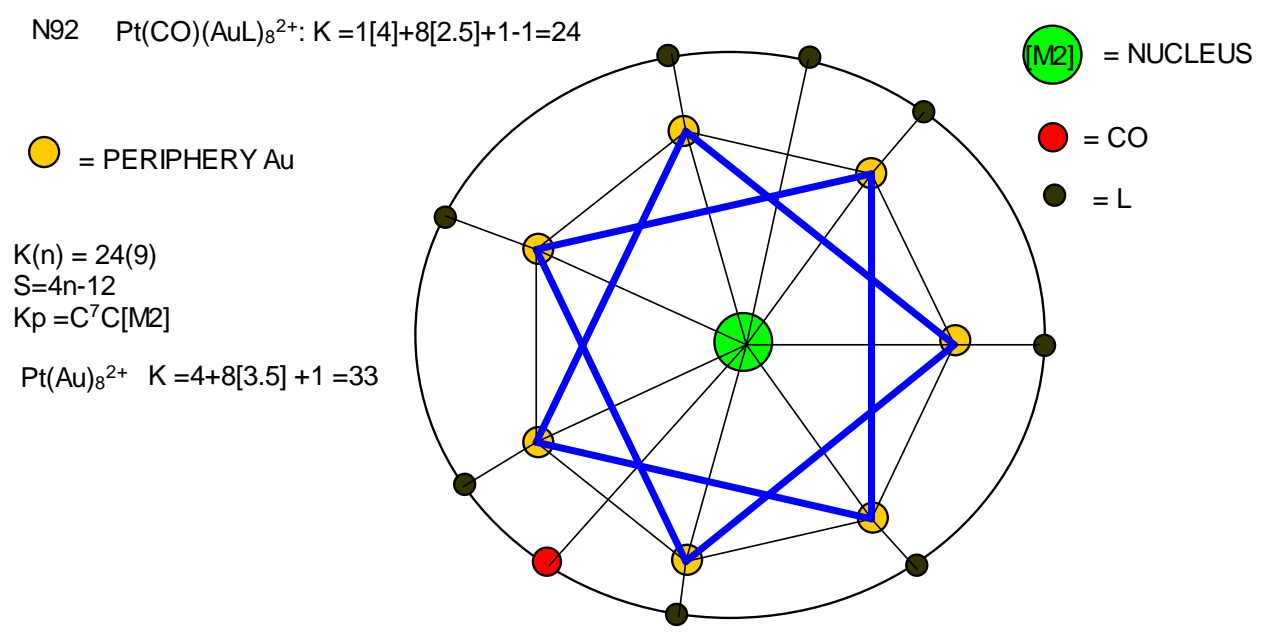

$\mathrm{KL}=33-24=9$

TNIS IMPLIES THAT EACH OF THE SKELETAL ELEMENT WILL HAVE A LIGAND.

[M2], $S=4 n+2, K=2 n-1=2(2)-1=3$

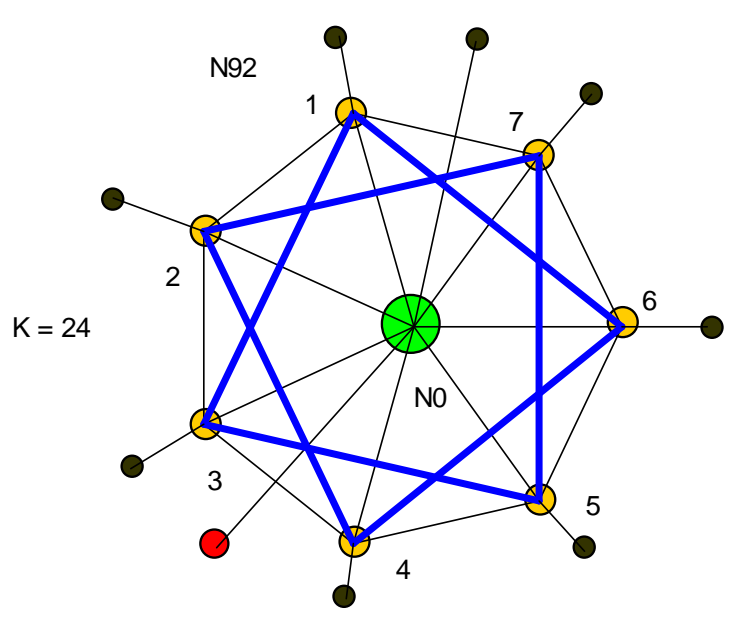

LIGAND DISTRIBUTION

$$
\begin{aligned}
\mathrm{N} 0 & =\left[\mathrm{PtAu}^{2+}\right] \\
\mathrm{K} 1 & =3.5-5(0.5) \\
\mathrm{K} 2 & =\mathrm{K} 1=1 \\
\mathrm{~K} 3 & =\mathrm{K} 1=1 \\
\mathrm{~K} 4 & =\mathrm{K} 1=1 \\
\mathrm{~K} 5 & =\mathrm{K} 1=1 \\
\mathrm{~K} 6 & =\mathrm{K} 1=1 \\
\mathrm{~K} 7 & =\mathrm{K} 1=1
\end{aligned}
$$$$
\mathrm{K} 1=3.5-5(0.5)=3.5-2.5=1
$$

KNO $=1[4]+1[3.5]+2(0.5)-7(0.5)-3=2$ THIS MEANS THAT 2 LIGANDS WILL BE BOUND TO THE 2 NUCLEAR SKELETAL ELEMENTS AS IN N92 
N93 $\left(\mathrm{ReCp}^{\star}\right)_{2}(\mathrm{BH})_{7} \quad: \mathrm{K}=2[5.5-2.5]+7[2.5-05]=20, \mathrm{n}=2+7=9, \mathrm{~K}(\mathrm{n})=20(9)$

$$
\mathrm{S}=4 \mathrm{n}-4, \mathrm{Kp}=\mathrm{C}^{3} \mathrm{C}[\mathrm{M} 6]
$$

The series predicts an ideal shape of a tri-capped octahedron.

[ReCp*], $(\mathrm{K}=5.5-2.5=3, \mathrm{~V}=6)$

$\mathrm{B},(\mathrm{K}=2.5, \mathrm{~V}=5), \mathrm{H}(\mathrm{K}=-0.5)$

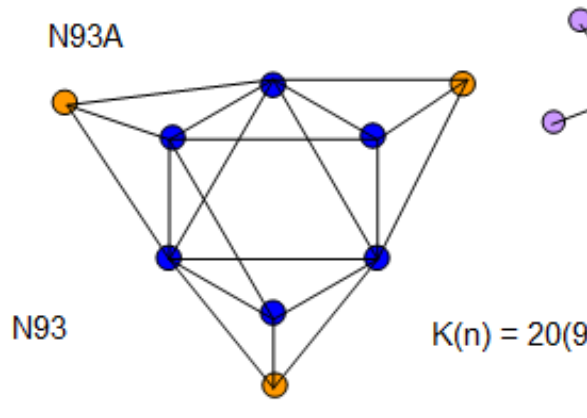

N93A -IDEAL SKELETAL SHAPE ASSUMING ALL SKELETAL ELEMENTS ARE SIMILAR.

$$
\begin{aligned}
& \text { N93B -SKELETAL SHAPE TAKING INTO } \\
& \text { ACCOUNT THE DIFFERENCE IN SKELETAL } \\
& \text { ELEMENTS. } \\
& \quad 0=\text { CAPPING ELEMENT } \\
& \text { Ideal skeletal sketch of }\left(\operatorname{ReCp}^{*}\right)_{2}(\mathrm{BH})_{7}
\end{aligned}
$$

N93B
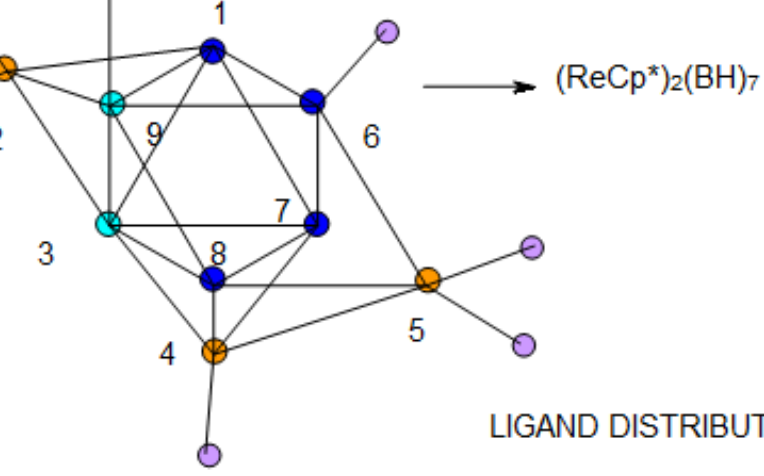

$\mathrm{K} 1=2.5-5(0.5)=0$

$\mathrm{K} 2=2.5-1.5=1$

$\mathrm{K} 3=3-3=0$

$\mathrm{K} 4=2.5-2=0.5$

$\mathrm{K} 5=2 \cdot 5-1 \cdot 5=1$

$\mathrm{K} 6=2.5-2=0.5$

$\mathrm{K} 7=2.5-2.5=0$

$\mathrm{K} 8=2.5-2.5=0$

$\mathrm{K} 9=3-2.5=0.5$

The rhenium homologous series are given by $\left(\mathbf{R e C p}^{*}\right)_{2}\left(\mathbf{B H}_{\mathbf{m}} ; \mathrm{m}=6-10\right.$. The increase from $\mathrm{m}=6$ to $\mathrm{m}=7$ is by $1[\mathrm{BH}]$ fragment. If the cluster $m=6$ belongs to $S=4 n-4$, then the increase of $1[\mathrm{BH}]=1[\mathrm{C}] ; S=4 n+0$. The new series formula when the cluster changes from $m=6$ to $m=7$ will be given by $S=[(4 n-4)(n=6)+(4 n+0)(n=1)=4 n-4(n=7)]$. Thus, the cluster series formula has remained the same despite $\mathrm{n}$ changing by 1 . In other words, the series will still remain tri-capped; $\mathrm{Kp}=\mathrm{C}^{3} \mathrm{C}[\mathrm{Mx}], \mathrm{x}=5-9$. This simply means, the capping index will remain the same, that is, same series but the nuclearity index will expand as it is observed (Fehlner \& Halet, 2007). 
Periphery $\mathrm{Au}$ Elements: All $\mathrm{Au}$ elements are equal; $\mathrm{K}=3.5-5(0.5)=3.5-2.5=1$, Nuclear $\mathrm{Au}^{3+}: \mathrm{K}=$ $3.5+3(0.5)-8(0.5)-1=5-5=0$. Each of the peripheral Au will carry 1 ligand while the nucleuswill have none. There is another way of calculating the linkages available on the skeletal structure for binding the ligands.

$\mathrm{Au}_{9} \mathrm{~L}_{8}{ }^{3+} \rightarrow \mathrm{Au}_{9}{ }^{3+}+8 \mathrm{~L} ; \mathrm{Au}_{9}{ }^{3+} ; \mathrm{K}=9[3.5]+3(0.5)=33$. Some of these linkages will be used for binding the skeletal elements and the rest to bind the ligands. In the calculation above in CC-28, $\mathrm{K}=25$. This means that these are for binding the skeletal elements in the cluster. Therefore those remaining to bind the ligands will be given by KL $=33-25$ $=8$. As expected, this agrees with the cluster formula. These will be evenly distributed onto the periphery Au skeletal elements as indicated in N95. Note that the nuclear element [M1] obeys the closo series formula $S=4 n+2, K=2 n-1=$ $2(1)-1=1$. Thus, the closo nuclear skeletal element in its own right has a $\mathrm{K}$ value of 1 . We can also calculate the number of skeletal linkages available for binding ligand(s). As can be seen from the raw skeletal structure in N95, each peripheral Au skeletal element has 5 linkages. Each linkage behaves as a [H•] ligand donating ONE electron to Au periphery skeletal atom. So we can calculate the respective $\mathrm{K}$ value as $1[3.5]-5(0.5)=1$. This shows that each peripheral $\mathrm{Au}$ skeletal element will bind ONE ligand as indicated in N95. The cluster of this formula has been described as bi-capped centered or crown centered (Konishi, 2014).

Let us illustrate these steps using the example of $\mathrm{Rh}_{10}(\mathrm{CO})_{21}{ }^{2-}: \mathrm{K}=23, \mathrm{n}=10 ; \mathrm{K}(\mathrm{n})=23(10) ; \mathrm{K}=2(10)-1 / 2 \mathrm{q}=23$, $\mathrm{q}=$ -6 and hence $S=4 n-6, K p=C^{4} C[M 6]$. The cluster has an octahedral CLOSO nucleus, $S=4 n+2, K=2 n-1=2(6)-1=11$. The ligand distributions have been indicated either numerically or diagrammatically or both.

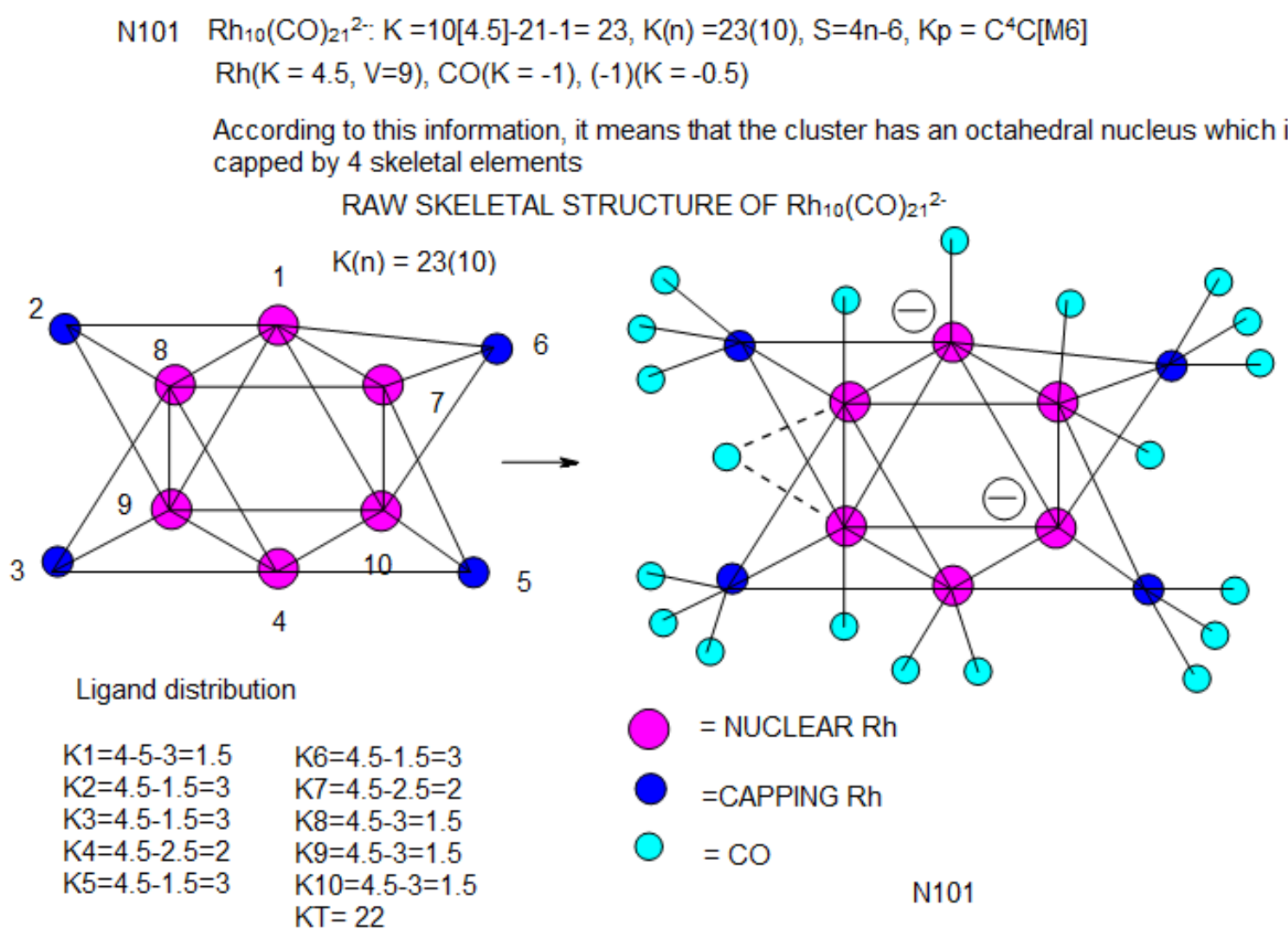


N102

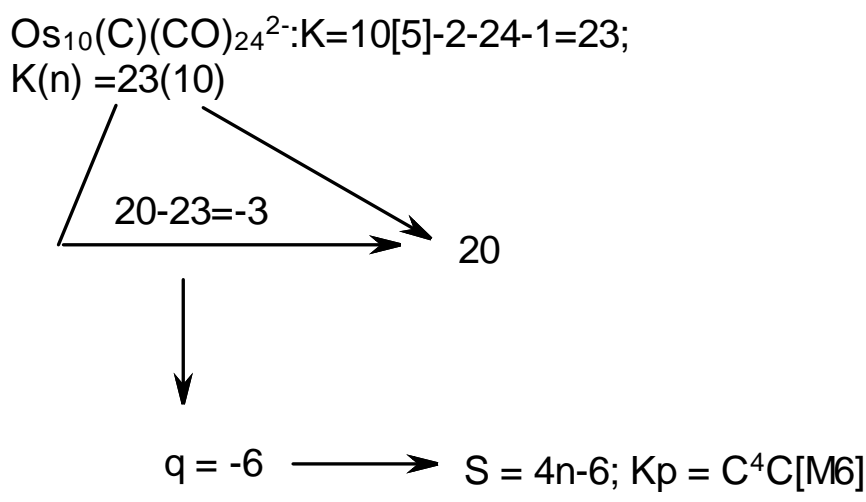

THIS MEANS, THE CLUSTER WILL HAVE AN OCTAHEDRAL NUCLEUS

4

CAPPED BY 4 OTHER SKELETAL ELEMENTS

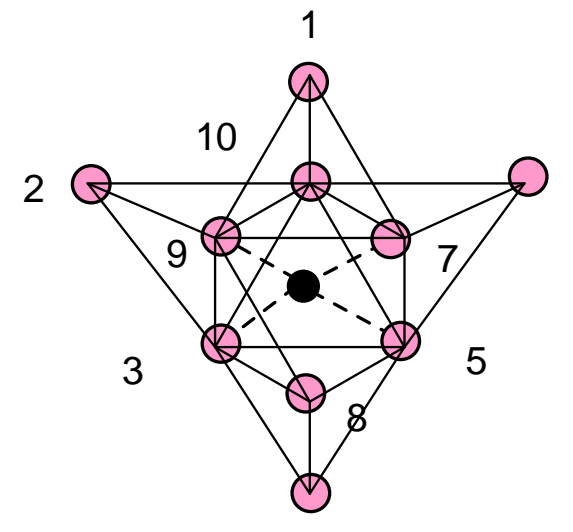

4

Ligand distribution

$\mathrm{K} 1=5-1.5=3.5$
$\mathrm{~K} 2=3.5$
$\mathrm{~K} 3=5-3.5=1.5$
$\mathrm{~K} 4=3.5$
$\mathrm{~K} 5=5-3.5=1.5$
$\mathrm{~K} 6=3.5$
$\mathrm{~K} 7=5-3=2$
$\mathrm{~K} 8=5-2=3$
$\mathrm{~K} 9=5-3.5=1.5$
$\mathrm{~K} 10=5-3.5=1.5$
$\mathrm{KT}=25$

N102

N103 Au ${ }_{10} L_{5} R_{4}: K=10[3.5]-5-2=28 ; K(n)=28(10), S=4 n-16, K p=C{ }^{y} C[M 1]$

In this cluster, one skeletal element will be at the nucleus surrounded by 9 other skeletal elements.

In this case, $\mathrm{L}=\mathrm{PPh}_{3}$ and $\mathrm{R}=\mathrm{C}_{6} \mathrm{~F}_{5}$

[M1], $S=4 n+2, K=2 n-1=2(1)-1=1$

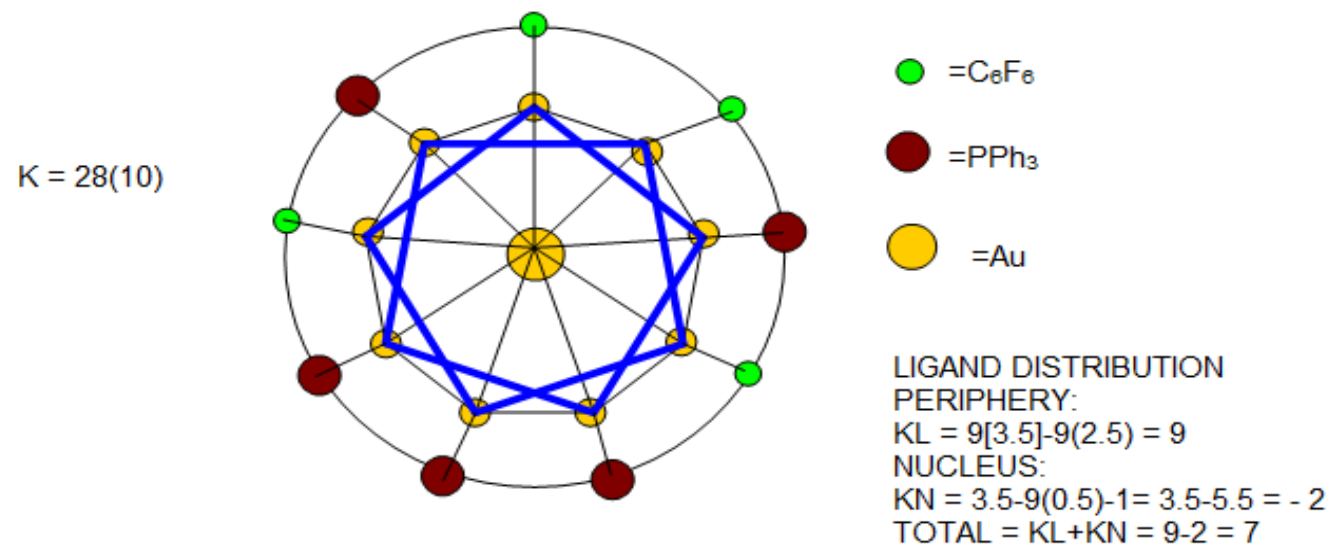

THIS MEANS THAT THE CLUSTER WILL ACCOMMODATE 7 TWO ELECTRON DONOR

LIGANDS. WHAT WE HAVE ON THE CLUSTER $=5 \mathrm{~L}+4 \mathrm{R}=5 \mathrm{~L}+2 \mathrm{~L}=7 \mathrm{~L}$ SINCE $2 \mathrm{R}=1 \mathrm{~L}$.

THUS THE LIGAND DISTRIBUTION FOLLOWS A SIMPLE MATHEMATICAL PRECISION 
$\mathrm{N} 103 \mathrm{Au}_{10} \mathrm{Cl}_{3} \mathrm{~L}_{6}+\mathrm{K}=10[3.5]-1.5-6+0.5=28 ; \mathrm{K}(\mathrm{n})=28(9), \mathrm{S}=4 \mathrm{n}-16, \mathrm{Kp}=\mathrm{C}^{9} \mathrm{C}[\mathrm{M} 1]$ $\mathrm{Au}(\mathrm{K}=3.5, \mathrm{~V}=7), \mathrm{Cl}(\mathrm{K}=-0.5), \mathrm{L}(\mathrm{K}=-1),(+1)(\mathrm{K}=0.5)$

[M1], $\mathrm{K}=1$
$\mathrm{K}=28$
$\mathrm{KS}=9+9+9+1=28$
$\bigcirc=L$
$=\mathrm{L} \quad \mathrm{O}=\mathrm{Cl}$
$\mathrm{Ve}=14 \mathrm{n}-16=14(10)-16=124$

ONUCLEAR Au

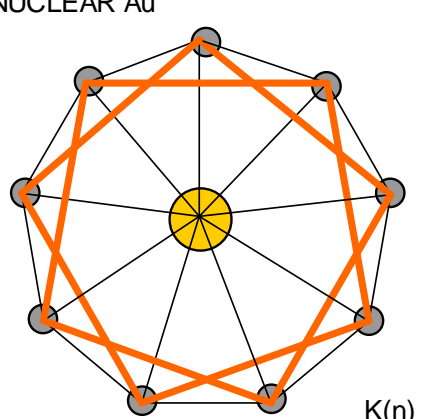

$\mathrm{K}(\mathrm{n})=28(9)$

$\mathrm{O}=$ CAPPING Au

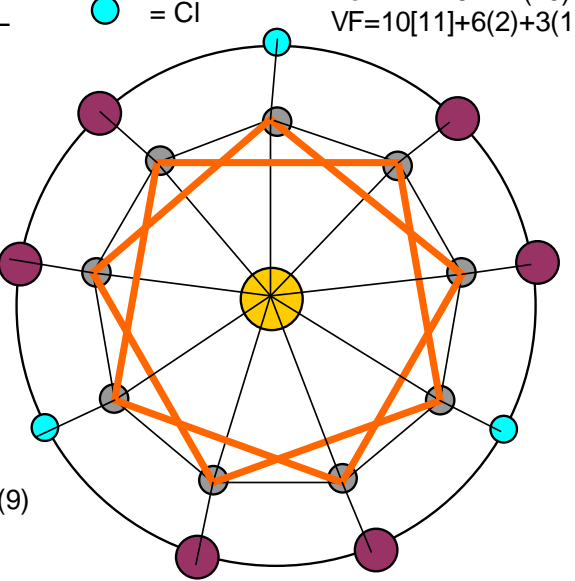

$\mathrm{KL}=10[3.5]+0.5-9[2.5]-9[0.5]-1=7.5$

THERE ARE 7.5 LINKAGES AVAILABLE FOR 7.5 LIGANDS $=6 \mathrm{~L}+3 \mathrm{Cl}$

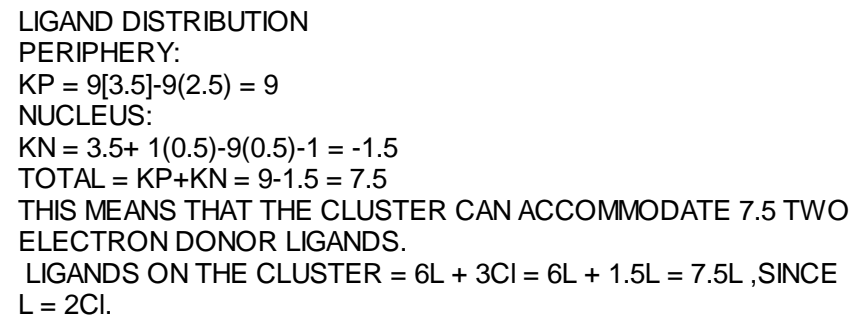

N111 (Cp*W) ${ }_{3} \mathrm{~B}_{8} \mathrm{H}_{9}: \mathrm{K}=3[6-2.5]-8[2.5]-4.5=26, \mathrm{n}=3+8=11, \mathrm{~K}(\mathrm{n})=26(11), \mathrm{S}=4 \mathrm{n}-8, \mathrm{Kp}=\mathrm{C}^{5} \mathrm{C}[6]$ Ideal shape is Penta-capped $\mathrm{O}_{\mathrm{h}}$.

$\mathrm{Ve}=4 \mathrm{n}-8+3[10]$ for metal adjustment $=4(11)-8+30=66 ; \mathrm{VF}=3[5+6]+8(3)+9=66$

$$
W C p^{*} K=3.5, V=7 \quad B, K=2.5, V=5
$$

Ligand distribution has been done according to the law of the valence of the skeletal fragments in N111

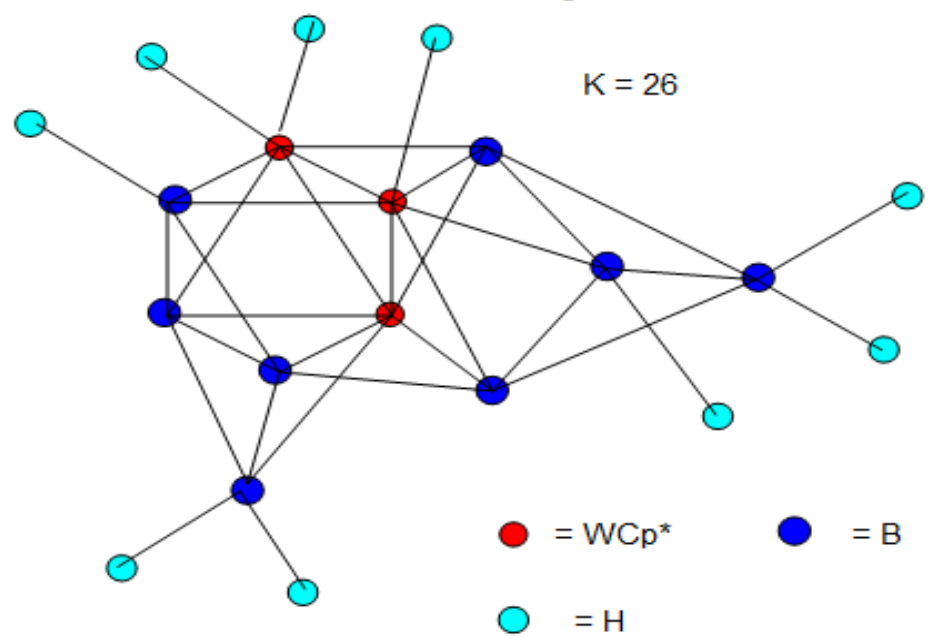

Raw isomeric skeletal structure of $\left(\mathrm{Cp}^{*} \mathrm{~W}\right)_{3} \mathrm{~B}_{8} \mathrm{H}_{9}$ 
$\mathrm{N} 112 \quad \mathrm{Au}_{11} \mathrm{~L}_{10^{5+}}$.

$\mathrm{K}=11[3.5]+2.5-10=31$;

$K(n)=31(11)$,

$S=4 n-18$,

$\mathrm{Kp}=\mathrm{C}^{10} \mathrm{C}[\mathrm{M} 1]$,

[M1], $S=4 n+2$,

$\mathrm{K}=2 \mathrm{n}-1=2(1)-1=1$

Ligand distribution

$\mathrm{K} 1=\mathrm{K} 2=\mathrm{K} 3=\mathrm{K} 4=\mathrm{K} 5$

$=\mathrm{K} 6=\mathrm{K} 7=\mathrm{K} 8=\mathrm{K} 9$

$=\mathrm{K} 10=3.5-2.5=1$

THIS MEANS THAT

EACH OF THE

PERIPHERY Au

ELEMENTS WILL CARRY 1

LIGAND.

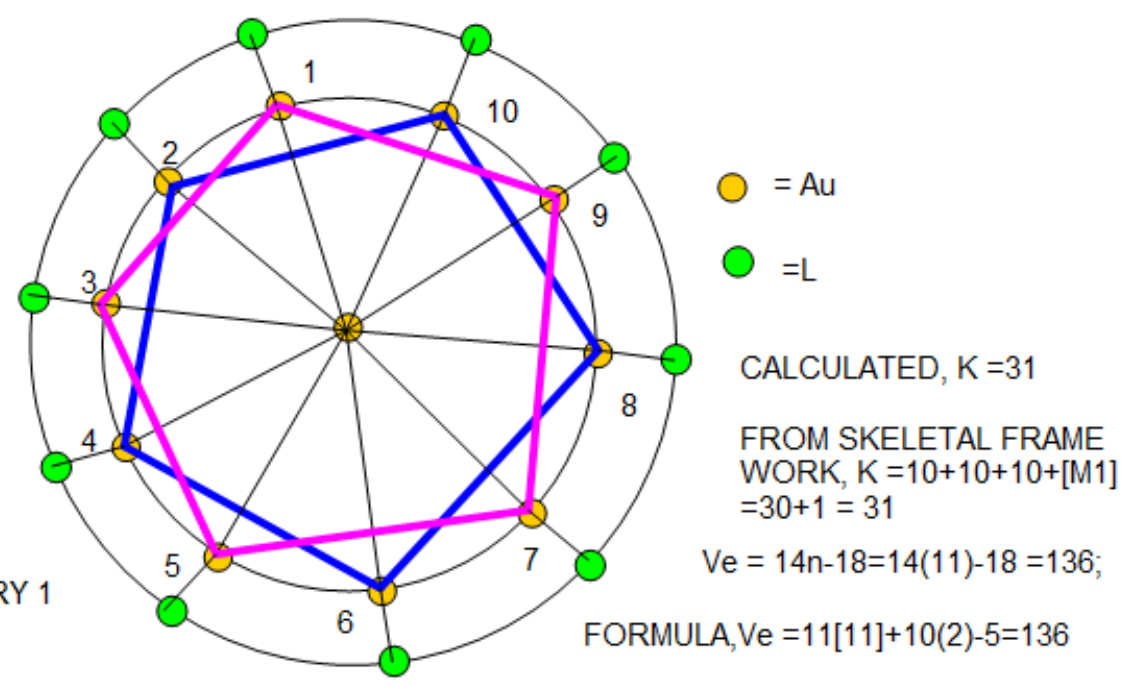

N112

FROM THE SYMBOL $K p=\mathrm{C}^{10} \mathrm{C}[M 1]$,MEANS THAT THERE IS ONE SKELETAL ELEMENT AT THE NUCLEUS SURROUNDED BY 10 OTHER SKELETAL ELEMENTS.

N121, N121 Cluster with a nucleus model

$\mathrm{Pd}_{6} \mathrm{Ru}_{6}(\mathrm{CO})_{24}{ }^{2-:} \mathrm{K}=6[4]+6[5]-24-1=29 ; \mathrm{K}(\mathrm{n})=29(12), \mathrm{S}=4 \mathrm{n}-10, \mathrm{Kp}=\mathrm{C}^{6} \mathrm{C}[\mathrm{M}-6]$

$\mathrm{K} 11=4-2.5=1.5$

$\mathrm{K} 12=5-2.5=2.5$

$\mathrm{K} 21=4-2.5=1.5$

$\mathrm{K} 22=5-2.5=2.5$

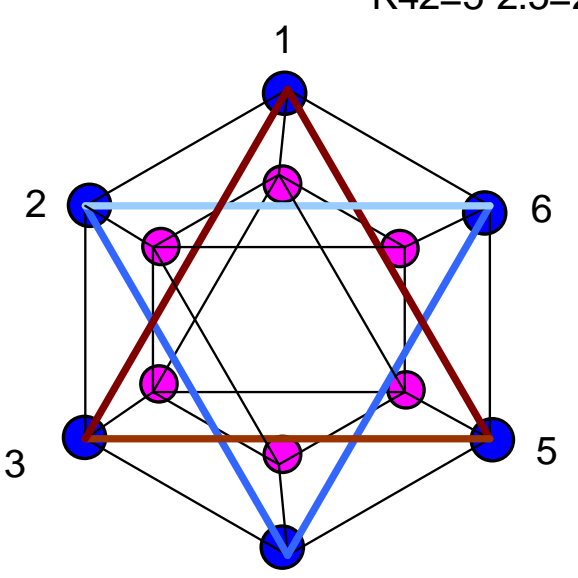

4 ISOMERIC SKELETAL

$=P d \quad$ STRUCTURES

$=$ CAPPING Ru
$\mathrm{K} 31=4-2.5=1.5$
$\mathrm{K} 32=5-2.5=2.5$
$\mathrm{K} 41=4-2=2$
$\mathrm{K} 42=5-2.5=2.5$
$\mathrm{K} 51=4-2.5=1.5$
$\mathrm{K} 52=5-2 \cdot 5=2.5$
$\mathrm{K} 61=4-2=2$
$\mathrm{K} 62=5-2.5=2.5$
$\mathrm{KT}=25$

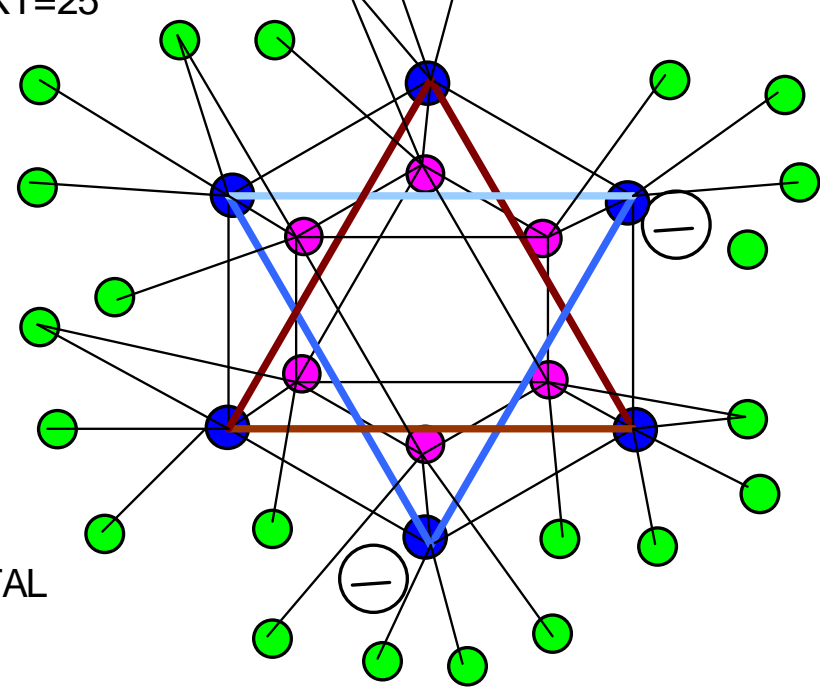

$\mathrm{O}=\mathrm{CO}$ 


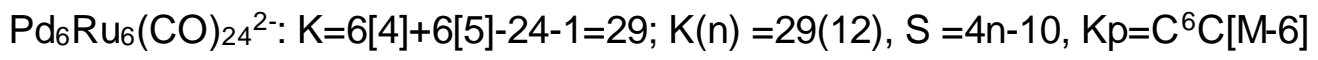

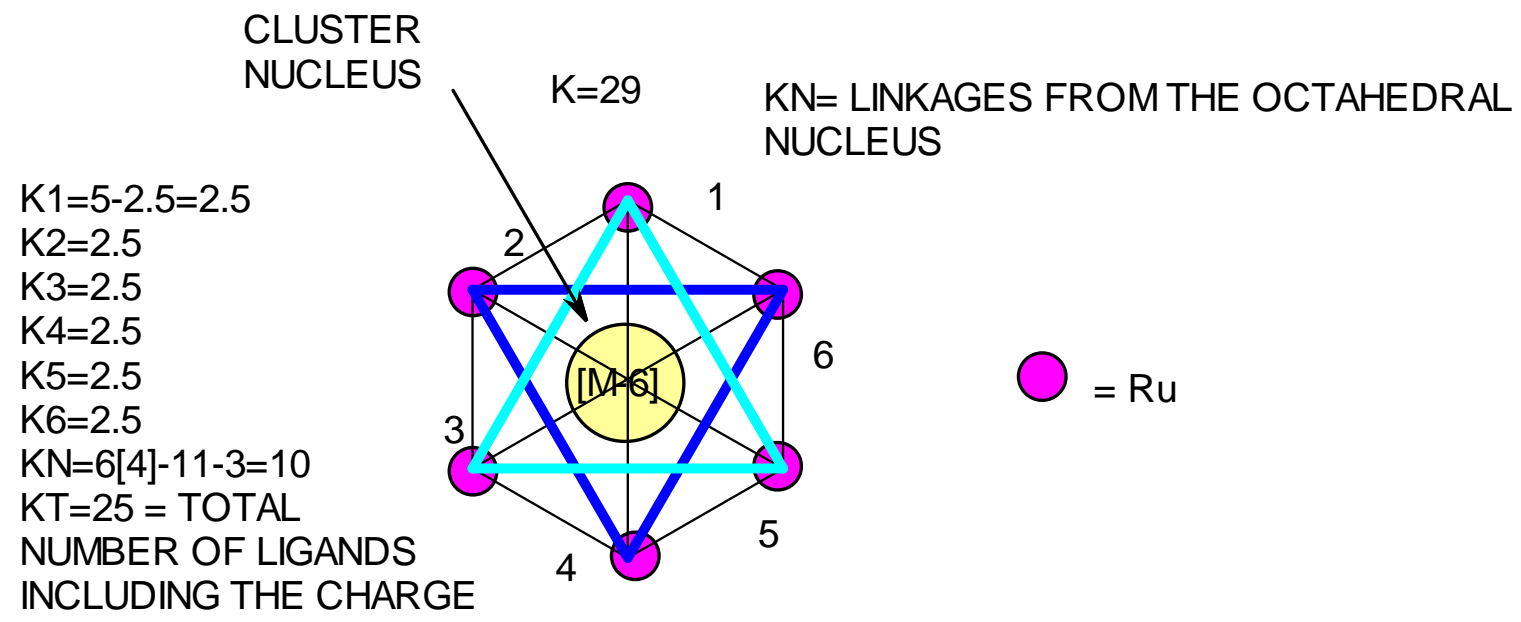

NUMBER OF LINKAGES FROM CLUSTER $=6+6+6+11=29$

THE CLUSTER HAS AN OCTAHEDRAL NUCLEUS CAPPED BY 6 OTHER

SKELETAL ELEMENTS. IT IS ASSUMED THAT THE ELEMENTS IN THE NUCLEUS ARE ALL Pd.

N122

$$
\mathrm{C}(\mathrm{K}=2, \mathrm{~V}=4), \mathrm{B}(\mathrm{K}=2.5, \mathrm{~V}=5)
$$

Ligand distribution

The ligands are added to the skeletal elements in such a way that the valence of each of the skeletal element is obeyed. Thus, the carbon element has a valence of 4 , so it will have 4 connections to it including the $\mathrm{H}$ atoms. In the case of the $B$ atom, there will be 5 connections to it including those from the $\mathrm{H}$ ligands if neccessary. The valence rule of the skeletal element should be observed. When this is done correctly, the cluster formula derived from the sketch is usually in agreement with the original cluster formula. It is clear from N122 sketch that we have 2C, $10 \mathrm{~B}$ and $12 \mathrm{H}$ corresponding to $\mathrm{C}_{2} \mathrm{~B}_{10} \mathrm{H}_{12}$ cluster formula.

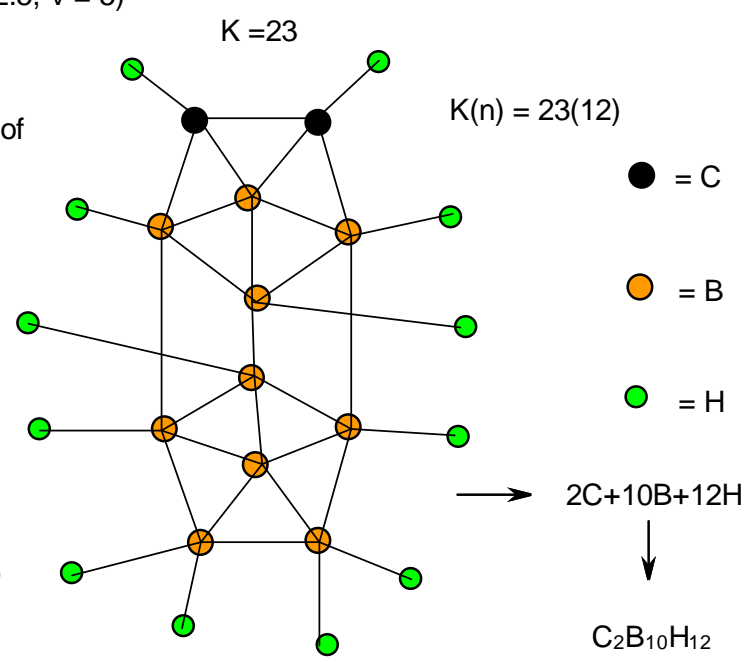

N122 
Available ligand linkages: PERIPHERY

There are 11 skeletal elements on the periphery each with $\mathrm{K}=3.5$. Also each sleletal element has 5 skeletal linkages each providing $1 \mathrm{e}$. Hence, ligand available to each $=1[3.5]-5(0.5)=1 . \ln$ total there will $11(1)=11$ ligands.

\section{NUCLEUS}

[M2] means there are two skeletal elements at the nucleus which obey the closo series rule, $S=4 n+2, K=2 n-1=2(2)-1=3$. It was assumed that each of the periphery skeletal element has an oxidation state of zero. It makes sense to assign +3 to the two nuclear skeletal elements. Hence we may regard the nucleus to comprise of $\mathrm{Au}_{2}{ }^{3+}$ fragment. This fragment has 11 single electron linkages in addition to the nuclear triple bond. Therefore the ligand linkages available at the nucleus $=2\lceil 3.5\rceil+3(0.5)-11(0.5)-3=0$. This predicts that there will be 2 nucear skeletal elements which do not bear ligands. Only 11 ligands will be available to the periphery skeletal elements.

This corres ponds to $10 \mathrm{~L}+2 \mathrm{Cl}$ ligands of the cluster. The $2 \mathrm{Cl}$ ligands are regarded as 1 electron donor while $L$ is a 2 electron donor.

N141 Re6Sesle $4-\quad K=6[5.5]+8[8]-3-2=36, K(n)=36(14), S=4 n-16, K p=C^{9} \mathrm{C}[M 5]$

SKELETAL LINKAGES $=9+9+9+9=36$

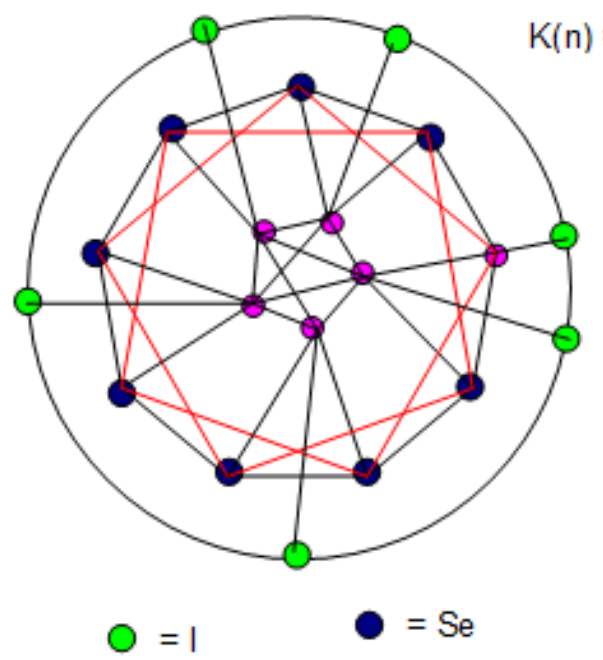

$K(n)=36(14)$

LIGAND LINKAGES PERIPHERY:

$8[1]-8(2.5)+1[5.5+-1(2.5)=-9$

NUCLEAR LINKAGES: $5[5.5]-9(0.5)-4(0.5)-9=12$

$\mathrm{Ve}=14 \mathrm{n}-20=14(13)-20=162$

$\mathrm{VF}=13[11]+2[1]+10[2]-3=162$

[M2], $\mathrm{S}=4 \mathrm{n}+2$, $\mathrm{K}=2 \mathrm{n}-1=2(2)-1=3$ NET LIGAND LINKAGES $=12-9=3$; THIS CORRESPONDS TO 6 IODINE LIGANDS

\section{ISOMERIC STRUCTURAL GRAPH OF ReeSe $816^{4-}$}

Let us consider another cluster G3- $\mathrm{Re}_{6} \mathrm{Se}_{8} \mathrm{I}_{6}^{4-}: \mathrm{K}=6[5.5]+8[1]-6(0.5)-4(0.5)=36 ; \mathrm{n}=14, \mathrm{~K}(\mathrm{n})=36(14), \mathrm{K}=2 \mathrm{n}-1 / 2 \mathrm{q}$, $36=2(14)-1 / 2 \mathrm{q}, \mathrm{q}=-16, \mathrm{~S}=4 \mathrm{n}-16, \mathrm{Kp}=\mathrm{C}^{9} \mathrm{C}[\mathrm{M} 5]$. According to series, the cluster has a trigonal bipyramid nucleus surrounded by 9 capping skeletal elements. If we assume that the [M5] comprises of Re skeletal elements then 8 Se and 
1 Re will be the capping elements. The $C^{9}$ means there 9 cappings $=9(3)=27$ linkages. The [M5] nucleus has $K=2 \mathrm{n}-1$ $=2(5)-1=9$ linkages. This gives us a grand total of 27+9 = 36 linkages. This is shown in sketch N141. Along with N141 is a calculation showing the net linkages available are 3. This means that the number of 2 electron donor ligands available are 3 or 6 single electron donor ligands. This agrees with the presence of 6 iodine ligands. What about the flow of $\mathrm{K}(\mathrm{n})$ numbers for $[\mathrm{M} 5]$ series? For [M5] we have $9(5) \rightarrow 12(6) \rightarrow 15(7) \rightarrow 18(8) \rightarrow 21(9) \rightarrow 24(10) \rightarrow 27(11) \rightarrow 30(12) \rightarrow 33(13) \rightarrow 36(14)$. Clearly, 36(14) is a member of [M5] series. What is observed for N141 is an octahedral cluster with 8 capping Se skeletal elements and 6 iodine ligands one on each Re skeletal elements in an octahedral nucleus (Fehlner \& Halet, 2007). The graph of the cluster is sketched in N141. The construction of isomeric skeletal structures of clusters is in accordance with the $4 \mathrm{n}$ series method and may be regarded to constitute the graph theory of the series approach.

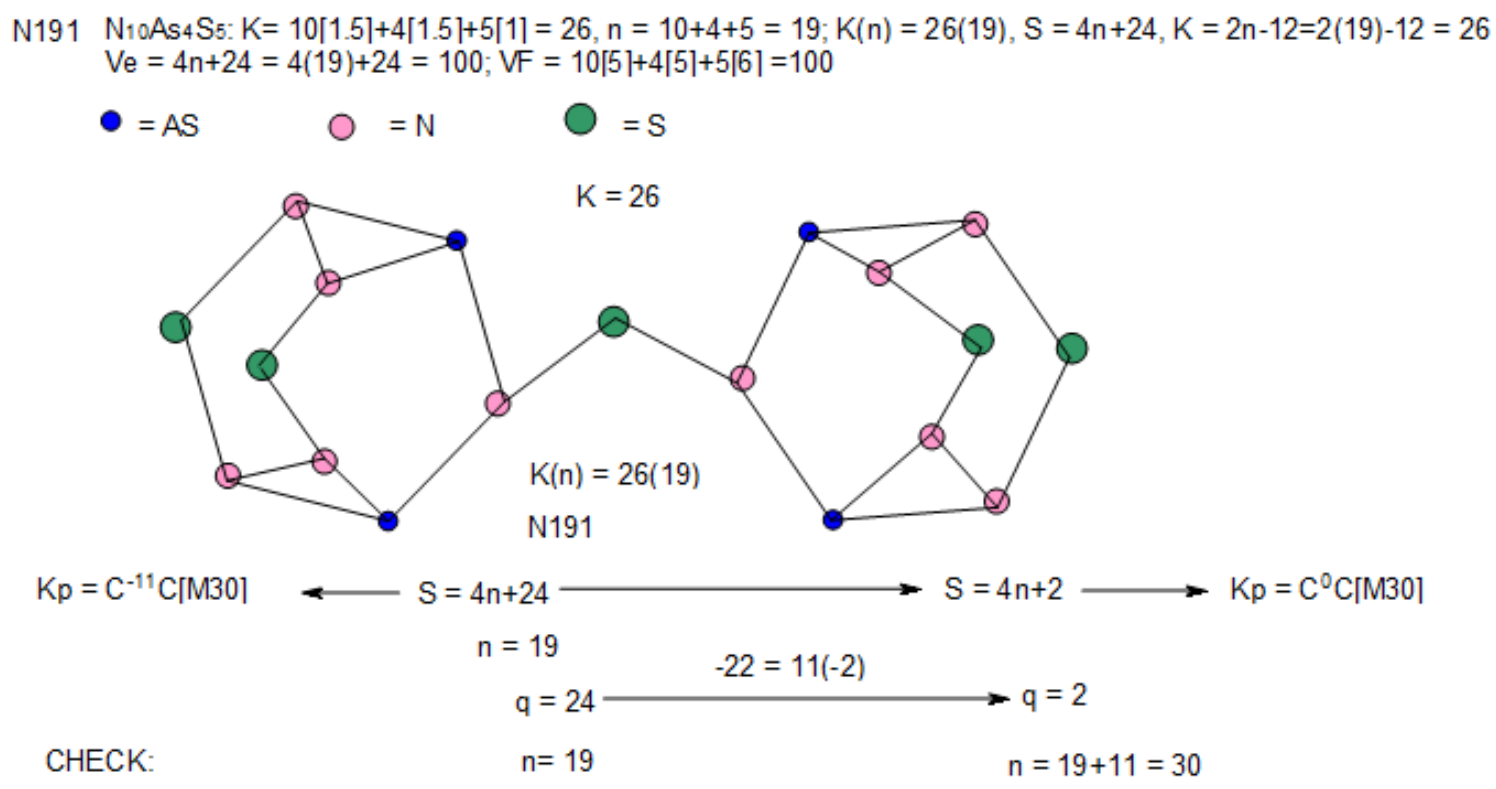

ГM $301, \mathrm{~S}=4 \mathrm{n}+2, \mathrm{~K}=2 \mathrm{n}-1=2(30)-1=59, \mathrm{~K}(\mathrm{n})=59(30)$

59(30), 56(29), 53(28), 50(27), 47(26), 44(25), 41(24), 38(23), 35(22), 32(21), 29(20), 26(19)

N331 Ni12 As $21^{3}: K=12[4]+21[1.5]-1.5=78 ; n=12+21=33, K(n)=78(33) ; S=4 n-24, K p=C^{13} C[M 20]$

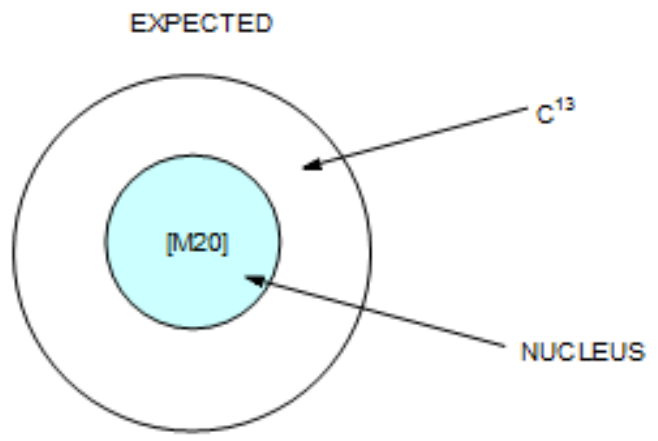


N331

$\mathrm{Ni}_{12} \mathrm{As}_{21}{ }^{3-}: \mathrm{K}=12[4]+21[1.5]-1.5=78 ; \mathrm{n}=12+21=33, \mathrm{~K}(\mathrm{n})=78(33) ; \mathrm{S}=4 \mathrm{n}-24, \mathrm{Kp}=\mathrm{C}^{13} \mathrm{C}[\mathrm{M} 20]$

This predicts a cluster of a nucleus comprising of 20 skeletal elements surrounded by 13 capping skeletal elements. THIS RESULT IS VERY FASCINATING INDEED. THIS IS BECAUSE THE 20 PREDICTED NUCLEAR ELEMENTS ARE ACTUALLY LOCATED ON THE OUTER LAYER COMPRISING OF As SKELETAL ELEMENTS AND THE 13 CAPPING ELEMENTS COMPRIZING OF 12 Ni INNER LAYER AND 1 As SITTING IN THE NUCLEUS. WHILE THE PREDICTION IS QUITE AMAZING, THE NATURAL FORCES HAVE DONE THE OPPOSITE.

The observed skeletal structure can graphically be reprsented as indicated in FIGURE LG-1.

Appears as

$\mathrm{Kp}=\mathrm{C}^{20}[\mathrm{M} 13]$

Expected

$\mathrm{Kp}=\mathrm{C}^{13} \mathrm{C}[\mathrm{M} 20]$

$\mathrm{K}(\mathrm{n})=78(33)$

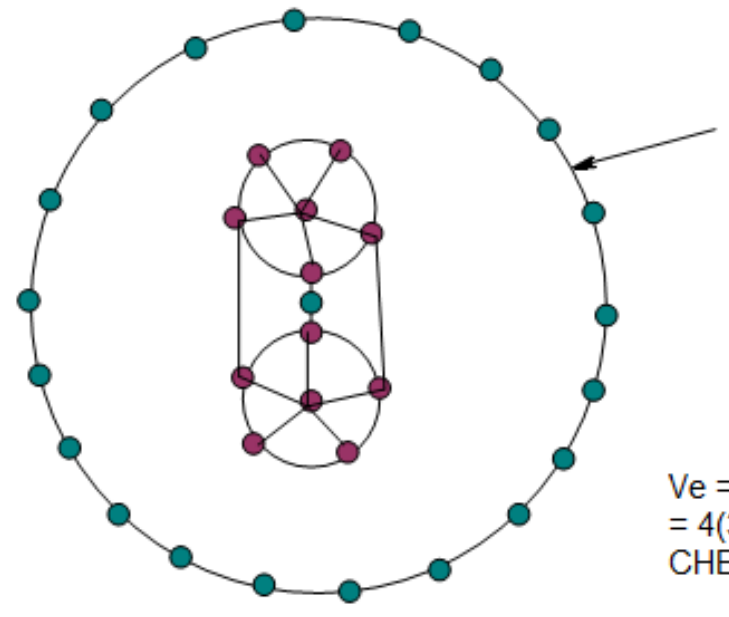

Graphical sketch of observed structure of $\mathrm{Ni}_{12} \mathrm{As}_{21}{ }^{3-}$
PREDICTED NUCLEUS ON THE OUTSIDE!!

- $=\mathrm{Ni}$

- $=$ As

$\mathrm{Ve}=4 \mathrm{n}-24+12[10]$ metal adjustment $=4(33)-24+120=228$

CHECK: VF= 12[10]+21[5]+3 =228

N37 Pd37(CO) $28 \mathrm{~L} 12: \mathrm{K}=37[4]-28-12=108 ; \mathrm{K}(\mathrm{n})=108(37), \mathrm{S}=4 \mathrm{n}-68, \mathrm{Kp}=\mathrm{C}^{35} \mathrm{C}[\mathrm{M}-2]$

Distribution of ligands onto the skeletal elements

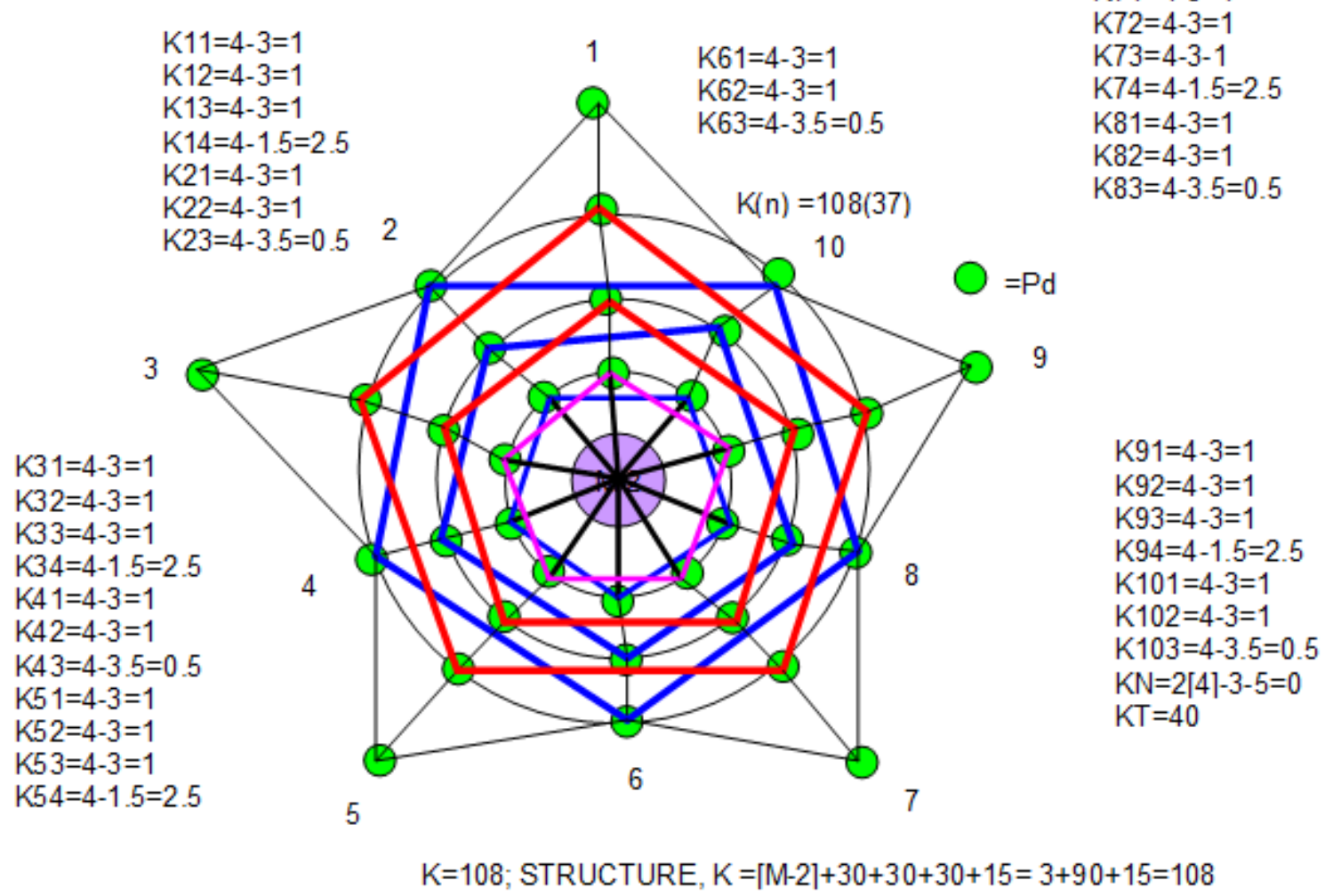


According to the series method, the cluster $\mathrm{Pd}_{37}(\mathrm{CO})_{28} \mathrm{~L}_{12}, \mathrm{~K}(\mathrm{n})=108(37), \mathrm{S}=4 \mathrm{n}-68, \mathrm{Kp}=\mathrm{C}^{35} \mathrm{C}[\mathrm{M} 2]$ reported in literature (Mednikov and Dahl, 2010) has central nucleus comprising of 2 skeletal elements with 35 capping skeletal elements based on series method.

N441 Nis8Pts $(\mathrm{CO}) 48(H)^{5-}: K=44\left[47-48-0.5-2.5=125, K(n)=125(44), S=4 n-74, K p=C^{38} \mathrm{C}[\mathrm{M} 6]\right.$

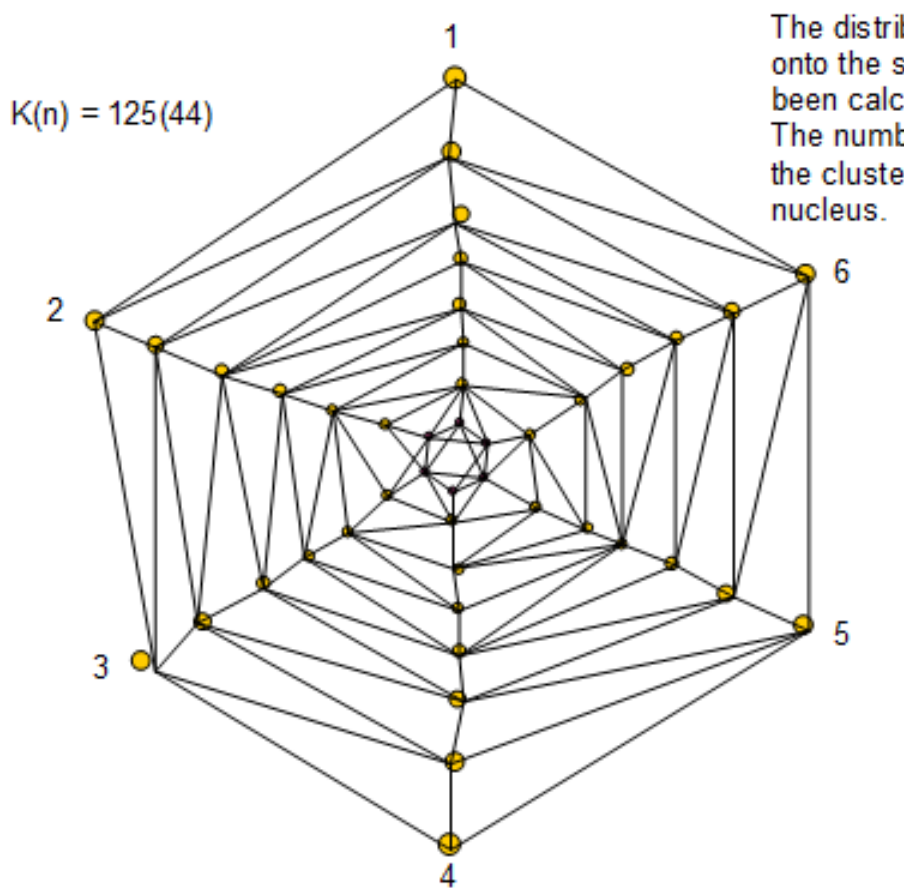

The distribution of the ligands onto the skeletal elements have been calculated and indicated numerically. The numbering of the kvalues of the cluster corners begin from the octahedral nucleus.

N441

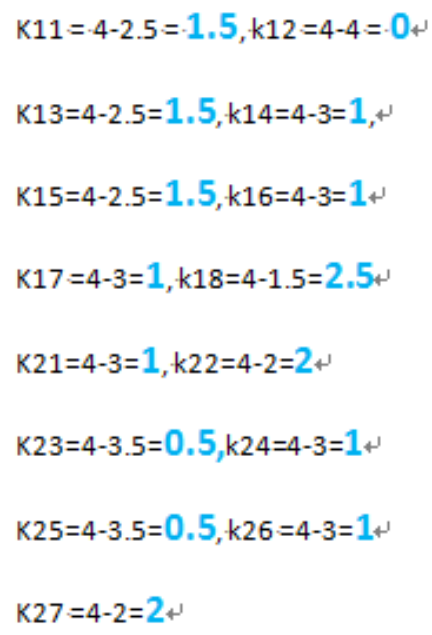

TOTAL·18

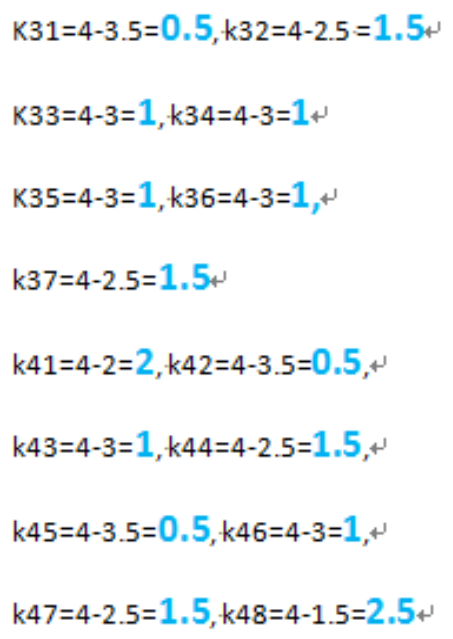

For example, $\mathrm{k} 11$ is at the nucleus while $\mathrm{k} 18$ is at the periphery. When the calculation is done correctly, the total nume rical value should correspond to the total number of ligands on the cluster. All the connections to a skeletal point should be regarded as a single electron donor.

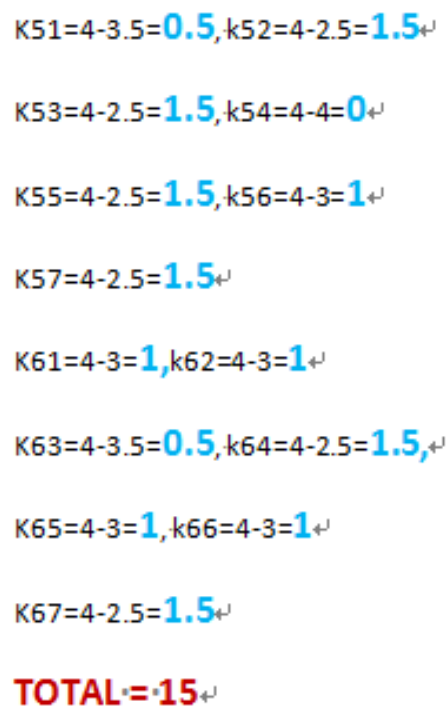


N561 $\mathrm{Ni}_{32} \mathrm{Pt}_{24}(\mathrm{CO})_{56} 6-: \mathrm{K}=32[4]+24[4]-56-3=165 ; \mathrm{n}=32+24=56, \mathrm{~K}(\mathrm{n})=165(56), \mathrm{S}=4 \mathrm{n}-106$, $\mathrm{Kp}=\mathrm{C}^{54} \mathrm{C}[\mathrm{M} 2]$

The capping symbol means that the cluster has 2 skeletal elements in the nucleus which belongs to CLOSO SERIES and is surrounded by 54 skeletal elements. It has been found that the capping for VERTICAL SERIES starts with the formation of a closo nucleus.

Cluster valence electrons are given by the series formula of transition metal clusters: $\mathrm{Ve}=14 \mathrm{n}-106=14(56)-106=678 ; \mathrm{VF}=32[10]+24[10]+56(2)+6=678$

Using the broad cluster categorization, the cluster belongs to GROUP [M2] OF THE VERTICAL SERIES.

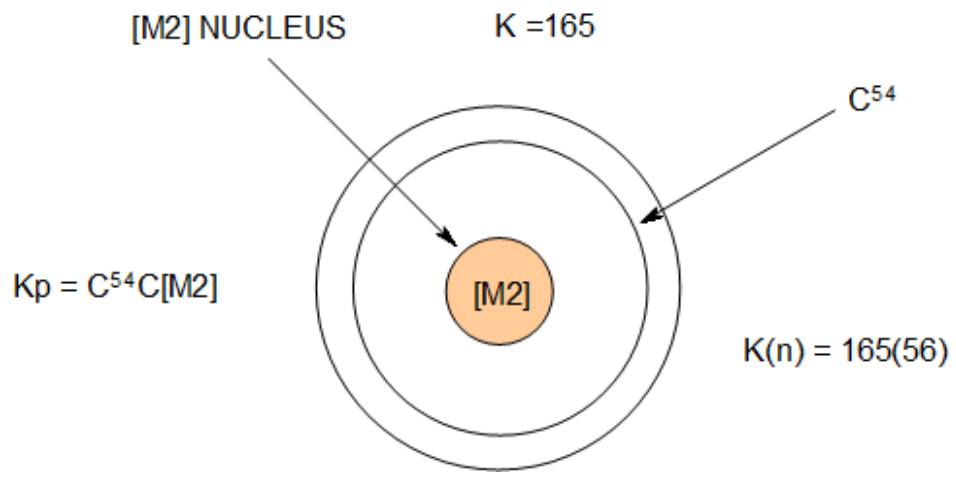

\subsection{Numerical Periodic Table of Chemical Clusters}

The examples of clusters given above cover a range of nuclearity index 1-56. By deriving the $\mathrm{K}(\mathrm{n})$ values of many clusters and carefully studying their relationship an interesting pattern was discerned. Firstly, the K(n) values of clusters covered an infinite range of $4 \mathrm{n}$ series. That is, $\mathrm{S}=4 \mathrm{n}+\mathrm{q}[\mathrm{q}=2,4,6,8,10,12, \ldots .$. (un-capping series); $\mathrm{q}=0,-2,-4,-6$, $-8,-10,-12, \ldots$. (capping series)]. This aspect has been illustrated in Table1. In addition, a grid map shown in Table 2 was obtained. The K(n) values of the clusters derived from the $4 \mathrm{n}$ series when carefully analyzed, are found to form an interesting series. A selected range of K(n) values from [M-10] through [M0] to [M14] are given in Table 2. This arrangement is similar to the usual $X$-axis of $x=-10$ to $x=+10$. This array of $K(n)$ values was discovered in earlier work (Kiremire, 2017a) but it is being re-introduced for the purpose of categorizing a vast range of capping chemical clusters.

The horizontal rows show the clusters arranged according to $S=4 n+q$ where $q$ is the same while the vertical columns indicate the cluster determinant $q$ varies by \pm 2 . Table 2 appears seemingly complex, but on close observation, it actually commences with one $K(n)$ value. This is demonstrated in Scheme SC-4. Starting with point A of $K(n)=11(6)$, the vertical movement upwards involves stepwise changes in $\mathrm{K}$ value by 3 units; while downward movements involves a decrease of $\mathrm{K}$ by the same amount of 3 units stepwise. Thus, the vertical axis can be extended in both directions indefinitely. Hence, new points B, C, D and E in scheme SC-4 are derived from A. Likewise, each of the points B, C, D and $\mathrm{E}$ can be handled in the same manner as a resulting in a seemingly complex cluster GRID MAP shown in Table 2. In a way, Table 2 is similar to an array of coordinates of a point $\mathrm{P}(\mathrm{x}, \mathrm{y})$ except in this case we have the K(n) VALUES where $\mathrm{K}$ represents the number of cluster linkages corresponding to $\mathrm{x}$ value of the $\mathrm{X}$-axis and $\mathrm{n}$ which represents the number of skeletal elements in a cluster corresponding to the $\mathrm{y}$ value of the $\mathrm{Y}$ axis in the Cartesian coordinate system. Thus, we have the correlation relationship $\mathrm{P}(\mathrm{x}, \mathrm{y}) \rightarrow(\mathrm{K}, \mathrm{n})$ but expressed as $\mathrm{K}(\mathrm{n})$. The base line has been chosen to correspond to the values of the horizontal clososeries, $S=4 n+2$. 
VERTICAL

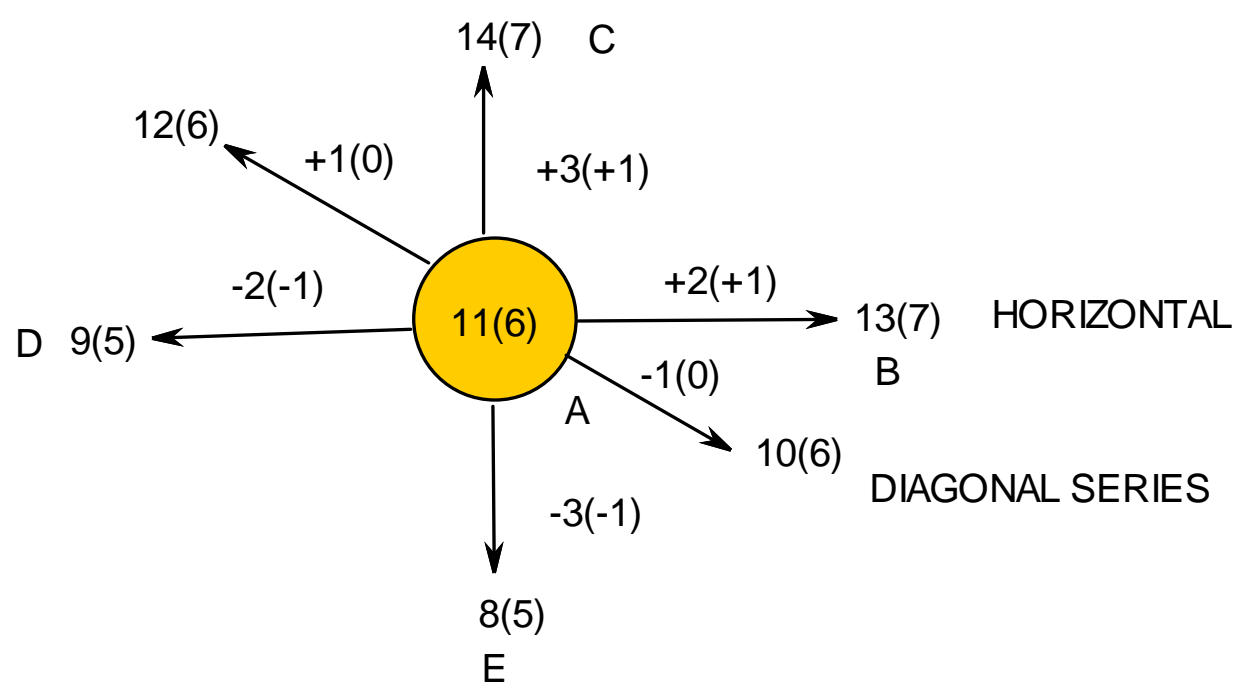

SC-4

Table 2. The Grid Map of K(n) Series

\begin{tabular}{|c|c|c|c|c|c|c|c|c|c|c|c|}
\hline \multicolumn{12}{|c|}{ TABLE 2A } \\
\hline $\mathrm{T}-2 \mathrm{~A}$ & [M-10] & [M-9] & {$[\mathrm{M}-8]$} & [M-7] & {$[\mathrm{M}-6]$} & {$[\mathrm{M}-5]$} & [M-4] & {$[\mathrm{M}-3]$} & [M-2] & [M-1] & [M0] \\
\hline $4 n-124$ & $168(53)$ & $170(54)$ & $172(55)$ & $174(56)$ & $176(57)$ & $178(58)$ & $180(59)$ & $182(60)$ & $184(61)$ & $186(62)$ & $188(63)$ \\
\hline $4 n-122$ & $165(52)$ & $167(53)$ & $169(54)$ & $171(55)$ & $173(56)$ & $175(57)$ & $177(58)$ & $179(59)$ & $181(60)$ & $183(61)$ & $185(62)$ \\
\hline $4 n-120$ & $162(51)$ & $164(52)$ & $166(53)$ & $168(54)$ & $170(55)$ & $172(56)$ & $174(57)$ & $176(58)$ & $178(59)$ & $180(60)$ & $182(61)$ \\
\hline $4 n-118$ & $159(50)$ & 161(51) & $163(52)$ & $165(53)$ & $167(54)$ & $169(55)$ & $171(56)$ & $173(57)$ & $175(58)$ & $177(59)$ & $179(60)$ \\
\hline $4 n-116$ & $156(49)$ & $158(50)$ & $160(51)$ & $162(52)$ & $164(53)$ & $166(54)$ & $168(55)$ & $170(56)$ & $172(57)$ & $174(58)$ & 176(59) \\
\hline $4 n-114$ & $153(48)$ & $155(49)$ & $157(50)$ & $159(51)$ & $161(52)$ & $163(53)$ & $165(54)$ & $167(55)$ & $169(56)$ & $171(57)$ & $173(58)$ \\
\hline $4 n-112$ & $150(47)$ & $152(48)$ & $154(49)$ & $156(50)$ & $158(51)$ & $160(52)$ & $162(53)$ & $164(54)$ & $166(55)$ & $168(56)$ & $170(57)$ \\
\hline $4 n-110$ & $147(46)$ & $149(47)$ & $151(48)$ & $153(49)$ & $155(50)$ & $157(51)$ & $159(52)$ & 161(53) & $163(54)$ & $165(55)$ & $167(56)$ \\
\hline $4 n-108$ & $144(45)$ & $146(46)$ & $148(47)$ & $150(48)$ & $152(49)$ & $154(50)$ & $156(51)$ & $158(52)$ & $160(53)$ & $162(54)$ & $164(55)$ \\
\hline $4 n-106$ & 141(44) & $143(45)$ & $145(46)$ & $147(47)$ & 149(48) & 151(49) & $153(50)$ & $155(51)$ & $157(52)$ & $159(53)$ & 161(54) \\
\hline $4 n-104$ & $138(43)$ & $140(44)$ & $142(45)$ & $144(46)$ & $146(47)$ & $148(48)$ & $150(49)$ & $152(50)$ & $154(51)$ & $156(52)$ & $158(53)$ \\
\hline $4 n-102$ & $135(42)$ & $137(43)$ & $139(44)$ & $141(45)$ & $143(46)$ & $145(47)$ & $147(48)$ & 149(49) & $151(50)$ & $153(51)$ & $155(52)$ \\
\hline $4 n-100$ & $132(41)$ & $134(42)$ & $136(43)$ & $138(44)$ & $140(45)$ & $142(46)$ & $144(47)$ & $146(48)$ & $148(49)$ & $150(50)$ & $152(51)$ \\
\hline $4 n-98$ & $129(40)$ & 131(41) & $133(42)$ & $135(43)$ & $137(44)$ & $139(45)$ & 141(46) & $143(47)$ & $145(48)$ & 147(49) & $149(50)$ \\
\hline $4 n-96$ & $126(39)$ & $128(40)$ & $130(41)$ & $132(42)$ & 134(43) & $136(44)$ & $138(45)$ & $140(46)$ & $142(47)$ & 144(48) & $146(49)$ \\
\hline $4 n-94$ & $123(38)$ & $125(39)$ & $127(40)$ & $129(41)$ & 131(42) & $133(43)$ & $135(44)$ & $137(45)$ & 139(46) & 141(47) & $143(48)$ \\
\hline $4 n-92$ & $120(37)$ & $122(38)$ & 124(39) & $126(40)$ & $128(41)$ & $130(42)$ & 132(43) & 134(44) & $136(45)$ & $138(46)$ & $140(47)$ \\
\hline $4 n-90$ & $117(36)$ & 119(37) & 121(38) & 123(39) & $125(40)$ & $127(41)$ & $129(42)$ & 131(43) & 133(44) & $135(45)$ & 137(46) \\
\hline $4 n-88$ & $114(35)$ & $116(36)$ & $118(37)$ & $120(38)$ & 122(39) & 124(40) & $126(41)$ & $128(42)$ & $130(43)$ & $132(44)$ & 134(45) \\
\hline $4 n-86$ & $111(34)$ & $113(35)$ & $115(36)$ & $117(37)$ & $119(38)$ & 121(39) & $123(40)$ & $125(41)$ & $127(42)$ & $129(43)$ & 131(44) \\
\hline $4 n-84$ & $108(33)$ & $110(34)$ & $112(35)$ & 114(36) & $116(37)$ & $118(38)$ & $120(39)$ & $122(40)$ & 124(41) & $126(42)$ & $128(43)$ \\
\hline $4 n-82$ & $105(32)$ & $107(33)$ & $109(34)$ & $111(35)$ & $113(36)$ & $115(37)$ & $117(38)$ & $119(39)$ & $121(40)$ & $123(41)$ & $125(42)$ \\
\hline $4 n-80$ & $102(31)$ & $104(32)$ & $106(33)$ & $108(34)$ & $110(35)$ & $112(36)$ & 114(37) & $116(38)$ & $118(39)$ & $120(40)$ & $122(41)$ \\
\hline $4 n-78$ & $99(30)$ & 101(31) & $103(32)$ & $105(33)$ & $107(34)$ & $109(35)$ & 111(36) & $113(37)$ & $115(38)$ & 117(39) & $119(40)$ \\
\hline $4 n-76$ & $96(29)$ & $98(30)$ & $100(31)$ & $102(32)$ & 104(33) & $106(34)$ & $108(35)$ & $110(36)$ & $112(37)$ & $114(38)$ & 116(39) \\
\hline $4 n-74$ & $93(28)$ & $95(29)$ & $97(30)$ & $99(31)$ & 101(32) & 103(33) & $105(34)$ & $107(35)$ & $109(36)$ & 111(37) & $113(38)$ \\
\hline $4 n-72$ & $90(27)$ & $92(28)$ & $94(29)$ & $96(30)$ & $98(31)$ & $100(32)$ & $102(33)$ & 104(34) & $106(35)$ & $108(36)$ & $110(37)$ \\
\hline $4 n-70$ & $87(26)$ & $98(27)$ & $91(28)$ & $93(29)$ & $95(30)$ & $97(31)$ & $99(32)$ & 101(33) & $103(34)$ & $105(35)$ & $107(36)$ \\
\hline $4 n-68$ & $84(25)$ & $86(26)$ & $88(27)$ & $90(28)$ & $92(29)$ & $94(30)$ & $96(31)$ & $98(32)$ & $100(33)$ & $102(34)$ & $104(35)$ \\
\hline $4 n-66$ & $81(24)$ & $83(25)$ & $85(26)$ & $87(27)$ & $89(28)$ & $91(29)$ & $93(30)$ & $95(31)$ & $97(32)$ & $99(33)$ & 101(34) \\
\hline & [M-10] & [M-9] & {$[\mathrm{M}-8]$} & [M-7] & {$[\mathrm{M}-6]$} & [M-5] & {$[\mathrm{M}-4]$} & [M-3] & {$[\mathrm{M}-2]$} & {$[\mathrm{M}-1]$} & [M0] \\
\hline $4 n-64$ & $78(23)$ & $80(24)$ & $82(25)$ & $84(26)$ & $86(27)$ & $88(28)$ & $90(29)$ & $92(30)$ & $94(31)$ & $96(32)$ & $98(33)$ \\
\hline $4 n-62$ & $75(22)$ & $77(23)$ & $79(24)$ & $81(25)$ & $83(26)$ & $85(27)$ & $87(28)$ & $89(29)$ & $91(30)$ & $93(31)$ & $95(32)$ \\
\hline $4 n-60$ & $72(21)$ & $74(22)$ & $76(23)$ & $78(24)$ & $80(25)$ & $82(26)$ & $84(27)$ & $86(28)$ & $88(29)$ & $90(30)$ & $92(31)$ \\
\hline $4 n-58$ & $69(20)$ & $71(21)$ & $73(22)$ & $75(23)$ & $77(24)$ & $79(25)$ & $81(26)$ & $83(27)$ & $85(28)$ & $87(29)$ & $89(30)$ \\
\hline
\end{tabular}




\begin{tabular}{|c|c|c|c|c|c|c|c|c|c|c|c|}
\hline $4 n-56$ & $66(19)$ & $68(20)$ & $70(21)$ & $72(22)$ & $74(23)$ & $76(24)$ & $78(25)$ & $80(26)$ & $82(27)$ & $84(28)$ & $86(29)$ \\
\hline $4 n-54$ & $63(18)$ & $65(19)$ & $67(20)$ & $69(21)$ & $71(22)$ & $73(23)$ & $75(24)$ & $77(25)$ & $79(26)$ & $81(27)$ & $83(28)$ \\
\hline $4 n-52$ & $60(17)$ & $62(18)$ & $64(19)$ & $66(20)$ & $68(21)$ & $70(22)$ & $72(23)$ & $74(24)$ & $76(25)$ & $78(26)$ & $80(27)$ \\
\hline $4 n-50$ & $57(16)$ & $59(17)$ & $61(18)$ & $63(19)$ & $65(20)$ & $67(21)$ & $69(22)$ & 71(23) & $73(24)$ & $75(25)$ & $77(26)$ \\
\hline $4 n-48$ & $54(15)$ & $56(16)$ & $58(17)$ & $60(18)$ & $62(19)$ & $64(20)$ & $66(21)$ & $68(22)$ & $70(23)$ & $72(24)$ & $74(25)$ \\
\hline $4 n-46$ & $51(14)$ & $53(15)$ & $55(16)$ & $57(17)$ & $59(18)$ & $61(19)$ & $63(20)$ & $65(21)$ & $67(22)$ & 69(23) & 71(24) \\
\hline $4 n-44$ & $48(13)$ & $50(14)$ & $52(15)$ & $54(16)$ & $56(17)$ & $58(18)$ & $60(19)$ & $62(20)$ & $64(21)$ & $66(22)$ & $68(23)$ \\
\hline $4 n-42$ & $45(12)$ & $47(13)$ & $49(14)$ & $51(15)$ & $53(16)$ & $55(17)$ & $57(18)$ & $59(19)$ & $61(20)$ & 63(21) & $65(22)$ \\
\hline $4 n-40$ & $42(11)$ & $44(12)$ & $46(13)$ & $48(14)$ & $50(15)$ & $52(16)$ & $54(17)$ & $56(18)$ & $58(19)$ & $60(20)$ & $62(21)$ \\
\hline $4 n-38$ & $39(10)$ & $41(11)$ & $43(12)$ & $45(13)$ & $47(14)$ & $49(15)$ & $51(16)$ & $53(17)$ & $55(18)$ & $57(19)$ & $59(20)$ \\
\hline $4 n-36$ & $36(9)$ & $38(10)$ & $40(11)$ & $42(12)$ & $44(13)$ & $46(14)$ & $48(15)$ & $50(16)$ & $52(17)$ & $54(18)$ & $56(19)$ \\
\hline $4 n-34$ & $33(8)$ & $35(9)$ & $37(10)$ & $39(11)$ & $41(12)$ & $43(13)$ & $45(14)$ & $47(15)$ & 49(16) & $51(17)$ & $53(18)$ \\
\hline $4 n-32$ & $30(7)$ & $32(8)$ & $34(9)$ & $36(10)$ & $38(11)$ & $40(12)$ & $42(13)$ & $44(14)$ & $46(15)$ & $48(16)$ & $50(17)$ \\
\hline $4 n-30$ & $27(6)$ & $29(7)$ & $31(8)$ & $33(9)$ & $35(10)$ & $37(11)$ & $39(12)$ & 41(13) & $43(14)$ & $45(15)$ & $47(16)$ \\
\hline $4 n-28$ & $24(5)$ & $26(6)$ & $28(7)$ & $30(8)$ & $32(9)$ & $34(10)$ & $36(11)$ & $38(12)$ & $40(13)$ & $42(14)$ & $44(15)$ \\
\hline $4 n-26$ & $21(4)$ & $23(5)$ & $25(6)$ & $27(7)$ & $29(8)$ & $31(9)$ & $33(10)$ & $35(11)$ & $37(12)$ & $39(13)$ & $41(14)$ \\
\hline $4 n-24$ & 18(3) & $20(4)$ & $22(5)$ & $24(6)$ & $26(7)$ & $28(8)$ & $30(9)$ & $32(10)$ & $34(11)$ & $36(12)$ & $38(13)$ \\
\hline $4 n-22$ & $15(2)$ & 17(3) & 19(4) & $21(5)$ & $23(6)$ & $25(7)$ & $27(8)$ & $29(9)$ & $31(10)$ & $33(11)$ & $35(12)$ \\
\hline $4 n-20$ & 12(1) & $14(2)$ & $16(3)$ & $18(4)$ & $20(5)$ & $22(6)$ & $24(7)$ & $26(8)$ & $28(9)$ & $30(10)$ & $32(11)$ \\
\hline $4 n-18$ & $9(0)$ & 11(1) & $13(2)$ & $15(3)$ & $17(4)$ & 19(5) & $21(6)$ & $23(7)$ & $25(8)$ & $27(9)$ & $29(10)$ \\
\hline $4 n-16$ & $6(-1)$ & $8(0)$ & $10(1)$ & $12(2)$ & 14(3) & $16(4)$ & $18(5)$ & $20(6)$ & $22(7)$ & $24(8)$ & $26(9)$ \\
\hline $4 n-14$ & $3(-2)$ & $5(-1)$ & $7(0)$ & $9(1)$ & $11(2)$ & $13(3)$ & $15(4)$ & $17(5)$ & $19(6)$ & $21(7)$ & $23(8)$ \\
\hline $4 n-12$ & $0(-3)$ & $2(-2)$ & $4(-1)$ & $6(0)$ & $8(1)$ & $10(2)$ & $12(3)$ & $14(4)$ & $16(5)$ & 18(6) & $20(7)$ \\
\hline $4 n-10$ & $-3(-4)$ & $-1(-3)$ & $1(-2)$ & $3(-1)$ & $5(0)$ & $7(1)$ & $9(2)$ & 11(3) & $13(4)$ & $15(5)$ & $17(6)$ \\
\hline $4 n-8$ & $-6(-5)$ & $-4(-4)$ & $-2(-3)$ & $0(-2)$ & $2(-1)$ & $4(0)$ & $6(1)$ & $8(2)$ & $10(3)$ & $12(4)$ & $14(5)$ \\
\hline $4 n-6$ & $-9(-6)$ & $-7(-5)$ & $-5(-4)$ & $-3(-3)$ & $-1(-2)$ & $1(-1)$ & $3(0)$ & $5(1)$ & $7(2)$ & $9(3)$ & 11(4) \\
\hline $4 n-4$ & $-12(-7)$ & $-10(-6)$ & $-8(-5)$ & $-6(-4)$ & $-4(-3)$ & $-2(-2)$ & $0(-1)$ & $2(0)$ & $4(1)$ & $6(2)$ & $8(3)$ \\
\hline $4 n-2$ & $-15(-8)$ & $-13(-7)$ & $-11(-6)$ & $-9(-5)$ & $-7(-4)$ & $-5(-3)$ & $-3(-2)$ & $-1(-1)$ & $1(0)$ & $3(1)$ & $5(2)$ \\
\hline $4 n+0$ & $-18(-9)$ & $-16(-8)$ & $-14(-7)$ & $-12(-6)$ & $-10(-5)$ & $-8(-4)$ & $-6(-3)$ & $-4(-2)$ & $-2(-1)$ & $0(0)$ & $2(1)$ \\
\hline $4 n+2$ & $-21(-10)$ & $-19(-9)$ & $-17(-8)$ & $-15(-7)$ & $-13(-6)$ & $-11(-5)$ & $-9(-4)$ & $-7(-3)$ & $-5(-2)$ & $-3(-1)$ & $-1(0)$ \\
\hline & [M-10] & {$[\mathrm{M}-9]$} & {$[\mathrm{M}-8]$} & {$[\mathrm{M}-7]$} & [M-6] & [M-5] & {$[\mathrm{M}-4]$} & {$[\mathrm{M}-3]$} & {$[\mathrm{M}-2]$} & {$[\mathrm{M}-1]$} & [M0] \\
\hline
\end{tabular}

\begin{tabular}{|c|c|c|c|c|c|c|c|c|c|c|c|c|}
\hline \multicolumn{13}{|c|}{ BLE 2B } \\
\hline T-2B & [M1] & [M2] & [M3] & [M4] & [M5] & [M6] & [M7] & [M8] & [M9] & [M10] & [M11] & [M12] \\
\hline $4 n-114$ & $175(59)$ & $177(60)$ & $179(61)$ & 181(62) & $183(63)$ & $185(64)$ & $187(65)$ & $189(66)$ & 191(67) & 193(68) & 195(69) & $197(70)$ \\
\hline $4 n-112$ & $172(58)$ & 174(59) & $176(60)$ & $178(61)$ & $180(62)$ & $182(63)$ & 184(64) & $186(65)$ & 188(66) & $190(67)$ & 192(68) & 194(69) \\
\hline $4 n-110$ & $169(57)$ & 171(58) & $173(59)$ & $175(60)$ & $177(61)$ & $179(62)$ & 181(63) & $183(64)$ & $185(65)$ & $187(66)$ & $189(67)$ & 191(68) \\
\hline $4 n-108$ & $166(56)$ & $168(57)$ & $170(58)$ & $172(59)$ & $174(60)$ & $176(61)$ & $178(62)$ & $180(63)$ & 182(64) & $184(65)$ & $186(66)$ & $188(67)$ \\
\hline $4 n-106$ & $163(55)$ & $165(56)$ & $167(57)$ & $169(58)$ & 171(59) & $173(60)$ & $175(61)$ & $177(62)$ & $179(63)$ & 181(64) & $183(65)$ & $185(66)$ \\
\hline $4 n-104$ & $160(54)$ & $162(55)$ & $164(56)$ & $166(57)$ & $168(58)$ & $170(59)$ & $172(60)$ & 174(61) & $176(62)$ & $178(63)$ & $180(64)$ & $182(65)$ \\
\hline $4 n-102$ & 157(53) & 159(54) & 161(55) & $163(56)$ & $165(57)$ & $167(58)$ & $169(59)$ & $171(60)$ & $173(61)$ & $175(62)$ & $177(63)$ & $179(64)$ \\
\hline $4 n-100$ & $154(52)$ & $156(53)$ & $158(54)$ & $160(55)$ & $162(56)$ & $164(57)$ & $166(58)$ & $168(59)$ & $170(60)$ & $172(61)$ & $174(62)$ & $176(63)$ \\
\hline $4 n-98$ & 151(51) & $153(52)$ & $155(53)$ & $157(54)$ & $159(55)$ & $161(56)$ & $163(57)$ & $165(58)$ & $167(59)$ & $169(60)$ & 171(61) & $173(62)$ \\
\hline $4 n-96$ & $148(50)$ & $150(51)$ & $152(52)$ & $154(53)$ & $156(54)$ & $158(55)$ & $160(56)$ & $162(57)$ & $164(58)$ & $166(59)$ & $168(60)$ & $170(61)$ \\
\hline $4 n-94$ & $145(49)$ & $147(50)$ & $149(51)$ & $151(52)$ & $153(53)$ & $155(54)$ & $157(55)$ & $159(56)$ & 161(57) & $163(58)$ & $165(59)$ & $167(60)$ \\
\hline $4 n-92$ & $142(48)$ & $144(49)$ & $146(50)$ & $148(51)$ & $150(52)$ & $152(53)$ & $154(54)$ & $156(55)$ & $158(56)$ & $160(57)$ & $162(58)$ & 164(59) \\
\hline $4 n-90$ & $139(47)$ & $141(48)$ & $143(49)$ & $145(50)$ & $147(51)$ & $149(52)$ & $151(53)$ & $153(54)$ & $155(55)$ & $157(56)$ & $159(57)$ & 161(58) \\
\hline $4 n-88$ & $136(46)$ & $138(47)$ & $140(48)$ & $142(49)$ & $144(50)$ & $146(51)$ & $148(52)$ & $150(53)$ & $152(54)$ & 154 & $156(56)$ & $158(57)$ \\
\hline $4 n-86$ & 133(45) & $135(46)$ & 137(47) & $139(48)$ & 141(49) & $143(50)$ & $145(51)$ & $147(52)$ & 149(53) & 151(54) & $153(55)$ & $155(56)$ \\
\hline $4 n-84$ & $130(44)$ & $132(45)$ & $134(46)$ & $136(47)$ & $138(48)$ & $140(49)$ & $142(50)$ & $144(51)$ & $146(52)$ & $148(53)$ & $150(54)$ & $152(55)$ \\
\hline $4 n-82$ & $127(43)$ & 129( & 131(45) & $133(46)$ & $135(47)$ & 137 & 139(49) & 141 & 143 & $145(52)$ & $147(53)$ & $149(54)$ \\
\hline $4 n-80$ & $124(42)$ & $126(43)$ & $128(44)$ & $130(45)$ & $132(46)$ & $134(47)$ & $136(48)$ & $138(49)$ & $140(50)$ & $142(51)$ & $144(52)$ & $146(53)$ \\
\hline $4 n-78$ & 121(41) & $123(42)$ & $125(43)$ & $127(44)$ & $129(45)$ & $131(46)$ & $133(47)$ & $135(48)$ & 137(49) & $139(50)$ & 141(51) & $143(52)$ \\
\hline $4 n-76$ & $118(40)$ & $120(41)$ & $122(42)$ & $124(43)$ & $126(44)$ & $128(45)$ & $130(46)$ & $132(47)$ & $134(48)$ & $134(49)$ & $136(50)$ & $138(51)$ \\
\hline $4 n-74$ & 115(39) & $117(40)$ & 119(41) & 121(42) & $123(43)$ & $125(44)$ & $127(45)$ & $129(46)$ & 131(47) & $133(48)$ & $135(49)$ & $137(50)$ \\
\hline $4 n-72$ & $112(38)$ & $114(3$ & $116(40)$ & $118(41)$ & $120(42)$ & 122(43) & $124(44)$ & $126(45)$ & $128(46)$ & & $132(48)$ & $134(49)$ \\
\hline $4 n-70$ & $109(37)$ & 111(38) & 113(39) & $115(40)$ & $117(41)$ & $119(42)$ & 121(43) & $123(44)$ & $125(45)$ & $127(46)$ & $129(47)$ & $131(48)$ \\
\hline & [M1] & [M2] & [M3] & [M4] & [M5] & [M6] & [M7] & [M8] & [M9] & [M10] & [M11] & [M12] \\
\hline $4 n-68$ & $106(36$ & $108(37$ & $110(38$ & $112(3$ & $114(40)$ & $116(4)$ & $118(42$ & $120(43)$ & $122(44)$ & $124(45)$ & $126(46)$ & $128(47)$ \\
\hline $4 n-66$ & $103(35)$ & $105(36)$ & $107(37)$ & $109(38)$ & 111(39) & $113(40)$ & $115(41)$ & $117(42)$ & $119(43)$ & 121(44) & $123(45)$ & $125(46)$ \\
\hline $4 n-64$ & $100(34)$ & $102(35)$ & 104(36) & $106(37)$ & $108(38)$ & $110(39)$ & $112(40)$ & $114(41)$ & $116(42)$ & $118(43)$ & $120(44)$ & $122(45)$ \\
\hline $4 n-62$ & $97(33)$ & $99(34)$ & 101(35) & 103(36) & $105(37)$ & $107(38)$ & 109(39) & & 113(41) & $115(42)$ & $117(43)$ & $119(44)$ \\
\hline $4 n-60$ & 94(32) & $96(33)$ & $98(34)$ & $100(35)$ & 102(36) & 104(37) & $106(38)$ & $108(39)$ & $110(40)$ & $112(41)$ & $114(42)$ & $116(43)$ \\
\hline $4 n-58$ & $91(31)$ & $93(32)$ & $95(33)$ & $97(34)$ & 99(35) & 101(36) & 103(37) & $105(38)$ & 107(39) & $109(40)$ & 111(41) & $113(42)$ \\
\hline
\end{tabular}




\begin{tabular}{|c|c|c|c|c|c|c|c|c|c|c|c|c|}
\hline $4 n-56$ & $88(30)$ & $90(31)$ & $92(32)$ & $94(33)$ & $96(34)$ & 98(35) & $100(36)$ & $102(37)$ & $104(38)$ & $106(39)$ & $108(40)$ & $110(41)$ \\
\hline $4 n-54$ & $85(29)$ & $87(30)$ & $89(31)$ & $91(32)$ & $93(33)$ & 95(34) & $97(35)$ & $99(36)$ & 101(37) & $103(38)$ & 105(39) & $107(40)$ \\
\hline $4 n-52$ & $82(28)$ & $84(29)$ & $86(30)$ & $88(31)$ & 90(32) & 92(33) & $94(34)$ & $96(35)$ & $98(36)$ & $100(37)$ & $102(38)$ & 104(39) \\
\hline $4 n-50$ & $79(27)$ & $81(28)$ & $83(29)$ & $85(30)$ & $87(31)$ & $89(32)$ & 91(33) & 93(34) & $95(35)$ & $97(36)$ & 99(37) & 101(38) \\
\hline $4 n-48$ & $76(26)$ & $78(27)$ & $80(28)$ & $82(29)$ & $84(30)$ & $86(31)$ & $88(32)$ & $90(33)$ & $92(34)$ & $94(35)$ & $96(36)$ & $98(37)$ \\
\hline $4 n-46$ & $73(25)$ & $75(26)$ & $77(27)$ & $79(28)$ & 81(29) & 83(30) & $85(31)$ & $87(32)$ & $89(33)$ & $91(34)$ & $93(35)$ & $95(36)$ \\
\hline $4 n-44$ & $70(24)$ & $72(25)$ & $74(26)$ & $76(27)$ & $78(28)$ & $80(29)$ & $82(30)$ & $84(31)$ & $86(32)$ & $88(33)$ & $90(34)$ & $92(35)$ \\
\hline $4 n-42$ & $67(23)$ & $69(24)$ & $71(25)$ & $73(26)$ & $75(27)$ & $77(28)$ & $79(29)$ & $81(30)$ & $83(31)$ & $85(32)$ & $87(33)$ & $89(34)$ \\
\hline $4 n-40$ & $64(22)$ & $66(23)$ & $68(24)$ & $70(25)$ & $72(26)$ & $74(27)$ & $76(28)$ & $78(29)$ & $80(30)$ & $82(31)$ & $84(32)$ & $86(33)$ \\
\hline $4 n-38$ & $61(21)$ & $63(22)$ & $65(23)$ & $67(24)$ & 69(25) & $71(26)$ & $73(27)$ & $75(28)$ & $77(29)$ & $79(30)$ & $81(31)$ & $83(32)$ \\
\hline $4 n-36$ & $58(20)$ & $60(21)$ & $62(22)$ & $64(23)$ & $66(24)$ & $68(25)$ & $70(26)$ & $72(27)$ & $74(28)$ & $76(29)$ & $78(30)$ & $80(31)$ \\
\hline $4 n-34$ & $55(19)$ & $57(20)$ & $59(21)$ & $61(22)$ & $63(23)$ & $65(24)$ & $67(25)$ & $69(26)$ & 71(27) & $73(28)$ & $75(29)$ & $77(30)$ \\
\hline $4 n-32$ & $52(18)$ & $54(19)$ & $56(20)$ & $58(21)$ & $60(22)$ & $62(23)$ & $64(24)$ & $66(25)$ & $68(26)$ & $70(27)$ & $72(28)$ & $74(29)$ \\
\hline $4 n-30$ & $49(17)$ & $51(18)$ & $53(19)$ & $55(20)$ & $57(21)$ & $59(22)$ & $61(23)$ & $63(24)$ & $65(25)$ & $67(26)$ & $69(27)$ & $71(28)$ \\
\hline & [M1] & [M2] & [M3] & [M4] & [M5] & [M6] & [M7] & [M8] & [M9] & [M10] & [M11] & [M12] \\
\hline $4 n-28$ & $46(16)$ & $48(17)$ & $50(18)$ & $52(19)$ & $54(20)$ & $56(21)$ & $58(22)$ & $60(23)$ & $62(24)$ & $64(25)$ & $66(26)$ & $68(27)$ \\
\hline $4 n-26$ & $43(15)$ & $45(16)$ & $47(17)$ & $49(18)$ & $51(19)$ & $53(20)$ & $55(21)$ & $57(22)$ & $59(23)$ & $61(24)$ & $63(25)$ & $65(26)$ \\
\hline $4 n-24$ & $40(14)$ & $42(15)$ & $44(16)$ & $46(17)$ & $48(18)$ & $50(19)$ & $52(20)$ & $54(21)$ & $56(22)$ & $58(23)$ & $60(24)$ & $62(25)$ \\
\hline $4 n-22$ & $37(13)$ & $39(14)$ & 41(15) & $43(16)$ & $45(17)$ & $47(18)$ & 49(19) & $51(20)$ & $53(21)$ & $55(22)$ & $57(23)$ & $59(24)$ \\
\hline $4 n-20$ & $34(12)$ & $36(13)$ & $38(14)$ & $40(15)$ & $42(16)$ & 44(17) & $46(18)$ & $48(19)$ & $50(20)$ & $52(21)$ & $54(22)$ & $56(23)$ \\
\hline $4 n-18$ & $31(11)$ & $33(12)$ & $35(13)$ & $37(14)$ & 39(15) & 41(16) & $43(17)$ & $45(18)$ & $47(19)$ & $49(20)$ & $51(21)$ & $53(22)$ \\
\hline $4 n-16$ & $28(10)$ & $30(11)$ & $32(12)$ & $34(13)$ & $36(14)$ & $38(15)$ & $40(16)$ & $42(17)$ & $44(18)$ & $46(19)$ & $48(20)$ & $50(21)$ \\
\hline $4 n-14$ & $25(9)$ & $27(10)$ & $29(11)$ & $31(12)$ & 33(13) & $35(14)$ & $37(15)$ & $39(16)$ & $41(17)$ & $43(18)$ & $45(19)$ & $47(20)$ \\
\hline & [M1] & [M2] & [M3] & [M4] & [M5] & [M6] & [M7] & [M8] & [M9] & [M10] & [M11] & [M12] \\
\hline $4 n-12$ & $22(8)$ & $24(9)$ & $26(10)$ & $28(11)$ & $30(12)$ & $32(13)$ & $34(14)$ & $36(15)$ & $38(16)$ & $40(17)$ & $42(18)$ & $44(19)$ \\
\hline $4 n-10$ & 19(7) & $21(8)$ & $23(9)$ & $25(10)$ & 27(11) & $29(12)$ & $31(13)$ & $33(14)$ & $35(15)$ & $37(16)$ & $39(17)$ & $41(18)$ \\
\hline $4 n-8$ & $16(6)$ & $18(7)$ & $20(8)$ & $22(9)$ & $24(10)$ & $26(11)$ & $28(12)$ & $30(13)$ & $32(14)$ & $34(15)$ & $36(16)$ & $38(17)$ \\
\hline $4 n-6$ & $13(5)$ & $15(6)$ & $17(7)$ & $19(8)$ & 21(9) & $23(10)$ & $25(11)$ & $27(12)$ & 29(13) & $31(14)$ & $33(15)$ & $35(16)$ \\
\hline $4 n-4$ & $10(4)$ & $12(5)$ & $14(6)$ & $16(7)$ & $18(8)$ & $20(9)$ & $22(10)$ & $24(11)$ & $26(12)$ & $28(13)$ & $30(14)$ & $32(15)$ \\
\hline $4 n-2$ & 7(3) & $9(4)$ & 11(5) & $13(6)$ & $15(7)$ & $17(8)$ & 19(9) & $21(10)$ & $23(11)$ & $25(12)$ & $27(13)$ & $29(14)$ \\
\hline $4 n+0$ & 4(2) & $6(3)$ & $8(4)$ & $10(5)$ & $12(6)$ & $14(7)$ & $16(8)$ & $18(9)$ & $20(10)$ & $22(11)$ & $24(12)$ & $26(13)$ \\
\hline
\end{tabular}

\section{TABLE 2C}

\section{RUDOLPH SYSTEM: BORANES AND RELATIVES}

\begin{tabular}{|c|c|c|c|c|c|c|c|c|c|c|c|c|}
\hline T-2C & [M1] & [M2] & [M3] & [M4] & [M5] & [M6] & [M7] & [M8] & [M9] & [M10] & [M11] & [M12] \\
\hline $4 n+2$ & 1(1) & $3(2)$ & $5(3)$ & $7(4)$ & $9(5)$ & $11(6)$ & $13(7)$ & $15(8)$ & 17(9) & $19(10)$ & 21(11) & $23(12)$ \\
\hline $4 n+4$ & & $0(1)$ & $2(2)$ & 4(3) & $6(4)$ & $8(5)$ & $10(6)$ & $12(7)$ & $14(8)$ & $16(9)$ & $18(10)$ & $20(11)$ \\
\hline $4 n+6$ & & & & 1(2) & $3(3)$ & $5(4)$ & $7(5)$ & $9(6)$ & 11(7) & $13(8)$ & $15(9)$ & $17(10)$ \\
\hline $4 n+8$ & & & & & $0(2)$ & $2(3)$ & $4(4)$ & $6(5)$ & $8(6)$ & $10(7)$ & $12(8)$ & $14(9)$ \\
\hline \multirow[t]{4}{*}{$4 n+10$} & & & & & & & 1(3) & $3(4)$ & $5(5)$ & $7(6)$ & $9(7)$ & 11(8) \\
\hline & & & & & & & & $0(3)$ & 2(4) & $4(5)$ & $6(6)$ & $8(7)$ \\
\hline & & & & & & & & & & 1(4) & $3(5)$ & $5(6)$ \\
\hline & & & & & & & & & & & $0(4)$ & $2(5)$ \\
\hline
\end{tabular}

\begin{tabular}{|c|c|c|c|c|c|}
\hline \multicolumn{6}{|c|}{ TABLE 2D } \\
\hline \multicolumn{6}{|l|}{ T-2D } \\
\hline & & [M11] & [M12] & [M13] & [M14] \\
\hline $\mathrm{C}^{26}$ & $4 n-50$ & $99(37)$ & $101(38)$ & 103(39) & $105(40)$ \\
\hline $\mathrm{C}^{25}$ & $4 n-48$ & $96(36)$ & $98(37)$ & $100(38)$ & 102(39) \\
\hline $\mathrm{C}^{24}$ & $4 n-46$ & $93(35)$ & $93(35)$ & $95(35)$ & $97(36)$ \\
\hline $\mathrm{C}^{23}$ & $4 n-44$ & $90(34)$ & $92(35)$ & $94(36)$ & $96(37)$ \\
\hline $\mathrm{C}^{22}$ & $4 n-42$ & $87(33)$ & $89(34)$ & $91(35)$ & $93(36)$ \\
\hline $\mathrm{C}^{21}$ & $4 n-40$ & $84(32)$ & $86(33)$ & $88(34)$ & $90(35)$ \\
\hline $\mathrm{C}^{20}$ & $4 n-38$ & $82(31)$ & $84(32)$ & $86(33)$ & $88(34)$ \\
\hline $\mathrm{C}^{19}$ & $4 n-36$ & $78(30)$ & $80(31)$ & $82(32)$ & $84(33)$ \\
\hline $\mathrm{C}^{18}$ & $4 n-34$ & $75(29)$ & $77(30)$ & $79(31)$ & $81(32)$ \\
\hline $\mathrm{C}^{17}$ & $4 n-32$ & $72(28)$ & $74(29)$ & $76(30)$ & $78(31)$ \\
\hline $\mathrm{C}^{16}$ & $4 n-30$ & $69(27)$ & $71(28)$ & $73(29)$ & $75(30)$ \\
\hline $\mathrm{C}^{15}$ & $4 n-28$ & $66(26)$ & $68(27)$ & $70(28)$ & $72(29)$ \\
\hline $\mathrm{C}^{14}$ & $4 n-26$ & $63(25)$ & $65(26)$ & $67(27)$ & $69(28)$ \\
\hline $\mathrm{C}^{13}$ & $4 n-24$ & $60(24)$ & $62(25)$ & $64(26)$ & $66(28)$ \\
\hline $\mathrm{C}^{12}$ & $4 n-22$ & $57(23)$ & $59(24)$ & $61(25)$ & $63(26)$ \\
\hline $\mathrm{C}^{11}$ & $4 n-20$ & $54(22)$ & $56(23)$ & $58(24)$ & $60(25)$ \\
\hline
\end{tabular}




\begin{tabular}{|c|c|c|c|c|c|}
\hline $\mathrm{C}^{10}$ & $4 n-18$ & $51(21)$ & $53(22)$ & $55(23)$ & $57(24)$ \\
\hline $\mathrm{C}^{9}$ & $4 n-16$ & $48(20)$ & $50(21)$ & $52(22)$ & $46(19)$ \\
\hline $\mathrm{C}^{8}$ & $4 n-14$ & $45(19)$ & $47(20)$ & $49(21)$ & $51(22)$ \\
\hline $\mathrm{C}^{7}$ & $4 n-12$ & $42(18)$ & $44(19)$ & $46(20)$ & $48(21)$ \\
\hline $\mathrm{C}^{6}$ & $4 n-10$ & $39(17)$ & $41(18)$ & $43(19)$ & $45(20)$ \\
\hline$C^{5}$ & $4 n-8$ & $36(16)$ & $38(17)$ & $40(18)$ & $42(19)$ \\
\hline $\mathrm{C}^{4}$ & $4 n-6$ & $33(15)$ & $35(16)$ & $37(17)$ & $39(18)$ \\
\hline $\mathrm{C}^{3}$ & $4 n-4$ & $30(14)$ & $32(15)$ & $34(16)$ & $36(17)$ \\
\hline $\mathrm{C}^{2}$ & $4 n-2$ & $27(13)$ & $29(14)$ & $31(15)$ & $33(16)$ \\
\hline $\mathrm{C}^{1}$ & $4 n+0$ & $24(12)$ & $26(13)$ & $28(14)$ & $30(15)$ \\
\hline $\mathrm{C}^{0}$ & $4 n+2$ & 21(11) & $23(12)$ & $25(13)$ & 27(14) \\
\hline $\mathrm{C}^{-1}$ & $4 n+4$ & $18(10)$ & $20(11)$ & $22(12)$ & $24(13)$ \\
\hline $\mathrm{C}^{-2}$ & $4 n+6$ & $15(9)$ & $17(10)$ & 19(11) & $21(10)$ \\
\hline $\mathrm{C}^{-3}$ & $4 n+8$ & $12(8)$ & $14(9)$ & $16(10)$ & $18(11)$ \\
\hline $\mathrm{C}^{-4}$ & $4 n+10$ & $9(7)$ & $11(8)$ & 13(9) & $15(10)$ \\
\hline $\mathrm{C}^{-5}$ & & $6(6)$ & $8(7)$ & $10(8)$ & $12(9)$ \\
\hline $\mathrm{C}^{-6}$ & & $3(5)$ & $5(6)$ & $7(7)$ & $9(8)$ \\
\hline
\end{tabular}

3.9 Outstanding Derivatives from Table 2

- THE BROAD MEANING OF TABLE 2

The table is extremely important. It represents $K(n)$ values of chemical clusters comprising of a single $(n=1)$ skeletal element to seventy $(\mathrm{n}=70)$ skeletal elements. Let us illustrate this with clusters which have whole number $\mathrm{K}$ values starting from small ones to large ones. The $K(n)=1(1)$ : this will represent all the elements such as $O(K=1), K(n)=1(1)$; $\mathrm{S}(\mathrm{K}=1), \mathrm{Se}(\mathrm{K}=1)$ and Tein group 6(16) in the periodic table(see Appendix 1). The $\mathrm{K}(\mathrm{n})=2(1)$ will be the carbon group $4(14) ; \mathrm{K}(\mathrm{n})=3(1) \rightarrow \mathrm{Be}$ group 2(12) or $\mathrm{Zn}$ group12(see Appendix 2), $\mathrm{K}(\mathrm{n})=4(1) \rightarrow \mathrm{NI}$ group 10 and $\mathrm{K}(\mathrm{n})=5(1) \rightarrow \mathrm{Fe}$ group 8 in the periodic table(see Appendix 2). The $\mathrm{K}(\mathrm{n})=1(2)$ represents clusters such as $\mathrm{X}_{2}$ ( group $17, \mathrm{X}=\mathrm{F}, \mathrm{Cl}$ ), $\mathrm{M}_{2}(\mathrm{CO})_{10}(\mathrm{M}=\mathrm{Mn}, \quad \mathrm{Tc}, \quad \mathrm{Re}) ; \quad \mathrm{Co}_{2}(\mathrm{CO})_{8}, \quad \mathrm{Mo}_{2}(\mathrm{Cp})_{2}(\mathrm{CO})_{6} ; 2(2) \rightarrow \mathrm{O}_{2}, \quad \mathrm{C} 2 \mathrm{H} 4, \quad \mathrm{Rh}_{2}(\mathrm{Cp})_{2}(\mathrm{CO})_{2} ; 3(2) \rightarrow \mathrm{N}_{2}$, $\mathrm{C}_{2} \mathrm{H}_{2}, \mathrm{Mo}_{2}(\mathrm{Cp})_{2}(\mathrm{CO})_{4} ; 3(3) \rightarrow \mathrm{C}_{3} \mathrm{H}_{6}, \quad \mathrm{Os}_{3}(\mathrm{CO})_{12} ; 6(4) \rightarrow \mathrm{C}_{4} \mathrm{R}_{4}, \quad \mathrm{M}_{4}(\mathrm{CO})_{12}(\mathrm{M}=\mathrm{Co}, \quad \mathrm{Rh}, \quad \mathrm{Ir}) ; \quad 8(5) \rightarrow \mathrm{B}_{5} \mathrm{H}_{9}, \mathrm{Fe}_{5}(\mathrm{C})(\mathrm{CO})_{15} ;$ $9(5) \rightarrow \mathrm{B}_{5} \mathrm{H}_{5}{ }^{2-}, \mathrm{Sn}_{5}{ }^{2-}, \mathrm{Os}_{5}(\mathrm{CO})_{16} ; 11(6) \rightarrow \mathrm{B}_{6} \mathrm{H}_{6}{ }^{2-}, \mathrm{Rh}_{6}(\mathrm{CO})_{16}, \mathrm{Co}_{6}(\mathrm{C})(\mathrm{CO})_{14}{ }^{-}$.

\section{- CAPPING CONCEPT FROM SERIES ELABORATED}

The capping symbol $\mathrm{Kp}=\mathrm{C}^{\mathrm{y}} \mathrm{C}[\mathrm{Mx}]$ that has been developed is very useful in explain the capping concept. The letter $\mathrm{y}$ (capping index) represents the number of capping skeletal elements outside the cluster nucleus $[\mathrm{Mx}](\mathrm{x}=$ nuclear index), represents the number of the skeletal elements in the nucleus of a cluster. If Table 2 were displayed on a larger space, it would cover the [Mx] range $\mathrm{x}=-10$ to $\mathrm{x}=+14$ expressed as [M-10] to [M14]. The construction of the table shows that the un-capped series commence at $x=2$ upwards, that is, $x \geq 2$. However, there are no un-capped series for $x \leq 1$. Therefore, the Rudolph concept of correlation of geometrical structures is more meaningful for clusters $x \geq 2$. A section of Table 2 has been numerically demarcated and labeled Table $2 \mathrm{C}(\mathrm{T}-2 \mathrm{C})$. If we focus on the closo base-line, $\mathrm{S}=4 \mathrm{n}+2$ As a reference, then clusters with genuine skeletal elements in the nucleus commence with [M1]. This means, these will be clusters which have a single element in the nucleus. This is the foundation of golden clusters referred to as torroidal clusters. According to the series in Table 2, the starting cluster on the vertical grid-line is numerically represented as [M1], K(n) $=1(1)$ and belongs to the CLOSO family of series $S=4 n+2$. The selected vertical range of $K(n)$ numbers are:

$\mathrm{K}(\mathrm{n}):[\mathrm{M} 1]$ SERIES

$\rightarrow 1(1) \rightarrow 4(2) \rightarrow 7(3) \rightarrow 10(4) \rightarrow 13(5) \rightarrow 16(6) \rightarrow 19(7) \rightarrow 22(8) \rightarrow 25(9) \rightarrow 28(10) \rightarrow 31(11) \rightarrow 34(12) \rightarrow 37(13)$.

Let us look at the following golden clusters: $A_{u_{6}} \mathrm{~L}_{6}{ }^{2+}: \mathrm{K}(\mathrm{n})=\mathbf{1 6}(\mathbf{6}), \mathrm{S}=4 \mathrm{n}-8, \mathrm{Kp}=\mathrm{C}^{5} \mathrm{C}[\mathrm{M} 1] ; \mathrm{Au}_{8} \mathrm{~L}_{7}{ }^{2+}: \mathrm{K}(\mathrm{n})=$ 22(8), $S=4 n-12, K p=C^{7} C[M 1] ; A u_{9} L_{8}^{3+}: K(n)=\mathbf{2 5}(9), S=4 n-14, K p=C^{8} C[M 1] ; A u_{10} L_{5} R_{4}: K(n)=28(10), S=4 n-16$, $\mathrm{Kp}=\mathrm{C}^{9} \mathrm{C}[\mathrm{M} 1] ; \mathrm{Au}_{10} \mathrm{Cl}_{3} \mathrm{~L}_{6}^{+1}: \mathrm{K}(\mathrm{n})=\mathbf{2 8}(\mathbf{1 0}), \mathrm{S}=4 \mathrm{n}-16, \mathrm{Kp}=\mathrm{C}^{9} \mathrm{C}[\mathrm{M} 1] ; \mathrm{Au}_{11} \mathrm{~L}_{10}{ }^{5+}: \mathrm{K}(\mathrm{n})=\mathbf{3 1}(\mathbf{1 1}), \mathrm{S}=4 \mathrm{n}-18$, $\mathrm{Kp}=\mathrm{C}^{10} \mathrm{C}[\mathrm{M} 1]$. All these clusters belong to the [M1] SERIES, that is, they belong to GROUP [M1] CLUSTERS. As mentioned earlier, these clusters are referred to as torroidal clusters (Mingos, 1984).

According to Table 2, the genuine un-capping series commences from [M2] and increases in the sequence [M3] $\rightarrow$ [M4] $\rightarrow[\mathrm{M} 5] \rightarrow[\mathrm{M} 6] \rightarrow[\mathrm{M} 7] \rightarrow[\mathrm{M} 8] \rightarrow[\mathrm{M} 9] \rightarrow[\mathrm{M} 10] \rightarrow[\mathrm{M} 11] \rightarrow[\mathrm{M} 12]$. If we use [M6] to illustrate capping, there will be un-capping series below it as can be seen from Table 2C. The clusters below [M6] can be regarded as 'build-up' clusters before reaching [M6] closo base-line. When we reach [M6], then we reach a zero capping base line, $\mathrm{Kp}=\mathrm{C}^{0} \mathrm{C}[\mathrm{M} 6]$. Moving vertically along [M6], then we get capped clusters of an octahedral nucleus. This idea of capping based on an octahedral nucleus can be illustrated in Schemes SC-5 and SC-6 and the Grid-line SC-7(BLUE LINE). The scheme SC-7 also indicates the capping series of [M2] (GREEN LINE) and [M1] (ORANGE LINE) series. 

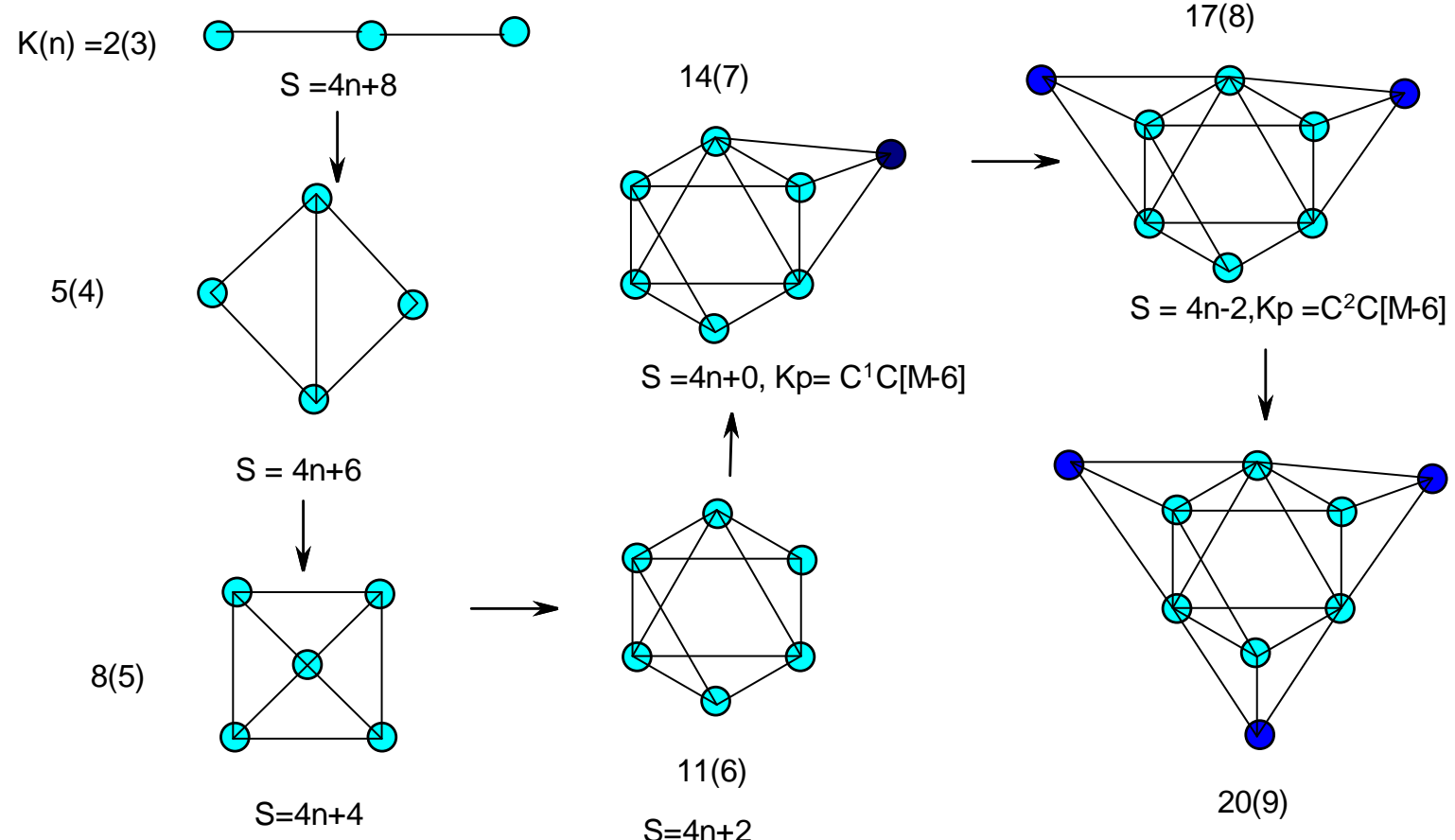

$$
\begin{array}{r}
11(6) \\
S=4 n+2
\end{array}
$$

20(9)

$$
S=4 n-4, K p=C^{3} C[M-6]
$$

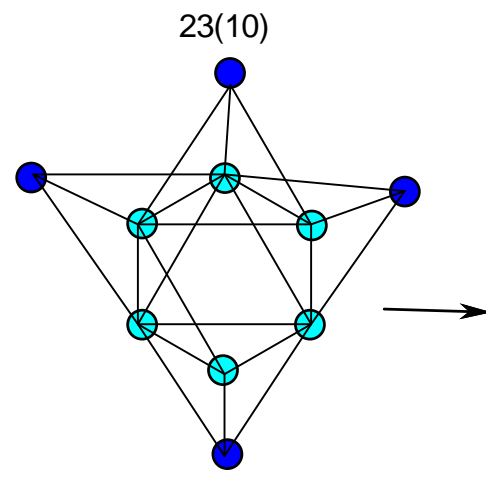

$S=4 n-6, K p=C^{4} C[M-6]$

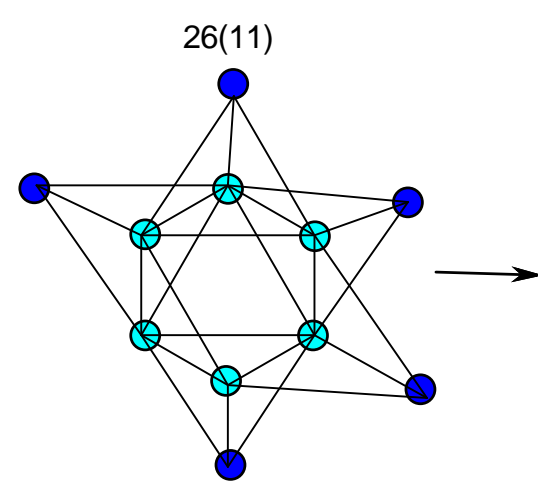

$S=4 n-8, K p=C^{5} C[M-6]$

SC-5

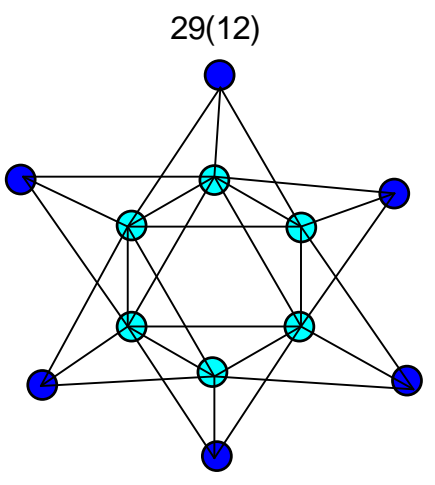

$S=4 n-10, K p=C^{6} C[M-6]$ 


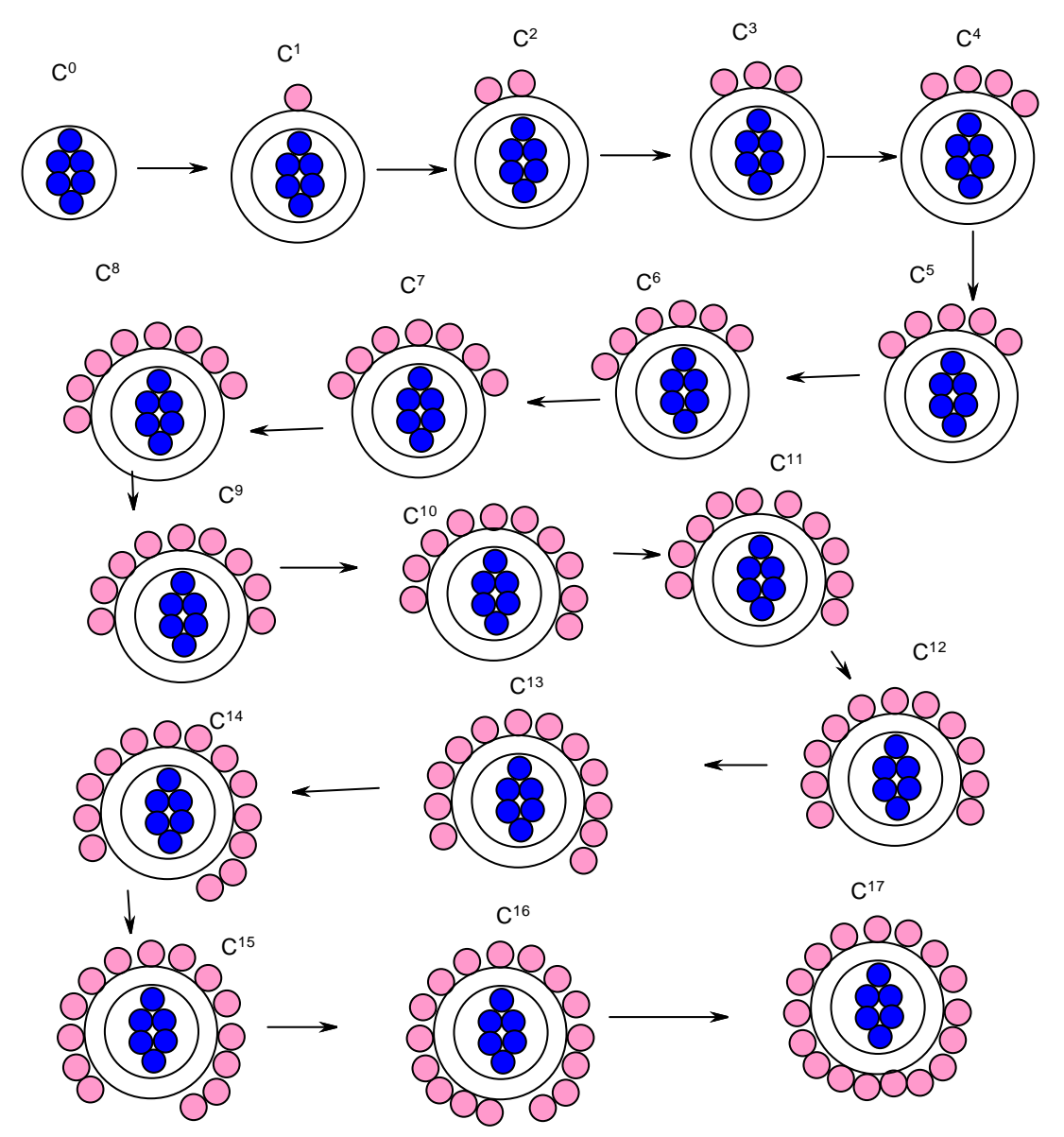

SC-6

\section{- CATEGORIZATION OF CLUSTERS BASED ON CLOSO GRID-LINES}

Let us illustrate this by monitoring some of the K(n) values based on the CLOSO VERTICAL LINE [M6], K(n) = 11(6), $\mathrm{S}=4 \mathrm{n}+2$. We can simply refer to this as [M6] gridline. This is indicated in BLUE in the scheme SC-5. The vertical numerical sequence starting with [M6], will be $K(n)=\left\{11(6), 4 n+2, K p=C^{0} C[M 6]\right\} ;\left\{14(7), 4 n+0, K p=C^{1} C[M 6]\right.$; $\left\{17(8) ; 4 \mathrm{n}-2, \mathrm{C}^{2} \mathrm{C}[\mathrm{M} 6]\right\},\left\{20(9), 4 \mathrm{n}-4, \mathrm{C}^{3} \mathrm{C}[\mathrm{M} 6]\right\}$, and so on. We may call all these clusters which line up on [M6] grid-line as CLUSTER GROUP 6. If we include clusters below [M6], $S=4 n+2$ base-line, then we will create Rudolph type of correlation. The cluster series below [M6] will include, $\left\{8(5), 4 n+4, C^{-1} C[M 6]\right.$, nido clusters $\},\{5(4), 4 n+6$, $\mathrm{C}^{-2} \mathrm{C}[\mathrm{M} 6]$, arachno clusters $\},\left\{2(3), 4 \mathrm{n}+8, \mathrm{C}^{-3} \mathrm{C}[\mathrm{M} 6]\right.$, hypho clusters $\}$ and so on. The horizontal movement below [M6], we get [M5], this corresponds to $S=4 n+2$ and $K(n)=9(5)$. The borane closo cluster that corresponds to this point is $\mathrm{B}_{5} \mathrm{H}_{5}{ }^{2-}$. The numerical movement upwards from 9(5), we get 12(6), 15(7), 18(8), 21(9), and so on. We can refer to these clusters as GROUP 5 clusters, [M5]. Continuing the horizontal movement left-wise, we get [M4], 7(4), $S=4 n+2$; then [M3], 5(3), 4n+2; [M2], 3(2), 4n+2. It has been found that a good range of golden clusters belong to GROUP 2, [M2]. Accordingly, their vertical [M2] numerical series will be; 3(2), 6(3), 9(4), 12(5), and so on. The group 2 clusters lie along the grid-line shown in GREEN in SC-7. These golden clusters which are [M2]-based have been referred to as SPHERICAL while those which are [M1]-based with a single element in the nucleus were referred to as TORROIDAL (Mingos, 1984). A good example of spherical golden cluster is $\mathrm{Au}_{9} \mathrm{~L}_{8}{ }^{+}: \mathrm{K}=9[3.5]-8+0.5=24, \mathrm{~K}(\mathrm{n})=24(9), \mathrm{S}=4 \mathrm{n}-12, \mathrm{Kp}$ $=C^{7} C[M 2]$. On the other hand the cluster of the same nuclearity index, $A_{1} L_{8}{ }^{3+}$ : has a $K$ value $25, K(n)=25(9), S=$ $4 n-14, K p=C^{8} C[M 1]$ is described as torroidal. The transformation from $\mathrm{Au}_{9} \mathrm{~L}_{8}{ }^{+}$to $\mathrm{Au}_{9} \mathrm{~L}_{8}{ }^{3+}$ results in the increase in $\mathrm{K}$ value by 1 . The increase in $\mathrm{K}$ value of a capping cluster by 1 results in the increase of the corresponding skeletal elements by 1 . That additional capping element is extracted from the nucleus. Hence, the [M2] (two skeletal elements in the nucleus) now becomes [M1] (one skeletal element in the nucleus). The group 2 clusters lie along the [M1] orange grid-line in SC-7.

\subsection{Categorization of Un-Capping Series}

This is simply the categorization of clusters below the closo [M6] grid-line (SC-7). The closo cluster [M6], $S=4 n+2, n$ 
$=6, K=2 n-1=2(6)-1=11, K(n)=11(6), K p=C^{0} C[M 6]$. If we use the grid-line $S C-7$ as a reference, upward movement by one step gives $K(n)=14(7), S=4 n+0, K p=C^{1} C[M 6]$. This will be a mono-capped octahedron. The next movement upwards by another one step will give us $K(n)=17(8), S=4 n-2, K p=C^{2} C[M 6]$. This is a bi-capped octahedron. Let us consider the movement downwards (opposite direction) on [M6] grid-line. This is numerically expressed as $\mathrm{K}(\mathrm{n})=$ 11(6) $\left\{\mathrm{S}=4 \mathrm{n}+2, \mathrm{Kp}=\mathrm{C}^{0} \mathrm{C}[\mathrm{M} 6]\right\} \rightarrow 8(5)\left\{\mathrm{S}=4 \mathrm{n}+4, \mathrm{Kp}=\mathrm{C}^{-1} \mathrm{C}[\mathrm{M} 6]\right.$, nido series $\}$; the next movement from nido series by one step will give us $\mathrm{K}(\mathrm{n})=5(4), \mathrm{S}=4 \mathrm{n}+6, \mathrm{Kp}=\mathrm{C}^{-2} \mathrm{C}[\mathrm{M} 6]$, arachno series $\}$. Since the movement is downwards from the closo base-line, the use of the negative capping index, $\mathrm{C}^{-1}$ and $\mathrm{C}^{-2}$ makes sense. Thus, we can categorize both the capping and de-capping clusters using the capping symbol $\mathrm{Kp}=\mathrm{C}^{\mathrm{y}} \mathrm{C}[\mathrm{Mx}]$, where $\mathrm{y}$ can have positive or negative values. A selected sample of clusters categorized like this is shown in Table 3.

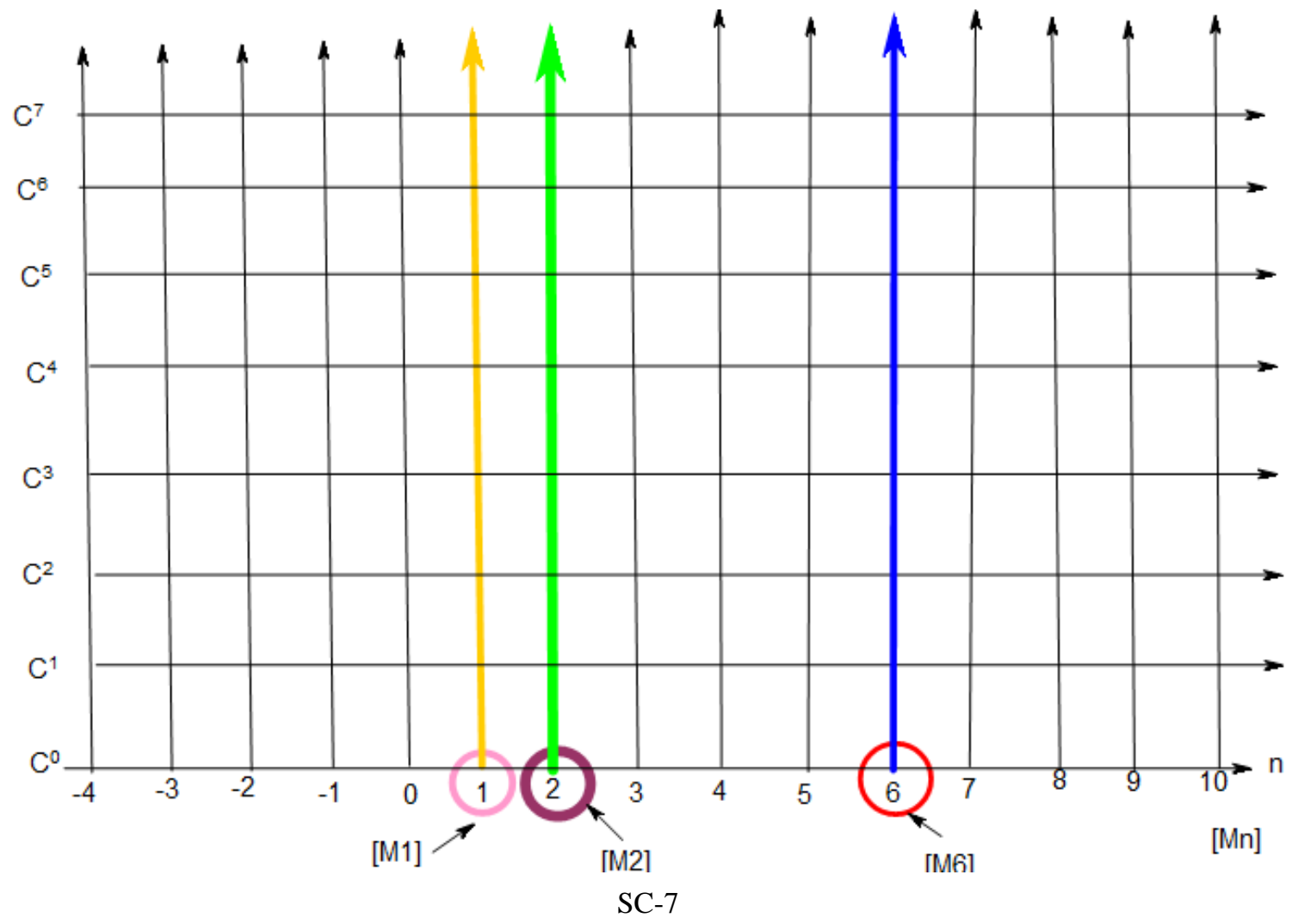

Table 3. Selected Examples Illustrating the Concept of Categorizing Clusters into their Closo Nuclearity Index

\begin{tabular}{|l|l|l|l|l|}
\hline \multicolumn{1}{|c|}{ CLUSTER } & $\mathrm{K}(\mathrm{n})$ & SERIES & NAME, $\mathrm{Kp}=\mathrm{C}^{\mathrm{y}} \mathrm{C}[\mathrm{Mx}]$ & {$[\mathrm{Mx}]$} \\
\hline $\mathrm{Pd}_{59}(\mathrm{CO})_{32} \mathrm{~L}_{21}$ & $183(59)$ & $4 \mathrm{n}-130$ & $\mathrm{C}^{66} \mathrm{C}[\mathrm{M}-7]$ & {$[\mathrm{M}-7]$} \\
\hline $\left.\mathrm{Pd}_{66} \mathrm{CO}\right)_{45} \mathrm{~L}_{16}$ & $203(66)$ & $4 \mathrm{n}-142$ & $\mathrm{C}^{72} \mathrm{C}[\mathrm{M}-6]$ & {$[\mathrm{M}-6]$} \\
\hline $\mathrm{Pd}_{52}(\mathrm{CO})_{36} \mathrm{~L}_{14}$ & $158(52)$ & $4 \mathrm{n}-108$ & $\mathrm{C}^{55} \mathrm{C}[\mathrm{M}-3]$ & {$[\mathrm{M}-3]$} \\
\hline $\mathrm{Pd}_{54}(\mathrm{CO})_{40} \mathrm{~L}_{14}$ & $162(54)$ & $4 \mathrm{n}-108$ & $\mathrm{C}^{55} \mathrm{C}[\mathrm{M}-1]$ & {$[\mathrm{M}-1]$} \\
\hline $\mathrm{Pd}_{39}(\mathrm{CO})_{23} \mathrm{~L}_{16}$ & $117(39)$ & $4 \mathrm{n}-78$ & $\mathrm{C}^{40} \mathrm{C}[\mathrm{M}-1]$ & {$[\mathrm{M}-1]$} \\
\hline $\mathrm{Pd}_{3}(\mathrm{CO})_{3} \mathrm{~L}_{4}$ & $5(3)$ & $4 \mathrm{n}+2$ & $\mathrm{C}^{0} \mathrm{C}[\mathrm{M} 3](\mathrm{closo})$ & {$[\mathrm{M} 3]$} \\
\hline $\mathrm{Pd}_{4}(\mathrm{CO})_{5} \mathrm{~L}_{4}$ & $7(4)$ & $4 \mathrm{n}+2$ & $\mathrm{C}^{0} \mathrm{C}[\mathrm{M} 3](\mathrm{closo})$ & {$[\mathrm{M} 3]$} \\
\hline $\mathrm{Au}_{4} \mathrm{~L}_{4}$ & $10(4)$ & $4 \mathrm{n}-4$ & $\mathrm{C}^{3} \mathrm{C}[\mathrm{M} 1]$ & {$[\mathrm{M} 1]$} \\
\hline $\mathrm{Au}_{6} \mathrm{~L}_{6}{ }^{2+}$ & $16(6)$ & $4 \mathrm{n}-8$ & $\mathrm{C}^{5} \mathrm{C}[\mathrm{M} 1]$ & {$[\mathrm{M} 1]$} \\
\hline $\mathrm{Au}_{6} \mathrm{~L}_{4} \mathrm{Cl}_{2}$ & $16(6)$ & $4 \mathrm{n}-8$ & $\mathrm{C}^{5} \mathrm{C}[\mathrm{M} 1]$ & {$[\mathrm{M} 1]$} \\
\hline $\mathrm{Au}_{8} \mathrm{~L}_{7}{ }^{2+}$ & $22(8)$ & $4 \mathrm{n}-12$ & $\mathrm{C}^{7} \mathrm{C}[\mathrm{M} 1]$ & {$[\mathrm{M} 1]$} \\
\hline $\mathrm{Au}_{9} \mathrm{~L}_{8}{ }^{3+}$ & $25(9)$ & $4 \mathrm{n}-14$ & $\mathrm{C}^{8} \mathrm{C}[\mathrm{M} 1]$ & {$[\mathrm{M} 1]$} \\
\hline $\mathrm{Au}_{11} \mathrm{~L}_{10}{ }^{5+}$ & $31(11)$ & $4 \mathrm{n}-18$ & $\mathrm{C}^{10} \mathrm{C}[\mathrm{M} 1]$ & {$[\mathrm{M} 1]$} \\
\hline $\mathrm{Pd}_{34}(\mathrm{CO})_{24} \mathrm{~L}_{12}$ & $100(34)$ & $4 \mathrm{n}-64$ & $\mathrm{C}^{33} \mathrm{C}[\mathrm{M} 1]$ & {$[\mathrm{M} 1]$} \\
\hline $\mathrm{Re}_{5}(\mathrm{C})(\mathrm{H})(\mathrm{CO})_{12}{ }^{2-}$ & $12(5)$ & $4 \mathrm{n}-4$ & $\mathrm{C}^{3} \mathrm{C}[\mathrm{M} 2]$ & {$[\mathrm{M} 2]$} \\
\hline $\mathrm{Au}_{9} \mathrm{~L}_{8}{ }^{+}$ & $24(9)$ & $4 \mathrm{n}-12$ & $\mathrm{C}^{7} \mathrm{C}[\mathrm{M} 2]$ & {$[\mathrm{M} 2]$} \\
\hline $\mathrm{Os}_{17}(\mathrm{CO})_{36}{ }^{2-}$ & $48(17)$ & $4 \mathrm{n}-28$ & $\mathrm{C}^{15} \mathrm{C}[\mathrm{M} 2]$ & {$[\mathrm{M} 2]$} \\
\hline $\mathrm{Pd}_{35}(\mathrm{CO})_{23} \mathrm{~L}_{15}$ & $102(35)$ & $4 \mathrm{n}-64$ & $\mathrm{C}^{33} \mathrm{C}[\mathrm{M} 2]$ & {$[\mathrm{M} 2]$} \\
\hline $\mathrm{Pd}_{37}(\mathrm{CO})_{28} \mathrm{~L}_{12}$ & $108(37)$ & $4 \mathrm{n}-68$ & $\mathrm{C}^{35} \mathrm{C}[\mathrm{M} 2]$ & {$[\mathrm{M} 2]$} \\
\hline $\mathrm{B}_{2} \mathrm{H}_{6}$ & $2(2)$ & $4 \mathrm{n}+4$ & $\mathrm{C}^{-1} \mathrm{C}[\mathrm{M} 3]$ & {$[\mathrm{M} 3]$} \\
\hline $\mathrm{Re}_{2} \mathrm{H}_{2}(\mathrm{CO})_{8}$ & $2(2)$ & $4 \mathrm{n}+4$ & $\mathrm{C}^{-1} \mathrm{C}[\mathrm{M} 3]$ & {$[\mathrm{M} 3]$} \\
\hline
\end{tabular}




\begin{tabular}{|c|c|c|c|c|}
\hline $\mathrm{Re}_{4} \mathrm{H}_{4}(\mathrm{CO})_{12}$ & $8(4)$ & $4 n+0$ & $\mathrm{C}^{1} \mathrm{C}[\mathrm{M} 3]$ & [M3] \\
\hline $\mathrm{Os}_{2}(\mathrm{CO})_{9}$ & $1(2)$ & $4 n+6$ & $\mathrm{C}^{-2} \mathrm{C}[\mathrm{M} 4]$ & [M4] \\
\hline $\mathrm{Re}_{3} \mathrm{H}_{3}(\mathrm{CO})_{10}{ }^{2-}$ & $4(3)$ & $4 n+4$ & $\mathrm{C}^{-1} \mathrm{C}[\mathrm{M} 4]$ & [M4] \\
\hline $\mathrm{B}_{4} \mathrm{H}_{4}^{2-}$ & $7(4)$ & $4 n+2$ & $\mathrm{C}^{0} \mathrm{C}[\mathrm{M} 4]$ & [M4] \\
\hline $\mathrm{Pd}_{6}(\mathrm{CO})_{4} \mathrm{~L}_{7}$ & $13(6)$ & $4 n-2$ & $\mathrm{C}^{2} \mathrm{C}[\mathrm{M} 4]$ & [M4] \\
\hline $\mathrm{Pt}_{19}(\mathrm{CO})_{22}{ }^{4-}$ & $52(19)$ & $4 n-28$ & $\mathrm{C}^{15} \mathrm{C}[\mathrm{M} 4]$ & [M4] \\
\hline $\mathrm{Pd}_{16} \mathrm{Ni}_{4}(\mathrm{CO})_{22} \mathrm{~L}_{2}^{2-}$ & $55(20)$ & $4 n-30$ & $\mathrm{C}^{16} \mathrm{C}[\mathrm{M} 4]$ & [M4] \\
\hline$(\mathrm{Au}) \mathrm{Pd}_{22}(\mathrm{CO})_{20} \mathrm{~L}_{8}{ }^{2+}$ & $64(23)$ & $4 n-36$ & $\mathrm{C}^{19} \mathrm{C}[\mathrm{M} 4]$ & [M4] \\
\hline $\mathrm{Pd}_{23}(\mathrm{CO})_{20} \mathrm{~L}_{8}$ & $64(23)$ & $4 n-36$ & $\mathrm{C}^{19} \mathrm{C}[\mathrm{M} 4]$ & [M4] \\
\hline $\mathrm{Pd}_{28} \mathrm{Pt}_{13} \mathrm{~L}_{13}$ & $118(41)$ & $4 n-72$ & $\mathrm{C}^{37} \mathrm{C}[\mathrm{M} 4]$ & [M4] \\
\hline $\mathrm{Au}_{39} \mathrm{~L}_{14} \mathrm{Cl}_{6}^{+}$ & $120(39)$ & $4 n-84$ & $\mathrm{C}^{43} \mathrm{C}[\mathrm{M} 4]$ & [M4] \\
\hline $\mathrm{Os}_{3}(\mathrm{CO})_{12}$ & $3(3)$ & $4 n+6$ & $\mathrm{C}^{-2} \mathrm{C}[\mathrm{M} 5]$ & [M5] \\
\hline $\mathrm{B}_{3} \mathrm{H}_{9}$ & $3(3)$ & $4 n+6$ & $\mathrm{C}^{-2} \mathrm{C}[\mathrm{M} 5]$ & [M5] \\
\hline $\mathrm{Os}_{4}(\mathrm{CO})_{14}$ & $6(4)$ & $4 n+4$ & $\mathrm{C}^{-1} \mathrm{C}[\mathrm{M} 5]$ & [M5] \\
\hline $\mathrm{Os}_{4} \mathrm{H}_{2}(\mathrm{CO})_{12}{ }^{2-}$ & $6(4)$ & $4 n+4$ & $\mathrm{C}^{-1} \mathrm{C}[\mathrm{M} 5]$ & [M5] \\
\hline $\mathrm{Rh}_{4}(\mathrm{CO})_{12}$ & $6(4)$ & $4 n+4$ & $\mathrm{C}^{-1} \mathrm{C}[\mathrm{M} 5]$ & [M5] \\
\hline $\mathrm{Re}_{4} \mathrm{H}_{4}(\mathrm{CO})_{13}{ }^{2-}$ & $6(4)$ & $4 n+4$ & $\mathrm{C}^{-1} \mathrm{C}[\mathrm{M} 5]$ & [M5] \\
\hline $\mathrm{B}_{4} \mathrm{H}_{8}$ & $6(4)$ & $4 n+4$ & $\mathrm{C}^{-1} \mathrm{C}[\mathrm{M} 5]$ & [M5] \\
\hline $\mathrm{CB}_{4} \mathrm{H}_{10}$ & $9(5)$ & $4 n+2$ & $\mathrm{C}^{0} \mathrm{C}[\mathrm{M} 5]$ & [M5] \\
\hline $\mathrm{B}_{3} \mathrm{C}_{2} \mathrm{H}_{5}$ & $9(5)$ & $4 n+2$ & $\mathrm{C}^{0} \mathrm{C}[\mathrm{M} 5]$ & [M5] \\
\hline $\mathrm{Os}_{5} \mathrm{H}(\mathrm{CO})_{15}$ & $9(5)$ & $4 n+2$ & $\mathrm{C}^{0} \mathrm{C}[\mathrm{M} 5]$ & [M5] \\
\hline $\mathrm{Os}_{6}(\mathrm{CO})_{18}$ & $12(6)$ & $4 n+0$ & $\mathrm{C}^{1} \mathrm{C}[\mathrm{M} 5]$ & [M5] \\
\hline $\mathrm{Os}_{10}(\mathrm{C})(\mathrm{CO})_{24}$ & $24(10)$ & $4 n-8$ & $\mathrm{C}^{5} \mathrm{C}[\mathrm{M} 5]$ & [M5] \\
\hline $\mathrm{Rh}_{14}(\mathrm{CO})_{25}{ }^{4-}$ & $36(14)$ & $4 n-16$ & $\mathrm{C}^{9} \mathrm{C}[\mathrm{M} 5]$ & [M5] \\
\hline $\mathrm{Rh}_{15}(\mathrm{CO})_{27^{3-}}$ & $39(15)$ & $4 n-18$ & $\mathrm{C}^{10} \mathrm{C}[\mathrm{M} 5]$ & [M5] \\
\hline $\mathrm{Pd}_{16}(\mathrm{CO})_{13} \mathrm{~L}_{9}$ & $42(16)$ & $4 n-20$ & $\mathrm{C}^{11} \mathrm{C}[\mathrm{M} 5]$ & [M5] \\
\hline $\mathrm{Rh}_{17}(\mathrm{CO})_{30}{ }^{3-}$ & $45(17)$ & $4 n-22$ & $\mathrm{C}^{12} \mathrm{C}[\mathrm{M} 5]$ & [M5] \\
\hline $\mathrm{Rh}_{22}(\mathrm{CO})_{37^{4-}}$ & $60(22)$ & $4 n-32$ & $\mathrm{C}^{17} \mathrm{C}[\mathrm{M} 5]$ & [M5] \\
\hline $\mathrm{Os}_{4}(\mathrm{CO})_{15}$ & $5(4)$ & $4 n+6$ & $\mathrm{C}^{-2} \mathrm{C}[\mathrm{M} 6]$ & [M6] \\
\hline $\mathrm{B}_{4} \mathrm{H}_{10}$ & $5(4)$ & $4 n+6$ & $\mathrm{C}^{-2} \mathrm{C}[\mathrm{M} 6]$ & [M6] \\
\hline $\mathrm{Os}_{5} \mathrm{H}_{2}(\mathrm{CO})_{18}$ & $8(5)$ & $4 n+4$ & $\mathrm{C}^{-1} \mathrm{C}[\mathrm{M} 6]$ & [M6] \\
\hline $\mathrm{B}_{4} \mathrm{H}_{8}(\mathrm{CoCp})$ & $8(5)$ & $4 n+4$ & $\mathrm{C}^{-1} \mathrm{C}[\mathrm{M} 6]$ & [M6] \\
\hline $\mathrm{B}_{5} \mathrm{H}_{9}$ & $8(5)$ & $4 n+4$ & $\mathrm{C}^{-1} \mathrm{C}[\mathrm{M} 6]$ & [M6] \\
\hline $\mathrm{B}_{4} \mathrm{H}_{8} \mathrm{Fe}(\mathrm{CO})_{3}$ & $8(5)$ & $4 n+4$ & $\mathrm{C}^{-1} \mathrm{C}[\mathrm{M} 6]$ & [M6] \\
\hline $\mathrm{Os}_{6}(\mathrm{CO})_{18}{ }^{2-}$ & $11(6)$ & $4 n+2$ & $\mathrm{C}^{0} \mathrm{C}[\mathrm{M} 6]$ & [M6] \\
\hline $\mathrm{Rh}_{5} \mathrm{Pt}(\mathrm{CO})_{15}$ & $11(6)$ & $4 n+2$ & $\mathrm{C}^{0} \mathrm{C}[\mathrm{M} 6]$ & [M6] \\
\hline $\operatorname{Re}_{6} \mathrm{C}(\mathrm{CO})_{19^{2-}}$ & $11(6)$ & $4 n+2$ & $\mathrm{C}^{0} \mathrm{C}[\mathrm{M} 6]$ & [M6] \\
\hline $\mathrm{B}_{4} \mathrm{C}_{2} \mathrm{H}_{6}$ & $11(6)$ & $4 n+2$ & $\mathrm{C}^{0} \mathrm{C}[\mathrm{M} 6]$ & [M6] \\
\hline $\mathrm{Pd}_{7}(\mathrm{CO})_{7} \mathrm{~L}_{7}$ & $14(7)$ & $4 n+0$ & $\mathrm{C}^{1} \mathrm{C}[\mathrm{M} 6]$ & [M6] \\
\hline $\mathrm{Os}_{7}(\mathrm{CO})_{21}$ & $14(7)$ & $4 n+0$ & $\mathrm{C}^{1} \mathrm{C}[\mathrm{M} 6]$ & [M6] \\
\hline $\mathrm{Rh}_{7}(\mathrm{CO})_{16^{3-}}$ & $14(7)$ & $4 n+0$ & $\mathrm{C}^{1} \mathrm{C}[\mathrm{M} 6]$ & [M6] \\
\hline $\mathrm{Re}_{7} \mathrm{C}(\mathrm{CO})_{21^{3-}}$ & $14(7)$ & $4 n+0$ & $\mathrm{C}^{1} \mathrm{C}[\mathrm{M} 6]$ & [M6] \\
\hline $\mathrm{Pd}_{8}(\mathrm{CO})_{8} \mathrm{~L}_{7}$ & $17(8)$ & $4 n-2$ & $\mathrm{C}^{2} \mathrm{C}[\mathrm{M} 6]$ & [M6] \\
\hline $\mathrm{Re}_{8} \mathrm{C}(\mathrm{CO})_{24}{ }^{2-}$ & $17(8)$ & $4 n-2$ & $\mathrm{C}^{2} \mathrm{C}[\mathrm{M} 6]$ & [M6] \\
\hline $\mathrm{Os}_{8}(\mathrm{CO})_{22}{ }^{2-}$ & $17(8)$ & $4 n-2$ & $\mathrm{C}^{2} \mathrm{C}[\mathrm{M} 6]$ & [M6] \\
\hline $\mathrm{Os}_{9} \mathrm{H}(\mathrm{CO})_{24}{ }^{-}$ & $20(9)$ & $4 n-4$ & $\mathrm{C}^{3} \mathrm{C}[\mathrm{M} 6]$ & [M6] \\
\hline $\mathrm{Rh}_{9}(\mathrm{CO})_{19}{ }^{3-}$ & $20(9)$ & $4 n-4$ & $\mathrm{C}^{3} \mathrm{C}[\mathrm{M} 6]$ & [M6] \\
\hline $\mathrm{Os}_{10}(\mathrm{CO})_{26}{ }^{2-}$ & $23(10)$ & $4 n-6$ & $\mathrm{C}^{4} \mathrm{C}[\mathrm{M} 6]$ & [M6] \\
\hline $\mathrm{Rh}_{10}(\mathrm{CO})_{21}{ }^{2-}$ & $23(10)$ & $4 n-6$ & $\mathrm{C}^{4} \mathrm{C}[\mathrm{M} 6]$ & [M6] \\
\hline $\mathrm{Os}_{10} \mathrm{H}_{2}(\mathrm{C})(\mathrm{CO})_{24}$ & $23(10)$ & $4 n-6$ & $\mathrm{C}^{4} \mathrm{C}[\mathrm{M} 6]$ & [M6] \\
\hline $\mathrm{Rh}_{13}(\mathrm{CO})_{24} \mathrm{H}_{2}^{3-}$ & $32(13)$ & $4 n-12$ & $\mathrm{C}^{7} \mathrm{C}[\mathrm{M} 6]$ & [M6] \\
\hline $\mathrm{Pd}_{16} \mathrm{Ni}_{4}(\mathrm{CO})_{22} \mathrm{~L}_{4}^{2-}$ & $53(20)$ & $4 n-26$ & $\mathrm{C}^{14} \mathrm{C}[\mathrm{M} 6]$ & [M6] \\
\hline $\mathrm{Pd}_{23}(\mathrm{CO})_{20} \mathrm{~L}_{10}$ & $62(23)$ & $4 n-32$ & $\mathrm{C}^{17} \mathrm{C}[\mathrm{M} 6]$ & [M6] \\
\hline $\mathrm{Pt}_{24}(\mathrm{CO})_{30}{ }^{2-}$ & $65(24)$ & $4 n-34$ & $\mathrm{C}^{18} \mathrm{C}[\mathrm{M} 6]$ & [M6] \\
\hline $\mathrm{Pd}_{29}(\mathrm{CO})_{28} \mathrm{~L}_{7}^{2-}$ & $80(29)$ & $4 n-44$ & $\mathrm{C}^{23} \mathrm{C}[\mathrm{M} 6]$ & [M6] \\
\hline $\mathrm{HPd}_{30}(\mathrm{CO})_{26} \mathrm{~L}_{10}$ & $83(30)$ & $4 n-46$ & $\mathrm{C}^{24} \mathrm{C}[\mathrm{M} 6]$ & [M6] \\
\hline $\mathrm{Au}_{2} \mathrm{Pd}_{28}(\mathrm{CO})_{26} \mathrm{~L}_{10}$ & $83(30)$ & $4 n-46$ & $\mathrm{C}^{24} \mathrm{C}[\mathrm{M} 6]$ & [M6] \\
\hline $\mathrm{Pt}_{38}(\mathrm{CO})_{44}^{2-}$ & $107(38)$ & $4 n-62$ & $\mathrm{C}^{32} \mathrm{C}[\mathrm{M} 6]$ & [M6] \\
\hline $\mathrm{Pd}_{33} \mathrm{Ni}_{9}(\mathrm{CO})_{41} \mathrm{~L}_{6}{ }^{4-}$ & $119(42)$ & $4 n-70$ & $\mathrm{C}^{36} \mathrm{C}[\mathrm{M} 6]$ & [M6] \\
\hline $\mathrm{Pd}_{8} \mathrm{Ni}_{36}(\mathrm{CO})_{48}{ }^{6-}$ & $125(44)$ & $4 n-74$ & $\mathrm{C}^{38} \mathrm{C}[\mathrm{M} 6]$ & [M6] \\
\hline $\mathrm{Ni}_{35} \mathrm{Pt}_{9}(\mathrm{CO})_{48}{ }^{6-}$ & $125(44)$ & $4 n-74$ & $\mathrm{C}^{38} \mathrm{C}[\mathrm{M} 6]$ & [M6] \\
\hline $\mathrm{Ni}_{38} \mathrm{Pt}_{6}(\mathrm{CO})_{48} \mathrm{H}^{5-}$ & $125(44)$ & $4 n-74$ & $\mathrm{C}^{38} \mathrm{C}[\mathrm{M} 6]$ & [M6] \\
\hline $\mathrm{Os}_{4}(\mathrm{CO})_{16}$ & $4(4)$ & $4 n+8$ & $\mathrm{C}^{-3} \mathrm{C}[\mathrm{M} 7]$ & [M7] \\
\hline $\mathrm{Os}_{5}(\mathrm{CO})_{18}$ & $7(5)$ & $4 n+6$ & $\mathrm{C}^{-2} \mathrm{C}[\mathrm{M} 7]$ & [M7] \\
\hline
\end{tabular}




\begin{tabular}{|c|c|c|c|c|}
\hline $\mathrm{Rh}_{5}(\mathrm{CO})_{15}$ & $7(5)$ & $4 n+6$ & $\mathrm{C}^{-2} \mathrm{C}[\mathrm{M} 7]$ & [M7] \\
\hline $\mathrm{B}_{5} \mathrm{H}_{11}$ & $7(5)$ & $4 n+6$ & $\mathrm{C}^{-2} \mathrm{C}[\mathrm{M} 7]$ & [M7] \\
\hline $\mathrm{B}_{6} \mathrm{H}_{10}$ & $10(6)$ & $4 n+4$ & $\mathrm{C}^{-1} \mathrm{C}[\mathrm{M} 7]$ & [M7] \\
\hline $\mathrm{Os}_{7} \mathrm{H}_{2}(\mathrm{CO})_{19}$ & $13(7)$ & $4 n+2$ & $\mathrm{C}^{0} \mathrm{C}[\mathrm{M} 7]$ & [M7] \\
\hline $\mathrm{Os}_{10}(\mathrm{C})(\mathrm{CO})_{24}{ }^{4-}$ & $22(10)$ & $4 n-4$ & $\mathrm{C}^{3} \mathrm{C}[\mathrm{M} 7]$ & [M7] \\
\hline $\mathrm{Pd}_{10}(\mathrm{CO})_{12} \mathrm{~L}_{6}$ & $22(10)$ & $4 n-4$ & $\mathrm{C}^{3} \mathrm{C}[\mathrm{M} 7]$ & [M7] \\
\hline $\mathrm{Rh}_{11}(\mathrm{CO})_{23^{3-}}$ & $25(11)$ & $4 n-6$ & $\mathrm{C}^{4} \mathrm{C}[\mathrm{M} 7]$ & [M7] \\
\hline $\mathrm{Pd}_{9} \mathrm{Ni}_{9}(\mathrm{CO})_{17} \mathrm{~L}_{9}$ & $46(18)$ & $4 n-20$ & $\mathrm{C}^{11} \mathrm{C}[\mathrm{M} 7]$ & [M7] \\
\hline $\mathrm{Ni}_{14} \mathrm{Pt}_{10}(\mathrm{CO})_{30}{ }^{4-}$ & $64(24)$ & $4 n-32$ & $\mathrm{C}^{17} \mathrm{C}[\mathrm{M} 7]$ & [M7] \\
\hline $\mathrm{Au}_{4} \mathrm{Pd}_{28}(\mathrm{CO})_{22} \mathrm{~L}_{16}$ & $88(32)$ & $4 n-48$ & $\mathrm{C}^{25} \mathrm{C}[\mathrm{M} 7]$ & [M7] \\
\hline $\mathrm{Au}_{4} \mathrm{Pd}_{32}(\mathrm{CO})_{28} \mathrm{~L}_{14}$ & $100(36)$ & $4 n-56$ & $\mathrm{C}^{29} \mathrm{C}[\mathrm{M} 7]$ & [M7] \\
\hline $\mathrm{Pd}_{36}(\mathrm{C})(\mathrm{CO})_{28} \mathrm{~L}_{14}$ & $100(36)$ & $4 n-56$ & $\mathrm{C}^{29} \mathrm{C}[\mathrm{M} 7]$ & [M7] \\
\hline $\mathrm{Ni}_{24} \mathrm{Pt}_{14}(\mathrm{CO})_{44}{ }^{4-}$ & $106(38)$ & $4 n-60$ & $\mathrm{C}^{31} \mathrm{C}[\mathrm{M} 7]$ & [M7] \\
\hline $\mathrm{Os}_{5}(\mathrm{CO})_{19}$ & $6(5)$ & $4 n+8$ & $\mathrm{C}^{-3} \mathrm{C}[\mathrm{M} 8]$ & [M8] \\
\hline $\mathrm{Os}_{6}(\mathrm{CO})_{21}$ & $9(6)$ & $4 n+6$ & $\mathrm{C}^{-2} \mathrm{C}[\mathrm{M} 8]$ & [M8] \\
\hline $\mathrm{CB}_{5} \mathrm{H}_{11}$ & $9(6)$ & $4 n+6$ & $\mathrm{C}^{-2} \mathrm{C}[\mathrm{M} 8]$ & [M8] \\
\hline $\mathrm{B}_{6} \mathrm{H}_{12}$ & $9(6)$ & $4 n+6$ & $\mathrm{C}^{-2} \mathrm{C}[\mathrm{M} 8]$ & [M8] \\
\hline $\mathrm{B}_{6} \mathrm{C}_{2} \mathrm{H}_{8}$ & $15(8)$ & $4 n+2$ & $\mathrm{C}^{0} \mathrm{C}[\mathrm{M} 8]$ & [M8] \\
\hline $\mathrm{Rh}_{8} \mathrm{C}(\mathrm{CO})_{19}$ & $15(8)$ & $4 n+2$ & $\mathrm{C}^{0} \mathrm{C}[\mathrm{M} 8]$ & [M8] \\
\hline $\mathrm{B}_{8} \mathrm{H}_{12}$ & $14(8)$ & $4 n+4$ & $\mathrm{C}^{-1} \mathrm{C}[\mathrm{M} 9]$ & [M9] \\
\hline $\mathrm{Rh}_{9} \mathrm{P}(\mathrm{CO})_{21}{ }^{2-}$ & $16(9)$ & $4 n+4$ & $\mathrm{C}^{-1} \mathrm{C}[\mathrm{M} 9]$ & [M10] \\
\hline $\mathrm{B}_{10} \mathrm{H}_{10}{ }^{2-}$ & $19(10)$ & $4 n+2$ & $\mathrm{C}^{0} \mathrm{C}[\mathrm{M} 10]$ & [M10] \\
\hline $\mathrm{B}_{10} \mathrm{H}_{14}$ & $18(10)$ & $4 n+4$ & $\mathrm{C}^{-1} \mathrm{C}[\mathrm{M} 11]$ & [M11] \\
\hline $\mathrm{SB}_{9} \mathrm{H}_{11}$ & $18(10)$ & $4 n+4$ & $\mathrm{C}^{-1} \mathrm{C}[\mathrm{M} 11]$ & [M11] \\
\hline $\mathrm{Au}_{6} \mathrm{Ni}_{32}(\mathrm{CO})_{44}{ }^{6-}$ & $102(38)$ & $4 n-52$ & $\mathrm{C}^{27} \mathrm{C}[\mathrm{M} 11]$ & [M11] \\
\hline $\mathrm{B}_{8} \mathrm{H}_{18}$ & $11(8)$ & $4 n+10$ & $\mathrm{C}^{-4} \mathrm{C}[\mathrm{M} 12]$ & [M12] \\
\hline $\mathrm{B}_{9} \mathrm{C}_{2} \mathrm{H}_{12}{ }^{-}$ & $20(11)$ & $4 n+4$ & $\mathrm{C}^{-2} \mathrm{C}[\mathrm{M} 12]$ & [M12] \\
\hline $\mathrm{B}_{12} \mathrm{H}_{12}{ }^{2-}$ & $23(12)$ & $4 n+2$ & $\mathrm{C}^{0} \mathrm{C}[\mathrm{M} 12]$ & [M12] \\
\hline $\mathrm{B}_{10} \mathrm{C}_{2} \mathrm{H}_{12}$ & $23(12)$ & $4 n+2$ & $\mathrm{C}^{0} \mathrm{C}[\mathrm{M} 12]$ & [M12] \\
\hline
\end{tabular}

- THE EXISTANCE OF THE NUCLEUS IN CAPPING CLUSTERS

All the capped clusters with a CLOSO nucleus are expressed as $\mathrm{Kp}=\mathrm{C}^{\mathrm{y}} \mathrm{C}[\mathrm{Mx}](\mathrm{x}=$ nuclear index, $\mathrm{y}=$ capping index $)$. Using the series method, a wide range of clusters have been found to possess CLOSO nuclei in capping clusters. For instance, the cluster $\mathrm{Ru}_{6} \mathrm{Pd}_{6}(\mathrm{CO})_{24}{ }^{2-} ; \mathrm{K}(\mathrm{n})=29(12), \mathrm{S}=4 \mathrm{n}-10, \mathrm{Kp}=\mathrm{C}^{6} \mathrm{C}[\mathrm{M} 6]$ was found to have a distorted octahedral nucleus of palladium skeletal elements capped by six ruthenium skeletal elements (Brivio, et al, 1994). Let us consider the giant cluster $\mathrm{Ni}_{38} \mathrm{Pt}_{6}(\mathrm{CO})_{48}(\mathrm{H})^{5-}: \mathrm{K}=125(44), \mathrm{S}=4 \mathrm{n}-74, \mathrm{Kp}=\mathrm{C}^{38} \mathrm{C}[\mathrm{M} 6]$. The series analysis tells us that this huge cluster has an octahedral nucleus surrounded by 38 capping elements. In actual fact, it was found that the octahedral nucleus comprised of platinum elements surrounded by 38 nickel skeletal elements by $\mathrm{x}$-ray analysis (Rossi, Zanello, 2011). The golden clusters, $\mathrm{Au}_{8} \mathrm{~L}_{7}{ }^{2+}: \mathrm{K}=8[3.5]-7+1=22, \mathrm{~K}(\mathrm{n})=22(8), \mathrm{S}=4 \mathrm{n}-12, \mathrm{Kp}=\mathrm{C}^{7} \mathrm{C}[\mathrm{M} 1], \mathrm{Au}_{9} \mathrm{~L}_{8}{ }^{3+}: \mathrm{K}$ $=9[3.5]-8+1.5=25, \mathrm{~K}(\mathrm{n})=25(9), \mathrm{S}=4 \mathrm{n}-14, \mathrm{Kp}=\mathrm{C}^{8} \mathrm{C}[\mathrm{M} 1]$, and $\mathrm{Au}_{10} \mathrm{Cl}_{3} \mathrm{~L}_{6}{ }^{+1}: \mathrm{K}=10[3.5]-1.5-6+0.5=28, \mathrm{~K}(\mathrm{n})=$ 28(10), $\mathrm{S}=4 \mathrm{n}-16, \mathrm{Kp}=\mathrm{C}^{9} \mathrm{C}[\mathrm{M} 1]$ were found to possess mono-skeletal nuclei as predicted by the series method(Mingos,1984).

\section{- A SET OF ALL CLUSTERS WHICH POSSESS K(n) VALUES}

Let us take $K(n)=11(6)$ as an illustration. With the help of skeletal numbers, the clusters with $K(n)=11(6)$ are readily identified. The Table 4 gives a sample of about 50 clusters identified in this way. Many more can be added to the table. The K(n) parameter acts as a 'car-park' in which clusters of $n$ skeletal elements and same $K$ values can be accommodated endlessly. This implies that each K(n) parameter in the CLUSTER TABLE represents a large number of clusters known and unknown. As for the ideal skeletal shapes and their isomers, in the case of $\mathrm{K}(\mathrm{n})=11(6) \rightarrow$ octahedral, $9(5) \rightarrow$ trigonal bipyramid, $8(5) \rightarrow$ square pyramid and $6(4) \rightarrow$ tetrahedral. 
Table 4. Selected sample of clusters with an ideal octahedral symmetry $\left(\mathrm{O}_{\mathrm{h}}\right)$

\begin{tabular}{|c|c|c|c|c|c|c|}
\hline & $K(n)=11(6)$ & & & & & \\
\hline & CLUSTER & $\mathrm{K}$ & $\mathrm{K}(\mathrm{n})$ & $\begin{array}{l}\text { SERIES, } \\
\mathrm{S}\end{array}$ & $\begin{array}{l}\text { VALENCE } \\
\text { ELECTRONS, Ve }\end{array}$ & CLASSIFICATION \\
\hline 1 & $\mathrm{Os}_{6}(\mathrm{CO})_{18}{ }^{2-}$ & $6[5]-18-1=11$ & $11(6)$ & $4 n+2$ & $14 n+2=14(6)+2=86$ & $\mathrm{CLOSO}, \mathrm{C}^{0} \mathrm{C}[\mathrm{M} 6]$ \\
\hline 2 & $\mathrm{Os}_{6}(\mathrm{H})(\mathrm{CO})_{18}{ }^{-}$ & 11 & $11(6)$ & $4 n+2$ & $14 n+2=14(6)+2=86$ & CLOSO, $\mathrm{C}^{0} \mathrm{C}[\mathrm{M} 6]$ \\
\hline 3 & $\mathrm{Rh}_{6}(\mathrm{CO})_{16}$ & $6[4.5]-16=11$ & $11(6)$ & $4 n+2$ & $14 n+2=14(6)+2=86$ & CLOSO, $\mathrm{C}^{0} \mathrm{C}[\mathrm{M} 6]$ \\
\hline 4 & $\mathrm{~B}_{6} \mathrm{H}_{6}^{2-}$ & $6[2.5]-3-1=11$ & $11(6)$ & $4 n+2$ & $4 n+2=4(6)+2=26$ & CLOSO, $\mathrm{C}^{0} \mathrm{C}[\mathrm{M} 6]$ \\
\hline 5 & $(\mathrm{CoCp})_{3} \mathrm{~B}_{3} \mathrm{H}_{5}$ & $3[4.5-2.5]+3[2.5]-2.5=11$ & $11(6)$ & $4 n+2$ & $26+3[10]=56$ & CLOSO, $\mathrm{C}^{0} \mathrm{C}[\mathrm{M} 6]$ \\
\hline 6 & $\mathrm{C}_{2} \mathrm{~B}_{4} \mathrm{H}_{6}$ & $2[2]+4[2.5]-3=11$ & $11(6)$ & $4 n+2$ & $4 n+2=4(6)+2=26$ & CLOSO, $\mathrm{C}^{0} \mathrm{C}[\mathrm{M} 6]$ \\
\hline 7 & $\mathrm{~B}_{4} \mathrm{H}_{6}(\mathrm{CoCp})_{2}$ & $4[2.5]+2[4.5-2.5]-3=11$ & 11(6) & $4 n+2$ & $26+2[10]=46$ & CLOSO, $\mathrm{C}^{0} \mathrm{C}[\mathrm{M} 6]$ \\
\hline 8 & $\mathrm{C}_{2} \mathrm{~B}_{3} \mathrm{H}_{5} \mathrm{Fe}(\mathrm{CO})_{3}$ & $2[2]+3[2.5]+1[5]-2.5-3=11$ & $11(6)$ & $4 n+2$ & $26+1[10]=36$ & CLOSO, $\mathrm{C}^{0} \mathrm{C}[\mathrm{M} 6]$ \\
\hline 9 & $\mathrm{Ru}_{6}(\mathrm{C})(\mathrm{CO})_{17}$ & $6[5]-2-17=11$ & $11(6)$ & $4 n+2$ & $14 n+2=14(6)+2=86$ & CLOSO, $\mathrm{C}^{0} \mathrm{C}[\mathrm{M} 6]$ \\
\hline 10 & $\mathrm{Ir}_{6}(\mathrm{CO})_{16}$ & 11 & $11(6)$ & $4 n+2$ & $14 n+2=14(6)+2=86$ & CLOSO, $\mathrm{C}^{0} \mathrm{C}[\mathrm{M} 6]$ \\
\hline 11 & $\mathrm{Co}_{6}(\mathrm{CO})_{13}(\mathrm{~N})^{-}$ & $6[4.5]-13-2.5-0.5=11$ & $11(6)$ & $4 n+2$ & $14 n+2=14(6)+2=86$ & $\mathrm{CLOSO}, \mathrm{C}^{0} \mathrm{C}[\mathrm{M} 6]$ \\
\hline 12 & $\mathrm{Ru}_{6}(\mathrm{CO})_{17}(\mathrm{~B})^{-}$ & $6[5]-17-1.5-0.5=11$ & $11(6)$ & $4 n+2$ & $14 n+2=14(6)+2=86$ & CLOSO, $\mathrm{C}^{0} \mathrm{C}[\mathrm{M} 6]$ \\
\hline 13 & $\mathrm{Ru}_{6}(\mathrm{C})(\mathrm{CO})_{16}{ }^{2-}$ & $6[5]-2-16-1=11$ & $11(6)$ & $4 n+2$ & $14 n+2=14(6)+2=86$ & CLOSO, $\mathrm{C}^{0} \mathrm{C}[\mathrm{M} 6]$ \\
\hline 14 & $\mathrm{Ru}_{6}(\mathrm{C})(\mathrm{CO})_{17}$ & $6[5]-2-17=11$ & $11(6)$ & $4 n+2$ & $14 n+2=14(6)+2=86$ & $\mathrm{CLOSO}, \mathrm{C}^{0} \mathrm{C}[\mathrm{M} 6]$ \\
\hline 15 & $\mathrm{Fe}_{6}(\mathrm{~N})(\mathrm{CO})_{15^{3-}}$ & $6[5]-2.5-15-1.5=11$ & $11(6)$ & $4 n+2$ & $14 n+2=14(6)+2=86$ & $\mathrm{CLOSO}, \mathrm{C}^{0} \mathrm{C}[\mathrm{M} 6]$ \\
\hline 16 & $\mathrm{Co}_{6}(\mathrm{C})(\mathrm{CO})_{13}{ }^{2-}$ & $6[4.5]-2-13-1=11$ & $11(6)$ & $4 n+2$ & $14 n+2=14(6)+2=86$ & CLOSO, $\mathrm{C}^{0} \mathrm{C}[\mathrm{M} 6]$ \\
\hline 17 & $\mathrm{Fe}_{6}(\mathrm{C})(\mathrm{CO})_{16}{ }^{2-}$ & $6[5]-2-16-1=11$ & $11(6)$ & $4 n+2$ & $14 n+2=14(6)+2=86$ & CLOSO, $\mathrm{C}^{0} \mathrm{C}[\mathrm{M} 6]$ \\
\hline 18 & $\mathrm{SFe}_{2} \mathrm{Ru}_{3}(\mathrm{CO})_{14}^{2-}$ & $1[1]+2[5]+3[5]-14-1=11$ & $11(6)$ & $4 n+2$ & $26+3[10]=56$ & CLOSO, $\mathrm{C}^{0} \mathrm{C}[\mathrm{M} 6]$ \\
\hline 19 & $\mathrm{Se}_{2} \mathrm{Mn}_{4}(\mathrm{CO})_{12}{ }^{2-}$ & $2[1]+4[5.5]-12-1=11$ & $11(6)$ & $4 n+2$ & $26+4[10]=66$ & CLOSO, $\mathrm{C}^{0} \mathrm{C}[\mathrm{M} 6]$ \\
\hline 20 & $\mathrm{Te}_{2} \mathrm{Ru}_{4}(\mathrm{CO})_{10}{ }^{2-}$ & $2[1]+4[5]-10-1=11$ & $11(6)$ & $4 n+2$ & $26+4[10]=66$ & CLOSO, $\mathrm{C}^{0} \mathrm{C}[\mathrm{M} 6]$ \\
\hline 21 & $\mathrm{Te}_{2} \mathrm{Ru}_{4}(\mathrm{CO})_{11}$ & $2[1]+4[5]-11=11$ & 11(6) & $4 n+2$ & $26+4[10]=66$ & CLOSO, $\mathrm{C}^{0} \mathrm{C}[\mathrm{M} 6]$ \\
\hline 22 & $\mathrm{Ru}_{6} \mathrm{H}(\mathrm{CO})_{18}{ }^{-}$ & $6[5]-0.5-18-0.5=11$ & $11(6)$ & $4 n+2$ & $14 n+2=14(6)+2=86$ & CLOSO, $\mathrm{C}^{0} \mathrm{C}[\mathrm{M} 6]$ \\
\hline 23 & $\operatorname{Re}_{6}(\mathrm{C})(\mathrm{CO})_{19}{ }^{2-}$ & 11 & 11(6) & $4 n+2$ & $14 n+2=14(6)+2=86$ & $\mathrm{CLOSO}, \mathrm{C}^{0} \mathrm{C}[\mathrm{M} 6]$ \\
\hline 24 & $\operatorname{Re}_{6}(\mathrm{C})(\mathrm{CO})_{19}(\mathrm{H})^{-}$ & 11 & $11(6)$ & $4 n+2$ & $14 n+2=14(6)+2=86$ & CLOSO, $\mathrm{C}^{0} \mathrm{C}[\mathrm{M} 6]$ \\
\hline 25 & $\operatorname{Re}_{6}(\mathrm{C})(\mathrm{CO})_{18}{ }^{3-}$ & 11 & $11(6)$ & $4 n+2$ & $14 n+2=14(6)+2=86$ & CLOSO, $\mathrm{C}^{0} \mathrm{C}[\mathrm{M} 6]$ \\
\hline 26 & $\operatorname{Re}_{6}(\mathrm{C})(\mathrm{CO})_{18}(\mathrm{H})_{2}{ }^{2-}$ & 11 & $11(6)$ & $4 n+2$ & $14 n+2=14(6)+2=86$ & CLOSO, $\mathrm{C}^{0} \mathrm{C}[\mathrm{M} 6]$ \\
\hline 27 & $\mathrm{Rh}_{6}(\mathrm{CO})_{13}(\mathrm{C})^{2-}$ & 11 & $11(6)$ & $4 n+2$ & $14 n+2=14(6)+2=86$ & CLOSO, $\mathrm{C}^{0} \mathrm{C}[\mathrm{M} 6]$ \\
\hline 28 & $\mathrm{Ru}_{5} \mathrm{Pd}(\mathrm{C})(\mathrm{CO})_{16}$ & 11 & $11(6)$ & $4 n+2$ & $14 n+2=14(6)+2=86$ & CLOSO, $\mathrm{C}^{0} \mathrm{C}[\mathrm{M} 6]$ \\
\hline 29 & $\mathrm{Ru}_{5} \mathrm{Co}(\mathrm{C})(\mathrm{CO})_{16}^{-}$ & 11 & $11(6)$ & $4 n+2$ & $14 n+2=14(6)+2=86$ & CLOSO, $\mathrm{C}^{0} \mathrm{C}[\mathrm{M} 6]$ \\
\hline 30 & $\mathrm{Ru}_{4}(\mathrm{H}) \mathrm{Co}_{2}(\mathrm{C})(\mathrm{CO})_{15}{ }^{-}$ & 11 & $11(6)$ & $4 n+2$ & $14 n+2=14(6)+2=86$ & CLOSO, $\mathrm{C}^{0} \mathrm{C}[\mathrm{M} 6]$ \\
\hline 31 & $\mathrm{Ru}_{6}(\mathrm{CO})_{18}{ }^{2-}$ & 11 & $11(6)$ & $4 n+2$ & $14 n+2=14(6)+2=86$ & CLOSO, $\mathrm{C}^{0} \mathrm{C}[\mathrm{M} 6]$ \\
\hline 32 & $\mathrm{Ni}_{6}(\mathrm{CO})_{12}{ }^{2-}$ & 11 & $11(6)$ & $4 n+2$ & $14 n+2=14(6)+2=86$ & CLOSO, $\mathrm{C}^{0} \mathrm{C}[\mathrm{M} 6]$ \\
\hline 33 & $\mathrm{Ge}_{6} \mathrm{R}_{2}$ & 11 & $11(6)$ & $4 n+2$ & $4 n+2=4(6)+2=26$ & CLOSO, $\mathrm{C}^{0} \mathrm{C}[\mathrm{M} 6]$ \\
\hline 34 & $\mathrm{C}_{3} \mathrm{~B}_{3} \mathrm{H}_{7}$ & 11 & $11(6)$ & $4 n+2$ & $4 n+2=4(6)+2=26$ & $\mathrm{CLOSO}, \mathrm{C}^{0} \mathrm{C}[\mathrm{M} 6]$ \\
\hline 35 & $\mathrm{Co}_{6}(\mathrm{CO})_{16}$ & 11 & $11(6)$ & $4 n+2$ & $14 n+2=14(6)+2=86$ & CLOSO, $\mathrm{C}^{0} \mathrm{C}[\mathrm{M} 6]$ \\
\hline 36 & $\mathrm{Rh}_{2} \mathrm{Fe}_{4}(\mathrm{~B})(\mathrm{CO})_{16}^{-}$ & 11 & $11(6)$ & $4 n+2$ & $14 n+2=14(6)+2=86$ & CLOSO, $\mathrm{C}^{0} \mathrm{C}[\mathrm{M} 6]$ \\
\hline 37 & $\mathrm{CB}_{5} \mathrm{H}_{7}$ & 11 & $11(6)$ & $4 n+2$ & $4 n+2=4(6)+2=26$ & CLOSO, $\mathrm{C}^{0} \mathrm{C}[\mathrm{M} 6]$ \\
\hline 38 & $(\mathrm{CoCp}) \mathrm{C}_{2} \mathrm{~B}_{3} \mathrm{H}_{5}$ & 11 & $11(6)$ & $4 n+2$ & $4 n+2=4(6)+2+1[10]=36$ & CLOSO, $\mathrm{C}^{0} \mathrm{C}[\mathrm{M} 6]$ \\
\hline 39 & $\mathrm{Ir}_{6}(\mathrm{CO})_{15}{ }^{2-}$ & 11 & $11(6)$ & $4 n+2$ & $14 n+2=14(6)+2=86$ & CLOSO, $\mathrm{C}^{0} \mathrm{C}[\mathrm{M} 6]$ \\
\hline 40 & $\mathrm{Pt}_{6}(\mathrm{CO})_{12}{ }^{2-}$ & 11 & $11(6)$ & $4 n+2$ & $14 n+2=14(6)+2=86$ & $\mathrm{CLOSO}, \mathrm{C}^{0} \mathrm{C}[\mathrm{M} 6]$ \\
\hline 41 & $\mathrm{Ru}_{4}(\mathrm{CO})_{9} \mathrm{~L}_{2}$ & 11 & $11(6)$ & $4 n+2$ & $14 n+2=14(6)+2=86$ & $\mathrm{CLOSO}, \mathrm{C}^{0} \mathrm{C}[\mathrm{M} 6]$ \\
\hline 42 & $\mathrm{Fe}_{2} \mathrm{Rh}_{4}(\mathrm{CO})_{16}{ }^{2-}$ & 11 & $11(6)$ & $4 n+2$ & $14 n+2=14(6)+2=86$ & CLOSO, $\mathrm{C}^{0} \mathrm{C}[\mathrm{M} 6]$ \\
\hline 43 & $\mathrm{FeRh}_{5}(\mathrm{CO})_{16}-$ & 11 & $11(6)$ & $4 n+2$ & $14 n+2=14(6)+2=86$ & CLOSO, $\mathrm{C}^{0} \mathrm{C}[\mathrm{M} 6]$ \\
\hline 44 & $\mathrm{Rh}_{5} \mathrm{Pt}(\mathrm{CO})_{15}{ }^{-}$ & 11 & $11(6)$ & $4 n+2$ & $14 n+2=14(6)+2=86$ & $\mathrm{CLOSO}, \mathrm{C}^{0} \mathrm{C}[\mathrm{M} 6]$ \\
\hline 45 & $\mathrm{Fe}_{5} \mathrm{Rh}(\mathrm{N})(\mathrm{CO})_{15}{ }^{2-}$ & 11 & $11(6)$ & $4 n+2$ & $14 n+2=14(6)+2=86$ & CLOSO, $\mathrm{C}^{0} \mathrm{C}[\mathrm{M} 6]$ \\
\hline 46 & $\mathrm{Ru}_{6}(\mathrm{C})(\mathrm{CO})_{16}(\mathrm{~L})$ & 11 & $11(6)$ & $4 n+2$ & $14 n+2=14(6)+2=86$ & CLOSO, $\mathrm{C}^{0} \mathrm{C}[\mathrm{M} 6]$ \\
\hline 47 & $\mathrm{Fe}_{4} \mathrm{Rh}_{2}(\mathrm{~N})(\mathrm{CO})_{15}{ }^{-}$ & 11 & $11(6)$ & $4 n+2$ & $14 n+2=14(6)+2=86$ & CLOSO, $\mathrm{C}^{0} \mathrm{C}[\mathrm{M} 6]$ \\
\hline 48 & $\mathrm{Fe}_{5} \mathrm{Ir}(\mathrm{N})(\mathrm{CO})_{15}{ }^{2-}$ & 11 & $11(6)$ & $4 n+2$ & $14 n+2=14(6)+2=86$ & $\mathrm{CLOSO}, \mathrm{C}^{0} \mathrm{C}[\mathrm{M} 6]$ \\
\hline 49 & $\mathrm{Rh}_{2} \mathrm{Os}_{4}(\mathrm{CO})_{18}$ & 11 & $11(6)$ & $4 n+2$ & $14 n+2=14(6)+2=86$ & $\mathrm{CLOSO}, \mathrm{C}^{0} \mathrm{C}[\mathrm{M} 6]$ \\
\hline 50 & $\mathrm{Ni}_{6}(\mathrm{CO})_{13}$ & 11 & $11(6)$ & $4 n+2$ & $14 n+2=14(6)+2=86$ & $\mathrm{CLOSO}, \mathrm{C}^{0} \mathrm{C}[\mathrm{M} 6]$ \\
\hline 51 & $\mathrm{Co}_{6}(\mathrm{C})(\mathrm{CO})_{12}{ }^{4-}$ & 11 & $11(6)$ & $4 n+2$ & $14 n+2=14(6)+2=86$ & CLOSO, $\mathrm{C}^{0} \mathrm{C}[\mathrm{M} 6]$ \\
\hline
\end{tabular}

\section{- IDENTICAL OR SIMILAR GEOMETRY}

Taking the $\mathrm{K}(\mathrm{n})=11(6)$ example, the ideal shape of this parameter is $\mathrm{O}_{\mathrm{h}}$ symmetry. This is sketched in Figure F-1. 


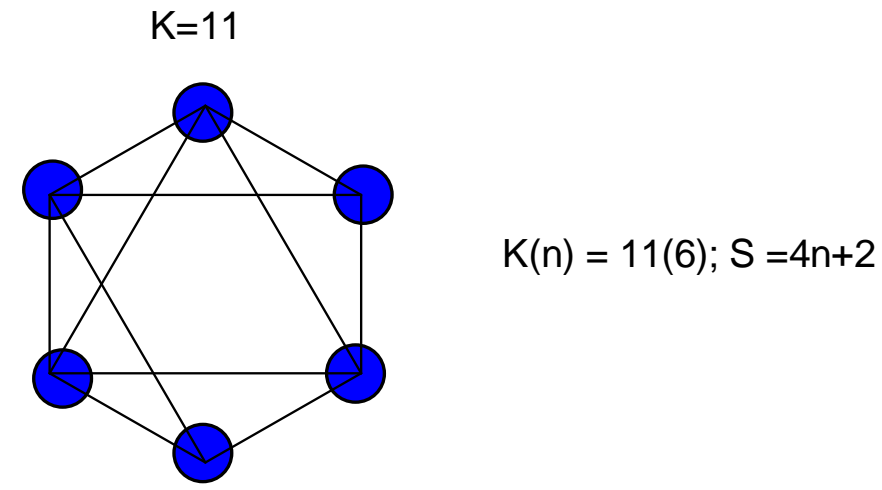

\section{IDEAL OCTAHEDRAL SKELETAL SHAPE BASED ON 4n SERIES}

F-1

However, in special cases, $\mathrm{K}$-isomerism occurs and a different shape with the same $\mathrm{K}$ value is observed. A good example is $\mathrm{H}_{2} \mathrm{Os}_{6}(\mathrm{CO})_{18} ; \mathrm{K}(\mathrm{n})=11(6)$ which portrays a capped square pyramid shape as sketched in Figure F-2 (Hughes and Wade, 2000).

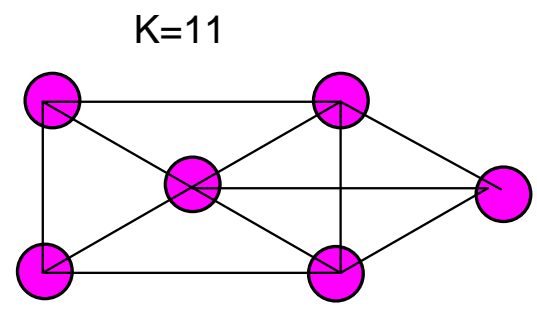

\section{- CLUSTER INTERCONVERSIONS}

Let us remain with $\mathrm{K}(\mathrm{n})=11(6)$ as an example. This parameter belongs to $\mathrm{S}=4 \mathrm{n}+2$ (CLOSO) series. If we need to determine the borane equivalent of the series, then we use the $[\mathrm{BH}]$ fragment which has a content of 4 electrons which will replace the [4] position in the series formula and then $\mathrm{n}=6$ and 2 will be the 2 electrons for closo systems. Hence, the borane cluster will be given by $\mathrm{FB}=[\mathrm{BH}](6)+2 \mathrm{e}=\mathrm{B}_{6} \mathrm{H}_{6}{ }^{2-}$. In order to derive the osmium equivalent cluster, we have to use the [14] electron content. Thus, $\mathrm{S}=14 \mathrm{n}+2 ; \mathrm{F}_{\mathrm{Os}}=\left[\mathrm{Os}(\mathrm{CO})_{3}\right](6)+2 \mathrm{e}=\mathrm{Os}_{6}(\mathrm{CO})_{18}{ }^{2-}$. We can also use it to derive the rhodium analogue: $\mathrm{F}_{\mathrm{Rh}}=\left[\mathrm{Rh}(\mathrm{H})(\mathrm{CO})_{2}\right](6)+\mathrm{CO}=\mathrm{Rh}_{6}(\mathrm{H})_{6}(\mathrm{CO})_{12}+\mathrm{CO}=\mathrm{Rh}_{6}(\mathrm{CO})_{3}(\mathrm{CO})_{12}+\mathrm{CO}=\mathrm{Rh}_{6}(\mathrm{CO})_{16}$. The clusters, $\mathrm{B}_{6} \mathrm{H}_{6}{ }^{2-}, \mathrm{Os}_{6}(\mathrm{CO})_{18}{ }^{2-}$ and $\mathrm{Rh}_{6}(\mathrm{CO})_{16}$ are well known (Housecroft \& Sharpe, 2005) .In the case of rhenium, $\mathrm{F}_{\mathrm{Re}}=$ $\left[\operatorname{Re}(\mathrm{H})(\mathrm{CO})_{3}\right](6)+\mathrm{CO}=\operatorname{Re}_{6}(\mathrm{H})_{6}(\mathrm{CO})_{18}+\mathrm{CO}=\operatorname{Re}_{6}(\mathrm{CO})_{3}(\mathrm{CO})_{18}+\mathrm{CO}=\operatorname{Re}_{6}(\mathrm{CO})_{22}$. One of the rhenium octahedral clusters has the formula $\operatorname{Re}_{6}(\mathrm{C})(\mathrm{CO})_{19}{ }^{2-}$ ( Hughes \& Wade, 2000). According to the series method, this is the same as $\operatorname{Re}_{6}(\mathrm{CO})_{22}$. What about Zintl clusters? Consider group 14 cluster such as lead: $\mathrm{F}_{\mathrm{Pb}}=4 \mathrm{n}+2=[\mathrm{Pb}](6)+2 \mathrm{e}=\mathrm{Pb}{ }_{6}{ }^{2-} \cdot \mathrm{What}$ type of ideal Zintl cluster of bismuth with $\mathrm{K}(\mathrm{n})=11(6)$ can we expect? In this case, we have to remove ONE electron from bismuth to conform to a $4 \mathrm{n}$ electron system. Hence, $\mathrm{Bi}-1 \mathrm{e}=\mathrm{Bi}^{+}$. Applying the series formula, $\mathrm{S}=4 \mathrm{n}+2(\mathrm{n}=6) ; \mathrm{F}_{\mathrm{Bi}}=$ $\left[\mathbf{B i}^{+}\right](\mathbf{6})+\mathbf{2} \mathbf{e}=\mathbf{B i}_{\mathbf{6}}{ }^{\mathbf{6}+}+\mathbf{2} \mathbf{e}=\mathbf{B i}_{\mathbf{6}}{ }^{\mathbf{}+}$. This cluster has the $\mathrm{K}$ value $=6[1.5]+2=11 ; \mathrm{K}(\mathrm{n})=11(6)$. Most of the information we can derive from the $\mathrm{K}(\mathrm{n})$ parameter is summarized in the sketch shown in Figure SC-8.

\section{- CLUSTER VALENCE ELECTRONS}

The calculation of cluster number $\mathrm{K}$ has already been explained in the chemical clusters CC-1 to CC-15 as well as in the examples given in Table 2. The skeletal numbers of elements are obtained from the appendices 1 and 2 . When the $\mathrm{K}$ value and the number of skeletal elements are known, then this gives us the $\mathrm{K}(\mathrm{n})$ parameter of the cluster from which the series formula is derived as summarized in the scheme SC-2 (page 14). The valence electrons of the cluster are directly calculated using the same series equation $S=4 n+q[V e=4 n+q]$ for the main group element clusters or Ve $=$ $14 n+q$ for transition metal clusters]. When the cluster comprises of both main group and transition metal elements, the calculation is adjusted to take into account the presence of transition metal elements due to the isolobal series relationship [S=4n+q $\leftrightarrow S=10 n+q]$ observed in previous work (Kiremire, 2015C).

(a) $\mathrm{B}_{6} \mathrm{H}_{6}{ }^{2-}: \mathrm{K}=6[2.5]-3-1=11 ; \mathrm{K}(\mathrm{n})=11(6), \mathrm{K}=2 \mathrm{n}-1 / 2 \mathrm{q}=11=2(6)-1 / 2 \mathrm{q}, 1 / 2 \mathrm{q}=12-11=1, \mathrm{q}=2 ; \mathrm{S}=4 \mathrm{n}+\mathrm{q}=4 \mathrm{n}+2$. Fortunately, the number of cluster valence electrons $(\mathrm{Ve})$ is directly obtained by using the same series formula 
by simply substituting the value of $\mathrm{n}$ in the series formula. In this case, $\mathrm{n}=6$ (number of boron skeletal elements) and hence, $\mathrm{Ve}=4(6)+2=26$. This number of cluster valence electrons can be checked from the valence electrons calculated from the cluster formula itself; thus VF $=6[3]+6(1)+2=18+6+2=26$. In case of transition metal clusters, $S=14 n+q$ and the cluster valence electrons will be given by $\mathrm{Ve}=14 \mathrm{n}+\mathrm{q}$. This is illustrated in the following example of the osmium cluster.

(b) $\mathrm{Os}_{6}(\mathrm{CO})_{18}{ }^{2-}: \mathrm{K}=6[5]-18-1=11, \mathrm{~K}(\mathrm{n})=11(6), \mathrm{S}=4 \mathrm{n}+2, \mathrm{Ve}=14 \mathrm{n}+2=14(6)+2=86$. This value can be compared to the value obtained from the cluster formula, $\mathrm{VF}=6[8]+18(2)+2=86$. The following example is a boron cluster with one metal skeletal element. The series formula is derived in the usual way and the valence electrons are determined by making an adjustment of one transition metal atom.

(c) $\mathrm{B}_{4} \mathrm{H}_{8}(\mathrm{CoCp}): \mathrm{K}=4[2.5]-4+1[4.5-2.5]=8, \mathrm{~K}(\mathrm{n})=8(5), \mathrm{S}=4 \mathrm{n}+4 ; \mathrm{Ve}=4 \mathrm{n}+4+1[10]=4(5)+2+10=32$

(d) $\mathrm{P}_{2} \mathrm{Co}_{2}(\mathrm{CO})_{6}: \mathrm{K}=2[1.5]+2[4.5]-6=6 ; \mathrm{n}=2+2=4 ; \mathrm{K}(\mathrm{n})=6(4) ; \mathrm{K}=2 \mathrm{n}-1 / 2 \mathrm{q}=6=2(4)-1 / 2 \mathrm{q}, 1 / 2 \mathrm{q}=4$; hence $\mathrm{S}=$ $4 n+4$. In this example, the cluster valence electrons will be calculated by assuming that all the skeletal elements are main group elements, $\mathrm{Ve}=4 \mathrm{n}+4+2[10]=4(4)+4+20=40$. Thus, the adjustment for the 2 transition metals is taken into account, giving us $\mathrm{Ve}=20+20=40$. This value can be checked from the calculation using the cluster formula, $\mathrm{VF}=2[5]+2[9]+6(2)=10+18+12=40$.

\section{- $\quad$ LIGAND DISTRIBUTIONS}

Skeletal numbers are very useful in the distribution of ligands among skeletal elements. This concept has been applied in many examples in this paper. Other examples can be found in literature (Kiremire, 2016b, 2017).

\section{- $\quad$ DOUBLE MEANING OF K(n)}

Ex-3: Let us consider $\mathrm{Os}_{6}(\mathrm{CO})_{18}{ }^{2-}$ example; $\mathrm{K}=6[5]-18-1=11 ; \mathrm{K}(\mathrm{n})=11(6), \mathrm{S}=4 \mathrm{n}+2$. The parameter $\mathrm{K}(\mathrm{n})=11(6)$ represents an octahedral shape. This means the skeletal elements are linked by 11 lines as in F-1. At the same time, it represents the number of electron pairs that will decompose the cluster into mono-skeletal fragments each of which will obey the 18 electron rule. This is illustrated in equation (i).

$$
\mathrm{Os}_{6}(\mathrm{CO})_{18^{2-}} \stackrel{+11 \mathrm{CO}}{\longrightarrow} \mathrm{Os}_{6}(\mathrm{CO})_{29^{2-}} \longrightarrow \mathrm{Os}_{6}(\mathrm{CO})_{30} \longrightarrow 6\left[\mathrm{Os}(\mathrm{CO})_{5}\right]
$$

Thus 6 complexes of $\mathrm{Os}(\mathrm{CO})_{5}$ are generated each of which obeys the 18 electron rule. This principle applies to even huge clusters. Let us consider $\mathrm{Pd}_{37}(\mathrm{CO})_{28} \mathrm{~L}_{12}$ : $\mathrm{K}=108$ (as calculated above): $\mathrm{K}(\mathrm{n})=108(37)$; $\mathrm{S}=4 \mathrm{n}-74, \mathrm{Kp}=\mathrm{C}^{35} \mathrm{C}[\mathrm{M} 2]$. According to the series method, the giant cluster of 37 skeletal elements is bound by 108 skeletal linkages. It also has a nucleus of two skeletal elements [M2] surrounded by 35 capping skeletal elements. This cluster, according to the series method, requires 108 electron pairs to be dismantled into individual mono-skeletal fragments each of which obeys the 18 electron rule. Since the $\mathrm{CO}$ ligand and L each donates 2 electrons to the skeletal elements, they are regarded as being equivalent. For simplicity, let us represent all of them by CO ligands. Then the cluster can be written as $\mathrm{Pd}_{37}(\mathrm{CO})_{40}$. Since each: CO ligand is 1 electron pair donor, then $\mathrm{K}=108$ will be equivalent to $108 \mathrm{CO}$ ligands. This is illustrated in equation (ii).

\section{$\mathrm{Pd}_{37}(\mathrm{CO})_{40} \stackrel{+108 \mathrm{CO}}{\longrightarrow} \mathrm{Pd}_{37}(\mathrm{CO})_{148} \longrightarrow 37\left[\mathrm{Pd}(\mathrm{CO})_{4}\right]$}

In this example, the addition of $108 \mathrm{CO}$ ligands to the cluster results in the formation of 37 fragments of $\left[\mathrm{Pd}(\mathrm{CO})_{4}\right]$ each of which obeys the 18 electron rule.

Since each CO ligand carries a pair of electrons for donation as a ligand, then in the case of rhodium cluster, $\mathrm{Rh}_{6}(\mathrm{CO})_{16}$ $+11 \mathrm{CO} \rightarrow \mathrm{Rh}_{6}(\mathrm{CO})_{27} \rightarrow 6\left[\mathrm{Rh}(\mathrm{CO})_{4.5}\right]$. Each fragment $\mathrm{Rh}(\mathrm{CO})_{4.5}$ obeys the 18 electron rule. Consider the cluster system: $\mathrm{Te}_{2} \mathrm{Ru} 4(\mathrm{CO})_{11}+9 \mathrm{CO}+4 \mathrm{H} \rightarrow 4\left[\mathrm{Ru}(\mathrm{CO})_{5}\right]+2 \mathrm{TeH}_{2}$. In this example, $\mathrm{Ru}(\mathrm{CO})_{5}$ obeys the 18 electron rule while $\mathrm{TeH}_{2}$ molecule obeys the 8 electron rule. The $9 \mathrm{CO}+4 \mathrm{H}$ donate an equivalent of 11 pairs of electrons when acting as ligands. Let us consider the last example $\mathrm{B}_{6} \mathrm{H}_{6}{ }^{2-}+11(2 \mathrm{H}) \rightarrow \mathrm{B}_{6} \mathrm{H}_{28}{ }^{2-}=\mathrm{B}_{6} \mathrm{H}_{30} \rightarrow 6\left[\mathrm{BH}_{5}\right]$. The fragment $\mathrm{BH}_{5}$ obeys the 8 electron rule. In general, based on series analysis, the $\mathrm{k}(\mathrm{n})$ parameter represents both the number of $\mathrm{k}$ linkages that bind a cluster of $\mathrm{n}$ skeletal elements on one hand, and a shortage of $\mathrm{k}$ electron pairs needed for each of the skeletal elements concerned to attain a noble gas configuration, on the other hand.

- Summary of information derived from $\mathrm{k}(\mathrm{n})$ parameter

Most of the important information that can be derived from the K(n) parameter is summarized in Figure SC-8. This includes, among others, the type of series, the cluster valence electrons, the possible shape of a cluster, and so on. 


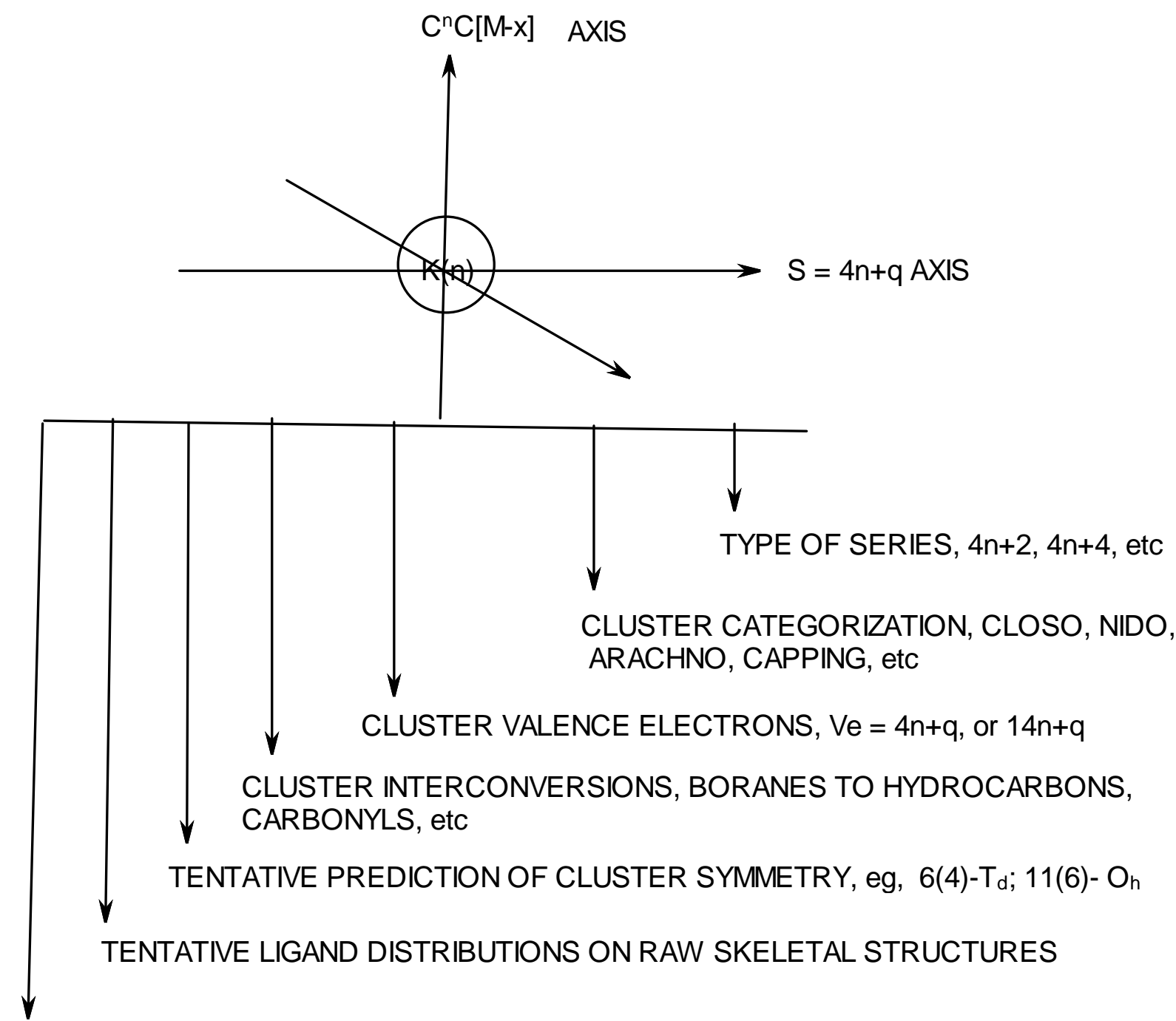

GROUPING TOGETHER CLUSTERS WITH THE SAME K(n) VALUE

$\mathrm{SC}-8$

\subsection{The Diagonal Series and the Shrinking Nucleus}

The diagonal series of clusters are also very interesting. Let us consider $\mathrm{Rh}_{6}(\mathrm{CO})_{16}$ as an illustration. This cluster as we know has an octahedral symmetry with $K(n)=11(6)$ parameter. It is a family member of the closo series, $S=4 n+2$. Its cluster valence electrons are given by $\mathrm{Ve}=14 \mathrm{n}+2=14(6)+2=86$. If we remove a CO ligand we will get $\mathrm{Rh}_{6}(\mathrm{CO})_{15}$ with a $K(n)=12(6)$. This belongs to the series $S=4 n+0$ with $K p=C^{1} C[M 5]$. Its cluster valence electron content is given by $\mathrm{Ve}=14 \mathrm{n}+0=14(6)+0=84$. The removal of the next $\mathrm{CO}$ ligand we will get $\mathrm{Rh}_{6}(\mathrm{CO})_{14}$ with a corresponding $\mathrm{K}(\mathrm{n})$ value of 13(6). This belongs to the series $S=4 n-2$ with $K p=C^{2} C[M 4]$. The cluster valence content will be $\mathrm{Ve}=14 \mathrm{n}-2$ $=14(6)-2=82$. The cluster becomes a bi-capped closo tetrahedron. The next cluster will be $\mathrm{Rh}_{6}(\mathrm{CO})_{13}$ with $\mathrm{K}(\mathrm{n})=$ 14(6). The corresponding series for this is $S=4 n-4$. This cluster will have a capping symbol $K p=C^{3} C[M 3]$. This is a tri-capped closo triangle. The next cluster of the series is $\mathrm{Rh}_{6}(\mathrm{CO})_{12}$. This has a $\mathrm{K}(\mathrm{n})$ parameter of $15(6)$. It belongs to the series $S=4 n-6, K p=C^{4} C[M 2]$. According to the series, the cluster will have 2 of its skeletal elements in the nucleus and 4 capping skeletal elements. The next fragment is $\mathrm{Rh}_{6}(\mathrm{CO})_{11}$ with $\mathrm{K}=16$. Its cluster parameter is $\mathrm{K}(\mathrm{n})=16(6)$. Its cluster series will be $S=4 n-8$ and $K p=C^{5} C[M 1]$. This is a cluster with a single skeletal element at the nucleus with 5 capping skeletal elements. The entire sequence of $\mathrm{K}(\mathrm{n})$ numbers will be: $11(6)\left[\mathrm{Rh}_{6}(\mathrm{CO})_{16}\right] \rightarrow 12(6)\left[\mathrm{Rh}_{6}(\mathrm{CO})_{15}\right] \rightarrow 13(6)\left[\mathrm{Rh}_{6}(\mathrm{CO})_{14}\right] \rightarrow 14(6)\left[\mathrm{Rh}_{6}(\mathrm{CO})_{13}\right] \rightarrow 15(6)\left[\mathrm{Rh}_{6}(\mathrm{CO})_{12}\right] \rightarrow 16(6)\left[\mathrm{Rh}_{6}(\mathrm{CO})_{11}\right]$ $\rightarrow 17(6)\left[\mathrm{Rh}_{6}(\mathrm{CO})_{10}\right] \rightarrow 18(6)\left[\mathrm{Rh}_{6}(\mathrm{CO})_{9}\right] \rightarrow 19(6)\left[\mathrm{Rh}_{6}(\mathrm{CO})_{8}\right] \rightarrow 20(6)\left[\mathrm{Rh}_{6}(\mathrm{CO})_{7}\right] \rightarrow 21(6)\left[\mathrm{Rh}_{6}(\mathrm{CO})_{6}\right] \rightarrow 22(6)\left[\mathrm{Rh}_{6}(\mathrm{CO})_{5}\right] \rightarrow$ $23(6)\left[\mathrm{Rh}_{6}(\mathrm{CO})_{4}\right] \rightarrow 24(6)\left[\mathrm{Rh}_{6}(\mathrm{CO})_{3}\right] \rightarrow 25(6)\left[\mathrm{Rh}_{6}(\mathrm{CO})_{2}\right] \rightarrow 26(6)\left[\mathrm{Rh}_{6}(\mathrm{CO})_{1}\right] \rightarrow 27(6) \quad\left[\mathrm{Rh}_{6}(\mathrm{CO})_{0}\right][\mathrm{S}=4 \mathrm{n}-30] . \quad$ These diagonal $\mathrm{K}(\mathrm{n})$ numbers are highlighted in RED in Table 2 and converted into series in Table 5. This movement 
involving the removal of a co ligand step-wise may be described as stripping series. In the stripping series $\mathrm{Kp}=$ $\mathrm{C}^{\mathrm{y}} \mathrm{C}[\mathrm{Mx}]$, both the nuclear index $\mathrm{x}$ and the capping index y change as we move from one step to the next. We also notice that as $y$ increases, $x$ decreases and vice versa. In the example of the octahedral cluster $\operatorname{Rh}_{6}(C O)_{16}$, the nuclear index $\mathrm{x}$ goes from 6 to 0 where all the 6 rhodium skeletal elements are capped. These changes are diagrammatically expressed in figure SC-17 below. Using the rhodium carbonyl cluster, $\mathrm{Rh}_{6}(\mathrm{CO})_{16}$ as a reference for illustration, the cluster is a member of the CLOSO family, $\mathrm{S}=4 \mathrm{n}+2, \mathrm{~K}(\mathrm{n})=12(6)$ and $\mathrm{Kp}=\mathrm{C}^{0} \mathrm{C}[\mathrm{M} 6]$. This is a 'borderline' cluster with zero capping skeletal element. When a $\mathrm{CO}$ ligand is removed via stripping, it becomes $\mathrm{Rh}_{6}(\mathrm{CO})_{15}, \mathrm{~K}=12(6), \mathrm{Kp}=$ $\mathrm{C}^{1} \mathrm{C}[\mathrm{M} 5]$. This represents a mono-capped trigonal bipyramid geometry. The next stripping of a $\mathrm{CO}$ ligand creates, $\mathrm{Kp}=$ $\mathrm{C}^{2} \mathrm{C}[\mathrm{M} 4]$ which is a bi-capped tetrahedral cluster. The next stripping gives us $\mathrm{Kp}=\mathrm{C}^{3} \mathrm{C}[\mathrm{M} 3]$ cluster which is a triangular tri-capped cluster. This is followed by a tetra-capped cluster with a two bi-skeletal nuclear cluster, $\mathrm{Kp}=$ $\mathrm{C}^{4} \mathrm{C}[\mathrm{M} 2]$. Further stripping generates $\mathrm{Kp}=\mathrm{C}^{5} \mathrm{C}[\mathrm{M} 1]$ which is a penta-capped mono-skeletal nuclear cluster. The next stripping creates a cluster $\mathrm{Kp}=\mathrm{C}^{6} \mathrm{C}[\mathrm{M} 0]$ where all the skeletal elements are capping and the nucleus is empty.

\section{Blackholes in the Nucleus and Ghost Skeletal Elements}

Further stripping creates clusters with negative nuclear indices. Thus, the cluster number 8 in Table $5, \mathrm{Rh}_{6}(\mathrm{CO})_{9}: \mathrm{K}(\mathrm{n})=$ $18(6), \mathrm{Kp}=\mathrm{C}^{7} \mathrm{C}[\mathrm{M}-1]$; shows that it has 7 capped skeletal elements. However in reality, the cluster has 6 skeletal elements not 7. Hence, we can regard the seventh elements as fictitious and just a creation of the series. We may call such an element created by the series as a hole or a ghost skeletal element. A closer look at Table 5 shows that the capping elements are being taken from the nucleus. When [M0] becomes [M-1], it means the capping fictitious element has been 'borrowed' from a nucleus which did not have any at all, hence [Mx], $\mathrm{x}=-1$ or according to series, $\mathrm{n}=-1$ at the nucleus. Since the nucleus is a member of CLOSO family, $S=4 n+2$ and $K=2 n-1=2(-1)-1=-3$. This means the cluster nucleus is indebted with -3 cluster linkages. As $\mathrm{x}$ in $[\mathrm{Mx}]$ becomes $\mathrm{x} \leq 0$, the number of nuclear skeletal linkages becomes more and more negative. We may regard such nuclei as having BLACK HOLES since they seem to be swallowing skeletal linkages. When all the CO ligands have been removed from $\mathrm{Rh} 6(\mathrm{CO})_{16}$ to become completely naked, cluster number 17 Table 5, $\mathrm{Rh}_{6}: \mathrm{K}(\mathrm{n})=27(6)$; and $\mathrm{Kp}=\mathrm{C}^{16} \mathrm{C}[\mathrm{M}-10]$. We can interpret this to mean that there are 16 capping skeletal elements, 6 genuine ones and 10 ghost ones borrowed from the cluster nucleus which develops a huge black-hole of $n=-10$ and $K=2 n-1=2(-10)-1=-21$ skeletal linkages. Can we then regard a cluster with a nucleus possessing a black-hole and ghost capping skeletal elements as a characteristic of a metallic character of a cluster? The nuclear changes in the stripping series of $\mathrm{Rh}_{6}(\mathrm{CO})_{16}$ up to [M0] are illustrated in SC-9. The decomposition fragments of $\mathrm{Rh}_{6}(\mathrm{CO})_{16}$ are shown in Table 5.

On the other hand, the addition of $\mathrm{CO}$ ligands to the $\mathrm{Rh}_{6}(\mathrm{CO})_{16}$ cluster reduces the $\mathrm{K}$ value from $\mathrm{K}=11$ to finally $\mathrm{K}=5$, the limiting $\mathrm{K}$ value when the cluster behaves as a saturated hydrocarbon analogue.

The cluster $\mathrm{Pd}_{23}(\mathrm{CO})_{20} \mathrm{~L}_{10}: \mathrm{K}(\mathrm{n})=62(23) ; \mathrm{S}=4 \mathrm{n}-32, \mathrm{Kp}=\mathrm{C}^{17} \mathrm{C}[\mathrm{M} 6]$; was chemically converted into $\mathrm{Pd}_{23}(\mathrm{CO})_{20} \mathrm{~L}_{8}$ : $\mathrm{K}(\mathrm{n})=64(23) ; \mathrm{S}=4 \mathrm{n}-36, \mathrm{Kp}=\mathrm{C}^{19} \mathrm{C}[\mathrm{M} 4]$. The two clusters were found to have different skeletal structures (Mednikov and Dahl, 2010). The former is described to have a $\mathrm{Pd}_{19}$ pseudo octahedral while the latter has a $\operatorname{Pd}_{15}$ kernel hexa-capped cubic with 8 capping Pd elements. The transformation can be explained using series in that $\operatorname{Pd}_{23}(\mathrm{CO})_{20} \mathrm{~L}_{10}$ has a $\mathrm{K}$ value of 62 with an octahedral nucleus [M6] while the cluster $\mathrm{Pd}_{23}(\mathrm{CO})_{20} \mathrm{~L}_{8}$ has a $\mathrm{K}$ value of 64 with a tetrahedral nucleus. According to the series method, the two clusters of the same nuclearity differ by 2 electron donor ligands and hence as expected as in line with the case of rhodium clusters discussed in SC-17, the removal of a ligand from a cluster of the same nuclearity results in the increase of $\mathrm{K}$ value and increase in the degree of capping. In the case of capping clusters, the increase in the capping corresponds to the decrease of the number of atoms in the nucleus. An increase in $\mathrm{K}$ value by 1 is accompanied by a decrease in the number of nuclear skeletal elements by 1 . What was also found to be exciting is the discovery that the series method predicts that the clusters $\mathrm{Pt}_{38}(\mathrm{CO})_{44}{ }^{2-}\left\{\mathrm{C}^{32} \mathrm{C}[\mathrm{M} 6]\right\}$, $\mathrm{H}_{6-\mathrm{n}} \mathrm{Pt}_{6} \mathrm{Ni}_{38}(\mathrm{CO})_{48}{ }^{\mathrm{n}-}\left\{\mathrm{C}^{38} \mathrm{C}[\mathrm{M} 6]\right\}, \mathrm{Pt}_{9} \mathrm{Ni}_{35}(\mathrm{CO})_{48}{ }^{6-}\left\{\mathrm{C}^{38} \mathrm{C}[\mathrm{M} 6]\right\}$, and $\mathrm{Pd}_{8} \mathrm{Ni}_{36}(\mathrm{CO})_{48}{ }^{6-}\left\{\mathrm{C}^{38} \mathrm{C}[\mathrm{M} 6]\right\}$ possess an octahedral nucleus and indeed they have all been described to have octahedral cores (Mednikov and Dahl, 2010). The series method can also be useful in rapid categorization of the products encountered in EDESI-MS work (Bucher, 2003). An illustration is given in Table 6. 

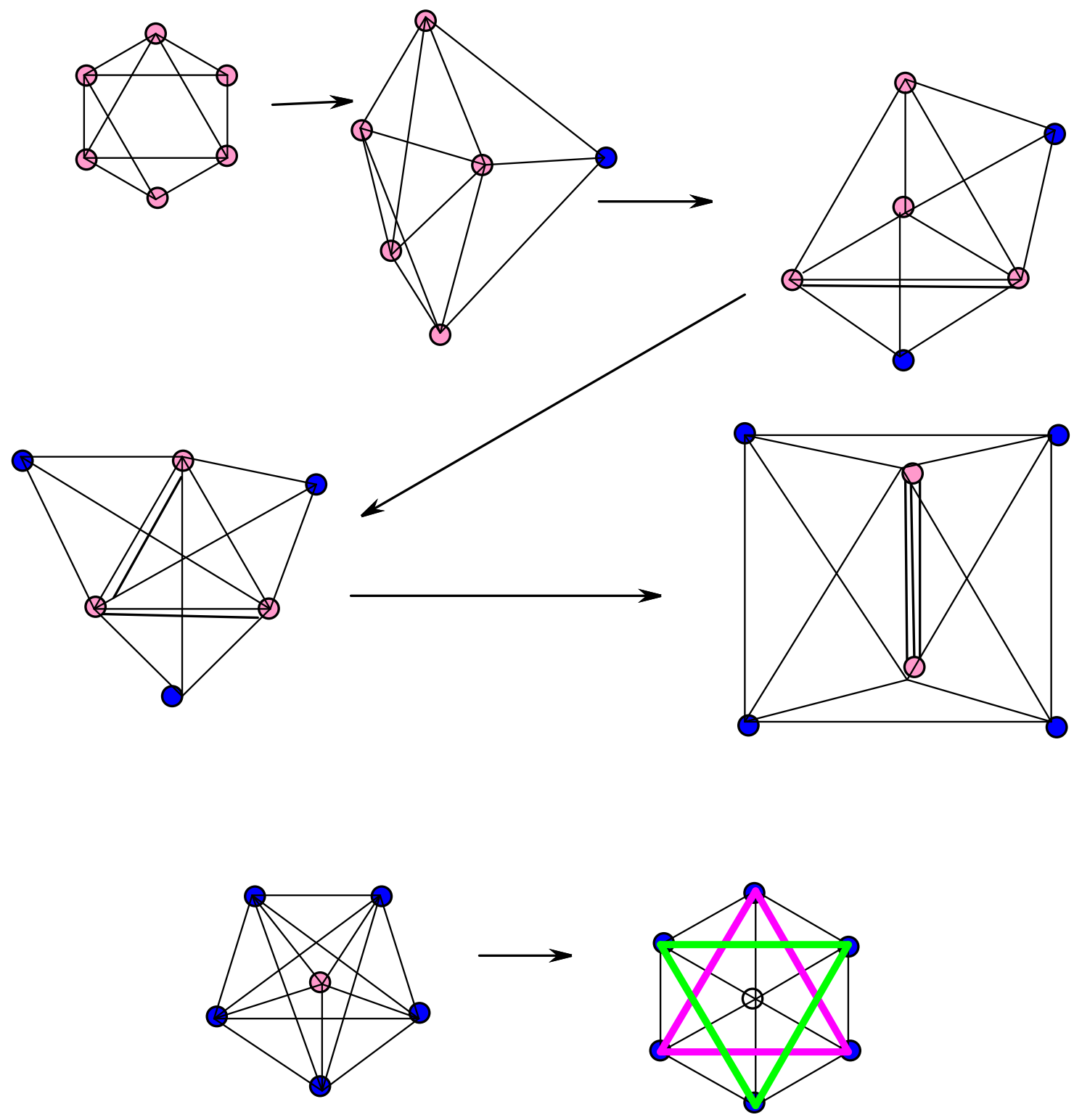

SC-9 
Table 5. Illustration of the Shrinking Nucleus of Diagonal Series

\begin{tabular}{|c|c|c|c|c|c|}
\hline & CLUSTER & $\mathrm{K}$ & $\mathrm{K}(\mathrm{n})$ & SERIES, $\mathrm{S}$ & $\mathrm{Kp}$ \\
\hline 1 & $\mathrm{Rh}_{6}(\mathrm{CO})_{16}$ & $6[4.5]-16=11$ & $11(6)$ & $4 n+2$ & $\mathrm{C}^{0} \mathrm{C}[\mathrm{M} 6]$ \\
\hline 2 & $\mathrm{Rh}_{6}(\mathrm{CO})_{15}$ & $6[4.5]-15=12$ & $12(6)$ & $4 n+0$ & $\mathrm{C}^{1} \mathrm{C}[\mathrm{M} 5]$ \\
\hline 3 & $\mathrm{Rh}_{6}(\mathrm{CO})_{14}$ & $6[4.5]-14=13$ & $13(6)$ & $4 n-2$ & $\mathrm{C}^{2} \mathrm{C}[\mathrm{M} 4]$ \\
\hline 4 & $\mathrm{Rh}_{6}(\mathrm{CO})_{13}$ & $6[4.5]-13=14$ & $14(6)$ & $4 n-4$ & $\mathrm{C}^{3} \mathrm{C}[\mathrm{M} 3]$ \\
\hline 5 & $\mathrm{Rh}_{6}(\mathrm{CO})_{12}$ & $6[4.5]-12=15$ & $15(6)$ & $4 n-6$ & $\mathrm{C}^{4} \mathrm{C}[\mathrm{M} 2]$ \\
\hline 6 & $\mathrm{Rh}_{6}(\mathrm{CO})_{11}$ & $6[4.5]-11=16$ & $16(6)$ & $4 n-8$ & $\mathrm{C}^{5} \mathrm{C}[\mathrm{M} 1]$ \\
\hline 7 & $\mathrm{Rh}_{6}(\mathrm{CO})_{10}$ & $6[4.5]-10=17$ & $17(6)$ & $4 n-10$ & $\mathrm{C}^{6} \mathrm{C}[\mathrm{M} 0]$ \\
\hline 8 & $\mathrm{Rh}_{6}(\mathrm{CO})_{9}$ & $6[4.5]-9=18$ & $18(6)$ & $4 n-12$ & $\mathrm{C}^{7} \mathrm{C}[\mathrm{M}-1]$ \\
\hline 9 & $\mathrm{Rh}_{6}(\mathrm{CO})_{8}$ & $6[4.5]-8=19$ & $19(6)$ & $4 n-14$ & $\mathrm{C}^{8} \mathrm{C}[\mathrm{M}-2]$ \\
\hline 10 & $\mathrm{Rh}_{6}(\mathrm{CO})_{7}$ & $6[4.5]-7=20$ & $20(6)$ & $4 n-16$ & $\mathrm{C}^{9} \mathrm{C}[\mathrm{M}-3]$ \\
\hline 11 & $\mathrm{Rh}_{6}(\mathrm{CO})_{6}$ & $6[4.5]-6=21$ & $21(6)$ & $4 n-18$ & $\mathrm{C}^{10} \mathrm{C}[\mathrm{M}-4]$ \\
\hline 12 & $\mathrm{Rh}_{6}(\mathrm{CO})_{5}$ & $6[4.5]-5=22$ & $22(6)$ & $4 n-20$ & $\mathrm{C}^{11} \mathrm{C}[\mathrm{M}-5]$ \\
\hline 13 & $\mathrm{Rh}_{6}(\mathrm{CO})_{4}$ & $6[4.5]-4=23$ & $23(6)$ & $4 n-22$ & $\mathrm{C}^{12} \mathrm{C}[\mathrm{M}-6]$ \\
\hline 14 & $\mathrm{Rh}_{6}(\mathrm{CO})_{3}$ & $6[4.5]-3=24$ & $24(6)$ & $4 n-24$ & $\mathrm{C}^{13} \mathrm{C}[\mathrm{M}-7]$ \\
\hline 15 & $\mathrm{Rh}_{6}(\mathrm{CO})_{2}$ & $26[4.5]-2=25$ & $25(6)$ & $4 n-26$ & $\mathrm{C}^{14} \mathrm{C}[\mathrm{M}-8]$ \\
\hline 16 & $\mathrm{Rh}_{6}(\mathrm{CO})_{1}$ & $6[4.5]-1=26$ & $26(6)$ & $4 n-28$ & $\mathrm{C}^{15} \mathrm{C}[\mathrm{M}-9]$ \\
\hline \multirow[t]{9}{*}{17} & $\mathrm{Rh}_{6}$ & $6[4.5]-0=27$ & $27(6)$ & $4 n-30$ & $\mathrm{C}^{16} \mathrm{C}[\mathrm{M}-10]$ \\
\hline & CLUSTER & $\mathrm{K}$ & $\mathrm{K}(\mathrm{n})$ & SERIES, $\mathrm{S}$ & $\mathrm{Kp}$ \\
\hline & $\mathrm{Rh}_{6}(\mathrm{CO})_{16}$ & $6[4.5]-16=11$ & $11(6)$ & $4 n+2$ & $\mathrm{C}^{0} \mathrm{C}[\mathrm{M} 6]$ \\
\hline & $\mathrm{Rh}_{6}(\mathrm{CO})_{17}$ & $6[4.5]-17=10$ & $10(6)$ & $4 n+4$ & $\mathrm{C}^{-1} \mathrm{C}[\mathrm{M} 7]$ \\
\hline & $\mathrm{Rh}_{6}(\mathrm{CO})_{18}$ & $6[4.5]-18=9$ & $9(6)$ & $4 n+6$ & $\mathrm{C}^{-2} \mathrm{C}[\mathrm{M} 8]$ \\
\hline & $\mathrm{Rh}_{6}(\mathrm{CO})_{19}$ & $6[4.5]-19=8$ & $8(6)$ & $4 n+8$ & $\mathrm{C}^{-3} \mathrm{C}[\mathrm{M} 9]$ \\
\hline & $\mathrm{Rh}_{6}(\mathrm{CO})_{20}$ & $6[4.5]-20=7$ & $7(6)$ & $4 n+10$ & $\mathrm{C}^{-4} \mathrm{C}[\mathrm{M} 10]$ \\
\hline & $\mathrm{Rh}_{6}(\mathrm{CO})_{21}$ & $6[4.5]-21=6$ & $6(6)$ & $4 n+12$ & $\mathrm{C}^{-5} \mathrm{C}[\mathrm{M} 11]$ \\
\hline & $\mathrm{Rh}_{6}(\mathrm{CO})_{22}$ & $6[4.5]-22=5$ & $5(6)$ & $4 n+14$ & $\mathrm{C}^{-6} \mathrm{C}[\mathrm{M} 12]$ \\
\hline
\end{tabular}

Table 6. Application of Series to Categorize the decomposition clusters from literature*

\begin{tabular}{|c|c|c|c|c|c|c|}
\hline \multicolumn{7}{|c|}{$\mathrm{Ru}_{3}(\mathrm{CO})_{12}$ Decomposition products } \\
\hline & $\mathrm{K}$ & $\mathrm{n}$ & $\mathrm{K}(\mathrm{n})$ & SERIES, S & $\mathrm{Kp}$ & Lit. \\
\hline $\mathrm{Ru}_{6}(\mathrm{CO})_{21}{ }^{2-}$ & $6[5]-21-1=8$ & 6 & $8(6)$ & $4 n+8$ & $\mathrm{C}^{-3} \mathrm{C}[\mathrm{M} 9]$ & Raft \\
\hline $\mathrm{Ru}_{6}(\mathrm{CO})_{20}{ }^{2-}$ & $6[5]-20-1=9$ & 6 & $9(6)$ & $4 n+6$ & $\mathrm{C}^{-2} \mathrm{C}[\mathrm{M} 8]$ & Raft \\
\hline $\mathrm{Ru}_{7}(\mathrm{CO})_{20}{ }^{2-}$ & $7[5]-20-1=14$ & 7 & $14(7)$ & $4 n+0$ & $\mathrm{C}^{1} \mathrm{C}[\mathrm{M} 6]$ & Mono-cap $\mathrm{O}_{\mathrm{h}}$ \\
\hline $\mathrm{Ru}_{6}(\mathrm{CO})_{18}{ }^{2-}$ & $6[5]-18-1=11$ & 6 & $11(6)$ & $4 n+2$ & $\mathrm{C}^{0} \mathrm{C}[\mathrm{M} 6]$ & $\mathrm{O}_{\mathrm{h}}$ \\
\hline $\mathrm{Ru}_{9}(\mathrm{CO})_{23}{ }^{2-}$ & $9[5]-23-1=21$ & 9 & $21(9)$ & $4 n-6$ & $\mathrm{C}^{4} \mathrm{C}[\mathrm{M} 5]$ & Tri-cap $\mathrm{O}_{\mathrm{h}}$ \\
\hline $\mathrm{Ru}_{8}(\mathrm{CO})_{21}{ }^{2-}$ & $8[5]-21-1=18$ & 8 & $18(8)$ & $4 n-4$ & $\mathrm{C}^{3} \mathrm{C}[\mathrm{M} 5]$ & Bi-cap $\mathrm{O}_{\mathrm{h}}$ \\
\hline $\mathrm{Ru}_{7}(\mathrm{CO})_{19}{ }^{2-}$ & $7[5]-19-1=15$ & 7 & $15(7)$ & $4 n-2$ & $\mathrm{C}^{2} \mathrm{C}[\mathrm{M} 5]$ & Mono-cap $\mathrm{O}_{\mathrm{h}}$ \\
\hline $\mathrm{Ru}_{6}(\mathrm{CO})_{17}{ }^{2-}$ & $6[5]-17-1=12$ & 6 & $12(6)$ & $4 n+0$ & $\mathrm{C}^{1} \mathrm{C}[\mathrm{M} 5]$ & Bi-cap $\mathrm{T}_{\mathrm{d}}$ \\
\hline $\mathrm{Ru}_{5}(\mathrm{CO})_{15}{ }^{2-}$ & $5[5]-15-1=9$ & 5 & $9(5)$ & $4 n+2$ & $\mathrm{C}^{0} \mathrm{C}[\mathrm{M} 5]$ & Trigonalbipy \\
\hline $\mathrm{Ru}_{4}(\mathrm{CO})_{13}{ }^{2-}$ & $4[5]-13-1=6$ & 4 & $6(4)$ & $4 n+4$ & $\mathrm{C}^{-1} \mathrm{C}[\mathrm{M} 5]$ & $\mathrm{T}_{\mathrm{d}}$ \\
\hline $\mathrm{Ru}_{3}(\mathrm{CO})_{11}{ }^{2-}$ & $3[5]-11-1=3$ & 3 & $3(3)$ & $4 n+6$ & $\mathrm{C}^{-2} \mathrm{C}[\mathrm{M} 5]$ & Triangle \\
\hline $\mathrm{Ru}_{9}(\mathrm{CO})_{22}{ }^{2-}$ & $9[5]-22-1=22$ & 9 & $22(9)$ & $4 n-8$ & $\mathrm{C}^{5} \mathrm{C}[\mathrm{M} 4]$ & Tri-cap $\mathrm{O}_{\mathrm{h}}$ \\
\hline $\mathrm{Ru}_{8}(\mathrm{CO})_{20}{ }^{2-}$ & $8[5]-20-1=19$ & 8 & $19(8)$ & $4 n-6$ & $\mathrm{C}^{4} \mathrm{C}[\mathrm{M} 4]$ & Bi-cap $\mathrm{O}_{\mathrm{h}}$ \\
\hline $\mathrm{Ru}_{7}(\mathrm{CO})_{18}{ }^{2-}$ & $7[5]-18-1=16$ & 7 & $16(7)$ & $4 n-4$ & $\mathrm{C}^{3} \mathrm{C}[\mathrm{M} 4]$ & Mono-cap $\mathrm{O}_{\mathrm{h}}$ \\
\hline $\mathrm{Ru}_{6}(\mathrm{CO})_{16}{ }^{2-}$ & $6[5]-16-1=13$ & 6 & $13(6)$ & $4 n-2$ & $\mathrm{C}^{2} \mathrm{C}[\mathrm{M} 4]$ & Bi-cap $T_{d}$ \\
\hline $\mathrm{Ru}_{5}(\mathrm{CO})_{14}{ }^{2-}$ & $5[5]-14-1=10$ & 5 & $10(5)$ & $4 n+0$ & $\mathrm{C}^{1} \mathrm{C}[\mathrm{M} 4]$ & Trigonalbipy \\
\hline $\mathrm{Ru}_{4}(\mathrm{CO})_{12}{ }^{2-}$ & $4[5]-12-1=7$ & 4 & $7(4)$ & $4 n+2$ & $\mathrm{C}^{0} \mathrm{C}[\mathrm{M} 4]$ & $\mathrm{T}_{\mathrm{d}}$ \\
\hline $\mathrm{Ru}_{3}(\mathrm{CO})_{10}{ }^{2-}$ & $3[5]-10-1=4$ & 3 & $4(3)$ & $4 n+4$ & $\mathrm{C}^{-1} \mathrm{C}[\mathrm{M} 4]$ & Triangle \\
\hline $\mathrm{Ru}_{6}(\mathrm{CO})_{15}{ }^{2-}$ & $6[5]-15-1=14$ & 6 & $14(6)$ & $4 n-4$ & $\mathrm{C}^{3} \mathrm{C}[\mathrm{M} 3]$ & Bi-cap $T_{d}$ \\
\hline $\mathrm{Ru}_{5}(\mathrm{CO})_{13}{ }^{2-}$ & $5[5]-13-1=11$ & 5 & $11(5)$ & $4 n-2$ & $\mathrm{C}^{2} \mathrm{C}[\mathrm{M} 3]$ & Trigonalbipy \\
\hline $\mathrm{Ru}_{3}(\mathrm{CO})_{9}{ }^{2-}$ & $3[5]-9-1=5$ & 3 & $5(3)$ & $4 n+2$ & $\mathrm{C}^{0} \mathrm{C}[\mathrm{M} 3]$ & Triangle \\
\hline $\mathrm{Ru}_{6}(\mathrm{CO})_{14}{ }^{2-}$ & $6[5]-14-1=15$ & 6 & $15(6)$ & $4 n-6$ & $\mathrm{C}^{4} \mathrm{C}[\mathrm{M} 2]$ & Bi-cap $T_{d}$ \\
\hline
\end{tabular}

\section{DIFFERENCES BETWEEN THE 4n SERIES METHOD AND THE SEP METHOD}

Arising from the applications of the $4 \mathrm{n}$ series method, some salient features of the differences between the method and the existing SEP method have emerged.

\section{- $\quad$ TOOLS OF ANALYSIS OF CLUSTERS}

The SEP method utilizes SEP and vertices concept to analyze the clusters while the $4 n$ method utilizes the SKELETAL NUMBERS and the $4 \mathrm{n}$ series to analyze and categorize the clusters of skeletal elements from the main group and transition metals. 


\section{- CAPPING AND NON-CAPPING CLUSTERS}

According to the $4 \mathrm{n}$ series method, all clusters comprising of skeletal elements from the MAIN GROUP or TRANSITION METALS are interrelated and can all be analyzed using the skeletal numbers and the $4 \mathrm{n}$ series method.

The series $S=4 n+q(q \geq 2)$ are non-capping types while $S=4 n+q(q \leq 0)$ represent capping clusters. The SEP method breaks clusters into groups such as $4 \mathrm{n}, 5 \mathrm{n}$ and $6 \mathrm{n}$ and finds some clusters which are described as "rule-breakers". On the other hand, there are no rule-breakers in the $4 \mathrm{n}$ series method.

\section{- CLUSTER VALENCE ELECTRONS(cve)}

The series method provides an easy method of calculating the cluster valence electrons directly from the series formula.

\section{- INTER-CONVERSION OF CLUSTERS}

The series formula can be used to generate analogous clusters in line with $K(n)$ parameter. For instance, $K(n)=11(6), S$ $=4 \mathrm{n}+2(\mathrm{n}=6)$ can be used to derive any appropriate octahedral cluster such as $\mathrm{B}_{6} \mathrm{H}_{6}{ }^{2-}, \mathrm{Rh}_{6}(\mathrm{CO})_{16}$ and $\mathrm{Os}_{6}(\mathrm{CO})_{18}{ }^{2-}$.

\section{- $\quad$ THE K(n) PARAMETER WITH DOUBLE MEANING}

The series method gives us a cluster number $\mathrm{K}$ which has a double meaning. For instance the oxygen atom has a $\mathrm{K}$ value of $1 ; \mathrm{O}(\mathrm{K}=1)$. This means it has the potential of contributing 1 bond in its chemical activity.

Hence, $\mathrm{O}(\mathrm{K}=1)+\mathrm{O}(\mathrm{K}=1) \rightarrow \mathrm{O}_{2}(\mathrm{~K}=2)$, that is, an oxygen molecule with a double bond, $\mathrm{O}=\mathrm{O}$. At the same time, for the single oxygen atom, $\mathrm{K}=1$, which means it has a shortage of 1 electron pair so as to attain the octet rule; $\mathrm{O}+2 \mathrm{e} \rightarrow \mathrm{O}^{2-}$. The $\left[\mathrm{O}^{2-}\right]$ fragment obeys the octet rule. In the case of $\mathrm{O}_{2}(\mathrm{~K}=2)$ with a double bond, it also means this diatomic molecule needs 2 pairs of electrons so that each of the 2 skeletal atoms obey the octet rule, that is, $\mathrm{O}_{2}+2(2 \mathrm{e}) \rightarrow 2\left[\mathrm{O}^{2-}\right]$. According to the series, $[\mathrm{H} \bullet]$ and $[1 \mathrm{e}]$ or [-1] are equivalent. Therefore the electron donations could take the form of hydrogen atoms:

$\mathrm{O}+2 \mathrm{H} \rightarrow \mathrm{H}_{2} \mathrm{O} ; \mathrm{O}_{2}+4 \mathrm{H} \rightarrow 2\left[\mathrm{H}_{2} \mathrm{O}\right]$. Similarly, $\mathrm{N}(\mathrm{K}=1.5)+3 \mathrm{H} \rightarrow \mathrm{NH}_{3} ; \mathrm{N}_{2}(\mathrm{~K}=3) \rightarrow \mathrm{N} \equiv \mathrm{N} ; \mathrm{N}_{2}+3[2 \mathrm{H}] \rightarrow 2 \mathrm{NH}_{3}$ and $\left[\mathrm{NH}_{3}\right]$ molecule obeys the octet rule. This concept also applies equally well to large clusters. For instance, $\mathrm{B}_{5} \mathrm{H}_{9}[\mathrm{~K}=5(2.5)-4.5$ $=8$ ]. This means that the 5 skeletal elements of B are bound by 8 linkages as shown in N51. The 8 linkages according to series also means that the cluster requires 8 pairs of electrons given directly as $8\left(2 \mathrm{e}^{-}\right)$or $8(2 \mathrm{H})$ atoms as ligands. That is,

$\mathrm{B}_{5} \mathrm{H}_{9}+8(2 \mathrm{H}) \rightarrow \mathrm{B}_{5} \mathrm{H}_{25} \rightarrow 5\left[\mathrm{BH}_{5}\right]$. The $\left[\mathrm{BH}_{5}\right]$ fragment obeys the octet rule. The $\left[\mathrm{BH}_{5}\right]$ fragment normally occurs in the form of $\left[\mathrm{BH}^{-}{ }^{-}\right.$] cluster ion. Since the skeletal number of boron, $\mathrm{K}=2.5$, its skeletal valence is 5 and this leads us to distribute the $\mathrm{H}$ ligands of $\mathrm{B}_{5} \mathrm{H}_{9}$ to generate a raw skeletal structure as in $\mathrm{F}-2$ and then propose a rearranged skeletal one in F-3 as is normally observed from $\mathrm{x}$-ray structural analysis.

\section{- BROAD CATEGORIZATION OF CLUSTERS}

By analyzing the cluster series, it has been possible to identify 3 broader clusters series, namely, the vertical, diagonal and horizontal ones. With this knowledge, it has now been possible to categorize all the clusters derived from the main group/transition metals according to their respective closo family members, [M0], [M1], [M2], and [M3] and so on. Being able to categorize clusters into groups, means that we have created a system of literally categorizing every cluster comprising of main group/transition metals with the help of a larger type of Rudolph system that operates numerically.

\section{- CATEGORIZATION OF GOLDEN CLUSTERS}

The series method has penetrated the golden clusters and showed that they all obey the cluster laws. As much as possible detailed analysis of each cluster regarding consistency with skeletal linkages and ligand distribution are explained for each cluster.

\section{- THE STRIPPING SERIES OF CLUSTERS}

The analysis and categorization of stripping series of clusters may assist in improvement of understanding and appreciation of the work by Butcher and his research groups (Butcher, et al, 2003).

\section{- CATALYSIS}

The concept can readily be applied in enhancing deeper understanding and selection of cluster catalysts such as the carbonyls. Selected examples of carbonyl tried for catalysis (Gates, 1995) are given in Table7. As can easily be seen from Table7, most of the clusters that have been tried in catalytic work belong to CLUSTER GROUP 5 OR GROUP 6. Furthermore, there is no sample of positive capping index, $K p=C^{y} C(y \geq 1)$ on the table list. 
Table 7. Selected carbonyl clusters that have been tested for catalysis

\begin{tabular}{|c|c|c|c|c|c|}
\hline $\mathrm{T}-7$ & CATALYSIS & & & & \\
\hline CLUSTER & $\mathrm{K}$ & $\mathrm{n}$ & $\mathrm{K}(\mathrm{n})$ & SERIES, S & $\begin{array}{l}\text { CATEGORIZATION, } \\
\text { Kp }\end{array}$ \\
\hline $\mathrm{Fe}_{3}(\mathrm{CO})_{12}$ & $3[5]-12=3$ & 3 & $3(3)$ & $4 n+6$ & $\mathrm{C}^{-2} \mathrm{C}[\mathrm{M} 5]$ \\
\hline $\mathrm{Co}_{4}(\mathrm{CO})_{12}$ & $4[4.5]-12=6$ & 4 & $6(4)$ & $4 n+4$ & $\mathrm{C}^{-1} \mathrm{C}[\mathrm{M} 5]$ \\
\hline $\mathrm{Os}_{3}(\mathrm{CO})_{12}$ & $3[5]-12=3$ & 3 & $3(3)$ & $4 n+6$ & $\mathrm{C}^{-2} \mathrm{C}[\mathrm{M} 5]$ \\
\hline $\mathrm{Ir}_{4}(\mathrm{CO})_{12}$ & $4[4.5]-12=6$ & 4 & $6(4)$ & $4 n+4$ & $\mathrm{C}^{-1} \mathrm{C}[\mathrm{M} 5]$ \\
\hline $\mathrm{Pt}_{15}(\mathrm{CO})_{30}{ }^{2-}$ & $15[4]-30-1=29$ & 15 & $29(15)$ & $4 n+2$ & $\mathrm{C}^{0} \mathrm{C}[\mathrm{M} 15]$ \\
\hline $\mathrm{HFe}_{3}(\mathrm{CO})_{11^{-}}$ & $3[5]-0.5-11-0.5=3$ & 3 & $3(3)$ & $4 n+6$ & $\mathrm{C}^{-2} \mathrm{C}[\mathrm{M} 5]$ \\
\hline $\mathrm{H}_{3} \mathrm{Os}_{4}(\mathrm{CO})_{12}-$ & $4[5]-1.5-12-0.5=6$ & 4 & $6(4)$ & $4 n+4$ & $\mathrm{C}^{-1} \mathrm{C}[\mathrm{M} 5]$ \\
\hline $\mathrm{HIr}_{4}(\mathrm{CO})_{11^{-}}$ & $4[4.5]-0.5-11-0.5=6$ & 4 & $6(4)$ & $4 n+4$ & $\mathrm{C}^{-1} \mathrm{C}[\mathrm{M} 5]$ \\
\hline $\mathrm{Ir}_{6}(\mathrm{CO})_{15}{ }^{2-}$ & $6[4.5]-15-1=11$ & 6 & $11(6)$ & $4 n+2$ & $\mathrm{C}^{0} \mathrm{C}[\mathrm{M} 6]$ \\
\hline $\mathrm{Ru}_{6}(\mathrm{C})(\mathrm{CO})_{16}{ }^{2-}$ & $6[5]-2-16-1=11$ & 6 & $11(6)$ & $4 n+2$ & $\mathrm{C}^{0} \mathrm{C}[\mathrm{M} 6]$ \\
\hline $\mathrm{Rh}_{6}(\mathrm{CO})_{16}$ & $6[4.5]-16=11$ & 6 & $11(6)$ & $4 n+2$ & $\mathrm{C}^{0} \mathrm{C}[\mathrm{M} 6]$ \\
\hline $\mathrm{Os}_{5}(\mathrm{C})(\mathrm{CO})_{14}{ }^{2-}$ & $5[5]-2-14-1=8$ & 5 & $8(5)$ & $4 n+4$ & $\mathrm{C}^{-1} \mathrm{C}[\mathrm{M} 6]$ \\
\hline $\mathrm{Os}_{10}(\mathrm{C})(\mathrm{CO})_{24}{ }^{2-}$ & $10[5]-2-24-1=23$ & 10 & $23(10)$ & $4 n-6$ & $\mathrm{C}^{4} \mathrm{C}[\mathrm{M} 6]$ \\
\hline $\mathrm{Rh}_{5}(\mathrm{CO})_{15^{-}}$ & $5[4.5]-15-0.5=7$ & 5 & $7(5)$ & $4 n+6$ & $\mathrm{C}^{-2} \mathrm{C}[\mathrm{M} 7]$ \\
\hline $\mathrm{Pt}_{6}(\mathrm{CO})_{12}{ }^{2-}$ & $6[4]-12-1=11$ & 6 & $11(6)$ & $4 n+2$ & $\mathrm{C}^{0} \mathrm{C}[\mathrm{M} 6]$ \\
\hline $\mathrm{Pt}_{9}(\mathrm{CO})_{18}{ }^{2-}$ & $9[4]-18-1=17$ & 9 & $17(9)$ & $4 n+2$ & $\mathrm{C}^{0} \mathrm{C}[\mathrm{M} 9]$ \\
\hline $\mathrm{Pt}_{12}(\mathrm{CO})_{24}{ }^{2}-$ & $12[4]-24-1=23$ & 12 & $23(12)$ & $4 n+2$ & $\mathrm{C}^{0} \mathrm{C}[\mathrm{M} 12]$ \\
\hline $\mathrm{H}_{4} \mathrm{Os}_{4}(\mathrm{CO})_{12}$ & $4[5]-2-12=6$ & 4 & $6(4)$ & $4 n+4$ & $\mathrm{C}^{-1} \mathrm{C}[\mathrm{M} 5]$ \\
\hline $\mathrm{Ir}_{6}(\mathrm{CO})_{16}$ & $6[4.5]-16=11$ & 6 & $11(6)$ & $4 n+2$ & $\mathrm{C}^{0} \mathrm{C}[\mathrm{M} 6]$ \\
\hline $\mathrm{Fe}_{2}(\mathrm{CO})_{6} \mathrm{~S}_{2}$ & $2[5]+2[1]-6=6$ & 4 & $6(4)$ & $4 n+4$ & $\mathrm{C}^{-1} \mathrm{C}[\mathrm{M} 5]$ \\
\hline $\mathrm{Fe}_{3}(\mathrm{CO})_{9} \mathrm{~S}_{2}$ & $3[5]+2[1]-9=8$ & 5 & $8(5)$ & $4 n+4$ & $\mathrm{C}^{-1} \mathrm{C}[\mathrm{M} 6]$ \\
\hline $\mathrm{Pt}_{30}(\mathrm{CO})_{60}{ }^{2-}$ & $30[4]-60-1=59$ & 30 & $59(30)$ & $4 n+2$ & $\mathrm{C}^{0} \mathrm{C}[\mathrm{M} 30]$ \\
\hline
\end{tabular}

\begin{tabular}{|l|l|l|l|l|l|}
\hline CLUSTER & $\mathrm{K}$ & $\mathrm{n}$ & $\mathrm{K}(\mathrm{n})$ & SERIES, $\mathrm{S}$ & CATEGORIZATION, Kp \\
\hline $\mathrm{Co}_{2} \mathrm{Ru}_{2}(\mathrm{CO})_{13}$ & $2[4.5]+2[5]-13=6$ & 4 & $6(4)$ & $4 \mathrm{n}+4$ & $\mathrm{C}^{-1} \mathrm{C}[\mathrm{M} 5]$ \\
\hline $\mathrm{Co}_{3} \mathrm{Ru}(\mathrm{H})(\mathrm{CO})_{12}$ & $3[4.5]+1[5]-0.5-12=6$ & 4 & $6(4)$ & $4 \mathrm{n}+4$ & $\mathrm{C}^{-1} \mathrm{C}[\mathrm{M} 5]$ \\
\hline $\mathrm{Co}_{2} \mathrm{Ru}_{2}(\mathrm{CO})_{12} \mathrm{H}_{2}$ & $2[4.5]+2[5]-12-1=6$ & 4 & $6(4)$ & $4 \mathrm{n}+4$ & $\mathrm{C}^{-1} \mathrm{C}[\mathrm{M} 5]$ \\
\hline $\mathrm{CoRu}_{3}(\mathrm{CO})_{12} \mathrm{H}_{3}$ & $1[4.5]+3[5]-12-1.5=6$ & 4 & $6(4)$ & $4 \mathrm{n}+4$ & $\mathrm{C}^{-1} \mathrm{C}[\mathrm{M} 5]$ \\
\hline $\mathrm{Ru}_{4} \mathrm{H}_{4}(\mathrm{CO})_{12}$ & $4[5]-2-12=6$ & 4 & $6(4)$ & $4 \mathrm{n}+4$ & $\mathrm{C}^{-1} \mathrm{C}[\mathrm{M} 5]$ \\
\hline $\left.\mathrm{Co}_{3} \mathrm{Rh}_{12} \mathrm{CO}\right)_{12}$ & $3[4.5]+1[4.5]-12=6$ & 4 & $6(4)$ & $4 \mathrm{n}+4$ & $\mathrm{C}^{-1} \mathrm{C}[\mathrm{M} 5]$ \\
\hline $\mathrm{Co}_{2} \mathrm{Rh}_{2}(\mathrm{CO})_{12}$ & $2[4.5]+2[4.5]-12=6$ & 4 & $6(4)$ & $4 \mathrm{n}+4$ & $\mathrm{C}^{-1} \mathrm{C}[\mathrm{M} 5]$ \\
\hline $\mathrm{Rh}_{4}(\mathrm{CO})_{12}$ & $4[4.5]-12=6$ & 4 & $6(4)$ & $4 \mathrm{n}+4$ & $\mathrm{C}^{-1} \mathrm{C}[\mathrm{M} 5]$ \\
\hline $\mathrm{H}_{3} \mathrm{Re}_{3}(\mathrm{CO})_{12}$ & $3[5.5]-1.5-12=3$ & 3 & $3(3)$ & $4 \mathrm{n}+6$ & $\mathrm{C}^{-2} \mathrm{C}[\mathrm{M} 5]$ \\
\hline $\mathrm{Re}_{2} \mathrm{Pt}(\mathrm{CO})_{12}$ & $2[5.5]+1[4]-12=3$ & 3 & $3(3)$ & $4 \mathrm{n}+6$ & $\mathrm{C}^{-2} \mathrm{C}[\mathrm{M} 5]$ \\
\hline
\end{tabular}

\section{- POLYMERIZATION OF CLUSTERS}

Let us consider two similar hypothetical reactions.

The dimerization of $\left.\mathrm{B}_{6} \mathrm{H}_{6}{ }^{2-} \mathrm{B}_{6} \mathrm{H}_{8}\right)$ to form $\mathrm{B}_{12} \mathrm{H}_{14}$ in the form of $\left(\mathrm{B}_{12} \mathrm{H}_{12}{ }^{2-}\right)$ known product (Housecroft \& Sharpe, 2005). In the case of the rhodium cluster $\mathrm{Rh}_{6}(\mathrm{CO})_{16}$, the removal of a $\mathrm{CO}$ ligand creates an additional linkage for binding the two fragments, the cluster $\mathrm{K}$ value goes from 11 to 23 for the combined 2 fragments $(11+1+11=23)$ according to the series to generate the dimeric cluster, $\mathrm{Rh}_{12}(\mathrm{CO})_{31}$ in the form $\mathrm{Rh}_{12}(\mathrm{CO})_{30}{ }^{2-}$ (Housecroft \& Sharpe, 2005). The hypothetical mechanism for the processes is given in P-1 and P-2. The possible extension of rhodium polymerization to produce longer chains is sketched in P-3.

\subsection{Unique Capping Clusters}

Predicting the structures of clusters or unique structures: This may be illustrated by the two examples, $\mathrm{Au}_{6} \mathrm{R}_{6} \mathrm{Br}_{2}(\mathrm{CO})_{2}{ }^{2-}$, $\mathrm{R}=\mathrm{CF}_{3} ; \mathrm{K}=6[3.5]-6(0.5)-2(0.5)-2(0.5)=14, \mathrm{n}=6, \mathrm{~K}(\mathrm{n})=14(6), \mathrm{S}=4 \mathrm{n}-4, \mathrm{Kp}=\mathrm{C}^{3} \mathrm{C}[\mathrm{M} 3]$. This predicts a cluster of 3 closo skeletal nucleus surrounded by 3 other skeletal elements. According to series approach, the prediction is a closo nucleus of 3 skeletal elements surrounded by 3 capping skeletal elements. However what is observed are two sets of separate trinuclear clusters (Martinez-Salvado et al, 2015). This is sketched in N611. A similar prediction is found in the dinitrogenhexagolden cluster $\mathrm{N}_{2}(\mathrm{AuL})_{6}{ }^{2+}: \mathrm{K}=2[1.5]+6[3.5-1]+1=19 ; \mathrm{n}=2+6=8, \mathrm{~K}(\mathrm{n})=19(8), \mathrm{S}=4 \mathrm{n}-6, \mathrm{Kp}=$ $\mathrm{C}^{4} \mathrm{C}[\mathrm{M} 4]$. Again two sets of 4 skeletal elements were observed (Gimeno, 2008). The predicted skeletal sketch and the observed one for $\mathrm{N}_{2}(\mathrm{AuL})_{6}{ }^{2+}$ are sketched in $\mathrm{N} 85$. Another interesting cluster is $\mathrm{Ni}_{12} \mathrm{As}_{21}{ }^{3-}$. The capping series Kp $=$ $\mathrm{C}^{13} \mathrm{C}[\mathrm{M} 20]$ predicts a nucleus of 20 skeletal elements surrounded by 13 capping skeletal elements. However, what is observed is the other way round; a dome of 20 skeletal elements encapsulating 13 others. The sketch of the cluster is given in N331. The last cluster on this list is the rhenium selenium cluster $\operatorname{Re}_{6} \mathrm{Se}_{8} \mathrm{I}_{6}{ }^{4-}$ : It has a capping symbol $\mathrm{Kp}=$ $\mathrm{C}^{9} \mathrm{C}[\mathrm{M} 5]$. The prediction here is that the cluster has a trigonal bipyramid nucleus surrounded by 9 capping elements. 
The x-ray analytical interpretation of the structure is 8 selenium capping elements with an octahedral nucleus. This revelation is quite fascinating as the prediction is 9 skeletal elements by the series and the observed are 8 . Since the series acts as a 'deaf and dumb' guide, this result is good enough and gives more confidence in understanding the language of the series method deeper. The cluster is sketched in N141.

\section{POLYMERIZATIONS}
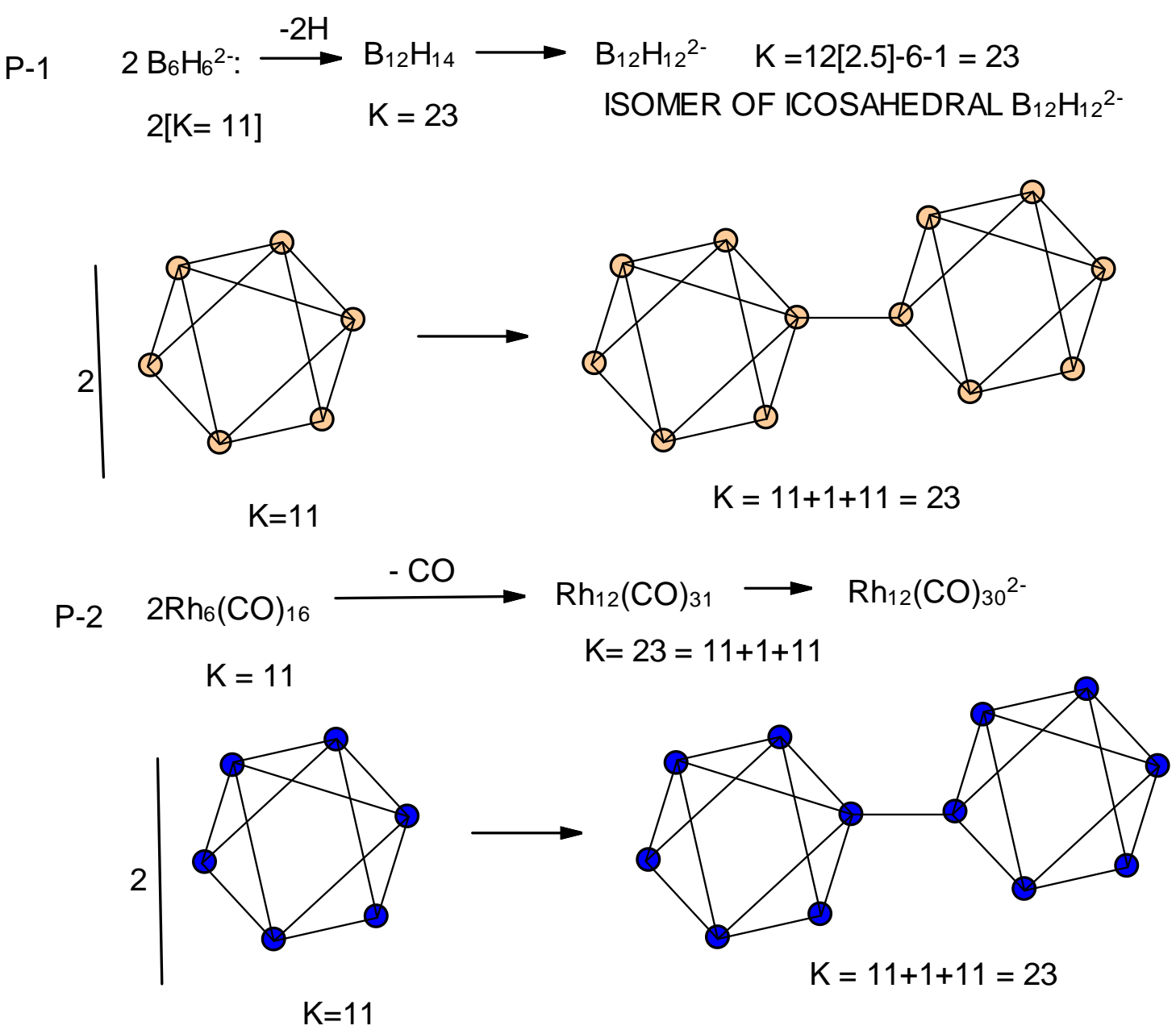
RHODIUMPOLYMERIZATIONS

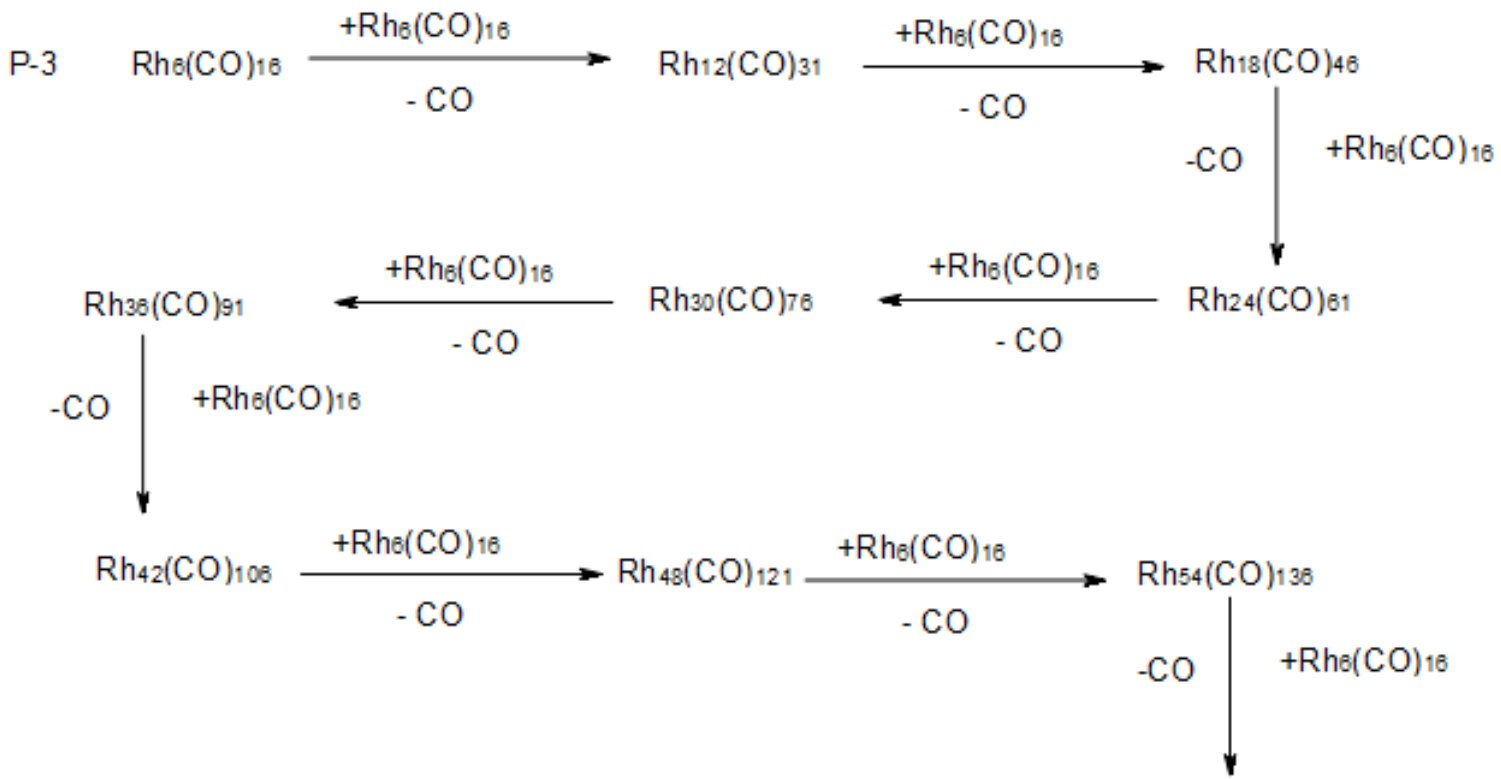

$\mathrm{Rh}_{80}(\mathrm{CO})_{151}$

\begin{tabular}{|c|c|c|c|c|c|c|c|c|c|c|}
\hline \multicolumn{11}{|c|}{ APPENDIX 1. SKELETAL NUMBERS OF MAIN GROUP ELEMENTS } \\
\hline $\mathbf{V}^{*}$ & \multicolumn{3}{|l|}{7} & 5 & \multicolumn{2}{|l|}{4} & 3 & 2 & 1 & $\mathbf{0}$ \\
\hline$K^{*}(n=1)$ & \multicolumn{2}{|l|}{3.5} & 3 & 2.5 & \multicolumn{2}{|l|}{2} & 1.5 & 1 & 0.5 & 0 \\
\hline $\mathrm{K}^{*}$ & \multicolumn{2}{|l|}{$2 n+1.5$} & $2 n+1$ & $2 n+0.5$ & \multicolumn{2}{|c|}{$2 n+0$} & $2 n-0.5$ & $2 n-1$ & $2 n-1.5$ & $2 n-2$ \\
\hline $\mathrm{S}$ & \multicolumn{2}{|l|}{$4 n-3$} & $4 n-2$ & $4 n-1$ & \multicolumn{2}{|c|}{$4 n+0$} & $4 n+1$ & $4 n+2$ & $4 n+3$ & $4 n+4$ \\
\hline \multirow[t]{6}{*}{$\mathrm{Ve}^{*}$} & \multicolumn{2}{|l|}{1} & 2 & 3 & \multicolumn{2}{|l|}{4} & 5 & 6 & 7 & 8 \\
\hline & \multicolumn{2}{|l|}{$\mathrm{Li}$} & $\mathrm{Be}$ & B & $\mathrm{C}$ & & $\mathrm{N}$ & $\mathrm{O}$ & F & $\mathrm{Ne}$ \\
\hline & $\mathrm{Na}$ & $\mathrm{M}$ & & $\mathrm{Al}$ & $\mathrm{Si}$ & & $\mathrm{P}$ & $\mathrm{S}$ & $\mathrm{Cl}$ & $\mathrm{Ar}$ \\
\hline & $\mathrm{K}$ & $\mathrm{C}$ & & $\mathrm{Ga}$ & $\mathrm{Ge}$ & & As & $\mathrm{Se}$ & $\mathrm{Br}$ & $\mathrm{Kr}$ \\
\hline & $\mathrm{Rb}$ & $\mathrm{S}$ & & In & $\mathrm{Sn}$ & & $\mathrm{Sb}$ & $\mathrm{Te}$ & I & $\mathrm{Xe}$ \\
\hline & $\mathrm{Cs}$ & $\mathrm{B}$ & & $\mathrm{Tl}$ & $\mathrm{Pb}$ & & $\mathrm{Bi}$ & Po & & $\mathrm{Rn}$ \\
\hline $\mathrm{V}^{*}=$ skelet & I valence & $\mathrm{K}^{*}=\mathrm{s}$ & letal num & ber, Ve* & valence & electron & $\mathrm{S}=$ series & & & \\
\hline APPEND & X 2.SK & LETA & NUMBE & RS OF & RANSTI & DN ME & ГALS & & & \\
\hline $\mathbf{V}^{*}$ & 15 & 14 & 13 & 12 & 11 & 10 & 9 & 8 & 7 & 6 \\
\hline $\mathrm{K}^{*}(\mathrm{n}=1)$ & 7.5 & 7 & 6.5 & 6 & 5.5 & 5 & 4.5 & 4 & 3.5 & 3 \\
\hline $\mathrm{K}^{*}$ & $2 n+5.5$ & $2 n+5$ & $2 n+4.5$ & $2 n+4$ & $2 n+3.5$ & $2 n+3$ & $2 n+2.5$ & $2 n+2$ & $2 n+1.5$ & $2 n+1$ \\
\hline$S$ & $4 n-11$ & $4 n-10$ & $4 n-9$ & $4 n-8$ & $4 n-7$ & $4 n-6$ & $4 n-5$ & $4 n-4$ & $4 n-3$ & $4 n-2$ \\
\hline $\mathrm{Ve}^{*}$ & 3 & 4 & 5 & 6 & 7 & 8 & 9 & 10 & 11 & 12 \\
\hline $\mathrm{E}^{*}$ & $\mathrm{Sc}$ & $\mathrm{Ti}$ & $\mathrm{V}$ & $\mathrm{Cr}$ & $\mathrm{Mn}$ & $\mathrm{Fe}$ & $\mathrm{Co}$ & $\mathrm{Ni}$ & $\mathrm{Cu}$ & $\mathrm{Zn}$ \\
\hline & $\mathrm{Y}$ & $\mathrm{Zr}$ & $\mathrm{Nb}$ & Mo & Tc & $\mathrm{Ru}$ & $\mathrm{Rh}$ & $\mathrm{Pd}$ & $\mathrm{Ag}$ & $\mathrm{Cd}$ \\
\hline & $\mathrm{La}$ & $\mathrm{Hf}$ & $\mathrm{Ta}$ & W & $\mathrm{Re}$ & Os & $\mathrm{Ir}$ & $\mathrm{Pt}$ & $\mathrm{Au}$ & $\mathrm{Hg}$ \\
\hline
\end{tabular}

\section{Conclusion}

Using skeletal numbers and the series method, chemical clusters have been divided into periodic groups. A capping symbol for non-capping clusters has been introduced. Sketching of clusters strictly following the rules of skeletal numbers and their valences according to series has been emphasized. This procedure has been termed "a simple graph theory of capping clusters". A wide range clusters have been sketched and tentative ligand distribution proposed. The golden clusters have generated very interesting and fascinating two dimensional geometrical structural frameworks. The grouping of clusters based on closo nuclear index will promote further understanding and possible synthesis of novel clusters and their applications.

\section{Acknowledgement}

The continued encouragement by Mrs. Merab Kambamu Kiremire to write up this paper and the editing assistance of Dr. P.E.T. Kiremire are greatly appreciated. 


\section{References}

Brivio, E., Cariotti, A., Pergola, R. D., Garlaschalli, L., Demartin,F., Manassero, M., Sansoni,M., \& Zanello, P. (1994). Synthesis and Solid-state structure of $\mathrm{Pd}_{6} \mathrm{Ru}_{6}(\mathrm{CO})_{24}{ }^{2-}$. J. Chem. Soc., 3237-3231.

Butcher, C. P. G., Dyson, P. J., Johnson, B. F. G., Khimyak, J., \& McIndoe, J. S. (2003). Fragmentation of Transition Metal Carbonyl Clusters Anions: Structural Insights from Mass Spectrometry. Chem. Eur. J., 9(4), 944-950. https://doi.org/10.1002/chem.200390116

Ciabatti, I. (2015). PhD Thesis. Homo- and Hetero-metal carbonyl Nanoclusters.

Dyson, P. J., Hearley, A. K., Johnson, B. F. G., McIndoe, J. S., \& Whyte, P.. R. L. S. C. (2001). Combining energy-dependent electrospray ionization with tandem mass spectrometry for the analysis of inorganic compounds. Rapid Comm. Mass Spec., 15, 885-897. https://doi.org/10.1002/rcm.314

Fehlner, T. P., \& Halet, J. F. (2007). Molecular Clusters, Cambridge University Press, UK. https://doi.org/10.1017/CBO9780511628887

Gates, B. C. (1995). Supported metal clusters: Synthesis, Structure, and Catalysis. Chem. Rev., 95, 511-522. https://doi.org/10.1021/cr00035a003

Gimeno, M. C. (2008). Modern Supramolecular Gold-Metal Interactive and Applications. Edited A. Laguna, 2008. Wiley-VCH, Weinheim

Greenwood, N. N., \& Earnshaw, A. (1998). Chemistry of the Elements, $2^{\text {nd }}$ Ed. Butterworth, Oxford.

Housecroft, C. E., \& Sharpe, A. G. (2005). Inorganic Chemistry, $2^{\text {nd }}$ Ed., Pearson, Prentice Hall, Harlow, England

Hughes, A. K., \& Wade, K. (2000). Metal-metal and metal-ligand strengths in metal carbonyl clusters. Coord. Chem. Rev., 197, 191-229. https://doi.org/10.1016/S0010-8545(99)00208-8

Jemmis, E. D. (2005). Building relationships between polyhedral boranes and elemental boron. Inorg. Chem. 18, 620-628.

Jemmis, E. D., \& Prasad, D. L. V. K. (2008). Unknowns in the chemistry of Boron. Current Science, 95(10), 1277-1283.

Jemmis, E. D., Jayasree, E. G., \& Parameswaran, P. (2006). Hypercarbons in polyhedral structures. Chem. Soc. Rev., 35, 157-168. https://doi.org/10.1039/B310618G

Kiremire, E. M. (2014). Validation and verification of the Expanded Table for Transition Metal Carbonyl and Main Group Element Cluster Series which obey the 18-Electron and the 8-Electron Rules Respectively. Orient. J. Chem., 30(4), 1475-1495. https://doi.org/10.13005/ojc/300404

Kiremire, E. M. (2015a). Classification of Transition Metal Carbonyl Clusters Using the 14n Rule Derived from Number Theory. Orient. J. Chem., 31(2), 605-618. https://doi.org/10.13005/ojc/310201

Kiremire, E. M. (2015b). Categorization and Structural Determination of Simple and More Complex Carbonyl Clusters of Rhenium and Osmium Using K-values and the Cluster Table. Orient. J. Chem., 31(1), 293-302. https://doi.org/10.13005/ojc/310133

Kiremire, E. M. (2015c). Isolobal Series of Chemical Fragments. Orient. J. Chem., 31(spl. Edn), 59-70.

Kiremire, E. M. (2015d). Classification of Transition Metal Carbonyl Clusters Using the 14n Rule Derived from Number Theory. Orient. J. Chem., 31(2), 605-618. https://doi.org/10.13005/ojc/310201

Kiremire, E. M. R. (2016a). The categorization and Structural Prediction of Transition Metal Carbonyl Clusters Using the 14n Series Numerical Matrix. Int. J. Chem. 8(1), 109-125. https://doi.org/10.5539/ijc.v8n1p109

Kiremire, E. M. R. (2016b). A Hypothetical Model for the Formation of Transition Metal Carbonyl Clusters Based Upon 4n Series Skeletal Numbers. Int. J. Chem., 8(4), 78-110. https://doi.org/10.5539/ijc.v8n4p78

Kiremire, E. M. R. (2016c). The Application of the 4n Series Method to Categorize Metalloboranes. Int. J. Chem., 8(3), 62-73. https://doi.org/10.5539/ijc.v8n3p62

Kiremire, E. M. R. (2016d). Classification of Zintl Ion Clusters Using 4n Series Approach. Orient. J. Chem., 32(4), 1731-1738. https://doi.org/10.13005/ojc/320401

Kiremire, E. M. R. (2017a). The Six Silent Laws of Chemical Clusters. Amer. J. Chem. 7(2), 21-47.

Kiremire, E. M. R. (2017b). Outstanding Applications of Skeletal Numbers to Chemical Clusters. Int. J. Chem., 9(3), 28-48. https://doi.org/10.5539/ijc.v9n3p28

Kiremire, E. M. R. (2017c). Boranes, Carboranes, Metalloboranes, Transition Metal Carbonyls, and Other Cluster 
Formulas Obey the Law of Skeletal Numbers and Their Valences. Amer. J. Chem., 7(4), 113-144.

Kiremire, E. M. R. (2017d). Numerical Characterization of Chemical Fragments, Molecules, and Clusters Using Skeletal Numbers and Nuclearity Trees. Amer. J. Chem., 7(3), 73-96.

Konishi, K. (2014). Phosphine-coordinated Pure Gold-Clusters and Unique Optical Properties/Responses. Structure and Bonding, 161, 49-86. https://doi.org/10.1007/430_2014_143

Lipscomb, W. N. (1963). Boron Hydrides. W. A. Bejamin, Inc., New York.

Luquin, A., Cerrada, E., \& Laguna, M. (2009). Pentafluorophenyl gold complexes. Gold Chemistry, Edited, Mohr, F., Wiley-VCH, Wuppertal, Germany. https://doi.org/10.1002/9783527626724.ch3

Martinez-Salvado, S., Falvello, L. R., Martin, A., \& Menjỏn, B. (2015). A Hexanuclear gold carbonyl Cluster. Chem. Sci., 6, 5506-5510. https://doi.org/10.1039/C5SC01578B

McIndoe, J. S., \& Henderson, M. S. (2013). Gas-phase reactivity of iron penta-carbonyls with anionic clusters. Inter. J. Mass Spec., 354-355, 257-262.

Mednikov, E. G., \& Dahl, L. F. (2010). Synthesis, structures and properties of primarily nano-sized homo/hetero metallic palladium $\mathrm{CO} / \mathrm{PR}_{3}$ ligated clusters. Phil., Trans., $R$. Soc. A, 368, 1301-1332. https://doi.org/10.1098/rsta.2009.0272

Mingos, D. M. P. (1972). A General Theory for Cluster and Ring Compounds of the Main Group and Transition Elements. Nature(London), Phys. Sci., 236, 99-102. https://doi.org/10.1038/physci236099a0

Mingos, D. M. P. (1984). Gold Cluster Compounds: Are they materials in miniature? Gold Bull., 17(1), 5-12. https://doi.org/10.1007/BF03214670

Mingos, D. M. P. (1987). Complementary spherical electron density model for coordination compounds. Pure and Appl. Chem., 59(2), 145-154. https://doi.org/10.1351/pac198759020145

Pergola, R. D., \& Garlaschelli, L. (1990). J. Chem. Soc., Dalton Trans., 127-135. https://doi.org/10.1039/DT9900000127

Rossi, F., \& Zanello, P. (2011). Electron Reservoir Activity of High-Nuclearity Transition Metal Carbonyl Clusters. Portugaliae Electrochimica Acta, 29(5), 309-327. https://doi.org/10.4152/pea.201105309

Rudolph, R. W. (1976). Boranes and heteroboranes: a paradigm for the electron requirements of clusters? Acc. Chem. Res., 9(12), 446-452. https://doi.org/10.1021/ar50108a004

Teo, B. K., Longoni, G., \& Chung, F. R. K. (1984). Applications of Topological Electron-Counting Theory to Polyhedral Metal Clusters. Inorg. Chem., 23(9), 1257-1266. https://doi.org/10.1021/ic00177a018

Wade, A. (1976). Structural and Bonding Patterns in Cluster Chemistry. Adv. Inorg. Chem. Radiochem., 18, 1-66. https://doi.org/10.1016/S0065-2792(08)60027-8

Wade, K. (1971). The structural significance of the number of skeletal bonding electron-pairs in carboranes, the higher boranes and borane ions and various transition metal carbonyl cluster compounds. Chem. Commun., 792-793. https://doi.org/10.1039/c29710000792

Welch, A. J. (2013). The significance of Wade's rules. Chem. Commun., 49, 3615-3616. https://doi.org/10.1039/c3cc00069a

Yvon, K. (2004). Transition Metal Hydride Complexes. Encyclopedia of Materials and Science Technology, 1-9.

\section{Copyrights}

Copyright for this article is retained by the author(s), with first publication rights granted to the journal.

This is an open-access article distributed under the terms and conditions of the Creative Commons Attribution license (http://creativecommons.org/licenses/by/4.0/). 